UNIVERSIDADE DE SÃO PAULO

INSTITUTO DE GEOCIENCIAS

\title{
“ AVALIAÇÃO dA APLICABILIDADE DE MÉTOdOS GEOFÍSICOS EM ESTUDOS DE CASOS DE CONTAMINAÇĀO DE ÁGUAS SUBTERRÂNEAS POR DIFERENTES FONTES"
}

Jamile Dehaini

Orientador: Prof. Dr. José Milton B. Mendes

DISSERTAÇÃO DE MESTRADO

COMISSÃO JULGADORA

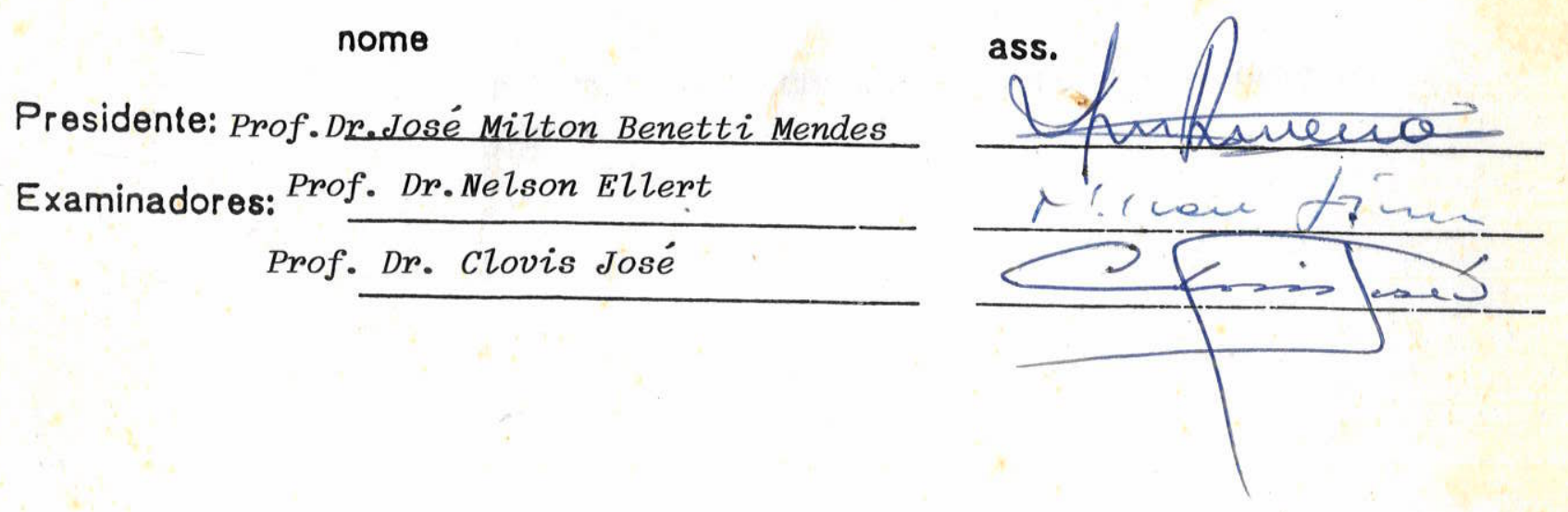




\section{UNIVERSIDADE DE SÃO PAULO INSTITUTO DE GEOCIÊNCIAS}

\section{"AVALIAÇ̃̃O DA APLICABILIDADE DE MÉTODOS GEOFÍSICOS EM ESTUDOS DE CASOS DE CONTAMINAÇÃO DE ÁGUAS SUBTERRÂNEAS POR DIFERENTES FONTES"}

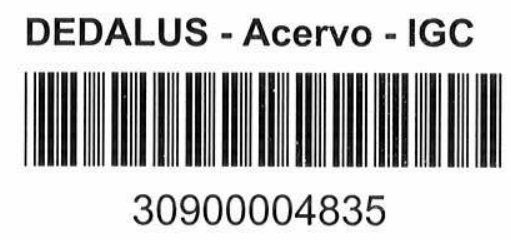

Jamile Dehaini

Orientador: Prof. Dr. José Milton B. Mendes

\section{DISSERTAÇÃO DE MESTRADO}

Área de Concentração: Recursos Minerais e Hidrogeologia

São Paulo

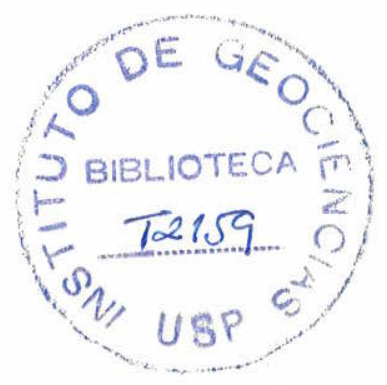

1995 


\section{AGRADECIMENTOS}

Com certeza o primeiro agradecimento devo a meu orientador José Milton, pela sua orientação e constante participação e interesse na realização deste trabalho.

Ao meu companheiro e amigo Gilberto Garcia del Pino.

Ao Centro de Pesquisas de Águas Subterrâneas (CEPAS) e ao Instituto de Geociências da USP, em especial ao Departamento de Geologia Econômica.

Ao Setor de Processos de Tratamento no Solo e Recuperação de Locais da CETESB (DDRS-CETESB).

Ao Setor de Tecnologia Minimização e Tratamento da CETESB (DDRT-CETESB).

À GEOSERVICE-Engenharia Ambiental, principalmente na pessoa de Ricardo Franciscone.

À GEO-AMBIENTE-Geologia Ambiental.

À Bascitrus Agro-Indústria S.A.

À Borracha Paulista Indústria e Comércio Ltda.

À CAPES, pela bolsa de estudo.

Ao geólogo Régis Bruno Graça Maset.

Aos meus colegas geofísicos do IAG, Douglas Bastianon e Iraldo Bragion.

Ao meu colega geólogo Tarcício Montanero.

A Artur do laboratório de Geocronologia do Instituto de Geociências da USP.

A Rodrigo e Mauro, alunos da graduação do Instituto de Geociências da USP.

A todos os professores e funcionários do Departamento de Geologia Econômica do Instituto de Geociências da USP pelo constante apoio e incentivo.

À Rita e Márcia da área de informática do Instituto de Geociências da USP.

Aos meus colegas que de uma maneira ou outra me apoiaram. 


\section{S U MÁRIO}

\section{PG}

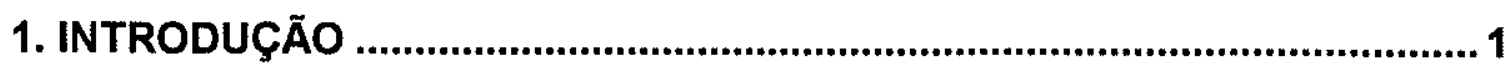

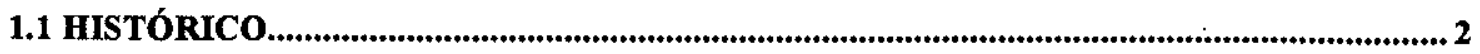

1.2 OBJETIVO

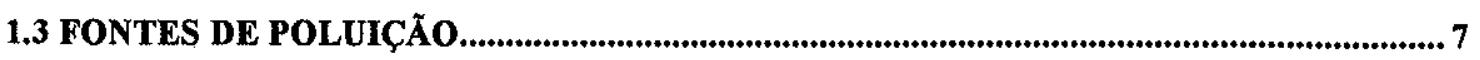

2. METODOLOGIA GEOFÍSICA UTILIZADA E EQUIPAMENTOS ....................8

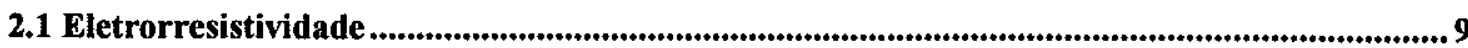

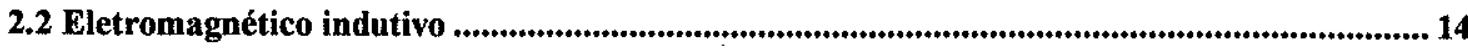

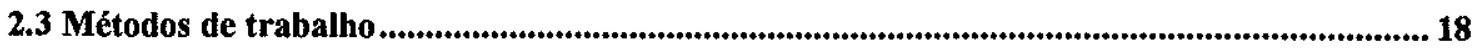

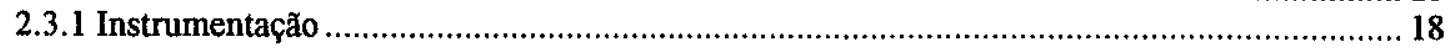

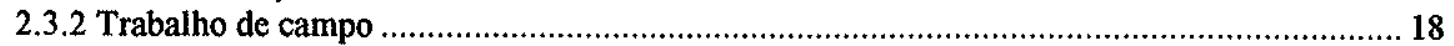

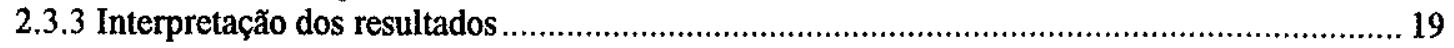

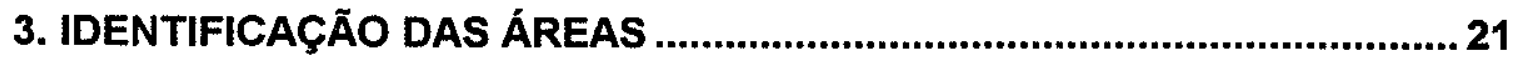

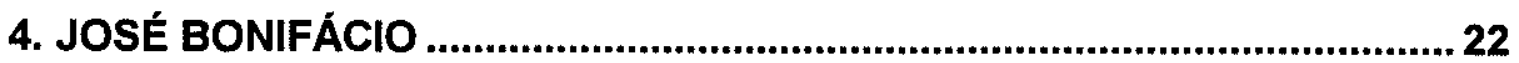

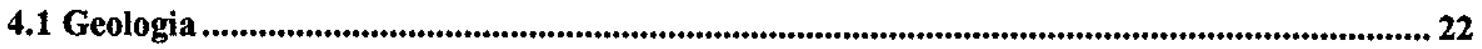

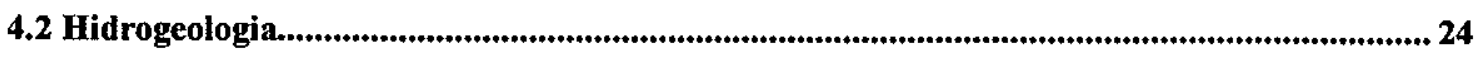

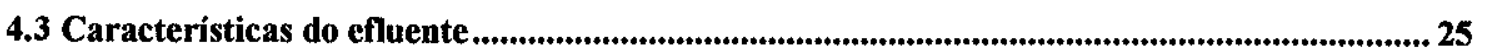

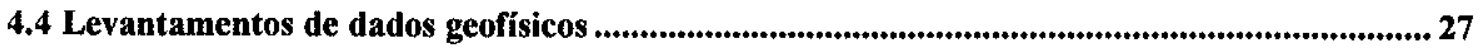

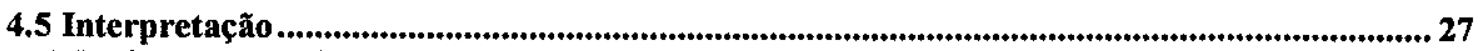

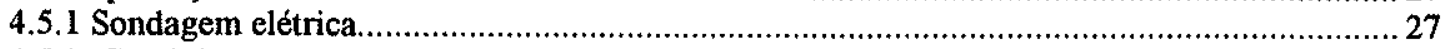

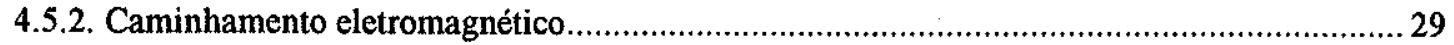

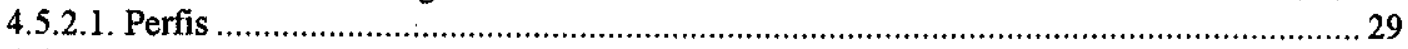

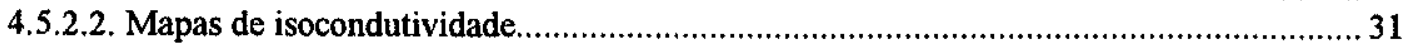

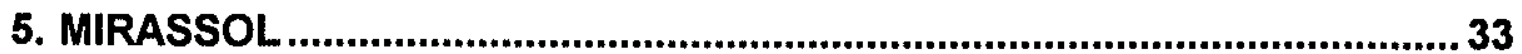

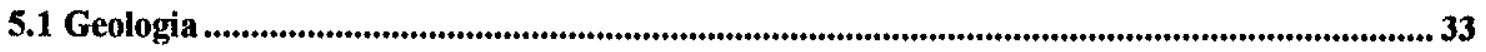

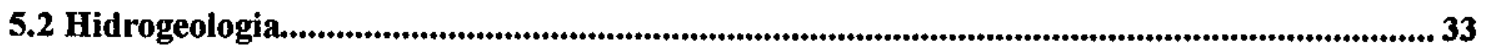

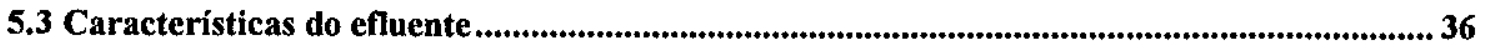

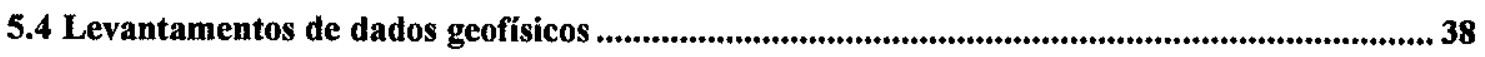

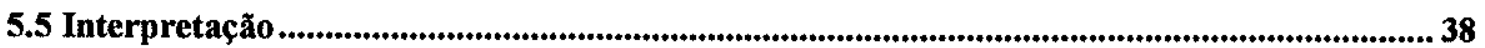

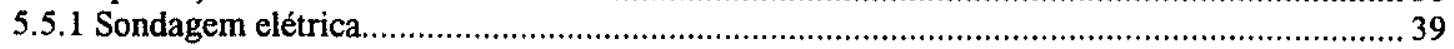




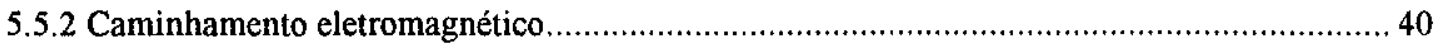

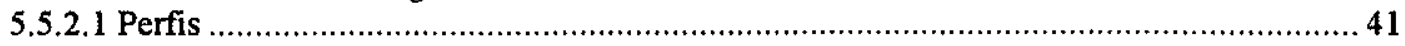

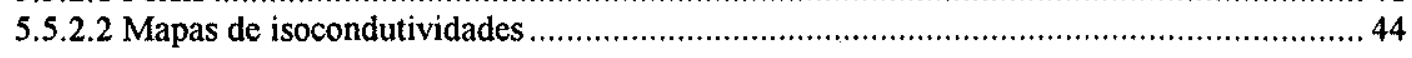

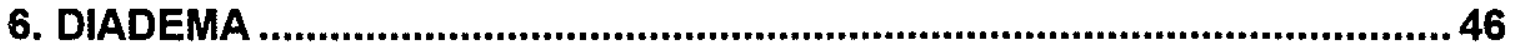

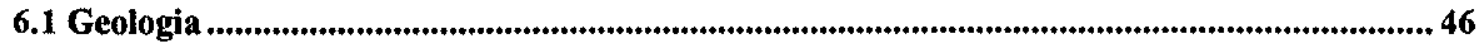

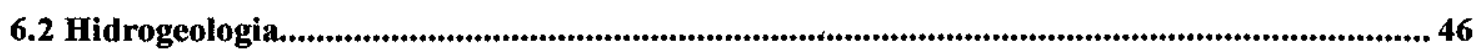

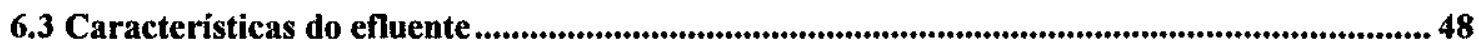

6.4 Levantamentos de dados geofísicos ................................................................................................. 51

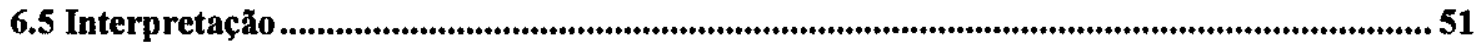

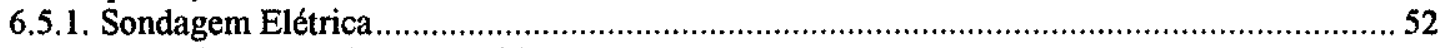

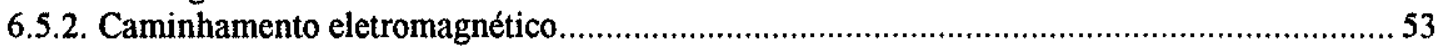

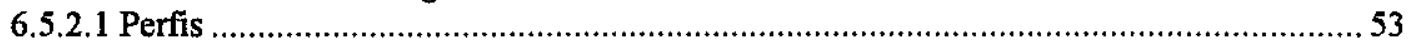

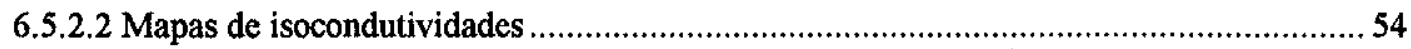

7. AVALIAÇÃO COMPARATIVA DOS DADOS ...............................................56

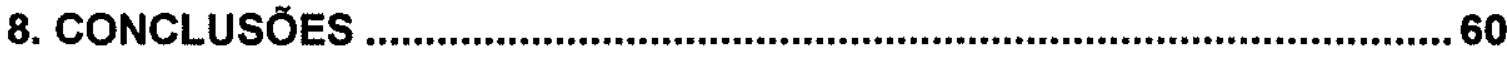

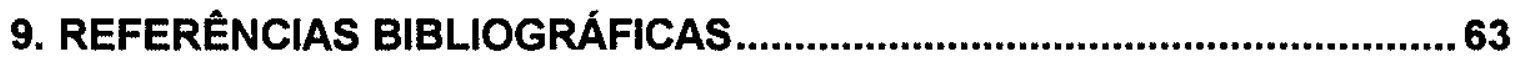




\section{LISTA DE ILUSTRAÇÕES}

FIGURAS

Figura 1 - Camada hemisferica pela qual a corrente I flui simetricamente a partir de um eletrodo pontual (modificada de Parasnis 1986).

Figura 2 - Disposiçăo dos eletrodos no campo para SE (modificadada de Braga 1988)

Figura 3 - Representação esquemática do método eletromagnético indutivo (modificada de Sheriff 1989)

Figura 4 - Mapa do Estado de Sáo Paulo com a localização das áreas de estudo (modificado de DAEE 1972)

Figura 5 - Representaçáo da área de estudo (destacada em azul) na carta do IBGE (1972) 23

Figura 6 - Mapa geológico da área de estudo (Fúlfaro \& Bjomberg 1993) 24

Figura 7 - Representaçáo da área de estudo (destacada em azul) na carta do IBGE (1972) 34

Figura 8 - Geologia da porção sudeste da RMSP e localizaçăo da área do lixăo (modificado da EMPLASA 1980)

Figura 9 - Gráficos representativos das intensidades de anomalias de condutividade elétrica

\section{TABELAS}

TABELA 1 - Características físico-químicas do efluente da indústria

TABELA 2 - Características físico-químicas do efluente da indústria

TABELA 3 - Definição da profundidade de N.A. a partir da interpretação das SEs executadas na área

TABELA 4 - Características físico-químicas do efluente e água amostrada de poço da indústria, e de outras indústrias com o mesmo tipo de efluente

TABELA 5 - Caracteristicas físico-químicas da água amostrada dos poços de monitoramento.

TABELA 6 - Resumo da interpretaçăo das sondagens elétricas

TABELA 7 - Definição da profundidade de N.A. a partir da interpretação das SEs executadas na área

TABELA 8 - Características físico-químicas e bacterológicas do chorume e pontos de amostragem na área de estudo

TABELA 9 - Resumo da interpretação das sondagens elétricas

TABELA 10 - Definição da profundidade de N.A. a partir da interpretação das SEs executadas na área 
QUADROS

QUADRO 1- Concentração de Na (mg/) e medida de CE ( $\mu \mathrm{S} / \mathrm{cm})$ no chorume 51 QUADRO 2 - Definição qualitativa de intensidade de anomalias geofísicas. 


\section{LISTA DE ANEXOS}

ANEXO I Plantas de Localização dos Pontos Investigados por Geofísica nas Áreas de Estudo.

ANEXO II Curvas de Resistividade Elétrica Aparente (SE)

ANEXO III Perfis de Condutividade Elétrica Aparente (CEM)

ANEXO IV Mapas de Isocondutividade e Modelos Tridimensionais das Medidas de Condutividade Elétrica Aparente (CEM) 


\section{LISTA DE SÍMBOLOS, SIGLAS, ABREVIATURAS E NOMENCLATURAS}

\section{SIMBOLOS}

$\mathbf{F}$

$\rho_{r}$

$\rho_{a}$

a

P

m

I

dv

$\mathbf{R}$

dl

$\mathbf{s}$

$\rho$

$\rho_{\mathbf{a}}$

$J$

E

$\sigma$

$\sigma_{\mathrm{a}}$

r

dr

$A \in B$

MeN

$\Delta \mathbf{V}$

K

E

$\mathrm{H}_{\mathrm{p}}$

$\mathbf{H}_{\mathrm{s}}$

$w$

f

$\mu_{0}$

S

i

Fator de formação

Resistividade média da rocha, matriz e poros incluidos

Resistividade da água contida nos poros da rocha

Coeficiente da fórmula da Lei de Archie (varia com a textura da rocha)

Porosidade

Expoente da fórmula da Lei de Archie ou parâmetro de cimentação

Corrente elétrica

Diferença de potencial infinitessimal

Resistência elétrica

Comprimento infinitessimal

Área de secção

Resistividade elétrica

Resistividade elétrica aparente

Densidade de corrente

Campo elétrico

Condutividade elétrica

Condutividade elétrica aparente

Raio da camada hemisférica

Espessura infinitessimal da camada hemisférica

Eletrodos de corrente

Eletrodos de potencial

Diferença de potencial medida em campo entre $\mathrm{M}$ e $\mathrm{N}$

Fator geométrico

Espessura da camada elétrica

Campo magnético primário

Campo magnético secundário

$2 \pi f$ (frequência e velocidade angular)

Frequência

Permeabilidade elétrica do espaço livre

Espaçamento interbobina

$\sqrt{-1}$ (Número complexo) 
SIGLAS

CETESB Companhia de Tecnologia e Saneamento Ambiental do Estado de São Paulo EPA Environmental Protection Agency

\section{ABREVIATURAS}

VLF Very Low Frequency

GPR Ground Penetrating Radar

ER Eletrorresistividade

EM Eletromagnético Indutivo

SEV Sondagem Elétrica Vertical

SE Sondagem Elétrica

CEM Caminhamento Eletromagnético

N.A. Nivel d'água

TDS Total Dissolved Solids

RT Resíduo Total

CE Condutividade Elétrica Especifica

COT Carbono Orgânico Total

RMSP Região Metropolitana de São Paulo

\section{NOMENCLATURAS}

EM-34/10m-H O instrumento EM-34 com o cabo de referência de 10 metros e eixo das bobinas na posição horizontal (profundidade de investigação até 7,5 metros)

EM-34/10m-V O instrumento EM-34 com o cabo de referência de 10 metros e eixo das bobinas na posição vertical (profundidade de investigação até 15 metros)

EM-34/20m-H O instrumento EM-34 com o cabo de referência de 20 metros e eixo das bobinas na posição horizontal (profundidade de investigação até 15 metros)

EM-34/20m-V O instrumento EM-34 com o cabo de referência de 20 metros e eixo das bobinas na posição vertical (profundidade de investigação até 30 metros) 


\section{ABSTRACT}

A large variety of aquifer-pollution sources in São Paulo State is related to different economical activities. The explotation of these aquifers is increasing and represents an important resource to many sites. The contamination detection by geophysical methods (e.g. resistivity and inductive eletromagnetic techniques) has been an efficient way to solve this kind of problem. However, those methods are questionable when the pollution content is poor (either qualitatively or quantitatively) in inorganic constituents.

The objectives of this study were: to evaluate anomalous detection by geophysical methods (ER and EM) in three distinct areas subjected to three different pollution sources; to determine chemical constituents and their concentrations in the effluents, which could be related to the anomalous patterns and be used as a standard to evaluate the applicability of such methods in other cases; to define the method sensibility through the intensity of the anomalies, correlating them to the quantity and quality of the polluent content.

Vertical electrical soundings (SE), Schlumberger array, and ground conductivity profiling (CEM) were carried out in the three areas studied. The first site was exposed to the effluent load deriving from a rubber production industry and spilled in an infiltration lake, in José Bonifácio region. The second site was exposed to the effluents of a citrus industry, which were disposed in a groove way to be seep, or utilized as fertirrigation in an area close to the industry, in Mirassol region. The third site was subjected to the contamination by leachate of a refuse dump in Diadema region. The first two cases, which are in the Parana Basin, are characterized by the presence of organic constituents. In the third area, where the basement rock is present, the leachate is rich in organic and inorganic constituents. The results obtained from geophysical application are correlated to the geology, hydrogeology, historical contaminant processes and physic-chemical analysis of the leachate and industrial effluents.

During the development of this study, it was possible to observe that the application of the methods in every case detected different degrees of anomalies. These anomalies were defined by intensity bands (low, medium, and high) and, in some cases, it was possible to correlate to the underground contamination. The chemical constituent $\mathrm{Na}$ is supposed to be the responsible for the anomaly detection of these methods, specially when organic effluent is predominant. The $\mathrm{Na}$ concentration was around $170 \mathrm{mg} / \mathrm{l}$, measured by chemical analysis. It is suggested this value as being the minimum to produce detectable anomalies, however, not the only factor, when these methods are used. 


\section{RESUMO}

As diversas fontes de poluição de aquíferos no Estado de São Paulo estão relacionadas direta ou indiretamente com suas variadas atividades econômicas. A exploraçăo destes aquíferos para diferentes fins é crescente, e em muitas regiöes é de fundamental importância. Portanto, a detecção da contaminação através dos métodods geofísicos da eletrorresistividade e do eletromagnético indutivo tem sido uma técnica rápida e eficiente em muitos casos, como primeiro passo para a solução do problema. No entanto, a utilização destas técnicas é questionável quando a fonte poluente é "pobre" qualitativa e quantitativamente em constituintes inorgânicos.

Os objetivos deste estudo foram: a avaliação da detectabilidade dos métodos geofísicos utilizados (ER e EM) em três áreas sujeitas a três tipos de fontes de poluição, conforme anomalias detectadas em cada caso; determinar os constituintes químicos, e suas concentrações nos efluentes, que poderiam estar relacionados com as anomalias produzidas e utilizá-las como referência para avaliar a possibilidade da utilização dos métodos em outros casos; definir a sensibilidade do método através de intensidade das anomalias e correlacioná-las com a quantidade e qualidade da carga poluente.

Foram executadas sondagens elétricas (SE) com arranjo Schlumberger e caminhamentos eletromagnéticos (CEM) em todos os casos. A primeira área do estudo estava exposta à carga de efluente de indústria de matéria-prima para produção de borracha despejada em uma lagoa de infiltração, na regiāo de José Bonifácio. O segundo caso tratou de uma área onde a fonte poluente é o efluente de uma indústria de produtos cítricos, dispostos em sulcos em forma de curva de nivel para infiltração, ou ainda para ser utilizado na fertirrigação de uma área anexa à indústria, na regiăo de Mirassol. O terceiro caso foi de um estudo em área sujeita à contaminação por chorume de um lixão na região de Diadema. Os dois primeiros casos possuem efluentes com predominância de constituintes orgânicos cujas áreas estão situadas nos domínios da Bacia do Paraná. Na última área estudada predominam as rochas do embasamento cristalino, e o líquido percolado (chorume) é rico em constituintes orgânicos e inorgânicos. Os resultados da aplicação dos métodos geofísicos foram correlacionados com dados existentes das áreas, como geologia, hidrogeologia, histórico do processo contaminante e análises físicoquímicas dos efluentes industriais e chorume.

Com o desenvolvimento do trabalho foi possivel obsevar que a aplicação dos métodos em todos os casos estudados detectou anomalias de graus variados. As anomalias detectadas foram definidas em faixas de intensidades baixa, média e alta, e foram relacionadas com contaminação em subsuperficie em boa parte dos casos, sendo que em outros tiveram origens diversas. O constituinte iônico $\mathrm{Na}$ foi assumido como possivel responsável pela detecção das anomalias através dos métodos utilizados, principalmente nos casos com efluentes de predominância orgânica. A sua concentração nas análises químicas dos efluentes é de aproximadamente $170 \mathrm{mg} /$, valor este sugerido como condição minima necessária existente, mas não suficiente, em efluentes industriais para que ocorra probabilidade de produzir anomalias, quando os métodos forem utilizados. 


\section{INTRODUÇÃO}

Com a expansão dos núcleos urbanos e rurais no território paulista, a "saúde" das águas subterrâneas, outrora menosprezada, passou a ser fundamental do ponto de vista de seu aproveitamento econômico. Para saneamento e prevenção dos problemas causados pela poluição, algumas instituiçöes e orgãos govemamentais tem demonstrado uma atenção especial estimulando a pesquisa, uma vez que, a médio prazo, há perspectiva de escassez de águas superficiais devido à alteração da qualidade em termos de potabilidade destas.

Uma série de atividades humanas e um vasto número de substâncias químicas têm sido identificadas como potencialmente prejudiciais à qualidade das águas subterrâneas (Gilham 1987).

A poluição nas camadas saturadas tem origem, por exemplo, na localizaçăo de lixões e indústrias em ambientes geológicos desfavoráveis, na forma inadequada da disposição de resíduos e efluentes industriais ou mesmo pela intrusão de água salgada no aquifero de áreas costeiras devido a poços de abastecimento mal locados ou mal explorados.

$\mathrm{Na}$ avaliação da poluição das águas subterrâneas dois fatores devem ser considerados. O primeiro é o conhecimento geológico e hidrogeológico do local e o outro está relacionado com as características dos poluentes. $O$ reconhecimento desses fatores possibilita determinar o comportamento dos poluentes no meio físico.

Uma dos métodos de pesquisa utilizados para caracterização geológica e hidrogeológica de uma área com problemas de contaminação subterrânea são os geofisicos. Quando executados com critérios técnicos, os seus resultados podem otimizar o reconhecimento prévio da profundidade do nivel d'água, direção e velocidade das águas subterrâneas, espessura de camadas aquiferas e confinantes e também detecção da pluma de poluição, no espaço e no tempo, visando um programa econômico de perfuração de sondagens mecânicas e/ou instalação de poços de monitoramento.

A eficácia dos métodos geofísicos em estudos de problemas ambientais, no entanto, depende de alguns parâmetros como por exemplo: o grau de contaminação, profundidade do produto enterrado, características geológicas da área alvo, variações laterais e heterogeneidades dos materiais geológicos e, consequentemente, da 
escolha criteriosa da técnica geofísca a ser empregada em cada situação (Matias et al. 1994).

Métodos geoelétricos têm sido utilizados extensivamente em estudos de contaminação de águas subterrâneas (Cartwright \& McComas 1968; Kelly 1976; Urish 1983; Greenhouse \& Harris 1983; Mendes 1987).

No estudo da poluição de águas subterrâneas já não se questiona a importância e eficiência dos métodos geoelétricos, principalmente a eletrorresistividade e o eletromagnético indutivo - métodos consagrados e incorporados aos projetos de controle ambiental sob fiscalização da CETESB (Companhia de Tecnologia e Saneamento Ambiental do Estado de São Paulo).

No atual estágio, tem-se buscado aprimoramento metodológico de modo a viabilizar o estudo de casos de contaminação por substâncias consideradas de baixa detectabilidade pelas técnicas usuais, ou ainda, quando os contaminantes estão presentes em baixa concentração. É nesse sentido que esse trabalho procura contribuir através do estudo de três casos por métodos geoelétricos. Dos três problemas tratados, dois estão relacionados com fontes contaminantes com pouca quantidade de substâncias detectáveis por esses métodos. O terceiro caso contem quantidade alta e variada dessas substâncias. Portanto, os métodos são avaliados quanto a detectabilidade de contaminação e determinação do elemento químico que propicia a deteç̧ão.

É óbvio que em todos os casos a caracterização geológica e hidrogeológica da área de estudo e entorno é de fundamental importância. Do mesmo modo são importantes os resultados das análises físico-químicas dos produtos das fontes poluentes. Os estudos geofísicos devem ainda ser complementados com as análises das águas coletadas nos poços de monitoramento locados com base em seus resultados.

\subsection{HISTÓRICO}

Os métodos geofísicos foram aplicados na exploração mineral desde 1640 para prospecção de ferro através de suas propriedades magnéticas, três séculos antes de serem utilizados na exploração do petróleo,onde teve seu maior incremento. Um dos pioneiros foi Robert Fox, que em 1815 descobriu que certos minerais exibiam polarização espontânea. Em 1913, Conrad Schlumberger utilizou esse efeito como 
medida, para localizar depósitos de sulfetos. Na mesma época ele desenvolveu técnicas aplicadas de campo para medidas de resistividade elétrica e linhas equipotenciais. Os métodos eletromagnéticos foram introduzidos por Hans Lundberg no meio da década de 20 , e passou por significativos avanços a partir da $2^{a}$ Guerra Mundial (Dobrin 1982). Na prospecção de águas subterrâneas os métodos geofísicos tem dado grande contribuição. No que se refere a poluição de aquíferos a sua utilização tem sido intensa $e$, com isso, novas linhas de pesquisa cada vez mais complexas são desenvolvidas.

$\mathrm{Na}$ quantificação de parâmetros hidrogeológicos das rochas, os métodos geoelétricos, principalmente $o$ da eletrorresistividade, tem exercido importante papel ao longo de sua história. Através da Lei de Archie $\left(\rho_{\mathrm{r}}=\mathrm{F} \rho_{\mathrm{a}}\right)$, definida empiricamente em 1942 para a indústria petroleira, pode-se relacionar, em alguns casos, os resultados de resistividade elétrica com as características litológicas. Por exemplo, como o fator de formação da rocha $\left(F=a^{-m}\right)$, dependente da porosidade $e$ cimentação da própria rocha, poderia ser aplicável para rochas livres de argila (Astier 1975; McNeill 1980a; Urish 1983; Bussian 1983; Parasnis 1986; Telford et al. 1990; Worthington 1993; Frohlic et al. 1994). Bussian (1983) utilizando-se de uma equação matemática correlaciona as propriedades elétricas de uma formação com as propriedades elétricas da rocha matriz e água a baixa frequência, com as formaçōes geológicas com conteúdo argiloso. Kwader (1986) demonstra que a lei é apropriada para situações específicas. Nesta mesma linha, Howard (1990) critica a utilização frequente desta lei de maneira errônea. Worthington (1993) discute a lei de Archie de um ponto de vista crítico, onde o uso indiscriminado dos valores de $\boldsymbol{m}$ (parâmetro de cimentação) e a (coeficiente relacionado com a textura das rochas), em vários trabalhos, são fisicamente insustentáveis.

Desde 1951 pesquisadores têm procurado estabelecer uma relação direta ou inversa entre resistividade elétrica e permeabilidade de aquiferos (Huntley 1986). Kelly (1978) utiliza medidas de resistividade elétrica para estimar condutividade hidráulica em aquiferos. Kosinski \& Kelly (1981) estabelecem relações empiricas entre propriedades elétricas e hidráulicas dos aquiferos. Mazác et al. (1990) ressaltam o importante papel da condutividade hidráulica na investigação da poluição de águas subterrâneas e a relaciona com parâmetros geoelétricos da zona saturada $e$ insaturada. Kalinski et al. (1993) utilizam métodos geofísicos (sondagem e caminhamento elétrico) como técnicas preventivas para avaliar a vulnerabilidade de aquiferos. A partir desses métodos eles correlacionam o tempo de transporte de um soluto em meios porosos (critério indicado pela EPA para quantificar os parâmetros 
de proteção de camadas geológicas ou do solo) com os parâmetros de Dar Zarrouk, em especial a condutância longitudinal.

Urish (1983), cita Swartz (1937) como sendo um dos primeiros pesquisadores a realizar estudos de contaminação de águas subterrâneas, utilizando-se do método da eletrorresistividade para delimitar a intrusão da cunha salina nas ilhas havaianas. A literatura (Kelly 1976; Greenhouse et al. 1983; Urish 1983; Mendes 1987) no entanto, sempre menciona Cartwright \& McComas (1968) devido a importância de seu trabalho no mapeamento de contaminantes (chorume), nos arredores de um aterro sanitário em Illinois-EUA. Kelly em 1976 utllizou sondagens elétricas para mapear a pluma de poluição e constatou, empiricamente, que existe uma boa correlação entre valores de condutividade elétrica específica (medida em amostras de água coletadas em piezômetros) com os resultados obtidos indiretamente pela eletrorresistividade. Greenhouse \& Harris (1983) aplicaram métodos geofísicos no monitoramento da qualidade da água subterrânea próximo a um depósito de lixo. Greenhouse et al. (1987) reunem em uma publicação cinco casos de contaminação de águas subterrâneas estudados com os métodos geofísicos da eletrorresistividade, eletromagnético indutivo e os métodos mais recentes, VLF e GPR, para mapeamento e monitoramento. Ebraheem et al. (1990), num levantamento para definir a resistividade elétrica de uma área contaminada definiram uma relação empírica entre resistividade elétrica e sólidos totais dissolvidos. Baker (1990) recomenda a execução de sondagens elétricas com arranjos mais sofisticados dos usuais, em áreas com águas subterrâneas contaminadas por aterro sanitário para reduzir a influência de efeitos laterais.

O atual desafio da geofísica nos estudos sobre poluição em águas subterrâneas é detectar os contaminantes orgânicos, principalmente aqueles derivados de petróleo. Hidrocarbonetos dissolvidos, provenientes do vazamento de tanques de combustivel enterrados, são relativamente móveis nas zonas saturadas e não saturadas e, além disso, persistem nas águas subterrâneas durante décadas ou mais (Cherry 1987; Cherry et al.1990; Kueper et al. 1991).

Olhoeft (1985) utilizando-se do método da polarização induzida detecta contrastes que podemem ter origem devido a processos geoquímicos entre as argilas presentes e os contaminantes orgânicos. Vanhala (1992) num estudo experimental utilizando o método da polarização induzida, fez medidas em laboratório, sobre amostras de tilito $(2,5 \%$ de argila) contaminadas por tolueno, heptano e etileno glicol, e também não contaminadas, observou que os elementos químicos orgânicos têm um efeito distinto nas medidas. No mesmo trabalho o pesquisador mostra, através de 
modelos teóricos, que o fenômeno medido em laboratório é detectável por investigações de campo. Borner (1993) também em laboratório executa experiências para detectar contaminantes orgânicos e inorgânicos utilizando polarização induzida a baixas frequências e demonstra que as partes real e imaginária da condutividade elétrica complexa são influenciadas pela presença do contaminante.

Pesquisadores das universidades de Waterloo e Colorado; têm realizado experimentos em uma célula estanque escavada no solo com injeção controlada de percloroetileno, utilizando o GPR (Ground Penetrating Radar) para detecção de contrastes e monitoramento, integrado com outros métodos geofísicos. Os resultados de monitoramento têm sido bem sucedidos, mas como detecção ainda são muito incertos (Annan et al 1991, Annan et al 1992, Brewster et al 1992a, Brewster et al 1992b, Brewster et al 1992c Greenhouse et al 1993, Redman 1992, Scheneider \& Greenhouse1992). Frolhich et al (1994) sugerem uma correlação entre os valores anômalos do fator de formação da rocha e a poluição, a partir das medidas definidas em campo e laboratório. Estes valores seriam causados por contaminantes orgânicos em conjunção com bactérias formadoras de ferro. Para o autor, caso essa hipótese seja demonstrada, ela seria uma opção para detecção de poluentes orgânicos através de métodos geoelétricos. Benson (1995) cita alguns estudos bem sucedidos com a utilização do GPR, como por exemplo, o mapeamento da contaminação de águas subterrâneas por hidrocarbonetos, ou a detecção de falhas superficiais e cavidades subterrâneas. Daniels et al (1995) aplicaram o método de GPR para detecção de contaminação por hidrocarboneto na zona não saturada e comprovaram a qualidade e repetibilidade dos dados através de um levantamento temporal.

Cruz-Sanjulián et al. (1992) sugerem uma correlação entre os valores medidos em uma zona de contaminação com altas concentrações de hidrocarbonetos precisamente sobre uma área com os menores valores de condutividade elétrica, a partir das medidas executadas em amostras de águas coletadas de piezômetros instalados na área de estudo.

Mazác et al. (1990) estudando a possibilidade de determinação da extensão de zonas contaminadas por derivados de óleo, desenvolveram um novo método geofísico designado por SB ("screening body"). Esse método baseia-se no modelamento matemático e de laboratório e análises teóricas e no estudo fez-se uma comparação com sondagem elétrica vertical.

O primeiro trabalho no Brasil que correlacionou valores de resistividade elétrica com as características dos sedimentos foi executado por Kollert em 1963 
(Mendes 1987). Ellert (1966) utilizando-se do método da eletrorresistividade aplicada à prospecção de águas subterrâneas no Estado de São Paulo, definiu os limites do método para cada situação geológica, determinou a resistividade (ou resistividades) de diferentes formações litológicas e correlacinou variações laterais de resistividade elétrica de uma camada geológica com variações de granulometria e litologia ou sais ainda dissolvidos na camada saturada.

Desde então os métodos geoelétricos têm sido aprimorados e cada vez mais difundidos na prospecção de águas subterrâneas. A partir de 1984, com a vinda do professor John P. Greenhouse para o Brasil, esses métodos tiveram um grande impulso em nosso pais na detecção da poluição subterrânea (Mendes 1987). Com o programa de convênio firmado em 1986 entre as universidades de Waterloo e de São Paulo, os métodos eletromagnéticos foram aplicados no estudo da contaminação de águas subterrâneas no Estado de São Paulo, onde os pesquisadores definiram, empiricamente, uma função que correlaciona valores de background de condutividade elétrica com valores de elevação, tendo como objetivo a possibilidade de uma correção topográfica (Greenhouse et al. 1987).

\subsection{OBJETIVO}

A dissertação se baseia em trabalhos geofísicos gerados pela autora e seu orientador, que abordam o problema de métodos geofísicos aplicados a diferentes casos de estudo de poluição de águas subterrâneas.

O objetivo da pesquisa é fazer uma avaliação da detectabilidade do método da eletrorresistividade integrado com o eletromagnético indutivo utilizados por estudos feitos em três áreas expostas a três tipos de fontes de poluição, procurando assim esclarecer a eficiência e precisão dos resultados. Nas áreas envolvidas o efluente era gerado pela fabricação de matéria prima para artefatos de borracha, moagem de produtos cítricos e líquido percolado de lixão (chorume).

Desta maneira procura-se caracterizar, através de métodos geofísicos aliados a outros dados existentes na área, a situação atual do local, para elaboração de projeto de recuperação, caso do lixão, de fertirrigação, caso da indústria de matéria prima de borracha e com os dois objetivos no caso da indústria de moagem de produtos citricos. Apesar do estudo realizado na indústria de borracha ser citado como projeto de caráter preventivo, existe no local uma pequena área com duas 
lagoas de infiltração de efluente em tomo das quais foi executado um levantamento geofísico produzindo dados que servirão para definir algum possivel contraste.

Com os casos concluidos separadamente, ou seja, numa discussão baseada no valor de background definido pelas condições naturais de cada área estudada, procura-se avaliar a eficiência dos métodos geofísicos conforme o caso estudado. É evidente que nos casos das indústrias citadas as anomalias condutoras relacionadas à contaminação apresentem menor intensidade do que as obtidas em torno do lixão já que o produto deste último, o chorume, contém quantidade de carga poluente muito mais elevada. Em termos de qualidade o chorume possui uma variedade de elementos muito maior do que os efluentes das indústrias, os quais apesar de possuirem características de compostos predominantemente orgânicos, contêm sais dissolvidos devido ao processo de industrialização.

A partir dos resultados das análises de caracterização físico-química dos efluentes industriais e do chorume serão determinados qualitativamente as concentraçōes dos elementos que poderiam estar relacionadas com as anomalias produzidas, para avaliar até que ponto os métodos geofísicos seriam utilizáveis em casos como o da indústria de cítricos e matéria prima para borracha, já que destes últimos tradicionalmente espera-se muito pouco em termos de detecção da pluma de poluição através de métodos geoelétricos. Neste sentido, os resultados dos casos estudados serão avaliados com o intuito de se definir a sensibilidade dos métodos conforme quantidade e qualidade da carga poluente.

\subsection{FONTES DE POLUIÇÃO}

As fontes poluidoras dos aquiferos, nos casos em estudo são as seguintes: uma indústria de produção de matéria prima para fabricação de borracha; uma indústria de moagem e industrialização de produtos cítricos; e o líquido percolado de lixão.

No primeiro caso, a indústria de borracha faz um estudo preventivo para melhor disposição de seus efluentes (rico em nitrogênio). No segundo caso, a "água amarela" é despejada em sulcos, em forma de curva de nivel, escavados no solo. Por último, as influências contaminantes que possam ser causadas pelo chorume. 


\section{METODOLOGIA GEOFÍSICA UTILIZADA E EQUIPAMENTOS}

O comportamento físico das rochas depende das propriedades e do modo de agregação de seus minerais e da forma, volume e conteúdo dos poros (geralmente água ou ar). As propriedades que interessam ao estudo de problemas práticos são as das rochas e minerais tal como se encontram na natureza, com suas impurezas, fraturas, fissuras, diáclases, umidade, etc... (Orellana 1982).

A geofísica é a ciência que estuda o comportamento dos materiais do subsolo a partir de medidas indiretas de suas propriedades físicas. Conforme as características de cada caso, utiliza-se o método que mede a grandeza física que melhor reflete as condiçōes dos materiais a serem estudados. No estudo de águas subterrâneas, os métodos geoelétricos são comprovadamente os mais eficientes e economicamente viáveis. Estes métodos se baseiam no estudo de propriedades eletromagnéticas das rochas, sendo geralmente, a magnitude mais significante a resistividade elétrica (ou sua inversa, a condutividade elétrica) (Keller \& Frischknecht 1966, Orellana 1982, Telford et al. 1990).

A resistividade elétrica das rochas, considerando apenas seus minerais constituintes, e da água, pura, é muito elevada, ou seja, elas são praticamente isolantes elétricos. No entanto, os tipos de águas presentes na natureza apresentam condutividade elétrica apreciável, pois sempre tem algum sal dissolvido, sendo que a quantidade e classe destes sais depende da natureza das rochas com que as águas tiveram contato em seu movimento subterrâneo ou na superficie do terreno, ou ainda dos gases em contato durante a precipitação. No caso das rochas, todas possuem poros e/ou fissuras em proporção maior ou menor, as quais podem estar ocupados total ou parcialmente por eletrólitos, do que resulta no conjunto, as rochas se comportarem como condutores iônicos, de resistividade muito variável conforme os casos (Orellana 1982).

Os métodos geoelétricos são muito versáteis e admitem uma variedade muito grande de formas de aplicação: o campo eletromagnético utilizado pode ser natural ou criado artificialmente, o contato com o solo pode ser galvânico ou indutivo, a corrente utilizada pode ser continua ou alternada e os procedimentos de medida também podem ser de vário tipos. 
Nos casos apresentados neste trabalho os métodos geofísicos utilizados foram a eletrorresistividade e o eletromagnético indutivo. A técnica de medidas, no primeiro caso, è a da sondagem elétrica (SE), ou sondagem elétrica vertical (SEV), pela qual se procura conhecer, por meio de um modelo de camadas onde temos resistividade elétrica e espessura, a estrutura geológica da área estudada, além de indicações sobre características hidrogeológicas dos estratos. No segundo método utiliza-se a técnica do caminhamento eletromagnético (CEM), o qual nos indica as áreas anomalamente condutoras que podem estar relacionadas à poluição.

\subsection{Eletrorresistividade}

A eletrorresistividade é um método geofísico que utiliza a propriedade física resistividade elétrica para identificação dos materiais do subsolo. Ela expressa a maior ou menor facilidade com que a corrente elétrica flui pelo material e depende da natureza e do estado fisico do corpo considerado.

A corrente elétrica I (ampére ou A) que atravessa um condutor curto, fino e linear de seç̧ão uniforme é dada pela lei de Ohm como,

$$
I=-\frac{d V}{R}
$$

onde $d V$ é a diferença de potencial (volt ou $V$ ) entre os extremos do condutor e $R$ (ohm ou $\Omega$ ) é a resistência do condutor. $O$ sinal negativo expressa o fato que o fluxo de corrente se dá a partir de potencial maior para potencial menor, ou seja, na direção oposta em que o potencial cresce (o gradiente). $\mathbf{R}$ é diretamente proporcional ao comprimento $\mathrm{dl}(\mathrm{m})$ do condutor e inversamente proporcional à área de secção que atravessa $s\left(\mathrm{~m}^{2}\right)$ sendo então expressa da seguinte forma,

$$
R=\rho \frac{d l}{\mathbf{s}}
$$

onde a constante de proporcionalidade $\rho$ (ohm.m) é a resistividade do material condutor. A resistência é uma característica de um fluxo de corrente elétrica bem definido, enquanto resistividade elétrica é uma propriedade física do material (Parasnis 1986). 


$$
\frac{I}{\mathbf{s}}=-\frac{1}{\rho} \frac{d V}{d l}
$$

O termo $\mathrm{U} / \mathrm{s}$ acima representa a densidade de corrente $\mathbf{J}$ (corrente por unidade de área da secçăo, $\left(\mathrm{Am}^{-2}\right)$, enquanto $-\mathrm{dV} / \mathrm{dl}$, expressa o campo elétrico $\mathbf{E}\left(\mathrm{Vm}^{-1}\right)$ na direção do vetor densidade de corrente, portanto,

$$
\mathbf{J}=\frac{\mathbf{E}}{\rho} \quad \text { ou } \quad \mathbf{E}=\rho \mathbf{J}
$$

alternativamente,

$$
\mathbf{J}=\sigma \mathbf{E}
$$

onde $\sigma(=1 / \rho)$ é a condutividade do material, e sua unidade é siemen por metro $\left(\mathrm{Sm}^{-1}\right)$, também designado por mho por metro $\left(\Omega^{-1} \mathrm{~m}^{-1}\right)$, sendo que 'mho' vem do inverso de 'ohm' (Parasnis 1986).

Tomando a equação 2.3 e fazendo com que dl tenda a zero e, consideremos o condutor um elemento linear de um meio contínuo, isotrópico e homogêneo, então qualquer uma das equações (2.4) ou (2.5) expressam a lei de Ohm para tal meio, e nessa situação o e $\rho$ são independentes da direção do fluxo de corrente (Parasnis 1986).

Consideremos um eletrodo pontual sobre a superficie de uma "terra" eletricamente isotrópica e homogênea, estendida para baixo até o infinito e tendo uma resistividade $\rho$.

No caso geral, tomando uma camada hemisférica de raio $r$ e espessura dr em torno do eletrodo, por simetria a corrente em qualquer ponto desta camada fluira na direção do raio (Figura 1). 


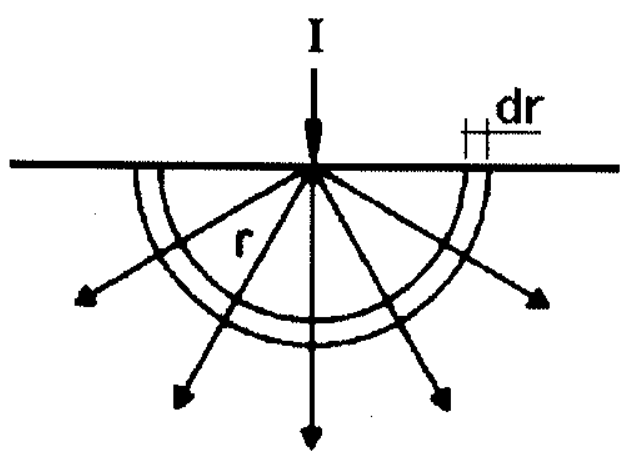

Figura 1 - Camada hemisférica pela qual a corrente I flui simetricamente a partir de um eletrodo pontual (modificada de Parasnis 1986).

Se a corrente total que passa através do eletrodo para dentro da terra é I, o potencial dV através da camada pode ser obtido utilizando a equação (2.3), como,

$$
d V=-\frac{I \rho}{2 \pi} \frac{d r}{r^{2}}
$$

integrando, obtemos,

$$
V(r)=\frac{I \rho}{2 \pi} \frac{1}{r}+C
$$

onde $\mathrm{C}$ é uma constante arbitrária. Se $\vee$ for considerado igual a zero em $r=\infty$, então $\mathrm{C}=0$ e teremos,

$$
V(r)=\frac{I \rho}{2 \pi} \frac{1}{r}
$$

(Parasnis 1986).

Funções potenciais são escalares, e desta maneira, podem ser adicionadas aritmeticamente. Se temos duas ou mais fontes de correntes, ou seja dois ou mais eletrodos pontuais, o potencial total em um ponto de observação pode ser calculado por adição das contribuições individuais de cada fonte. Desta maneira, para $\mathbf{n}$ fontes de correntes distribuidas em um meio homogêneo e isotrópico, o potencial em um ponto de observação $M$, será, 


$$
V_{M}=\frac{\rho}{2 \pi}\left[\frac{I_{1}}{a_{1}}+\frac{I_{2}}{a_{2}}+\ldots \ldots \ldots+\frac{I_{n}}{a_{n}}\right]
$$

onde $I_{n}$ é a corrente que sai do enéssimo eletrodo de corrente e $a_{n}$ é a distância da enéssima fonte ao ponto $M$ (Keller \& Frischknecht 1966).

A equação (2.9) é de importância prática na determinação das resistividades da "terra". As quantidades fisicas medidas em um levantamento de campo para determinar as resistividades são a corrente I, que flui entre dois eletrodos (geralmente chamados $\mathrm{A}$ e $\mathrm{B}$ ); a diferença de potencial $\Delta \mathrm{V}$, entre dois pontos de medidas através de eletrodos denominados por $M$ e $N$; e as distâncias entre os eletrodos. Portanto, os potenciais de cada eletrodo de corrente, considerando-os pontuais, imaginando que um deles se encontra no "infinito" em relação aos pontos de medidas, são expressos pelas seguintes relações:

$$
\begin{aligned}
& V_{M(A)}=\frac{\rho I}{2 \pi} \frac{1}{A M} \\
& V_{N(A)}=-\frac{\rho I}{2 \pi} \frac{1}{A N} \\
& V_{M(B)}=-\frac{\rho I}{2 \pi} \frac{1}{B M} \\
& V_{N(B)}=\frac{\rho I}{2 \pi} \frac{1}{B N}
\end{aligned}
$$

portanto,

$$
\Delta V=\frac{\rho I}{2 \pi}\left(\frac{1}{A M}-\frac{1}{B M}-\frac{1}{A N}+\frac{1}{B N}\right)
$$

ou,

$$
\rho=\frac{\Delta V}{I} K
$$


onde: $\quad K=\frac{2 \pi}{\frac{1}{A M}-\frac{1}{B M}-\frac{1}{A N}+\frac{1}{B N}}$, representa somente o efeito das distâncias de separação dos eletrodos, chamado de fator geométrico. O fator geométrico varia conforme o arranjo de eletrodos utilizado (Keller \& Frischknecht 1966).

Com base neste princípio, o método, através de equipamentos dispostos na superficie, determina a resistividade elétrica dos materiais do subsolo a diferentes profundidades. Desta forma, detecta-se os contrastes nas propriedades elétricas que são reflexos das características das diferentes camadas rochosas abaixo da superfície.

O levantamento de dados é feito sobre a área a ser pesquisada por técnicas que são definidas conforme objetivo do trabalho a ser realizado, sendo o mais indicado no caso de pesquisa de águas subterrâneas a sondagem elétrica.

A técnica de campo consiste em introduzir uma corrente elétrica no subsolo possibilitando determinar as resistividades a várias profundidades. Em linhas gerais o equipamento, um resistivímetro, é constituido de uma fonte de corrente, um miliamperímetro, um milivoltímetro e acessórios.

Também é necessário para o trabalho de campo 4 eletrodos que são cravados no solo. Dois eletrodos ( $A B$ ou eletrodos de corrente) têm a função de introduzir corrente elétrica no subsolo, enquanto através dos outros dois (MN ou eletrodos de potencial) mede-se a diferença de potencial devido a corrente elétrica gerada. A disposição, ou arranjo, dos eletrodos (que pode ser simétrica ou assimétrica) está ilustrada na Figura 2:

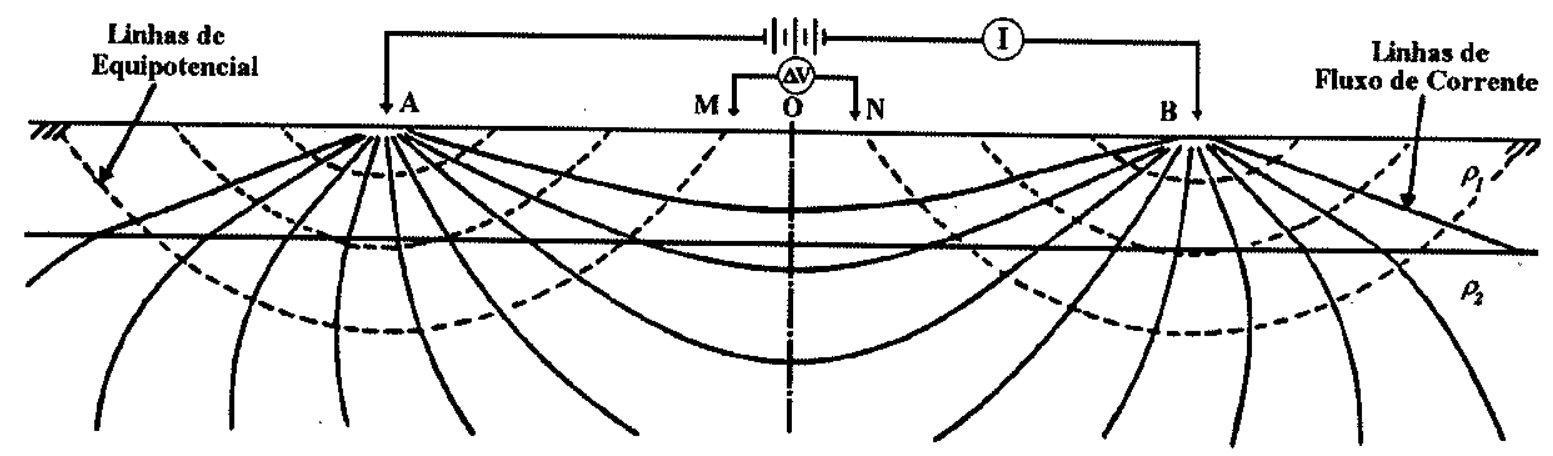

Figura 2 - Disposiçåo dos eletrodos no campo para SE (modificada de Braga 1988)

O arranjo dos eletrodos mais utilizado é do tipo Schlumberger onde a distância $M N$, teoricamente, tende a zero em relação à distância $A B$, o que facilita tanto na 
interpretação (qualidade das curvas de campo e cálculo de curvas teóricas) como no trabalho de campo pois atenua alguns sinais indesejáveis que podem ser adquiridos no mesmo e, é de fácil e rápida execução.

A equaçăo (2.15) obtida para resistividade em um meio homogêneo é aplicável também para um meio heterogêneo, o que é mais comum nos solos, só que neste caso a magnitude medida é denominada por resistividade elétrica aparente $\left(\rho_{a}\right)$.

$$
\rho_{a}=\left(\frac{\Delta V}{I}\right) K
$$

onde: $K=\pi\left(\frac{A M \times A N}{M N}\right)$

Enfim, executar a SE significa realizar uma série de medidas para definir as resistividades elétricas em subsuperfície, efetuadas com o mesmo tipo de arranjo e separação crescente entre os eletrodos de corrente. Durante as medições permanecem fixos a direção e o centro do arranjo AMNB. A medida que se aumenta a distância entre $A$ e $B$, o volume total da subsuperficie amostrada também aumenta, possibilitando alcançar camadas cada vez mais profundas.

Os dados de resistividade aparente $\left(\rho_{\mathbf{a}}\right.$ em ohm.m) são representados em escala logaritmica em função das distâncias entre os eletrodos de corrente (AB/2 em metros) também na mesma escala. Obtem-se assim uma curva da SE, denominada Curva de Resistividade Aparente, que em seguida é interpretada por meio de ábacos (curvas teóricas) ou por meio de programas computacionais. Com a interpretação feita obtêm-se as resistividades verdadeiras das camadas e suas respectivas espessuras, que aliadas a outras informações de teor geológico da região permitem avaliar a estrutura geológica abaixo da superfície estudada.

\subsection{Eletromagnético indutivo}

Os métodos eletromagnéticos empregam ondas eletromagnéticas. Em linhas gerais o princípio do método se baseia em um campo primário, ou emissor, gerado por uma bobina que cria um campo eletromagnético alternado que é detectado por uma bobina receptora (Orellana 1973). 
Se existe um corpo condutor abaixo da superficie então estabelece-se um campo secundário criado por correntes induzidas pelo campo primário (Figura 3), com a mesma frequência do primário mas com uma diferença de direção, fase e/ou amplitude. Esta diferença é detectada pela bobina receptora em forma de anomalia. O estudo destas anomalias permite detectar as heterogeneidades existentes no subsolo, e determinar seu tamanho e profundidade (Orellana 1973).

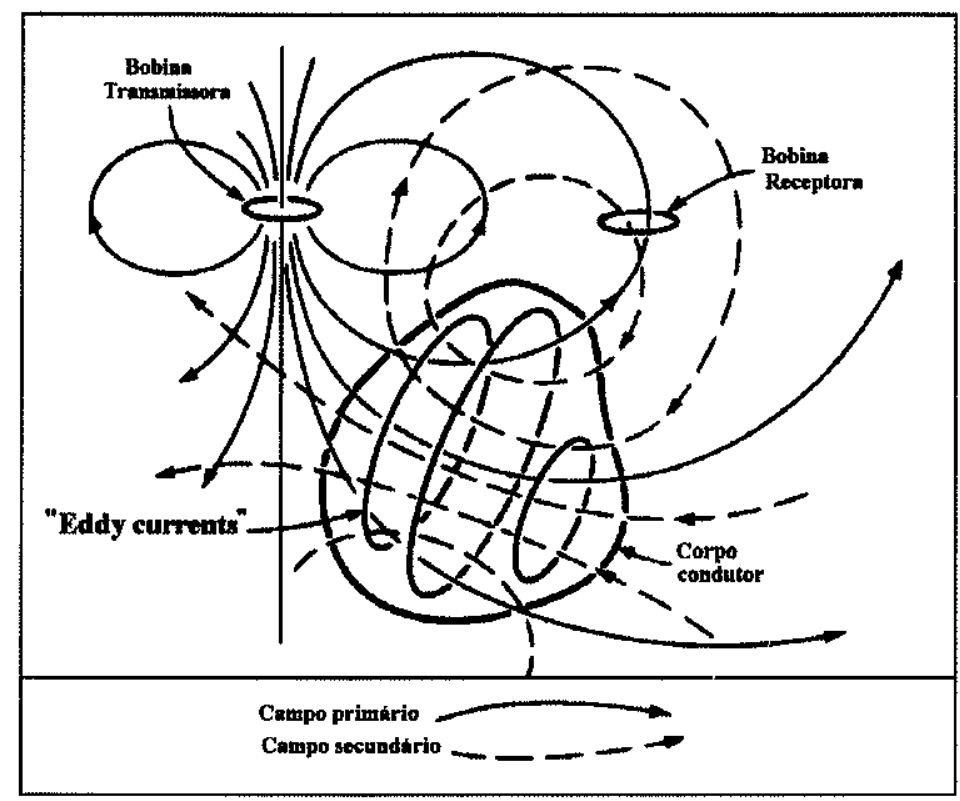

Figura 3 - Representaçăo esquemática do método eletromagnético indutivo (modificada de Sheriff 1989)

Pode-se estudar diferentes características do campo total medido na bobina receptora: amplitude, fase ou inclinação $\theta$ em relação ao campo primário. 0 método mais simples é o da medida de inclinação, segundo Astier (1975). No entanto este método parece ser eficiente apenas em casos onde o corpo condutor possui condutividade elevada. No caso da medida de amplitude, se determina a componente em fase, medida em fase com a tensão induzida primária na bobina receptora (componente real) ou a componente em quadratura, medida a $90^{\circ}$ da componente real (componente imaginária) ou, as duas (Sherrif 1989). O critério de escolha da componente que proporcionaria melhores resultados neste caso está relacionado com o grau de condutividade do corpo pertubador. Existe um método onde se mede a relação de amplitude e a diferença de fase do campo medido entre dois pontos próximos, denominado Turam (Astier 1975). Medidas eletromagnéticas também podem ser descritas em termos da elipse de polarização, onde dos parâmetros medidos, o principal é o ângulo de inclinação que o eixo maior da elipse faz com o plano horizontal ("tilt-angle). Também muitos métodos medem somente a direção do 
campo magnético induzido, como por exemplo o "dip-angle" (ângulo que o plano da elipse de polarização faz com o plano horizontal) ou "vertical-loop" (Sherrif 1989).

Geralmente, a condutividade elétrica aparente pode ser obtida indiretamente através da parte real e imaginária obtida do campo secundário induzido, ou em termos de porcentagem do campo resultante em relação ao primário, ou de parâmetros de polarização elíptica. No equipamento utilizado nesta pesquisa é possivel ler diretamente o valor de condutividade elétrica aparente obtido de maneira indireta, a partir da relaçäo entre campo magnético secundário e campo magnético primário ( $\mathrm{Hs} / \mathrm{Hp}$ ) como pode ser observado na expressão abaixo (McNeill 1980b):

$$
\sigma_{a}=\frac{4}{i w \mu_{0} s^{2}} \frac{H_{s}}{H_{p}}
$$

onde:

$$
\begin{aligned}
H_{p} & - \text { campo magnético primário } \\
H_{s} & -\quad " \quad \text { secundário } \\
w & -2 \pi f \\
f & - \text { frequência }(\mathrm{Hz}) \\
\mu_{0} & - \text { permeabilidade elétrica do espaço livre } \\
\sigma_{a} & - \text { condutividade elétrica aparente }(\mathrm{mho} / \mathrm{m}) \\
s & - \text { espaçamento interbobina }(\mathrm{m}) \\
i & -\sqrt{-1}
\end{aligned}
$$

Como já foi discutido no item anterior, a SE nos fornece o contraste de resistividade elétrica das camadas, suas espessuras e, consequentemente, uma projeção aproximada da configuração estrutural da geologia em subsuperfície. $O$ equipamento utilizado nesta pesquisa permite medir a magnitude condutividade elétrica $(\sigma)$ e tem sido extensivamente utilizado para detecção da pluma de poluição com conteúdo de compostos inorgânicos nas águas subterrâneas, caracterizada por seu aumento de condutividade elétrica.

A profundidade de investigação depende parcialmente de dois fatores que se podem variar: a distância emissor-receptor e a frequência da corrente indutora (Astier, 1975). Outros fatores que devem ser levados em conta são a resistividade elétrica do meio pelo qual a onda se propaga e orientação relativa entre as bobinas.

No equipamento utilizado, EM-34, quando os eixos das bobinas são mantidos na horizontal é possivel medir a condutividade elétrica até a profundidade de 0,75 vezes a distância existente entre as bobinas, e com os eixos na posiçăo vertical 
atinge-se até a profundidade de 1,5 vezes a distância entre elas. As duas situações diferem fisicamente entre si pelo fato de que, na vertical praticamente todas as "linhas" do campo magnético estão penetrando no subsolo, enquanto que na horizontal somente metade, o restante se encontra no "espaço livre". O EM-34 possui 3 cabos de referência que definem as distâncias de 10,20 e 40 metros entre as bobinas. Portanto, teoricamente, as profundidades de investigações atingidas através desse equipamento são de $7,5,15,30$ e 60 metros. Nesta pesquisa as profundidades investigadas são consideradas como próximas das definidas pelo manual do aparelho, pois estas não devem ser consideradas como exatas devido a heterogeneidade dos meios geológicos que, consequentemente, apresentam meios que propiciam maior ou menor penetração das ondas eletromagnéticas.

Dependendo da metodologia de campo e instrumento utilizado são analisados apenas algumas componentes ou aspectos do campo. De acordo com a literatura a denominação do método utilizado nos casos do nosso estudo varia. Método Slingram, é como Orellana (1974) prefere chamar, ou método do emissor e receptor móveis, como Parasnis (1986) denomina, que tem como caracteristica principal o movimento simultâneo da bobina transmissora e receptora, mantendo fixa a distância entre elas sendo que o arranjo pode ser variável. Para Sheriff (1989) Slingram é o nome dado aos arranjos coplanares.

O procedimento de medida utilizado foi o caminhamento eletromagnético (CEM), pelo qual é possivel observar a variação lateral no subsolo a uma certa profundidade, propiciando uma definição aproximada da extensão da pluma. São utilizados 2 arranjos de bobinas, o horizontal coplanar e vertical coplanar, os quais definem duas profundidades de investigação para cada distância entre as mesmas, pois, teoricamente, a profundidade atingida depende da distância entre as bobinas e da inclinação das mesmas.

A condutividade elétrica obtida é aparente, pois é resultado da integração da condutividade de cada parcela de solo desde a superfície até a profundidade de investigação do equipamento. Portanto, diferentemente do método da eletrorresistividade que nos dá informações tanto de teor qualitativo quanto quantitativo, no eletromagnético indutivo obtem-se apenas uma interpretação qualitativa indicando os contrastes da área estudada, sendo que a determinação de dados quantitativos relativos à espessura, profundidade e dimensões de uma maneira geral, de corpos em sub-superfície, é bastante limitada através deste método. 


\subsection{Métodos de trabalho}

Os métodos de trabalho estão apresentados nos itens a seguir, que indicam a sequência do trabalho executado e a descrição do tratamento dado aos valores medidos.

\subsubsection{Instrumentação}

Nos trabalhos de campo foram utilizados um conjunto de resistividade fabricado pela TECTROL Equipamentos Elétricos e Eletrônicos Ltda, modelo TDC 1000-12 e um condutivímetro modelo EM-34-3DL fabricado pela GEONICS Limited, com seus acessórios. Também foram utilizados um instrumento para medir $\mathrm{pH}$ e outro para medir CE das águas de poços de monitoramento quando não se dispunha dessas informações.

Foi utilizado também um fotômetro de chama, modelo B-262 da Micronal, para análise de alguns cátions em amostras de águas de poços de monitoramento.

Na parte de escritório foram utilizados microcomputadores, scanner e mesa digitalizadora.

\subsubsection{Trabalho de campo}

Os trabalhos de campo nas áreas de borracha, cítricos e lixão foram concluidos conforme planejado.

Nas três áreas de estudo procurou-se levantar todos os dados geológicos e hidrogeológicos existentes que pudessem, de alguma forma, auxiliar a interpretação dos dados geofísicos e o entendimento dos processos de contaminação decorrentes das atividades antrópicas ali instaladas.

Os dados de SE foram levantados antes do CEM, com exceção do lixão, procedimento este fundamental para definição do cabo de referência a ser utilizado. No caso do lixão devido a informações obtidas sobre a profundidade do nível d'água em alguns pontos foi conveniente iniciar com o CEM para um esboço inicial das áreas anomalamente condutoras, para posterior detalhamento, se necessário. 
Durante os trabalhos de campo, principalmente, procurou-se adquirir todas as informações relativas aos efluentes e águas subterrâneas, fundamentais para o estudo proposto, através de banco de dados das indústrias. Foram adotadas como informações fundamentais nessa fase dos trabalhos:

- medidas de nivel d'água em poços e cacimbas existentes nas áreas de estudo.

- perfil descritivo litológico disponiveis sobre as áreas.

- dados de parâmetros hidrogeológicos.

- análises físico-químicas para obter concentração de elementos iônicos comuns nos efluentes industriais e chorume.

- medidas de condutividade elétrica específica dos efluentes e poços de monitoramento (Kelly 1976).

\subsubsection{Interpretação dos resultados}

Os dados de SE foram interpretados preliminarmente, através de comparação com curvas teóricas, a partir dos quais foram definidos valores aproximados de espessuras e resistividades das camadas elétricas. Estes valores foram utilizados como parâmetros iniciais no programa RESIST, desenvolvido especialmente para este tipo de interpretação, onde procura-se minimizar o desvio padrão como também definir valores coerentes do ponto de vista global da região. O método do programa é direto, ou seja, um modelo de curva é sugerido, no nosso caso, a partir dos valores interpretados manualmente. A partir deste modelo o programa compara sua curva com a curva de campo e calcula o erro, em porcentagem, do desvio de cada ponto do modelo em relação ao respectivo ponto da curva de campo, então fica a cargo do geofísico avaliar se o modelo sugerido concorda com a situação real da área de estudo. Portanto, acreditou-se ser o mais conveniente por ser uma interpretação automática controlada, pois durante a interpretação o conhecimento geológico e hidrogeológico adquirido da área estudada pode ser inferido pelo interpretador, questão fundamental para que a interpretação não se torne apenas uma questão matemática.

Os dados de CEM serão interpretados qualitativamente, através de gráficos de condutividade elétrica $x$ posição da medida para cada caminhamento, onde se definem os valores de background $e$, consequentemente, valores anômalos em relação aos naturais. Os gráficos estão apresentados tanto em cores como símbolos diferentes para cada profundidade investigada. Estes dados também estão representados por mapas de isocondutividades e modelos tridimensionais para as 
respectivas profundidades investigadas, produzidos através do programa SURFER, os quais propiciam outra maneira de se visualizar a situação da área.

Para a confecção do mapa de contorno de superfície através do SURFER, utiliza-se o processo de "GRID" o qual cria um "grid" de pontos espaçados regularmente a partir de dados com pontos espaçados irregularmente. O "GRID" pode ser executado por vários métodos de interpolação. Dos vários métodos matemáticos disponiveis neste programa para o cálculo das isolinhas, foi escolhido criteriosamente o da Mínima Curvatura, devido a distribuição espacial dos dados levantados serem dispersos e irregualres. "Este processo interpolador é amplamente utilizado em ciências da terra. A superfície gerada por interpolação através deste método é análoga a uma camada fina linearmente-elástica passando através de cada dado com uma mínima quantidade de curvatura. A Minima Curvatura gera uma superfície o mais suavizada possivel ao mesmo tempo que tenta manter fidelidade ao dado o mais próximo possível. No entanto não é um interpolador exato, o que significa que seus valores nem sempre são exatamente fiéis aos dados." (traduzido do "Help" do software SURFER)

Como pode ser observado nestes mapas e modelos, foi possivel utilizar cores para valores máximos e mínimos, o que contribui para o aspecto visual das anomalias, quando existentes. Os mapas estão representados esquematicamente em termos de escala e localização, sendo que utilizou-se o desenho digitalizado em ACADR12 dos perfis de caminhamentos como referencial para as análises e coordenadas de referência.

Os arranjos utilizados serão indicados pela seguinte nomenclatura, por exemplo:

\section{EM-34/10m-H}

onde: EM-34 - é referente ao instrumento utilizado

$10 \mathrm{~m}$ - significa que o cabo de referência utilizado foi de 10 metros (distância entre bobinas)

H - o eixo da bobina é horizontal ( $V$ - quando o eixo da bobina estiver vertical)

No sentido de contribuir com a interpretação, todos os pontos investigados são apresentados em mapas de localização das áreas estudadas com curvas de nivel (Anexo I), como também mapas de situação das áreas e mapas geológicos. 


\section{IDENTIFICAÇÃO DAS ÁREAS}

O estudo na área de produção de matéria prima para fabricação de artefatos de borracha fica em José Bonifácio-SP. A área com problemas de contaminação por efluente resultante da moagem e industrialização de produtos citrícos está situada em Mirassol-SP. A área onde localiza-se o lixão fica em Diadema-SP. A Figura 4 indica a localização das áreas no mapa do Estado de São Paulo (DAEE 1972). Os casos estudados são denominados nos itens a seguir pelo nome do local do estudo.

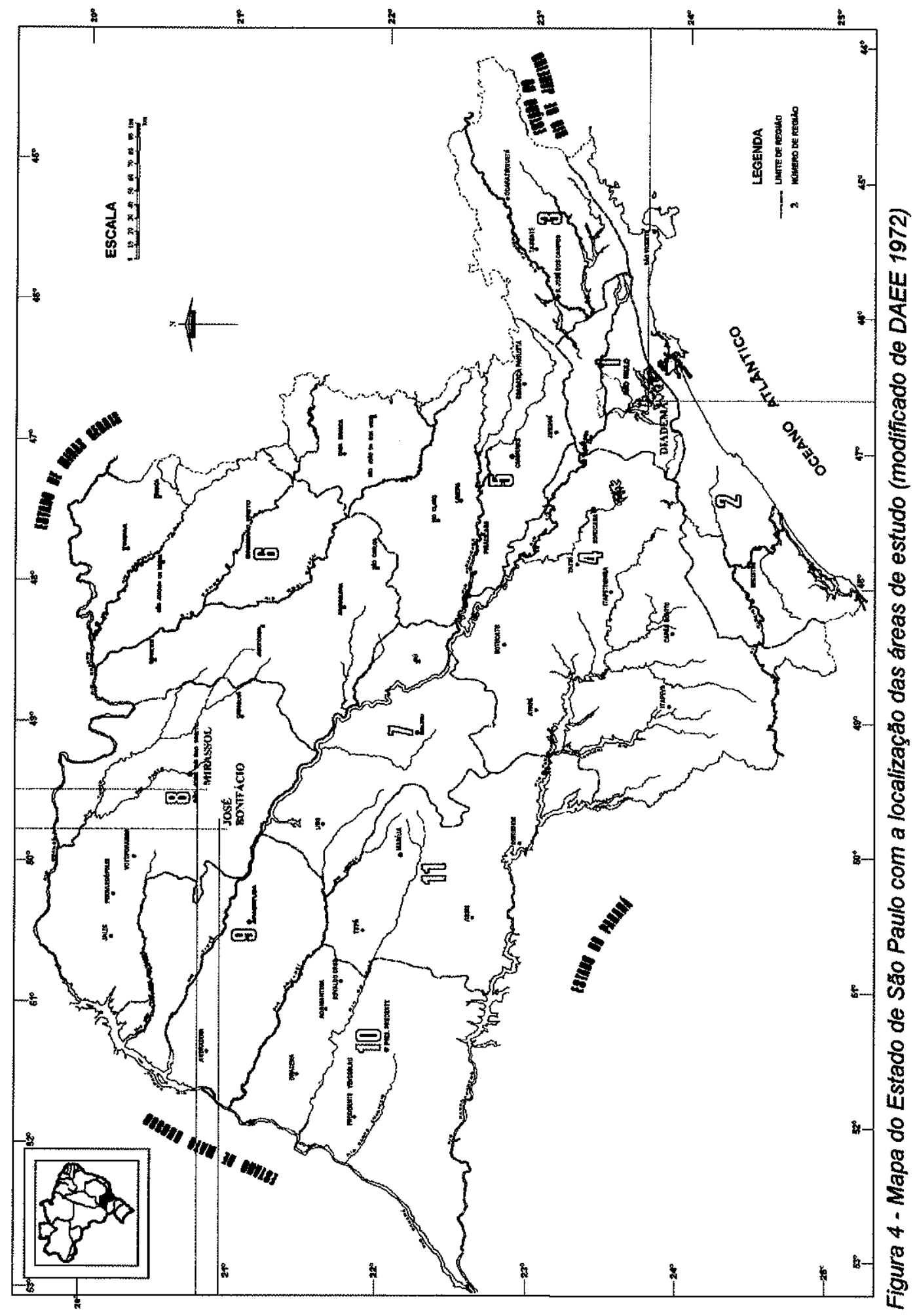




\section{JOSÉ BONIFÁCIO}

Os trabalhos geofísicos descritos foram realizados na área da Borracha Paulista Indústria e Comércio Ltda, em setembro de 1992. A Figura 5 representa a área de estudo, destacada em azul, situada na carta do IBGE (1972).

\subsection{Geologia}

De acordo com o mapa geológico do IPT (1981), na região afloram sedimentos do Grupo Bauru, (Cretáceo Superior), representado na área pela Formação Adamantina, representada no mapa da Figura 6, "a unidade de maior distribuição em superficie no Estado de São Paulo" (Soares 1980).

O Grupo Bauru é caracterizado por arenitos, arenitos argilosos e siltito, com ou sem cimentação carbonática. A espessura deștes sedimentos possui uma grande variação em função da geologia e da morfologia, sendo mimima nos vales dos rios de maior expressão onde afloram os basaltos da Formação Serra Geral, até o máximo de 250 metros nos espigões e depressões estruturais do basalto (CETESB, 1977).

Estratigraficamente a Formação Adamantina recobre as Formações Caiuá e Santo Anastácio e é recoberta pela Formação Marilia. Apresenta estratificação planoparalela e cruzada de pequeno a médio porte. De origem predominantemente flúviolacustre é constituída de bancos de arenitos, que variam entre 2 e 20 metros, de granulação fina com coloração rósea e castanha, alternados com lamitos, siltitos e arenitos lamíticos (Soares 1980). Em estudos posteriores (Barcelos et al. 1984; Fúlfaro \& Bjomberg 1993), a Formação Itaqueri foi anexada ao Grupo Bauru, como pode ser observado na Figura 5.

Os sedimentos da Formação Santo Anastácio afloram apenas nos locais de cotas mais baixas como nos vales dos rios afluentes do rio Paraná, na região oeste do Estado. São constituídos predominantemente por arenitos avermelhados de granulação fina a média, com espessura máxima em torno de 100 metros. Seu ambiente de deposição não está devidamente esclarecido.

$\mathrm{Na}$ região estudada afloram sedimentos da Formação Adamantina que somados aos da Formação Santo Anastácio, sotoposta, perfazem cerca de 120 metros de espessura. 


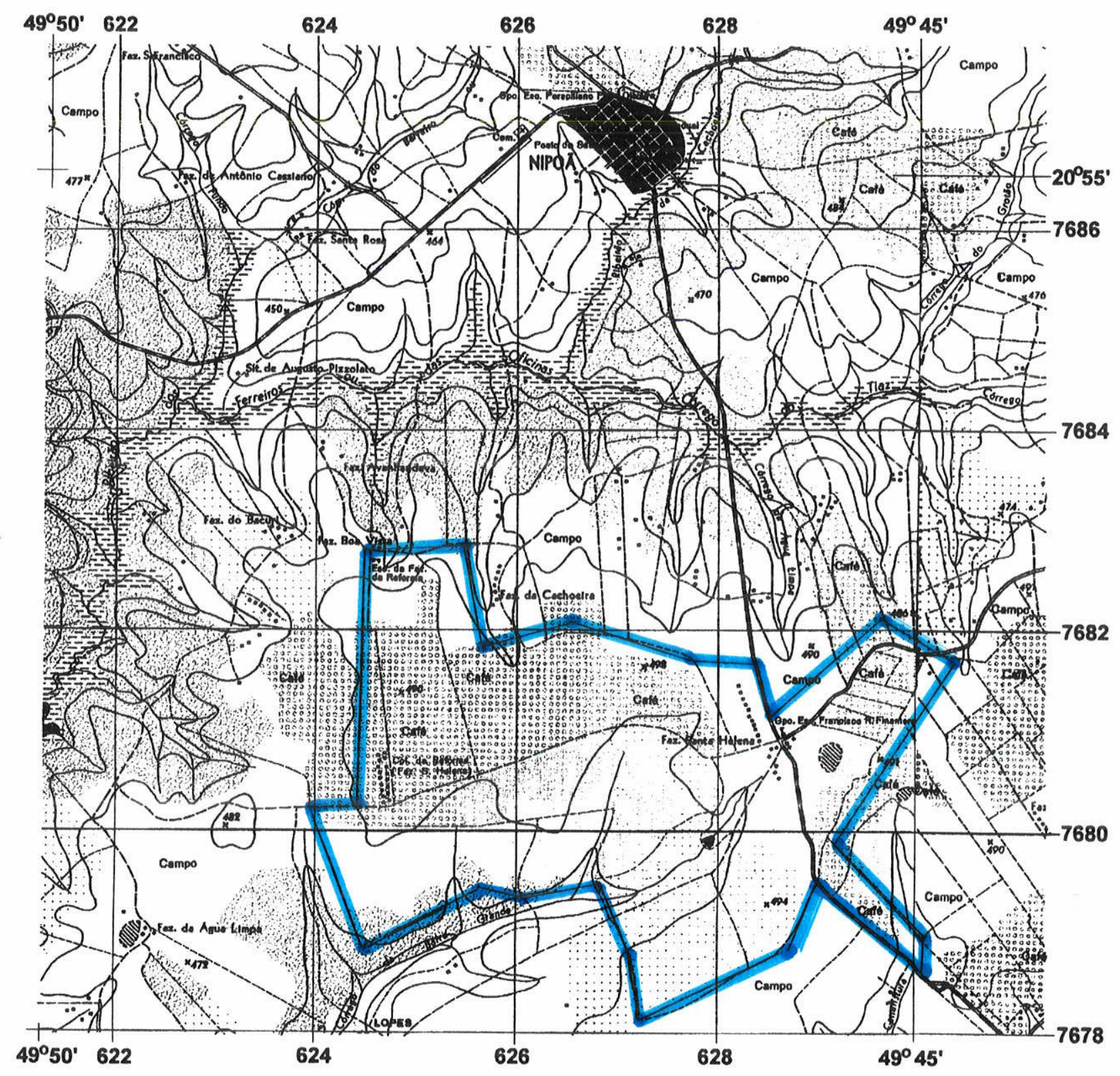

HIDROGRAFIA

Mangue. Salina

Curso d'água intermitente

Lago ou lagoa Intermitente

Terreno sujeito a inundaçăo

Brejo ou pantano

Poço (água). Nascente

Salto, cascata ou catarata

Cachoeira

Corredeira, rápido, travessăo

Barragens: terra, alvenaria

Fundeadouro

Arela

Campo de emergencla. Farol

Igreja. Escola. MIna

VEgetação

Mata, floresta. Cerrado, macega,

Cultura: permanente, temporarla
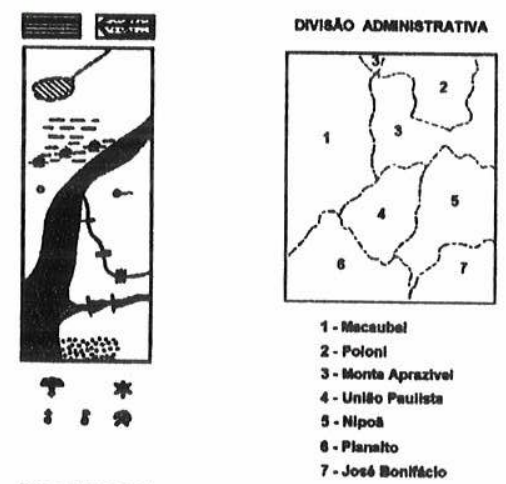

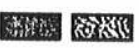

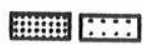

DECUNACAO MAGNÉTICA 1972 E CONVERGENCIA MERIDIANA
DO CENTRO DA FOLHA

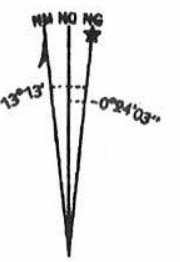

A DECLINAGÁ MAGNÉtica CREsce $\boldsymbol{\theta}$ ' ANUALMENTE

ESCALA GRAFICA

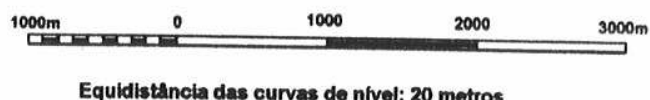

Equidistancia das curvas de nivel: 20 metros

Figura 5 - Representação da área de estudo (destacada em azul) na carta do IBGE (1972) 


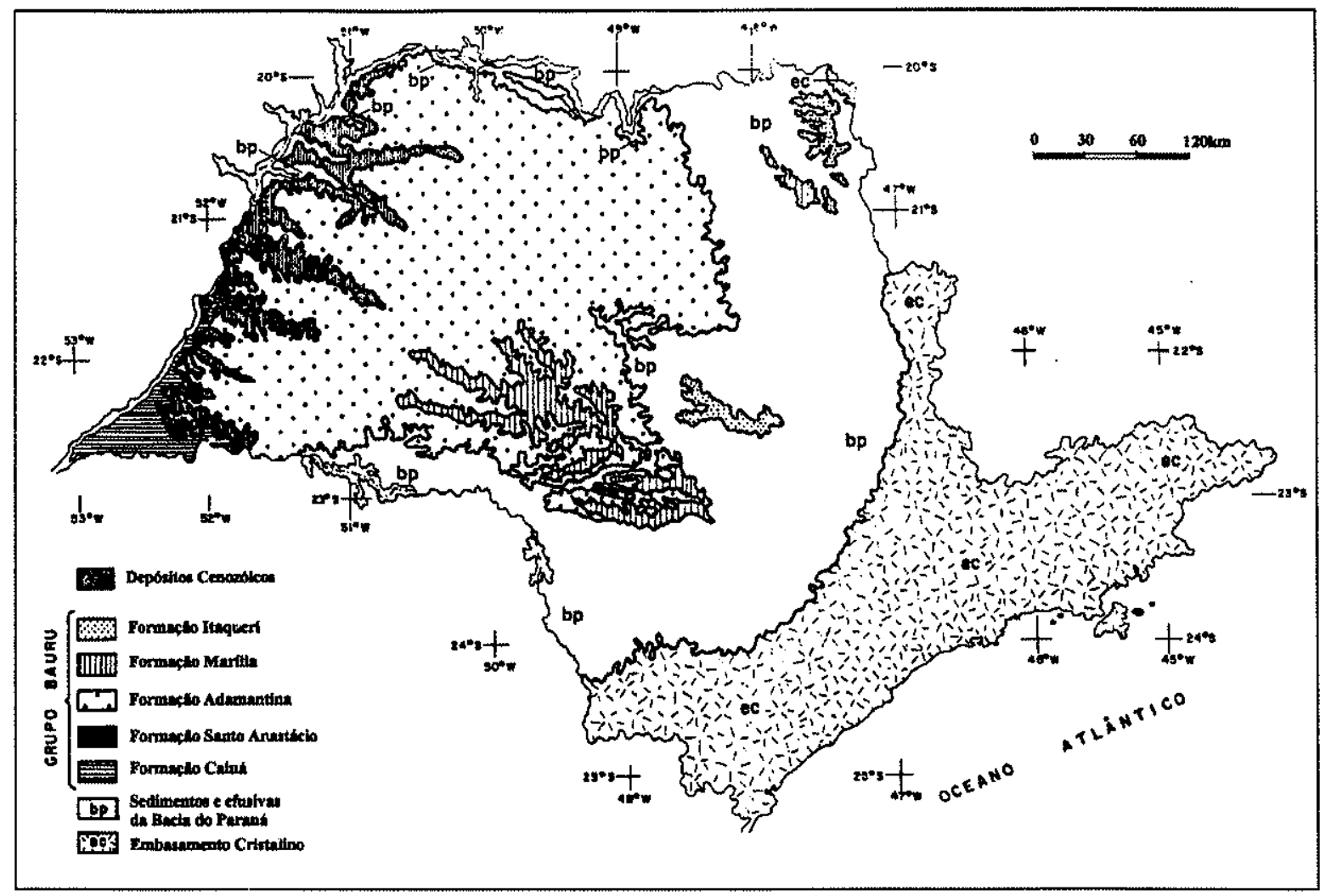

Figura 6 - Mapa geologico da área de estudo (Fúlfaro \& Bjomberg1993)

O topo do basalto da Formação Serra Geral, que constitui o embasamento para estes sedimentos, encontra-se nas áreas de interesse, em torno da cota 380 a 420 metros.

Localmente, observou-se, em superficie, a predominância de sedimentos arenosos com granulação média a média-fina, cor variando de marrom avermelhado a castanho escuro, formato dos grãos predominantemente subangular e com predomínio do mineral quartzo entre os grãos de areia. Análises granulométricas não especificadas, encomendadas pela empresa interessada, indicam o predominio de areia (69 a 77\%) na área, sendo que a ocorrência de silte (6 a $8 \%$ ) e argila (15 a $25 \%)$ é secundária.

\subsection{Hidrogeologia}

Segundo relatório do DAEE (1976), os aquíferos explorados na região pertencem às formações geológicas do Grupo Bauru e formações Serra Geral e Botucatu-Pirambóia. 
Na região de São José do Rio Preto o Aquífero Botucatu é confinado pelos derrames de basalto que o capeiam (Serra Geral). A base do aquífero é formada por camadas impermeáveis do Grupo Estrada Nova e camadas argilosas e siltosas. Em José Bonifácio o topo do Botucatu está situado aproximadamente $\mathbf{3 8 0}$ metros abaixo do nivel do mar e o topo do basalto 375 metros acima, sem registro de afloramentos no local.

O Sistema Aquífero Bauru é o mais explorado na região sendo formado por uma sequência de camadas de areia fina, areia argilosa, camadas argilosas, siltosas, bancos de arenito calcifero e calcário compacto, e às vezes horizontes de conglomerados. A estratificação desse aquifero é definida por 3 litofácies que determinam a maior ou menor permeabilidade do mesmo. No geral este aquifero é considerado permeável devido às intercalações de camadas permeáveis e semipermeáveis.

Segundo Campos (1987), que realizou um estudo hidrogeoquímico do Grupo Bauru, as águas subterrâneas, em âmbito regional, têm baixa salinidade $e$ apresentam dois tipos químicos dominantes: águas bicarbonatadas cálcicas e águas bicarbonatadas cálcico-magnesianas.

De um modo geral, as águas no Estado de São Paulo são ligeiramente ácidas (CETESB, 1977). No aquifero Bauru apresenta-se pH entre 5,0 a 5,5 de acordo com o trabalho da CETESB (1977).

Em um trabalho mais recente, produto de convênio entre IG-CETESB-DAEEEMBRAPA, o aquífero na área é denominado por Aquifero Adamantina. Tem extensão regional, de característica granular, livre a semi-confinado.

Um levantamento hidrogeológico preliminar mostrou que o fluxo subterrâneo das águas se dá no sentido dos locais topograficamente mais altos para os mais baixos a uma velocidade média de $3,382 \times 10^{-5} \mathrm{~cm} / \mathrm{s}$, ou, $3,3 \mathrm{~cm} /$ dia.

\subsection{Características do efluente}

O efluente é constituido de uma suspensão em água de partículas de látex em estado coloidal e/ou emulsão, sendo que a borracha contribui com 30 a $40 \%$ na constituição do látex e o restante é formado por proteínas, carboidratos, gorduras, ácidos orgânicos e constituintes minerais. 
Para a conservação do látex no processo de produção são utilizados hidróxido de amônio e ácido acético como coagulante. $O$ volume de efluente gerado situa-se ao redor de $350 \mathrm{~m}^{3} / \mathrm{dia}$, podendo ser reduzido a $200 \mathrm{~m}^{3} /$ dia com a reutilização desta água no processo. Utiliza-se soda cáustica para correção de $\mathrm{pH}$, na fase de flotação.

As características físico-químicas analisadas nos efluentes estão na Tabela 1. As unidades estão em $\mathrm{mg} / \mathrm{l}$, com exceção de condutividade elétrica $(\mu \mathrm{S} / \mathrm{cm})$ e pH (adimensional). Optou-se por desprezar os valores adquiridos nas análises de resíduos parciais (filtrável, volátil, fixo, etc), sendo considerado apenas o resíduo total, que segundo Freeze \& Cherry (1979) representa a concentração de sólidos totais dissolvidos (TDS), os quais constituem-se na sua maioria por inorgânicos e muito pouca quantidade de matéria orgânica. Portanto, existe uma relação direta entre TDS e condutividade elétrica.

TABELA 1 - Características físico-químicas do efluente da indústria

\begin{tabular}{rrrr}
\multicolumn{1}{c}{$\begin{array}{c}\text { Parâmetros } \\
\text { físico-químicos }\end{array}$} & $\begin{array}{c}\text { Medidas } \\
(\mathrm{mg} / \mathrm{l})\end{array}$ & $\begin{array}{c}\text { Parâmetros } \\
\text { físico-químicos }\end{array}$ & $\begin{array}{c}\text { Medidas } \\
(\mathrm{mg} / \mathrm{l})\end{array}$ \\
\hline $\mathbf{C a}$ & 3,29 & $\mathbf{N O}$ & nd \\
$\mathbf{C u}$ & 0,72 & $\mathrm{NKT}$ & 800 \\
$\mathrm{Na}$ & 192 & $\mathrm{NOrg}$ & 510 \\
$\mathbf{K}$ & 540 & $\mathrm{DBO}$ & 518 \\
$\mathbf{F e}$ & 1,82 & $\mathbf{D Q O}$ & 1130 \\
$\mathbf{P}$ & 450 & $\mathbf{C O T}$ & 305 \\
$\mathbf{M g}$ & 77 & $\mathbf{R T}$ & $9,56 \times 10^{3}$ \\
$\mathrm{SO}_{\mathbf{4}}$ & 13 & $\mathbf{C E}(\mu \mathrm{S} / \mathrm{cm})$ & $3,23 \times 10^{3}$ \\
$\mathrm{NH}_{\mathbf{4}}$ & 290 & $\mathbf{p H}$ & 4,9 \\
$\mathbf{N O}_{\mathbf{3}}$ & 0,20 & & \\
\hline
\end{tabular}

Na Tabela 1 observa-se que as maiores concentrações iônicas são de $\mathbf{K}, \mathbf{P}$, $\mathrm{Na}, \mathrm{Mg}$ e do $\mathrm{NH}_{4}$. O critério adotado para definir a maior concentração dentre os elementos iônicos foi relativo aos outros parâmetros analisados.

Foram adquiridos através da CETESB dados mais recentes de análises de águas amostradas dos poços de monitoramento da lagoa de armazenamento de residuos e do efluente. Os resultados mais significantes são das medidas de CE 
( $\mu \mathrm{S} / \mathrm{cm})$, o qual no poço a montante é de 8820 e nos dois poços a jusante são de 15120 e 13272 . $\mathrm{O}$ pH variou entre 5.3 e 4.9 nos três poços.

\subsection{Levantamentos de dados geofísicos}

Foram executadas 12 SEs com os eletrodos de corrente $(A B)$ distanciados entre si de até 200 metros, suficientes para investigar profundidades em torno de 60 metros.

O CEM foi executado ao longo de 18 perfis, com pontos de medidas a cada 10 metros. As medidas de condutividade elétrica foram realizadas para profundidades de investigação de até 7,5 metros (EM-34/10m-H) e 15 metros (EM-34/10m-V), aproximadamente.

Os pontos de investigação estão representados no mapa da área, Anexo I.

\subsection{Interpretação}

De acordo com a logística do levantamento de dados em campo, os dados de SEs foram interpretados primeiramente e são apresentados nessa ordem, para em seguida os dados dos caminhamentos eletromagnéticos serem analisados.

\subsubsection{Sondagem elétrica}

A Tabela 2 expressa o resultado da interpretação das sondagens elétricas, onde os valores de resistividade elétrica $(\rho)$ estão em ohm.m e da espessura (E) em metros. Pode ser observado que as curvas são divididas em grupos de 3,4 e 5 camadas elétricas. Seguindo a padronização russa de morfologia das curvas a SE-8, única de 3 camadas, é do tipo K. As sondagens de 4 camadas variam em termos de tipo, sendo as SEs-2, 4, 10 e 11 do tipo HK, as SEs-7 e 9 do tipo KQ, a SE-1 do tipo KH e a SE-12 do tipo QQ. Quanto às SEs-3, 5 e 6 são do tipo KHK. O Anexo II apresenta as curvas de resistividade elétrica com suas respectivas interpretações para cada SE. 
TABELA 2 - Resumo da interpretação das sondagens elétricas

\begin{tabular}{|c|c|c|c|c|c|c|c|c|c|c|}
\hline & \multicolumn{2}{|c|}{ 1a camada } & \multicolumn{2}{|c|}{ 2a camada } & \multicolumn{2}{|c|}{ 3a camada } & \multicolumn{2}{|c|}{ 4a camada } & \multicolumn{2}{|c|}{ 5a camada } \\
\hline & $E$ & $\rho$ & $\mathbf{E}$ & $\rho$ & E & $\rho$ & E & $\rho$ & $\mathbf{E}$ & $\rho$ \\
\hline SE- 1 & 1,0 & 1350 & 3,0 & 1800 & 10,0 & 170 & - & 300 & - & - \\
\hline SE- 2 & 3,5 & 2000 & 10,0 & 650 & 3,0 & 1400 & - & 140 & - & - \\
\hline SE- 3 & 1,0 & 2000 & 1,5 & 4750 & 10,0 & 800 & 4,5 & 2000 & - & 110 \\
\hline SE- 4 & 3,0 & 3150 & 13,0 & 700 & 3,0 & 1500 & - & 100 & - & - \\
\hline SE- 5 & 1,0 & 1000 & 2,3 & 3000 & 6.0 & 650 & 6,0 & 1450 & - & 130 \\
\hline SE- 6 & 1,0 & 1700 & 1,3 & 4050 & 5,5 & 270 & 7,5 & 1100 & - & 140 \\
\hline SE- 7 & 1,5 & 2400 & 6,0 & 3500 & 14,0 & 1400 & - & 170 & - & - \\
\hline SE- 8 & 13,0 & 500 & 7,0 & 2050 & - & 50 & $=$ & - & - & - \\
\hline SE- 9 & 1,0 & 1300 & 5,0 & 3400 & 19,0 & 1300 & - & 85 & - & - \\
\hline SE-10 & 3,0 & 4100 & 9,0 & 1350 & 4,0 & 1800 & - & 170 & - & - \\
\hline SE-11 & 3,6 & 4200 & 14,0 & 750 & 4,0 & 1900 & - & 200 & - & - \\
\hline SE-12 & 2,0 & 1900 & 4,0 & 1300 & 11,0 & 400 & $=$ & 100 & - & - \\
\hline
\end{tabular}

Em todas as SEs onde foram definidas 3 e 5 camadas elétricas, as duas primeiras correspondem a solo/sedimento seco, acima do nível d'água com resistividades variando entre 500 a 2000 na primeira camada e, 2050 e 4750 na segunda. As demais camadas correspondem a sedimentos saturados, com resistividades entre 50 e 800 na terceira camada. Nas SEs com 5 camadas a parte saturada se subdivide talvez devido à variação na quantidade de argila, com resistividades entre 1100 e 2000 na quarta camada e 110 e 140 na quinta.

As SEs-1, 7 e 9, com 4 camadas, se enquadram na interpretação dada às de 3 e 5 camadas. Portanto, as duas primeiras correspondem a solo/sedimento seco com resistividades entre 1300 e 2400 na primeira e 1800 e 3500 na segunda. Já nas SEs-2, 4, 10, 11 e 12 apenas a primeira camada deve ser considerada solo/sedimento seco com resistividade entre 1900 e 4200, sendo que os sedimentos saturados estariam representados pelas demais.

A partir do resultado da interpretação foi possivel definir a camada elétrica correspondente aos sedimentos saturados, e então foi elaborado a Tabela $3 \mathrm{com}$ os dados de interesse sobre o nível d'água em cada ponto investigado. 
TABELA 3 - Definição da profundidade de N.A. a partir da interpretação das SEs executadas na área

\begin{tabular}{cccc}
\hline Sondagem & Cota & Nivel d'água & Cota do N.A. \\
\hline SE-1 & 486 & 4,0 & 482,0 \\
SE-2 & 487 & 3,5 & 483,5 \\
SE-3 & 492 & 2,5 & 489,5 \\
SE-4 & 491 & 3,0 & 488,0 \\
SE-5 & 489 & 3,3 & 485,7 \\
SE-6 & 475 & 2,3 & 472,7 \\
SE-7 & 485 & 7,5 & 477,5 \\
SE-8 & 492 & 20,0 & 472,0 \\
SE-9 & 491 & 6,0 & 485,0 \\
SE-10 & 490 & 3,0 & 487,0 \\
SE-11 & 492 & 3,6 & 488,4 \\
SE-12 & 479 & 2,0 & 477,0 \\
\hline
\end{tabular}

Com exceção da SE-8 (N.A. = 20 metros) o nivel d'água ficou definido entre 2,0 e 7,5 metros. O valor de N.A. para a SE-8, com certeza discrepante, pode ser explicado como sendo consequência do rebaixamento do lençol devido ao bombeamento de 5 poços profundos concentrados próximos ao local.

\subsubsection{Caminhamento eletromagnético}

A interpretação e discussão dos caminhamentos eletromagnéticos são apresentadas a seguir de maneira separada no que diz respeito a forma de apresentação visual dos dados. Os perfis discutidos estão no Anexo III e o mapas de isocondutividade com seus respectivos modelos tridimensionais, no Anexo IV. Os mapas de isocondutividade estão em coordenadas de referência apenas.

\subsubsection{Perfis}

O caminhamento eletromagnético indutivo permite uma avaliação mais segura no que diz respeito ao aspecto qualitativo da interpretação, isto é, a partir do contraste dos valores de condutividade elétrica medidos, e da forma geométrica das 
anomalias, é perfeitamente possivel a localização das fontes poluentes e mapear a distribuição espacial de seus efeitos, a partir da superfície.

Os dados do caminhamento estão apresentados individualmente no Anexo III, na forma de perfis de condutividade aparente para as duas posições de bobinas. A análise individual dos mesmos permite que se chegue a importantes interpretações de conjunto.

Existem quatro grupos de perfis: aqueles onde os valores de condutividade elétrica para os dois arranjos de bobinas estão situados numa faixa de até 10 $\mathrm{mmho} / \mathrm{m}$, os que variam entre 10 e $30 \mathrm{mmho} / \mathrm{m}$, os que estão numa situação intermediária entre estas duas e aquelas que mesclam duas destas situações.

No primeiro grupo, o maior, estão os perfis P-I, P-IV, P-VI, P-VII, P-VIII, P-IX, P-XIII, P-XIV, P-XV, P-XVI e P-XVII; no segundo grupo estão P-II e P-III; no terceiro $P-X, P-X I$ e $P-X I l$ e no quarto $P-V$ e $P-X V I I I$.

De modo geral os valores de condutividade abaixo de $10 \mathrm{mmho} / \mathrm{m}$ e os acima deste valor, porém medidos quando os perfis cruzam as drenagens, expressam as condições normais da área de estudo. Dentro destas características estão a maioria dos perfis do primeiro grupo e todos do quarto grupo.

O P-ll apresentou valores de condutividade elétrica elevados porque os pontos de medida estão próximos e foram distribuídos paralelamente a um brejo. $O$ P-III, principalmente em sua parte central, está na mesma situação.

Os perfis $\mathrm{P}-\mathrm{X}, \mathrm{P}-\mathrm{XI}$ e P-XII apresentam valores elevados para o primeiro grupo. $O$ interessante é que eles não cruzam a drenagens. $O$ que eles têm em comum é a proximidade com as lagoas, o que permite deduzir que há influência do efluente na qualidade da água subterrânea nos locais investigados. Em função do pequeno contraste de condutividade, pode-se concluir que a contaminação é pequena ou ainda que a carga de substâncias iônicas seja pouca. É interessante notar, ainda, que a condutividade dos perfis P-IX, P-XIII e P-XIV, também próximos às lagoas, está dentro dos limites do intervalo definido para o primeiro grupo, porém num patamar mais elevado que os restantes do mesmo grupo. Esta condição parece expressar uma situação de contaminação, porém em menor escala.

Para o entendimento desta interpretação é preciso ter claro que, para cada arranjo de bobina, a profundidade de investigação ao longo dos perfis é, 
teoricamente, constante. Assim, para um mesmo arranjo é lógico esperar que em condições normais as medidas feitas em pontos de cotas mais baixas, como os fundos de vales que correspondem às drenagens, onde o nível d'água está mais raso, devam acusar valores de condutividade mais altos do que nos pontos de cotas mais elevadas do perfil, pois dentro do pacote investigado existirão mais camadas saturadas. O mesmo raciocínio é válido para arranjos que investigam profundidades maiores. Por isto, para um mesmo perfil e arranjo de bobinas os valores de condutividade são maiores junto às drenagens. Do mesmo modo, para um mesmo ponto, a condutividade deve ser maior quando medida com o arranjo EM-34/10m-V, que investiga até 15 metros, do que com o EM-34/10m-H, cujo o alcance é de 7,5 metros, aproximadamente.

\subsubsection{Mapas de isocondutividade}

Mapas de isocondutividade, produzidos automaticamente através de softwares como o SURFER, podem correr o risco de representarem situações bem distantes da realidade, como ficou demonstrado no caso estudado da região de José Bonifácio. Observa-se nos mapas do Anexo IV, visualmente, que existem quatro áreas com tendências de valores anômalos em relação ao valor de background ( 5 a $10 \mathrm{mmho} / \mathrm{m})$ :

- área 1: anomalia a partir do P-XVIII, entre as "coordenadas" 30 e 50 na parte leste do mapa e entre 85 e 110 a sul do mapa.

- área 2: anomalia entre 10 e 30 a sul do mapa e entre 30 e 50 a oeste do mapa.

- área 3: anomalia entre 10 e 30 a sul e 85-110 a leste do mapa.

- área 4: anomalia na parte central do mapa em torno dos perfis P-X, P-XI, P-XII, PXIII e P-XIV, próximos às lagoas.

Com certeza as áreas 1, 2 e 3 não representam áreas contaminadas em subsuperficie, pois nestes locais nem sequer existem perfis de medidas. Isto demonstra a limitação do método matemático que deveria executar interpolações em torno dos pontos com medidas, principalmente. Desprezando essas áreas, podem ser observados aumento de valores em torno das lagoas, equivalente à área 4 , e nos perfis próximos às drenagens.

Ao analisarmos os mapas de isocondutividade para as duas profundidades investigadas, Anexo IV, fica clara a tendência de integração dos valores à medida que se atinge profundidades maiores. 
O mesmo é válido para os modelos tridimensionais que acompanham estes mapas e representam os mesmos. 


\section{MIRASSOL}

A área de estudo pertence à Bascitrus Agro-Indústria S.A., situada no km45 da Rodovia Feliciano Salles Cunha. O levantamento foi realizado em duas etapas, sendo que a Etapa I foi em agosto de 1992 e a Etapa II em novembro de 1993. A figura 7 destaca em azul a área de estudo na carta do IBGE (1972). Na primeira etapa procurou-se levantar dados para contribuir com projeto de recuperação e na segunda para auxiliar no monitoramento de área destinada à fertirrigação.

\subsection{Geologia}

A região de Mirassol está situada no mesmo contexto geológico regional de José Bonifácio, onde a Formação Adamantina é a unidade aflorante, do Grupo Bauru. No caso do topo do Botucatu está situado 500 metros abaixo do nível do mar e o topo do basalto tem 400 metros acima, o que pode ser observado nos mapas de profundidade de topo do DAEE (1976). Esse quadro define uma espessura para o pacote sedimentar sobrejacente superior a 130 metros, na região.

\subsection{Hidrogeologia}

Regionalmente as características hidrogeológicas são definidas pelas particularidades do Sistema Aquífero Bauru como no caso da região de José Bonifácio.

$\mathrm{Na}$ área de estudo existem dois poços tubulares profundos (P-1 e P-2), um poço de monitoramento abandonado $(P)$ e quatro poços de monitoramento construídos recentemente (PM-1, 2, 3 e 4), cujos dados permitem avaliar de forma mais detalhada as características hidrogeológicas locais e estão apresentados no mapa do Anexo I.

O poço P-2, executado em setembro/91, possui o nivel estático a $25 \mathrm{~m}$ e o dinâmico a $110 \mathrm{~m}$ de profundidade, com uma vazão na época da instalação de $38 \mathrm{~m}^{3}$. Não há registro de teste de vazão máxima. 


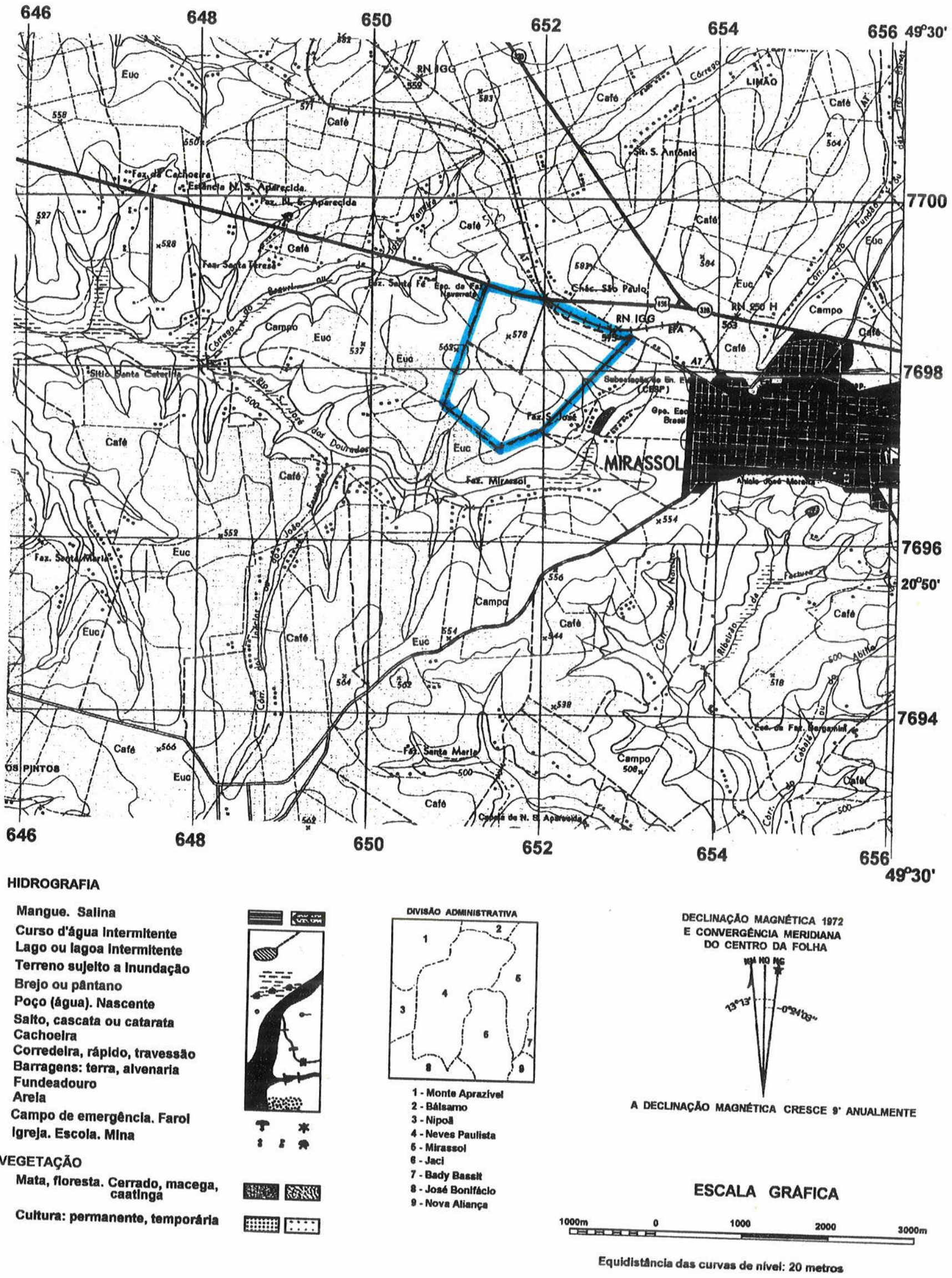

Figura 7 - Representação da área de estudo (destacada em azul) na carta do IBGE (1972) 
A profundidade investigada foi de $171 \mathrm{~m}$, sendo que até $135 \mathrm{~m}$ a caracterização geológica é de predominância arenosa, com variações em alguns niveis para arenito fino siltoso, siltito arenoso, arenito fino siltoso com lentes de argilito e arenito fino e médio siltoso, com lentes de argilito. As cores variam entre cinza, amarelado e bege e o pacote foi caracterizado como pertencente à Formação Adamantina. De $135 \mathrm{~m}$ a $170 \mathrm{~m}$ ocorreu em toda sua extensão arenito fino e médio de cor marrom arroxeado e foi caracterizado como Formação Santo Anastácio. A partir de $170 \mathrm{~m}$ foi observado o basalto da Formação Serra Geral.

As informações do poço $P-1$, perfurado em junho/91, em comparação com o citado acima são incompletas. A descrição é de areia silto argilosa marrom amarelada até $10 \mathrm{~m}$ de profundidade, passando para areia cinza amarelada até $30 \mathrm{~m}$ de profundidade.

Na mesma época foi construído um poço de monitoramento $P$ com o objetivo de monitorar a qualidade das águas subterrâneas no local. Com $30 \mathrm{~m}$ de profundidade, foi descrito como areia fina siltosa, cinza e amarelada em todo seu perfil. Consta dos dados técnicos que o nível estático na época foi de $8 \mathrm{~m}$. No dia $23 / 07 / 92$ o nivel d'água era $3,5 \mathrm{~m}$ de profundidade. Esse poço é um exemplo do mal dimensionamento de muitos poços de monitoramento, visto a discrepância entre a profundidade necessária para a construção do poço de monitoramento $( \pm 5,0 \mathrm{~m})$ e a executada, seis vezes mais profundo. Geralmente, esses poços são projetados e locados sem um estudo prévio das condições geológicas e hidrogeológicas em subsuperfície.

Na Etapa I foi elaborado um mapa potenciométrico com base na medidas de nivel d'água $e$, principalmente nas pronfundidades definidas pelas sondagens elétricas. A direção do fluxo das águas subterrâneas definida perpendicularmente às isolinhas de potencial se dá dos pontos topograficamente mais altos para os mais baixos, coincidentes com as drenagens e brejos existentes na área. As curvas potenciométricas se mostraram aproximadamente paralelas às curvas de nivel, com exceção da área próxima aos poços tubulares P-1 e P-2, onde elas se inteceptam.

Atualmente existem 4 poços de monitoramento, a jusante da área da Etapa II (atual área de fertirrigação), que foram instalados em 1994. A profundidade do nivel d'água varia entre 1,20 e 8,48 metros. A localização desses poços também está apresentada no mapa do Anexo I. 


\subsection{Características do efluente}

Foram obtidas informações de boletins de análises tanto da água do poço de monitoramento $\mathrm{P}$ (mais antigo) como do efluente, denominado por "água amarela". A Tabela 4 mostra os resultados das análises. Também foram utilizados dados de outras indústrias da região, CUTRALE de Olímpia-SP e FRUTESP de Bebedouro-SP, que produzem o mesmo tipo de efluente. Na CUTRALE, além do efluente, utilizou-se dados de análise de água de uma mina situada próxima à área de infiltração e de um "curva de nivel", sulco escavado para disposição do efluente. A Tabela 5 apresenta dados de análises feitas em águas coletadas em junho de 1995 dos 4 poços de monitoramento a jusante da área de fertirrigação.

Deve-se observar que o constituinte iônico de maior concentração nas análises de efluentes da Tabela 4 é o $\mathrm{Na}$, o que é explicado pela utilização de soda cáustica na água de lavagem das instalações industriais para evitar a corrosão. Atualmente a proporção de soda cáustica na água de lavagem é de $1,5 \%$, proporcionando assim uma otimização do seu uso. Na época do levantamento geofísico a proporção era de $5 \%$. As análises são datadas de 1991 . O critério adotado para definir a maior concentração iônica foi relativo aos dados analisados da Bascitrus, no entanto, para reforçar essa escolha, pode-se observar que o dado de análise de concentração de $\mathrm{Na}$ proveniente de efluente da Cutrale é praticamente o mesmo.

Todos os valores das Tabelas 4 e 5 estão em mg/l, com exceção de pH. 
TABELA 4 - Características físico-químicas do efluente e água amostrada de poço da indústria, e de outras indústrias com o mesmo tipo de efluente

\begin{tabular}{|c|c|c|c|c|c|c|}
\hline $\begin{array}{l}\text { PARÁMETROS } \\
\text { FísICO- } \\
\text { QUÍMICOS }\end{array}$ & $\begin{array}{c}\text { ÁGUA DE } \\
\text { POÇO } \\
\text { (BASCITRUS) } \\
\text { (mg/l) } \\
\end{array}$ & $\begin{array}{c}\text { ÁGUA } \\
\text { AMARELA } \\
\text { (BASCITRUS) } \\
\text { (mg/l) }\end{array}$ & $\begin{array}{c}\text { MINA } \\
\text { (CUTRALE) } \\
\text { (mg/l) } \\
\end{array}$ & $\begin{array}{c}\text { EFLUENTE } \\
\text { BRUTO } \\
\text { (CUTRALE) } \\
\text { (mg/l) } \\
\end{array}$ & $\begin{array}{c}\text { CURVA DE } \\
\text { NÍVEL } \\
\text { (CUTRALE) } \\
\text { (mg/l) } \\
\end{array}$ & $\begin{array}{c}\text { EFLUENT } \\
\text { BRUTO } \\
\text { (FRUTESP } \\
\text { (mg/l) } \\
\end{array}$ \\
\hline $\mathrm{pH}$ & $6,16^{*}$ & 4,08 & 8,3 & 5,4 & 7,5 & 6.1 \\
\hline $\mathrm{Na}$ & 4,94 & 172,6 & 78 & - & 168 & - \\
\hline $\mathrm{Cl}$ & - & - & 14,2 & - & 19,2 & - \\
\hline $\mathrm{PO}_{4}$ & 0,03 & 0,61 & 1,0 & 3 & 1,0 & 0,750 \\
\hline $\mathrm{K}$ & 3,04 & 47,2 & 7,2 & - & 11,4 & - \\
\hline $\mathrm{Ca}$ & 7 & 21,3 & - & 32 & - & - \\
\hline $\mathrm{SiO}_{2}$ & - & - & 4,0 & - & 2,0 & - \\
\hline $\mathrm{N}$ & 0,56 & 5,82 & - & 10,6 & - & - \\
\hline $\mathbf{P}$ & - & 45,0 & - & - & - & 146 \\
\hline Sulfetos & 8 & 45,76 & - & 5,3 & - & - \\
\hline DBO & 5,7 & 19128 & - & 3000 & - & 4540 \\
\hline DQO & 12,5 & 33678 & - & 6000 & - & 6400 \\
\hline $\begin{array}{l}\text { Oleos e } \\
\text { graxas }\end{array}$ & 124 & 275 & - & 60 & - & 264 \\
\hline Sol. totais & 460 & 1130 & - & - & - & - \\
\hline Sol. tot. fixos & 190 & 895 & - & - & - & - \\
\hline Sol. tot.vol. & 270 & 235 & - & - & - & - \\
\hline $\mathrm{CaCO}_{3}$ & - & - & 290 & - & 590 & - \\
\hline Dureza total & - & 92,6 & 110 & - & 140 & - \\
\hline Residuo total & 90 & 1015 & - & 2500 & - & 1960 \\
\hline
\end{tabular}

* o valor é resultado da média de quatro valores entre 1991 e 1992.

TABELA 5 - Características físico-químicas da água amostrada dos poços de monitoramento.

\begin{tabular}{cccccccc}
\hline & $\begin{array}{c}\text { CE } \\
(\mu \mathrm{S} / \mathrm{cm})\end{array}$ & pH & $\begin{array}{c}\text { Eh } \\
(\mathrm{mV})\end{array}$ & $\begin{array}{c}\mathrm{Na} \\
(\mathrm{mg} / \mathrm{l})\end{array}$ & $\begin{array}{c}\mathrm{K} \\
(\mathrm{mg} / \mathrm{l})\end{array}$ & $\begin{array}{c}\text { P } \\
(\mathrm{mg} / \mathrm{l})\end{array}$ & $\begin{array}{c}\text { N.A. } \\
(\mathrm{m})\end{array}$ \\
\hline PM-1 & 59,4 & 4,44 & 144 & 0,4 & 8,7 & - & 8,48 \\
PM-2 & 99,9 & 5,97 & 57 & 0,8 & 3,6 & 0,56 & 2.20 \\
PM-3 & 57,6 & 6,28 & 40 & 0,7 & 0,9 & 0,42 & 1,20 \\
PM-4 & 136,8 & 5,06 & 108 & 0,9 & 3,3 & 1,01 & 4,98 \\
\hline
\end{tabular}




\subsection{Levantamentos de dados geofísicos}

O levantamento de dados na área foi executado em 2 etapas. A primeira, de agosto de 1992, envolveu a execução de 9 sondagens elétricas e 9680 metros de caminhamento eletromagnético. Teve como objetivo mapear a pluma de poluição na água subterrânea, e por isso foi executada em torno da área de retenção. As SEs tiveram os eletrodos de corrente distanciados de até 100 metros, o suficiente para investigar até a profundidade de 40 metros. O CEM foi distribuído ao longo de 16 perfis com ponto de medidas a cada 20 metros, sendo utilizados os arranjos EM$34 / 20-\mathrm{H}$, que investiga o pacote de 0 a 15 metros e o EM-34/20-V que investiga de 0 a 30 metros de profundidade.

A segunda etapa, executada em novembro de 1993, teve como objetivo principal o estudo de uma área destinada a fertirrigação com o efluente da indústria. Neste caso procurou--se definir valores de resistividade e condutividade aparentes naturais da área, para futuramente servirem de referência para monitoramento da qualidade da água subterrânea e também determinar o sentido do fluxo subterrâneo para orientar a instalação de poços de monitoramento. Foram feitas 8 SEs e 3000 metros de CEM. Nas SEs os eletrodos de corrente foram distanciados de até 200 metros, o suficiente para investigar profundidades de até 60 metros. O CEM foi feito através de 4 perfis com pontos de medidas a cada 20 metros. Devido a área localizar-se em cota topográfica mais baixa em relação a área da etapa antecedente e, portanto, com nível d'água mais raso, em torno de 5 metros, utilizou-se o cabo de referência de 10 metros, ou seja, investigou-se até 7,5 metros e 15 metros de profundidade, com exceção do perfil P-XVII que por localizar-se na cota mais alta da área também utilizou o cabo de referência de 20 metros.

O mapa com a localização dos pontos investigados encontra-se no Anexo I.

\subsection{Interpretação}

A exemplo da fase de levantamento de dados, o tratamento dos dados e interpretação das sondagens elétricas precedeu o do caminhamento eletromagnético. 


\subsubsection{Sondagem elétrica}

O resultado das intepretaçōes executadas com o programa RESIST para sondagem elétrica está representado na Tabela 6 . As sondagens elétricas referentes à segunda etapa estão assinaladas com asterisco, lembrando que os valores de resistividade elétrica $(\rho)$ estão em ohm.m e de espessura (E) em metros. As curvas de resistividade aparente correspondentes às sondagens elétricas estão apresentadas nos gráficos do Anexo II.

TABELA 6 - Resumo da interpretação das sondagens elétricas

\begin{tabular}{|c|c|c|c|c|c|c|c|c|}
\hline & \multicolumn{2}{|c|}{ 1a camada } & \multicolumn{2}{|c|}{ 2a camada } & \multicolumn{2}{|c|}{ 3a camada } & \multicolumn{2}{|c|}{ 4a camada } \\
\hline & $E$ & $\rho$ & $E$ & $\rho$ & $E$ & $\rho$ & $E$ & $\rho$ \\
\hline SE- 1 & 1,0 & 220 & 7,0 & 1300 & 11,0 & 70 & - & 50 \\
\hline SE- 2 & 1,0 & 340 & 6,0 & 2300 & 17,0 & 400 & - & 18 \\
\hline SE- 3 & 1,0 & 700 & 6,2 & 2200 & 18,0 & 600 & - & 55 \\
\hline SE- 4 & 1,0 & 310 & 5,5 & 970 & 10,0 & 80 & - & 32 \\
\hline SE- 5 & 1,0 & 520 & 6,0 & 2400 & 16,5 & 200 & - & 35 \\
\hline SE- 6 & 1,5 & 130 & 3,5 & 380 & 10,0 & 35 & - & 25 \\
\hline SE- 7 & 2,6 & 410 & 8,7 & 35 & - & 180 & - & - \\
\hline SE- 8 & 1,5 & 120 & 3,5 & 480 & - & 35 & - & - \\
\hline SE- 9 & 1,5 & 490 & 4,0 & 2600 & 16,0 & 200 & - & 40 \\
\hline SE-10* & 1,0 & 130 & 5,5 & 1900 & - & 45 & - & - \\
\hline SE-11* & 1,0 & 100 & 4,0 & 2500 & - & 26 & - & - \\
\hline SE- 12* & 1,0 & 105 & 3,4 & 2500 & - & 25 & - & - \\
\hline SE- $13^{*}$ & 2,0 & 165 & 2,5 & 1600 & 10,0 & 100 & $=$ & 30 \\
\hline SE- 14* & 1,0 & 135 & 3,6 & 2700 & - & 25 & - & - \\
\hline SE- $15^{*}$ & 4,2 & 140 & 11,0 & 18 & - & 32 & - & - \\
\hline SE- 16* & 1,2 & 130 & 4,3 & 2000 & - & 26 & - & - \\
\hline SE- $17^{*}$ & 1,0 & 170 & 3,9 & 1950 & - & 24 & - & - \\
\hline
\end{tabular}

As SEs correspondem a curvas de 3 e 4 camadas elétricas onde, com exceção da SE-7 e SE-15, as duas primeiras correspondem sempre ao solo seco, acima do nivel d'água. Nos casos das exceções, apenas a primeira camada define a porção não saturada. As camadas saturadas, em cada sondagem, apresentam valores de resistividade bem mais baixos que os niveis secos e entre elas estes valores serão mais baixos quanto maior for o teor em argilas. 
Analisando a morfologia das curvas das 17 sondagens executadas, observase que as curvas com 3 camadas são do tipo K (SE-1, SE-2, SE-3, SE-5, SE-7, SE-8 e SE-16), com exceção das SE-6 e SE-15 que representam curvas do tipo $H$. As curvas com 4 camadas pertencem ao grupo do tipo KQ (SE-4, SE-9, SE-10, SE-11, SE-12, SE-13, SE-14 e SE-17).

A variação da profundidade do nivel d'água, nos pontos investigados ficou entre 2,6 e 8,2 metros, aproximadamente. Considerando as cotas topográficas dos locais das sondagens, foi elaborada a Tabela 7.

TABELA 7 - Definição da profundidade de N.A. a partir da interpretação das SEs executadas na área

\begin{tabular}{cccc}
\hline Sondagem & Cota & Nivel d'água & Cota do N.A. \\
\hline SE-1 & 571 & 8,0 & 563,0 \\
SE-2 & 566 & 7,0 & 559,0 \\
SE-3 & 567 & 7,2 & 559,8 \\
SE-4 & 576 & 6,5 & 569,5 \\
SE-5 & 566 & 7,0 & 559,0 \\
SE-6 & 558 & 5,0 & 553,0 \\
SE-7 & 542 & 2,6 & 539,4 \\
SE-8 & 553 & 5,0 & 548,0 \\
SE-9 & 561 & 5,5 & 555,5 \\
SE-10* & 571 & 6,5 & 564,9 \\
SE-11* & 564 & 5,0 & 559,3 \\
SE-12* & 553 & 4,4 & 548,6 \\
SE-13* & 547 & 4,5 & 542,3 \\
SE-14* & 564 & 4,6 & 559,6 \\
SE-15* & 541 & 4,2 & 537,1 \\
SE-16* & 553 & 5,5 & 547,3 \\
SE-17* & 546 & 5,9 & 540,9 \\
\hline
\end{tabular}

Estes dados permitiram a elaboração de mapa potenciométrico com indicação de áreas para instalação de poços de monitoramento.

\subsubsection{Caminhamento eletromagnético}

Como mencionado, o levantamento foi executado em duas áreas com situações diferentes em relação à contaminação. Portanto, a discussão deste item se dará em duas partes, onde a primeira estará relacionada com a área da etapa l e a 
segunda com a área da etapa II. Os perfis dos caminhamentos estão representados em gráficos no Anexo III e os mapas de isocondutividade e seus respectivos modelos tridimensionais no Anexo IV.

\subsubsection{Perfis}

\section{ETAPA I}

Analisando os perfis, observa-se que os valores de background considerados nesta área para os dois arranjos de bobinas são iguais ou menores de $10 \mathrm{mmho} / \mathrm{m}$. Valores entre 10 e $30 \mathrm{mmho} / \mathrm{m}$ serão, geralmente, considerados anômalos, com exceção de alguns perfis que apresentam esses valores devido à disposição superficial de rejeitos $e$, portanto, não representam anomalias em subsuperfície. Os valores maiores para o arranjo que investiga profundidade maior se explica pelo fato de estar sendo medido, neste caso, uma maior espessura de camadas saturadas.

Os perfis P-l, Pll e P-XIII, que são próximos, paralelos e por isso correlacionáveis, refletem uma situação interessante: nota-se uma tendência da condutividade aumentar do início para o final do caminhamento, passando de valores menores que $10 \mathrm{mmho} / \mathrm{m}$ para até maiores que $30 \mathrm{mmho} / \mathrm{m}$. A parte inicial do $P$-ll e principalmente do P-XIII estão influenciadas por rejeitos sólidos, como bagasso, dispostos na superfície do terreno e os valores de condutividade relativamente altos aí encontrados não têm relação com poluição subterrânea. $O$ comportamento dos valores ao longo do $\mathrm{P}-\mathrm{I}$ refletem melhor as condições de sub-superfície no local. Nota-se que para fora da área da indústria não há depósitos de rejeito.

O P-XII, também paralelo aos perfis analisados anteriormente, porém situado a uma distância de aproximadamente 250 metros da área da indústria, apresenta um comportamento diferente e uniforme. Os valores de condutividade elétrica situam-se abaixo de $10 \mathrm{mmho} / \mathrm{m}$ para os dois arranjos de bobinas e a julgar pela posição do perfil estes podem ser assumidos como valores de "background" para a área estudada. Os valores maiores para o arranjo que investiga profundidade maior se explica pelo fato de estar sendo medido, neste caso, uma maior espessura de camadas saturadas.

O perfil P-VI, que praticamente corta O P-I e o P-XIl em suas extremidades finais tem um comportamento bastante coerente com o que até aqui foi analisado, pois os valores medidos na sua parte inicial estão próximos dos valores obtidos em $\mathrm{P}-\mathrm{I}$ neste trecho, e os valores na parte final do P-VI estão semelhantes aos do P-XII. 
Os perfis P-lll e P-VII, que são próximos e paralelos, são também muito parecidos quanto aos valores de condutividade, pois começam entre 10 e 20 $\mathrm{mmho} / \mathrm{m}$, para as duas profundidades de investigação, sobem para até $30 \mathrm{mmho} / \mathrm{m}$ em torno do ponto 200 metros, para cair para valores de "background" na segunda metade do caminhamento. Este comportamento reflete com nitidez uma provável situação de contaminação subterrânea pela infiltração do efluente na área que corresponde à parte inicial dos dois perfis e ausência do problema na metade final, exatamente como sugere o resultado do P-I, que possui valores de "background" nos seus primeiros 300 metros.

Já o perfil P-VIII, que é paralelo a estes dois, mas que deles dista aproximadamente 200 metros, apresenta um comportamento homogêneo ao longo de todo o caminhamento. Os valores de condutividade relativamente elevados, entre 10 e $20 \mathrm{mmho} / \mathrm{m}$ para os dois arranjos de bobinas, se deve à prática da fertirrigação que se faz com o efluente no local, a nivel experimental, e está relacionada apenas à uma maior concentração do produto na superfície. Isto pode ser comprovado, durante os trabalhos de campo, quando a bobina transmissora era colocada próxima a uma poça de "água amarela".

Os perfis P-V e P-XI, que são paralelos e portanto correlacionáveis, mostram uma tendência inusitada. Os valores de condutividade encontrados são bastante elevados, principalmente no primeiro caso, indicando uma possivel contaminação subterrânea no sentido da rodovia, e mostrando que possivelmente também ocorra um fluxo de águas nesse sentido. Os valores de condutividade da extremidade final do perfil coincidem com os da parte final dos perfis P-I, P-II e P-XIII.

Os perfis $P-1 X$ e P-X foram executados na área de retenção, entre os sulcos para infiltração do efluente. Por corresponder a área reconhecidamente contaminada, os valores de condutividade encontrados entre 20 e $30 \mathrm{mmho} / \mathrm{m}$, aproximadamente, definem o nível máximo de poluição subterrânea. A condutividade medida no inicio do perfil P-IX é igual aquela do início do P-III, situado a pequena distância.

Os perfis P-IV, P-XIV e P-XV são paralelos, próximos e também correlacionáveis. De fato eles apresentam um comportamento bastante semelhante, iniciando com valores de condutividade entre 10 e $20 \mathrm{mmho} / \mathrm{m}$, para os dois arranjos de bobinas, e terminando em torno de $30 \mathrm{mmho} / \mathrm{m}$, o que caracteriza situação de contaminação acentuada dos materiais do sub-solo junto à extremidade final do 
caminhamento. O perfil P-XVI desenvolve-se próximo ao local onde os elevados valores de condutividade caracterizam o estado de contaminação subterrânea.

Por último, nota-se ainda uma grande coerência entre os valores de condutividade medidos para diferentes perfis, porém em locais próximos, como por exemplo: partes iniciais do P-XIX e P-VIII, início do P-VII e proximidades do ponto 200 do P-XIV, extremidades iniciais do P-IV, P-III e P-IX, inicio do P-X como ponto 220 do $P-I V$, etc.

Pode-se comprovar em campo que o efluente excerce influência nas medidas, quando a bobina transmissora era colocada próxima a uma poça de "água amarela". Os valores de condutividade relativamente elevados em alguns perfis, entre 10 e 20 $\mathrm{mmho} / \mathrm{m}$ para os dois arranjos de bobinas, se deve à prática da fertirrigação que se faz com o efluente no local, a nível experimental, e está relacionada apenas à uma maior concentração do produto na superficie. Os perfis executados entre os sulcos para infiltração do efluente definiram valores de condutividade entre 20 e $30 \mathrm{mmho} / \mathrm{m}$, podendo ser considerados o nivel máximo de poluição subterrânea na área.

\section{ETAPA II}

No perfil P-XVII o comportamento da condutividade aparente é bastante semelhante em todas as profundidades investigadas. Os valores relativamente mais elevados para os arranjos que investigam profundidades maiores se justificam pelo fato deles corresponderem a uma seção onde é maior a influência do aquífero saturado, mais condutor. Este comportamento pode ser observado tanto nos arranjos para uma mesma distância de bobinas quanto para mais de uma.

O perfil P-XVIII apresenta um comportamento e valores de condutividade aparente bastante semelhantes ao P-XVII.

A exemplo dos casos anteriores, o P-XIX também apresenta um comportamento homogêneo e linear ao longo de todo caminhamento, não revelando a presença de nenhuma anomalia condutora. Nota-se apenas que os valores de condutividade são um pouco mais elevados por ele corresponder a local de cota mais baixa.

O perfil $\mathrm{P}-X X$ é o único que não apresenta comportamento homogêneo. $\mathrm{Na}$ sua extremidade inicial os valores de condutividade elétrica são os mais baixos medidos na área. Entre os pontos 300 e 500, aproximadamente, eles são os mais 
altos. Neste local o nivel d'água está mais raso e o perfil se estende por trecho de cota mais baixa, aproximando-se da nascente. $\mathrm{Na}$ extremidade final $\mathrm{O}$ comportamento dos valores tendem ao normal para a área.

Nesta área, como se esperava, os valores de condutividade elétrica medidos foram baixos. Os valores relativamente mais elevados para os arranjos que investigam profundidades maiores se justificam pelo fato deles corresponderem a uma seção onde é maior a influência do aquífero saturado, mais condutor. Este comportamento pode ser observado tanto nos arranjos para uma mesma distância de bobinas quanto para mais de uma. Nos perfis situados em cotas topográficas mais baixas também apresentaram valores relativamente mais altos, fato explicado pela maior proximidade do topo da camada saturada, nestes casos.

\subsubsection{Mapas de isocondutividades}

A análise dos dados, neste caso, através do mapa de isocondutvidade possibilita visualizarmos a situação da área em termos mais generalizados, pois os contrastes ficam evidentes e podem ser relacionados a pluma de poluição.

Estes mapas foram produzidos com base nos dados adquiridos na Etapa I. Os dados da Etapa II não foram incluídos, pois estes refletem uma situação diferenciada, já que os valores são relativamente maiores devido a cota topográfica menor.

Os mapas que representam as duas profundidades investigadas nesta área (Anexo IV) apresentam uma tendência de valores anômalos, principalmente a norte da coordenada de referência 30 , sendo que no mapa de profundidade maior ocorre um aumento de valores em relação ao de profundidade menor. A configuração e localização da anomalia são semelhantes nos dois mapas.

Os focos de anomalia concentram-se entre a área de retenção do efluente e a estrada. Ocorre uma concentração de isolinhas na coordenada de referência 35-40 a leste e 35-40 a norte, representando valores maiores do que os medidos na área e em local sem medidas, no mapa que representa as medidas com o EM-34/20m-H. Isto reforça a idéia de precaução quanto à interpretação desses mapas, já comentada na discussão do caso de estudo anterior. 
Nos modelos tridimensionais os altos evidenciam mais claramente as anomalias detectadas nos mapas. 


\section{DIADEMA}

O depósito de lixo estudado, conhecido como "Lixão do Alvarenga" está situado na porção oeste da Bacia Hidrográfica Billings, próximo à represa, e é utilizado pelas prefeituras de Diadema e São Bernado do Campo. Os estudos nele realizados são de dezembro de 1993 e março-maio de 1995.

\subsection{Geologia}

A região da grande São Paulo está encravada em uma zona constituida predominantemente pelo embasamento pré-Cambriano e secundariamente por rochas sedimentares do Cenozóico, sendo estas representadas por sedimentos aluvionares recentes e sedimentos terciários da Bacia de São Paulo (Figura 8).

De acordo com o mapa do IPT (1980) estão mapeados na área em torno do lixão os granitos da Fácies Cantareira (PS $\gamma c)$ e xistos do Complexo Pilar (PSpX). No mapa da EMPLASA (1980), o local é caracterizado por micaxisto e/ou meta-arenito de médio grau de metamorfismo. Inclui também xistos miloniticos em zonas de movimentação tectônica $(p \in A m x)$ e, ainda pertencente ao pré-Cambriano, granitos a granodioritos normais ou em parte gnaíssicos, equigranulares e porfiróides ( $p \in A g g$ ).

Os sedimentos terciários, na área, são da Formação São Paulo (TQs). Do ponto de vista litológico ela é formada predominantemente por argilas, siltes e areias argilosas finas, com raras ocorrências de areias grossas e cascalhos finos (IPT 1980). Os sedimentos do Quatenário (Qa) provenientes de aluviões fluviais são constituídos por argilas, areias e cascalhos (EMPLASA 1980).

No local são observados afloramentos de micaxistos bastante intemperizados e pedoturbados.

\subsection{Hidrogeologia}

Na Região da Grande São Paulo o aquifero pode ser dividido em 2 tipos (DAEE 1975), aquifero cristalino e aquífero clástico, sendo o último subdividido em aluvial e de sedimentos terciários. 


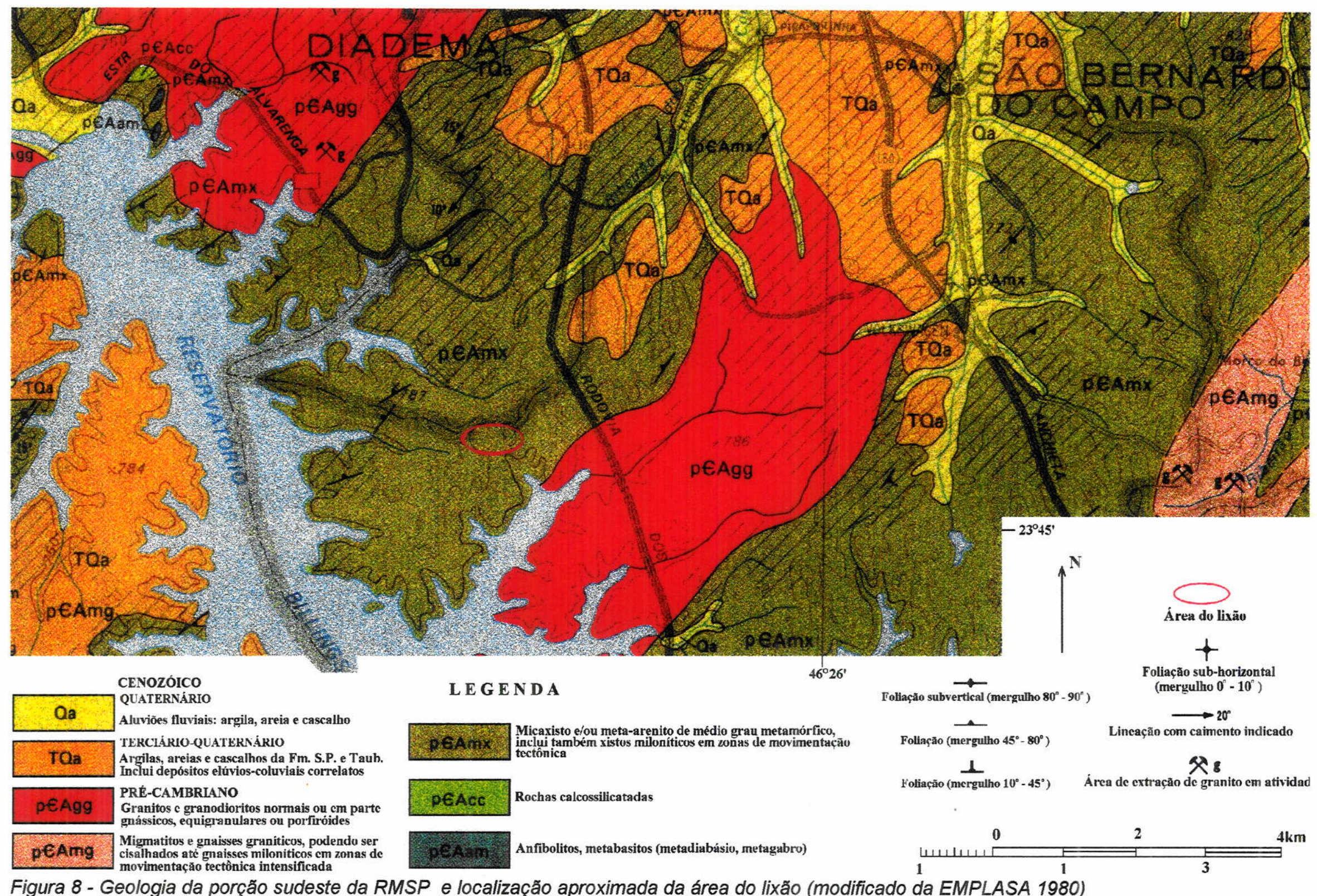


Os aquíferos cristalinos são praticamente impermeáveis e, portanto, os de pior qualidade em termos de vazão, a não ser que ocorram fissuras e falhas, decomposição mecânica, ou alteração parcial nas rochas, propiciando condições de percolação das águas subterrâneas.

Baseado em dados de poços o relatório do DAEE (1975) chega-se à conclusão que, nesse caso, geralmente existe uma baixa transmissividade, armazenamento de água limitado, na vizinhança do poço e falta de ligação hidrológica aos corpos de água no aquífero a uma maior distância. É também sugerido que o aquifero menos promissor corresponde à rocha granítica e o melhor às rochas xistosas.

No estudo preliminar da CETESB (1977), as águas subterrâneas da região apresentam valores de pH igual a 5,3, de característica ácida.

Nos poços cristalinos perfurados próximo dos reservatórios Billings e Guarapiranga, a vazão específica média é de $0,19 \mathrm{~m}^{3} / \mathrm{h} / \mathrm{m}$ (DAEE 1975).

Quanto aos aquíferos sedimentares, existe predominância de camadas argilosas, Os niveis arenosos ocorrem em horizontes relativamente curtos e na forma de lentes.

\subsection{Caracteristicas do efluente}

Foram realizadas algumas amostragens de água para análises em áreas consideradas a jusante do lixão. As amostras denominadas por $C_{n}$ foram coletadas ao longo de um córrego a jusante do lixão e as $\mathbf{P}_{\mathbf{n}}$ foram coletadas de cacimbas existentes nas casas, também a jusante do lixão. Foi amostrado chorume apenas para análise de coliformes. Os pontos de coletas estão indicados no mapa do Anexo I. 
TABELA 8 - Características físico-químicas e bacterológicas do chorume e pontos de amostragem na área de estudo

\begin{tabular}{|c|c|c|c|c|c|c|c|c|c|c|c|}
\hline & ${ }^{*} \mathrm{Na}$ & ${ }^{\star} \mathrm{K}$ & ${ }^{\star} \mathrm{Ca}$ & ${ }^{*} \mathrm{Mg}$ & ${ }^{*} \mathrm{Fe}$ & ${ }^{*} \mathrm{Zn}$ & ${ }^{*} \mathrm{Cu}$ & ${ }^{*} \mathrm{CE}$ & ${ }^{\star \star} \mathrm{pH}$ & ${ }^{\star * \star} \mathrm{CT}$ & ${ }^{* * *} \mathrm{CF}$ \\
\hline $\mathrm{C}_{1}$ & 22,5 & 35,0 & 9,5 & 6,0 & 5,30 & 0,05 & 0,04 & 101 & 3,70 & $17 \times 10^{4}$ & $13 \times 10$ \\
\hline $\mathrm{C}_{2}$ & 3,9 & 1,7 & 1,6 & 1,4 & 0,60 & 0,04 & 0,03 & 102 & 3,35 & $90 \times 10^{2}$ & $50 \times 10$ \\
\hline $\mathrm{C}_{3}$ & 10,5 & 10,0 & 4,8 & 3,0 & 2,45 & 0,05 & 0.04 & 98 & 3,29 & $50 \times 10^{4}$ & $13 \times 10$ \\
\hline$C_{4}$ & 14 & 6,6 & 19,4 & 3,8 & 2,50 & 0,01 & $<0,01$ & 94 & 2,70 & - & - \\
\hline$C_{5}$ & 28,0 & 8,5 & 7,5 & 3,3 & 0,64 & 0,06 & 0,04 & 91 & 3,50 & - & - \\
\hline P06 & 3,8 & 0,8 & 2,0 & 0,2 & 0,04 & 0,05 & 0,03 & - & - & $30 \times 10^{2}$ & $30 \times 10$ \\
\hline P10 & 24,0 & 5,4 & 9,1 & 2,9 & 0,04 & 0,13 & 0,07 & 100 & 3,13 & 300 & 300 \\
\hline P18 & 6,5 & 1,9 & 9,1 & 2,1 & 0,03 & 0,08 & 0,03 & - & - & $130 \times 10^{2}$ & $80 \times 10$ \\
\hline P21 & - & $=$ & $=$ & - & - & $=$ & - & 2,8 & 4,5 & $1,7 \times 10^{3}$ & $5 \times 10$ \\
\hline P22 & 5,1 & 0,9 & 0,5 & 0,8 & 0,05 & 0,05 & 0,03 & 96 & 3,35 & - & - \\
\hline P23 & 167,5 & 45,0 & 4,8 & 5,0 & 0,08 & 0,07 & 0,03 & 108 & 3,54 & 40 & 40 \\
\hline P27 & 11,0 & 0,8 & 4,1 & 0,5 & 0,72 & 0,06 & 0,03 & 108 & 2,85 & $>1,6 \times 10^{4}$ & $9 \times 10$ \\
\hline P29 & 10,2 & 1,5 & 5,8 & 2,5 & 0,07 & 0,05 & 0,03 & 104 & 2,85 & $1,4 \times 10^{3}$ & $7 \times 10$ \\
\hline P36 & 1,5 & 1,3 & 1,2 & 0,6 & 0,25 & 0,05 & 0,03 & 102 & 2,54 & - & $=$ \\
\hline P45 & 2,5 & 0,3 & 0,3 & 0,1 & 0,19 & 0,05 & 0,03 & 100 & 3,20 & - & - \\
\hline P47 & 13,0 & 16,5 & 25,8 & 5,0 & 3,54 & 0,05 & 0,03 & 98 & 3,91 & 80 & 80 \\
\hline Chorume & - & - & - & - & - & - & - & - & - & $80 \times 10^{4}$ & $80 \times 10$ \\
\hline
\end{tabular}

Obs: "os dados físico-químicos estão em mg/l

${ }^{* \star}$ os valores de condutividade elétrica (CE) estão em $\mu \mathrm{S} / \mathrm{cm}$ e os de $\mathrm{pH}$ são adimensionais.

**os valores de coliformes totais e fecais (CT e CF) foram obtidos a partir de contagem dos mesmos para cada $100 \mathrm{ml}$ de água

Analisando os valores de concentrações dos constituintes iônicos, verifica-se, no geral, que os mais significativos são de $\mathrm{Na}, \mathbf{K}$ e $\mathrm{Ca}$. No entanto, são baixos em termos de contaminação e assim não apresentam indícios da mesma. O maior valor, $167 \mathrm{mg} / \mathrm{l}$ de $\mathrm{Na}$, ocorre em uma cacimba distante da fonte poluente e, portanto, não pode-se estabelecer uma relação com contaminação devido ao lixão. Em contrapartida, os valores de análises bioquímicas são relativamente altos na maioria dos poços analisados. A contaminação sob este ponto de vista é evidente, mas, provavelmente está relacionada com a má disposição das fossas, problema típico de comunidades de baixa renda que não possuem rede de esgoto e os poços não são protegidos, como a existente na área. 
Diante das dificuldades técnicas para análises do chorume que proporcionassem dados de caráter físico-quimico, recorreu-se a um levantamento de dados junto a CETESB, para obtenção de valores característicos de chorume, que podem ser relacionados com o percolado do lixão estudado. Os dados foram adquiridos do Relatório Interno da CETESB, não divulgado, "CARACTERIZAÇÃO E ESTUDO DE TRATABILIDADE DE LIQUIDOS PERCOLADOS DE ATERROS SANITÁRIOS", desenvolvido pelo setor de pesquisa de resíduos domésticos e hospitalares.

O estudo apresenta as principais caracteristicas de chorume de aterros de idade recente ( 1 ano) e idade antiga (+20 anos), sendo que o Lixão do Alvarenga se encaixa no segundo caso, já que está ativo desde 1974. O mesmo estudo apresenta um levantamento analítico realizado nos EUA com valores médios e faixa de concentrações de parâmetros analisados de 23 amostragens de vários aterros sanitários. Os aterros sanitários de Santo André, dos Bandeirantes e de Itapecirica da Serra foram os selecionados pela pesquisa para estudo analítico. Os parâmetros analisados estão organizados em uma tabela do próprio relatório. Em Freeze \& Cherry (1979) adquiriu-se a concentração típica de Na medida em chorume.

As concentrações de $\mathrm{Na}$ são os dados de maior interesse deste trabalho pois eles foram escolhidos como valores de referência para as 3 áreas estudadas. Portanto foi elaborado o Quadro 1, contendo estes valores, onde estão apresentados os dados de aterro antigo, aterro recente, de um levantamento analítico de aterros dos Estados Unidos e dos 3 aterros selecionados pelo estudo do relatório citado acima e o dado citado em Freeze \& Cherry (1979). As medidas de condutividade elétrica disponiveis, estão relacionadas, pois podem ser correlacionadas com TDS (Freeze \& Cherry 1979, Ebraheem et al. 1990) e com as medidas de resistividade elétrica obtidas nas SEs (Kelly 1976).

As faixas de valores de $\mathrm{Na}$ e CE para os aterros foram definidos a partir da tabela do Relatório, CETESB (1993), que apresenta para cada aterro várias colunas de valores para o mesmo parâmetro. O relatório não deixa claro se essas colunas referem-se a amostragens periódicas ou a pontos de amostragens diferentes em cada aterro. A faixa de valores no Quadro 1 indica o valor mínimo e valor máximo obtidos entre eles. 


\begin{tabular}{|c|c|c|c|}
\hline & $\mathrm{Na}$ & CE & $\mathbf{R T}$ \\
\hline Aterro Antigo ( +20 anos) & 380 & - & - \\
\hline Aterro Recente (1 ano) & 1590 & 一 & - \\
\hline $\begin{array}{c}\text { Levantamento Analítico } \\
\text { nos EUA }\end{array}$ & $\begin{array}{l}\text { Média - } \quad 350 \\
\text { Faixa - } \quad 43-2500 \\
\end{array}$ & - & - \\
\hline Freeze \& Cherry (1979) & $200-1200$ & - & $5000-40000$ \\
\hline Santo André & $49-700$ & $7500-97000$ & $3760-7830$ \\
\hline Bandeirantes & $370-1200$ & 16900 & 8810 \\
\hline Itapecirica da Serra & $285-300$ & $4330-4580$ & $3800-10700$ \\
\hline
\end{tabular}

\subsection{Levantamentos de dados geofisicos}

Os trabalhos de campo foram desenvolvidos procurando contemplar toda possivel área de influência do efluente, extrapolando a área do lixão. Foram executados 6 perfis de caminhamento eletromagnético, totalizando em 2300 metros com pontos de medida a cada 10 metros primeiramente, sendo que devido às observações dos valores que mantinham uma certa homogenidade, foram feitas medidas a cada 20 metros e os dados foram interpolados. Foram utilizados os cabos de referência de 10, 20 metros, escolhidos de acordo com a profundidade de nivel d'água medida nas cacimbas existentes na área. Foram executadas 6 SEs com abertura de eletrodos de corrente $A B / 2$ ate 100 metros, nas SEs-1, 2 e 3, o suficiente para investigar profundidades até 60 metros, e com isto atingir o topo da camada saturada. Nos casos das SEs-4, 5 e 6, executadas em cotas mais baixas, os eletrodos tiveram $A B / 2$ estendidos até 160 metros para cada lado, na tentativa de detectar o topo rochoso.

Os pontos investigados pelos métodos geofísicos encontram-se no mapa do Anexol.

\subsection{Interpretação}

Em primeiro lugar foram interpretadas as curvas de resistividade aparente correspondente às sondagens elétricas e em seguida, os perfis de condutividade aparente referentes ao caminhamento eletromagnético. 


\subsubsection{Sondagem Elétrica}

A Tabela 9 expressa o resultado da interpretação das curvas de resistividade aparente, onde os valores de resistividade $(\rho)$ estão em ohm.m e da espessura (E) em metros. Pode ser observado que as curvas são divididas em grupos de 5 e 6 camadas elétricas, com morfologia semelhantes. As sondagens interpretadas com 5 camadas são do tipo KHK (SE-1, SE-2, SE-3 e SE-5) e as com 6 camadas são KHKH (SE-4 e SE-6). O Anexo II apresenta as curvas de resistividade aparente com suas respectivas interpretações.

TABELA 9 - Resumo da interpretação das sondagens elétricas

\begin{tabular}{|c|c|c|c|c|c|c|c|c|c|c|c|c|}
\hline & \multicolumn{2}{|c|}{ 1a camada } & \multicolumn{2}{|c|}{ 2a camada } & \multicolumn{2}{|c|}{ 3a camada } & \multicolumn{2}{|c|}{ 4a camada } & \multicolumn{2}{|c|}{5 a camada } & \multicolumn{2}{|c|}{ 6a camada } \\
\hline & $\mathbf{E}$ & $\rho$ & $E$ & $\rho$ & $E$ & $\rho$ & $E$ & $\rho$ & E & $\rho$ & $E$ & $\rho$ \\
\hline SE- 1 & 2,0 & 600 & 3,0 & 2000 & 1,0 & 500 & 13,0 & 4000 & - & 750 & - & $=$ \\
\hline SE- 2 & 1,0 & 1000 & 3,0 & 4500 & 1,0 & 400 & 14,0 & 8000 & - & 600 & - & - \\
\hline SE- 3 & 1,0 & 850 & 2,0 & 2500 & 3,0 & 700 & 17,0 & 3100 & - & 400 & - & - \\
\hline SE- 4 & 2,0 & 50 & 5,0 & 1000 & 5,0 & 50 & 20,0 & 2000 & 10,0 & 400 & - & 800 \\
\hline SE- 5 & 1,5 & 90 & 2,8 & 400 & 2,0 & 35 & 15,0 & 2500 & - & 100 & - & $=$ \\
\hline SE- 6 & 1,0 & 600 & 2,0 & 1150 & 4,0 & 850 & 5,0 & 2000 & 25,0 & 420 & - & 600 \\
\hline
\end{tabular}

Nas SE-1 e SE-6 as duas primeiras camadas elétricas correspondem a solo/sedimento seco, acima do nível d'água com resistividade variando na primeira camada de 600 e, 2000 e 1150, respectivamente, na segunda. As demais camadas corresponderiam a sedimentos saturados com resistividades de 500 e 850 na terceira camada e 750 e 420 na quinta. A quarta camada nestas sondagens apresenta valor de resistividade elétrica maior, talvez devido a menor quantidade de argilas. Ainda nesse grupo a SE-6 possui uma sexta camada com uma aumento de resistividade sutilmente maior em relação a resistividade da quinta camada, a qual com certeza não representa o embasamento.

As SE-2 e SE-3 apresentam uma interpretação de curvas muito semelhante às SE-1 e SE-6, no entanto deve-se considerar primeiro que estas sondagens foram executadas em cotas topográficas mais altas e segundo que de acordo com informações obtidas de medidas de nivel d'água em cacimbas nas proximidades, a profundidade do N.A. varia entre 15 e 20 metros, portanto atribuiu-se à profundidade de topo da quinta camada elétrica como sendo representativa do topo do pacote saturado. A terceira camada que possui resistividade relativamente baixa, provavelmente representa um pacote com conteúdo maior de argila. 
As SEs-4 e 5, com 6 e 5 camadas respectivamente, possuem nivel d'água praticamente aflorante, condição observada em campo através do córrego próximo a sondagem. As variações de resistividade nas camadas devem estar relacionadas a menor ou maior quantidade de argilas e muito provavelmente os valores abaixo de $100 \mathrm{ohm} . \mathrm{m}$ da primeira camada podem estar relacionados à contaminação dessas águas.

A partir do resultado da interpretação foi possivel definir a camada elétrica correspondente aos sedimentos saturados, e então foi elaborado um quadro (Tabela 10) com os dados de interesse sobre o nivel d'água em cada ponto investigado.

TABELA 10 - Definição da profundidade de N.A. a partir da interpretação das SEs executadas na área

\begin{tabular}{cc}
\hline Sondagem & $\begin{array}{c}\text { Nivel d'água } \\
(\mathbf{m})\end{array}$ \\
\hline SE-1 & 5,0 \\
SE-2 & 19,0 \\
SE-3 & 23,0 \\
SE-4 & sub-aflorante \\
SE-5 & sub-aflorante \\
SE-6 & 3,0 \\
\hline
\end{tabular}

Os valores de nivel d'água ficaram definidos de sub-aflorante a 21,0 metros.

\subsubsection{Caminhamento eletromagnético}

\subsubsection{Perfis}

Os dados dos perfis de condutividade aparente relativos ao caminhamento eletromagnético, Anexo III, admitem apenas uma interpretação qualitativa. Admitindose que o lixo acumulado no local de estudo produza chorume, rico em elementos inorgânicos (Freeze \& Cherry 1979), e contamine as águas subterrâneas do local, estas apresentariam uma condutividade maior que o normal (background) $e$, anomalias positivas, ou condutoras, poderiam ser associadas à contaminação das águas subterrâneas (Cartwright \& Sherman 1972 apud. Ebraheem et al. 1990). 
Analisando-se conjuntamente os perfis de caminhamento, observa-se que os perfis P-ll, P-IV, P-V e trechos 800-900 do P-I e 70-140 do P-VI, apesar de estarem próximos da fonte poluidora, aparentemente não apresentam anomalias, portanto baseado nesta análise poderão ser considerados como "background" valores entre 1 e $5 \mathrm{mmho} / \mathrm{m}$.

Nos trechos 250-600 do P-l e 0-200 do P-IIl pode ser observado um aumento dos valores de condutividade nas medidas de todos arranjos, provavelmente devido à contaminação nas águas subterrâneas. No P-III, entre os pontos 200 e 400 ocorrem valores anômalos para o arranjo que investiga a profundidade mais superficial (EM$34 / 10 \mathrm{~m}-\mathrm{H}$ ) podendo ser reflexo de chorume retido no solo, já que dias antes do levantamento devido à chuva foi possivel observar chorume fluindo pela rua. No trecho 0-250 do $\mathrm{P}-\mathrm{l}$ os valores anômalos nas medidas feitas pelo arranjo que utilizou - cabo de $20 \mathrm{~m}$ se mantêm e deve-se chamar a atenção para o fato de que apesar desses valores serem anômalos em relação aos estabelecidos como background, eles são menores dos valores anômalos obtidos pelos arranjos com o cabo de $10 \mathrm{~m}$, ao contrário do esperado para profundidades maiores. Isto pode ser explicado pela ocorrência de uma camada mais resistiva eletricamente que contribui para que os valores de condutividade adquiridos em profundidade maior fossem menores, o que concorda com a interpretação da SE-6, executada nesse trecho.

As medidas com o arranjo EM-34/10m-H, entre os pontos 0-100 e 700-800 do $P-1$, refietem uma pequena anomalia explicada pela passagem do caminhamento sobre córrego. No trecho $0-70$ do $\mathrm{P}-\mathrm{VI}$ pode-se observar anomalias devido a influência superficial (fios de alta tensão), observada em campo.

\subsubsection{Mapas de isocondutividades}

Todos os mapas de isocondutividade desta área, Anexo IV, apresentam dois focos anômalos que podem ser levados em consideração, no entanto fica claro que as anomalias são restritas à profundidade que investigou até 7,5 metros, com o EM$34 / 10 \mathrm{~m}-\mathrm{H}$. Nesta profundidade são observados os maiores valores e nos mapas seguintes não ocorre a tendência de aumentar os valores, o que normalmente acontece com a utilização desse instrumento devido a integração de todos os valores de condutividade do pacote. Conclui-se que os pacotes inferiores à profundidade analisada primeiramente possuem resistividades elétricas maiores.

Infelizmente nos mapas produzidos repete-se o problema das isolinhas extrapolarem os dados dos pontos de medidas, originando focos de anomalias 
"fictícias", principalmente no mapa do arranjo EM-34/20m-H. Em todos os mapas isto acontece nas coordenadas 335100 e 335200 a sul de 7373900 e entre as coordenadas 335000 e 335200 a norte de 7374350 . 


\section{AVALIAÇÃO COMPARATIVA DOS DADOS}

Do ponto de vista qualitativo observa-se que, de acordo com a interpretação dos dados geofísicos, ocorreram contrastes de valores de condutividade elétrica relacionados à contaminação que podem ser considerados como anomalias significativas em relação ao valor de background nas três áreas. No entanto, deve-se ter claro que nem sempre anomalias positivas definidas na interpretação refletem situação de contaminação, podendo estas estarem relacionadas com situações naturais como áreas com córregos, brejos, etc.

Em termos de análises físico-químicas, o elemento comum detectado nos três tipos de efluente, com concentrações relativamente maiores é o $\mathrm{Na}$. O $\mathrm{Na}$ eleva a condutividade elétrica ocasionando anomalias positivas. Provavelmente é neste elemento que reside a maior relação entre a detectabilidade do método em se tratando de contaminação das águas subterrâneas por efluentes industriais, enquanto que no lixão ele é apenas um dos componentes que contribui para o aumento da condutividade elétrica.

Analisando os dados do ponto de vista qualitativo, as anomalias foram classificadas em intensidade baixa, média e alta. Essa classificação foi elaborada com base na média de padrões de valores de condutividade elétrica anômalos das profundidades para cada área sendo expressadas pelo Quadro 2 e pelos gráficos das Figuras $9 \mathrm{a}, 9 \mathrm{~b}$ e $9 \mathrm{c}$ :

QUADRO 2 - Definição qualitativa de intensidade de anomalias geofísicas.

\begin{tabular}{c|c|c|c|c|c} 
& $\begin{array}{c}\text { Concentração de } \\
\text { Na nos Efluentes } \\
(\mathrm{mg} / \mathrm{l})\end{array}$ & $\begin{array}{c}\text { Intensidade } \\
\text { Baixa } \\
(\mathrm{mmho} / \mathrm{m})\end{array}$ & $\begin{array}{c}\text { Intensidade } \\
\text { Média } \\
(\mathrm{mmho} / \mathrm{m})\end{array}$ & $\begin{array}{c}\text { Intensidade } \\
\text { Alta } \\
(\mathrm{mmho} / \mathrm{m})\end{array}$ & $\begin{array}{c}\text { Valor de } \\
\text { Background } \\
\text { (mmho/m) }\end{array}$ \\
\hline JOSÉ BONIFÁCIO & 192 & $5-11$ & $11-20$ & $20-35$ & $2-10$ \\
\hline MIRASSOL & 173 & $5-10$ & $10-30$ & $30-44$ & $2-10$ \\
\hline DIADEMA & $\begin{array}{c}49 \text { a 1200 } \\
\text { (CETESB 1993) }\end{array}$ & $5-10$ & $10-20$ & $20-60$ & $1-5$
\end{tabular}




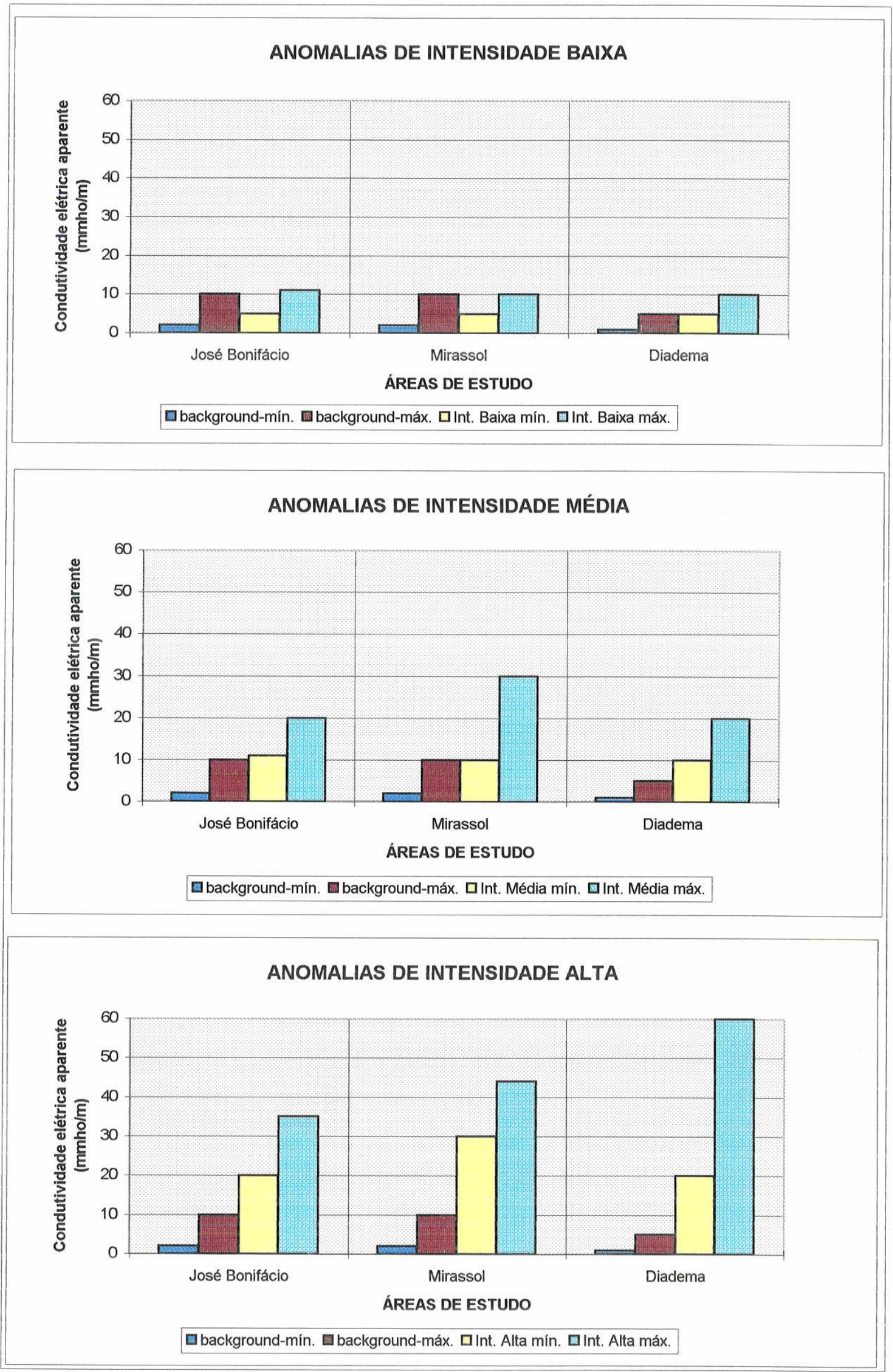

Figura 9 - Gráficos representativos das intensidades de anomalias de condutividade elétrica 
No caso de José Bonifácio a faixa de valores definidos como intensidade baixa, para os perfis próximos a lagoa de infiltraçăo (P-IX, P-XIII e P-XIV) e intensidade média para perfis em torno da lagoa ( $P-X, P-X I$ e P-XII) estão relacionados com a contaminação. A faixa de valores de condutividade definida como intensidade alta na área, foi interpretadada como decorrente da proximidade de drenagens ou brejos e, assim, não corresponde a situação de contaminação, a qual está identificada como dito acima, em anomalias positivas de intensidade baixa a média.

Da mesma maneira, que o valor de concentração de Na presente no efluente da indústria de cítricos, é próximo ao do caso caso anterior, as faixas de valores de intensidades definidas são próximas e o valor de background é o mesmo, o que é coerente por se tratar regionalmente da mesma geologia. Nesta área os valores de intensidade média estão relacionados à contaminação subterrânea. A faixa de valores de intensidade baixa definem a contaminação subterrânea em perfis mais afastados do foco principal da pluma. A faixa de intensidade máxima reflete problemas de contaminação na superfície como também em subsuperfície.

Como era de se esperar a contaminação devido ao lixão produz contrastes maiores em relação aos casos anteriores. A faixa de concentração de $\mathrm{Na}$ adotada para o chorume foi a mesma obtida no lixão de Santo André, devido à proximidade das duas áreas. Neste caso a anomalia representativa de contaminação é de intensidade máxima. Cabe chamar a atenção que a expectativa era do chorume proporcionar contrastes maiores e em boa parte dos perfis de caminhamentos executados, já que estes situavam-se a jusante da área do lixão. No entanto, as anomalias ficaram restritas a um caminhamento perpendicular ao lixão e trecho central do caminhamento paralelo ao mesmo. Provavelmente, a geologia local é um condicionante de um sistema hidrogeológico complexo. Os dados de análises químicas em poços a jusante do lixão reforçam essa idéia, pois raramente apresentam um valor de concentração significativa de algum constituinte relacionado ao chorume. As anomalias detectadas na área estão relacionadas a contaminação em camadas superficiais pois quando a profundidade de investigação aumenta, os valores de condutividade elétrica geralmente diminuem.

A soma de constituintes inorgânicos no efluente de José Bonifácio é maior do que no efluente de Mirassol e apesar da geologia ser semelhante nas duas áreas, observa-se efeito contrário nas anomalias, ou seja, não ocorrem valores representativos de anomalias relacionadas à contaminação de intensidade alta no primeiro caso como ocorreu no segundo. Neste trabalho não cabe esclarecer a causa 
deste problema de caráter complexo, no entanto pode-se sugerir algumas hipóteses como: a quantidade e o tempo que o efluente é jogado na lagoa, a existência de "impermeabilização" no fundo e paredes da lagoa que atenuam a contaminação ou até a possibilidade dos constituintes orgânicos influenciarem nas medidas de modo oposto aos inorgânicos.

Em linhas gerais, podemos adotar como valores qualitativos de intensidade baixa entre 5 e 10 , os de intensidade média entre 10 e 30 e os de intensidade alta entre 30 e $60 \mathrm{mmho} / \mathrm{m}$. 


\section{CONCLUSÕES}

Os trabalhos descritos fazem parte de experimentos práticos, frutos de trabalhos contratados por indústrias ou orgãos públicos com problemas agudos de poluição e contaminação de águas subterrâneas já instalados e em processo de desenvolvimento.

$\mathrm{Na}$ avaliação da sensibilidade dos métodos geofisicos utilizados, optou-se pelo $\mathrm{Na}$ como elemento de referência nos processos de contaminação por ser uma constante nos efluentes e por suas características físico-quimicas que the atribuem uma ótima condição de indicador de contaminação.

O levantamento geofísico feito na área da indústria de matéria-prima para fabricação de borracha, constitui parte de um projeto de fertirrigação onde pretendese utilizar o efluente, que, de acordo com análises químicas preliminares, é rico em nitrogênio. Para tanto o projeto executou uma caracterização da área do ponto de vista geológico/hidrogeológico/pedológico, como também do efluente. Foi permitido o acesso a estes dados os quais auxiliaram na correlação com os resultados geofísicos obtidos a partir de levantamentos de campo que cobriram toda área da fazenda. $A$ aplicabilidade dos métodos geofísicos, neste caso, foi testada por meio de caminhamentos eletromagnéticos e sondagens elétricas feitas em torno das lagoas de infiltração da indústria, pelos quais se obtiveram valores de baixa e média intensidade, conforme definido anteriormente. A presença de $\mathrm{Na}$ com concentração de aproximadamente $192 \mathrm{mg} / \mathrm{l}$ nesse caso provavelmente contribuiu para ocorrencia de contrastes, mas não foi responsável única pelas anomalias, tendo em vista que outros constituintes iônicos estavam presentes em concentrações maiores.

O levantamento geofísico feito na indústria de produtos cítricos faz parte de um projeto maior do qual foi possivel obter alguns dados de análises físico-químicas do efluente como também de análises de águas coletadas em poços de monitoramento, locados de acordo com as indicações do levantamento geofísico realizado na Etapa II. Neste caso as anomalias foram evidentes e, provaveimente estão relacionadas com o teor de $\mathrm{Na}$ observado nas análises dos efluentes, onde a interpretação dos resultados demonstrou reflexo de contaminação.

O levantamento na área do lixão visou detectar a extensão da pluma de poluição, a exemplo dos casos anteriormente citados. Como pode ser observado através dos métodos geofísicos utilizados, provaveimente, o fluxo subterrâneo possui 
uma direção principal a partir do lixão, onde as anomalias ficam evidentes. Se o chorume possuisse apenas $\mathrm{Na}$ seria o suficiente para produzir contrastes, pois geralmente ocorre com altas concentrações. De acordo com o levantamento bibliográfico os elementos que contribuem para o aumento de condutividade elétrica são muitos e têm elevada concentração, ocasionando como resultante anomalias de alta intensidade. Nesse caso se encaixa o Lixão do Alvarenga. A anomalia relacionada à contaminação nesse caso é de intensidade máxima.

Do ponto de vista qualitativo, através do caso de Mirassol, pode-se indicar que a concentração necessária de Na no efluente que possibilite contrastes nas medidas geofísicas seria de aproximadamente $173 \mathrm{mg} / \mathrm{l}$, tendo-se claro que essa quantidade é uma condição necessária mínima mas não suficiente, como pode ser observado no caso de José Bonifácio.

Neste trabalho com finalidades de aplicação prática, o principal objeto de discussão são as consequências da interação dos efluentes e o chorume com o meio, refletidas nas medidas geofisicas. Portanto a discussão isolada sobre características dos líquidos contaminantes ou da influência do meio geológico não ocorreu, mas sim procurou-se parâmetros desses dois fatores que fundamentassem a possibilidade de deteç̧ão de contrastes. Para os contaminantes, analisou-se o possivel elemento que provocasse tais contrastes. $O$ meio físico contribuiu isoladamente no estudo de cada área na medida em que possibilitou a determinação dos valores de "background", isto é, sem contribuição, permitindo assim, a identificação das anomalias condutoras.

Os métodos geofísicos utilizados provaram ser aplicáveis e eficientes nos casos estudados. São aplicáveis à medida que, como nos casos estudados, a contaminação subterrânea ocasionou contrastes nas medidas e eficientes a partir do momento que em um periodo relativamente curto e com custos bem mais baixos do que dos métodos diretos, delinou-se a situação de contaminação em subsuperfície em todos os casos discutidos, de maneira preliminar, mas o suficiente para traçar um plano de caracterização e monitoramento por métodos diretos de maneira otimizada.

O caso de José Bonifácio mostra que a definição de áreas contaminadas não depende apenas da análise dos valores de condutividade ao longo dos perfis eletromagnéticos. A observação de detalhes relativos à geologia, hidrogeologia e topografia, entre outros, e uma análise do conjunto das informações disponiveis calcada no bom senso, com atribuição de pesos adequados a cada fator, em cada 
caso, é a maneira correta que o pesquisador tem de avaliar as reais condições de uma área sob o ponto de vista ambiental. 


\section{REFERÊNCIAS BIBLIOGRÁFICAS}

ANNAN, A.P.; BREWSTER, M.L.; GREENHOUSE, J.P.; REDMAN, J.D.; SCHNEIDER, G.W.; OLHOEFT, G.R., SANDER, K.A. (1992) Geophysical monitoring of DNAPL migration in a sandy aquifer. Expanded Abstracts SEG 62nd Annual Meeting. New Orleans.

ANNAN, A.P.; BAUMAN, P.; GREENHOUSE, J.P.; REDMAN, J.D. (1991). Geophysics and DNAPLS. Ground Water Management $\mathrm{n}^{\mathfrak{Q}} 5$. Proceedings of the Fifth National Outdoor Action Conference on Aquifer Restoration, Ground Water Monitoring and Geophysical Methods. Las Vegas, Nevada. p 963-977.

ASTIER, J.L. (1975) Geofisica Aplicada a la Hidrogeologia. Madrid, Editora Paraninfo. 344p

BARCELOS, J.H.; SOUZA, F ${ }^{\circ}$, E.E. de; FÚLFARO, V.J.; LANDIM, P.M.B.; COTTAS, L.R.; WU, F.T.; GODOY, H.M. (1984) A Formação Itaqueri, um exemplo de tectofácies. Atas do $4^{2}$ Simpósio Reg. Geol. SBG/USP. São Paulo. v. 1, p 245-261.

BARKER, R.D. (1990) Improving the quality of resistivity sounding data in landfill studies. In: Stanley H. Ward (Editor), Geotechnical and Environmental Geophysics, SEG. v. 2, p 245 251.

BENSON, A.K. (1995) Aplications of ground penetrating radar in assessing some geological hazards: examples of groundwater contamination, faults, cavities. Journal of Applied Geophysics. Elsevier Science Publishers B.V., Amsterdam. v. 33, p 177-193.

BÖRNER, F.; GRUHNE M.; SCHÖN, J. (1993) Contamination Indications Derived from Electrical Properties in the Low Frequency Range. Geophysical Prospecting. v. 41, p 83-98.

BRAGA, A.C.O. (1988) Aperfeiçoamento em geologia de engenharia e mineração. In: São Paulo, IPT. (Apostila).

"BREWSTER, M.L.; REDMAN, J.D.; ANNAN, A.P. (1992a) Monitoring a controlled injection of perchloroethylene in a sandy aquifer with ground penetrating radar and time domain reflectometry. Proceedings of the Symposium on the Application of Geophysics to Engineering and Environmental Problems. Chicago, Illinois, (in press). 
BREWSTER, M.L.; ANNAN, A.P.; REDMAN, J.D. (1992b) GPR Monitoring of DNAPL Migration in a Sandy Aquifer. Proceedings of Fourth International Conference on Ground Penetrating Radar. Rovaniemi, Finland. Geological Survey of Finland, Special Paper (in Press).

BREWSTER, M.L.; ANNAN, A.P.; GREENHOUSE, J.P.; SCHNEIDER, G.W.; REDMAN, J.D. (1992c) Geophysical detection of DNAPLs: field experiments. Paper presented at the IAH Conference "Modern trends in Hydrogeology". Hamilton, Ontario, Canada.

BUSSIAN, A.E. (1983) Electrical conductance in a porous medium. Geophysics. v. 48, n 9, p 1258-1268.

CAMPOS, H.C.N.S. (1987) Contribuição ao Estudo Hidrogeoquímico do Grupo Bauru no Estado de São Paulo. São Paulo. (Dissertação de Mestrado - Instituto de Geociências/USP)

CARTWRIGHT, K. \& McCOMAS, M.R. (1968) Geophysical surveys in the vicinity of sanitary landfills in northcastern Illinois. Ground Water. Ohio-USA. v. 6, n 5, p 23-30.

CASTANY, G. (1975) Prospección y explotación de las aguas subterráneas. Barcelona, Ediciones Omega.

COMPANHIA DE TECNOLOGIA E SANEAMENTO AMBIENTAL-CETESB (1993) Caracterização e estudo de tratabilidade de líquidos percolados de aterros sanitários. Relatório interno (no prelo). São Paulo. 66p

COMPANHIA DE TECNOLOGIA E SANEAMENTO AMBIENTAL-CETESB (1977) Poluị̧ão das águas subterrâneas no Estado de São Paulo. Estudo preliminar. São Paulo. $88 p$

CHERRY, J.A. (1987) Groundwater contamination by petroleum products. Paper presented at the Twelfth World Petroleum Congress. Houston, Texas. p 115-123.

CHERRY, J.A.;FEENSTRA, S; KUEPER, B.H.; McWHORTER, D.W. (1990) Status of in situ technologies for cleanup of aquifer contaminated by DNAPLs below the water table. Paper prepared for: International Specialty Conference on How Clean is Clean? Cleanup Criteria for Contaminated Soil and Groundwater Air and Waste Management Association. 17p 
CLEARY, R.W. (1989) Águas subterrâneas - Engenharia Hidrológica. Coleção ABRH de Recursos Hídricos. Rio de Janeiro, Editora UFRJ. v. 2, p 293-404.

CRUZ-SANJULIÁN, J.; OLÍAS, M.; VALLE, M.; RUBIO, J.C. (1992) Hidrogeological investigation of ground water in Albolote (Granada, Spain). Ground Water Monitoring Review. Summer, p 188-194.

DEPARTAMENTO DE ÁGUAS E ENERGIA ELÉTRICA DO ESTADO DE SÃO PAULODAEE (1976) Estudo de Águas Subterrâneas - Região Administrativa 7,8,9 (Bauru, S.J.do Rio Preto, Araçatuba). v. 2 (texto), 82p.

DEPARTAMENTO DE ÁGUAS E ENERGIA ELÉTRICA DO ESTADO DE SÃO PAULODAEE (1975) Estudo de Águas Subterrâneas - Região Administrativa 1 (Grande São Paulo). v. 1 (texto), 220p.

DEPARTAMENTO DE ÁGUAS E ENERGIA ELÉTRICA DO ESTADO DE SÃO PAULODAEE (1972) Avaliação Preliminar.

DANIELS, J.J.; ROBERTS, R.; VENDL, M. (1995) Ground penetrating radar for the detection of liquid contaminants. Journal of Applied Geophysics. Elsevier Science Publishers B.V., Amsterdam. v. 33. p 195-207.

DILL, A.C. (1993) Spatial Variability in Porous Aquifer Properties. (Synthetical approach by geophysics, tracer techiques and groundwater flow parameters.) Neuchâtel, Suíça. (Tese de Doutoramento - Science Faculty of The University of Neuchâtel)

DOBRIN, M.B. (1981) Introduction to Geophysical Prospecting. International Student Edition. 630p

EBRAHEEM, A. M.; HAMBURGER, M.W.; BAYLESS, E.R.; KROTHE, N.C. (1990) A Study of Acid Mine Drainage using earth resisitivity measurements. Ground Water. v. 28, n $3, \mathrm{p} 361-368$.

ELLERT, N. (1966) Investigação de camadas aquíferas por métodos geoelétricos no Estado de São Paulo. São Paulo. (Tese de Doutoramento - Instituto de Geociências/USP).

EMPRESA METROPOLITANA DE PLANEJAMENTO DA GRANDE SÃO PAULOEMPLASA (1980) Carta Geológica da Região Metropolitana de S.P. - Escala 1:100000. 
FREEZE, R.A. \& CHERRY, J.A. (1979) Groundwater. Prentice-Hall International, Inc., Englewood Cliffs, N.J. 604p

FROLHIC, R.K.; URISH, D.W.; FULLER, J.; O'REILLY, M. (1994) Use of geoelectrical methods in groundwater polluiton surveys in a coastal environment. Journal of Applied Geophysics. Elsevier Science Publishers B.V., Amsterdam. n 32, p 139-154.

FÚlFARO, V.J. \& BJOMBERG, A.J.S. (1993) Geologia. In: CINTRA, J.C.A. \& ALBIERO, J.H. Solos do Interior de São Paulo. ABMS e D.G.E.E. da UNIVERSIDADE DE SÃO CARLOS. São Carlos. Cap. 1, p 1-44.

GILHAM, R.W. (1987) Processes of contaminant migration in groundwater. In: Proceedings CSCE Centennial Symposium on Management of Waste Contamination of Groundwater. Montreal, Quebec. p 1-31.

GREENHOUSE, J.; BREWSTER, M; SCHNEIDER, G.; REDMAN, D.; ANNAN, P.; OLHOEFT, G; LUCIUS, J.; SANDER, K.; MAZELLA, A. (1993) Geophysics and Solvents: The Borden Experiment. The Leading Edge. p 261-267.

GREENHOUSE, J.P.; MONIER-WILLIAMS, M.E.; ELLERT, N.; SLAINE, D.D. (1987) Geophysical methods in groundwater contamination studies. Presented at EXPLORATION '87, The Third Decennial International Conference on Geophysical and Geochemical Exploration for Minerals and Groundwater. Toronto.

GREENHOUSE, J.P. \& HARRIS, R.D. (1983) Migration of contaminants in groundwater at a landfill: a case study. 7. DC, VLF, and inductive resistivity surveys. In: J.A. Cherry (GuestEditor), Migration of Contaminants of Groundwater at a Landifill: A Case Study. J. Hydrol., 63:177-197.

HOEKSTRA, P.; LATHI, R.; HILD, J.; BATES, C.R.; PHILLIPS, D. (1992) Case Histories of Shallow Time Domain Eletromagnetics in Environmental Site Assessment. Ground-Water Monitoring Review. Fall, p 110-117.

HOWARD, K.W.F. (1990) The Role of Well Logging in Contaminant Transport Studies. In: Stanley H. Ward (Editor), Geotechnical and Environmental Geophysics, SEG. v. 2, p 289301.

IAKUBOVSKII, Iu.V. \& LIAJOV, L.L. (1980) Exploración elétrica. Espanha, Editora Reverté. 
INSTITUTO BRASILEIRO DE GEOGRAFIA ESTATÍSTICA-IBGE (1972) Carta do Brasil Esc. 1:50 000 - Folha SF-22-X-A-VI-3. Macaubal (SP).

INSTITUTO BRASILEIRO DE GEOGRAFIA ESTATÍSTICA-IBGE (1972) Carta do Brasil Esc. 1:50 000 - Folha SF-22-X-A-VI-3. Mirassol (SP).

IG-CETESB-DAEE-EMBRAPA. Mapeamento da vulnerabilidade e risco de poluição das águas subterrâneas no Estado de São Paulo. (no prelo)

INSTITUTO DE PESQUISAS TECNOLÓGICAS-IPT (1981) Mapa geológico do Estado de São Paulo. São Paulo, IPT. Escala 1:500000. v. I e II

JANSEN, J.; HADDAD, B.; FASSBENDER, B.; JURCEK, P. (1992) Frequency Domain Eletromagnetic Induction Sounding Surveys for Landifill Site Characterization Studies. Ground-Water Monitoring Review. Fall, p 103-109.

KALINSKI, R.J.; KELLY, W.E.; BOGARDI, I. (1993) Combined Use of Geoleletric Sounding and Profiling to Quantify Aquifer Protection Properties. Ground Water. v. 31, n 4, p 538544.

KELLY, W.E. (1977) Geoeletric Sounding for Estimating Aquifer Hydraulic Conductivity. Ground Water. v. 15, n 6, p 420-425.

KELLY, W.E. (1976) Geoeletric Sounding for Delineating Ground-Water Contamination. Ground Water. v. 14, n'1, p 6-10.

KELLER, G.V. \& FRISCHKNECHT, F.C. (1966) Electrical methods in geophysical prospecting. Pergamon Press Inc. N.Y. 519p.

KOSINSKI, W.K. \& KELLY, W.E. (1981) Geoeletric Soundings for Predicting Aquifer Properties. Ground Water. v. 19, n 2, p 163-171.

KUEPER, B.H.; HAASE, C.S.; KING, H.L. (1991) Consideration of DNAPL in the operation and monitoring of waste disposal ponds constructed in fractured rock and clay. For publication in Proceedings, First Canadian Conference on Environmental Geotechnics. Canadian Geotechnical Society. Montreal, Canada.

KWADER, T. (1986) The use of geophysical logs for determining formation water quality.

Ground Water. v. 24, p 11-25. 
MACKAY, D.M.; ROBERTS, P.V.; CHERRY, J.A. (1985) Transport of Organics Contaminants in Groundwater. Environmental Science Technology. v. 19, n 5, p 384-392.

MATIAS, M.S.; SILVA, M.M.; FERREIRA, P.; RAMALHO, E. (1994) A geophysical and hydrogeological sudy of aquifers contamination by a landfill. Journal of Applied Geophysies. Elsevier Science B.V. n 32 p 155-162.

MAZÁC, O.; BENES, L.; LANDA, I.; MASKOVA, A. (1990) Determination of the extent of oil contamination in groundwater by geoelectrical methods. In: Stanley H. Ward (Editor), Geotechnical and Environmental Geophysies, SEG. v. 2, p 107-112.

MAZÁC, O.; CÍSLEROVÁ, M.; KELLY, W.E.; LANDA, I.; VENHODOVÁ, D. (1990) Determination of Hudraulic Conductivites by Surface Geoelectrical Methods. In: Stanley H. Ward (Editor), Geotechnical and Environmental Geophysics, SEG. v. 2, p 125-131.

McNEILL, J.D. (1980a) Electrical terrain conductivity of soils and rocks. Technical Note TN-5, Geonics Limited. Mississauga, Ont. Canada.

McNEILL, J.D. (1980b) Eletromagnetic terrain conductivity measuremente at low induction numbers. Technical Note TN-6, Geonics Limited. Mississauga, Ont. Canada.

MENDES, J.M.B. (1987) Técnicas Geofísicas Aplicadas no Mapeamento e Monitoramento de Poluição e Contaminação de Águas Subterrâneas. São Paulo. (Tese de Doutoramento Instituto de Geociências/USP)

MONIER-WILLIAMS, M.E.; GREENHOUSE, J.P.; MENDES, J.M.; ELLERT, N. (1990) Terrain condutivity mapping with topographic corrections at three waste disposal sites in Brazil. In: Stanley H. Ward (Editor), Geotechnical and Environmental Geophysics, SEG. v. 2, p 41-55.

OLHOEFT, G.R. (1985) Low-frequency electrical properties. Geophysics. v. 50, n. 12, p. 24922503.

ORELLANA, E. (1974) Prospeccion geoelectrica por campo variables. Madrid, Editora Paraninfo. 571p

ORELlANA, E. (1982) Prospeccion geoelectrica en corriente continua. Madrid, Editora Paraninfo. 578p 
PACHECO, A.; ESPÍNDOLA, R.S.; BATELLO, E.R.; MENDES, J.M.B.; DEHAINI, J. (1994) A problemática do lixo urbano na região metropolitana de São Paulo - O Lixão do Alvarenga $\mathrm{e}$ as águas subterrâneas. Anais do $2^{\circ}$ Congresso Latinoamericano de Hidrologia Subterrânea. Santiago, Chile. p 127-140.

PARASNIS, D.S. (1986) Principles of Applied Geophysics. New York, Chapman and Hall. $402 p$

PREFEITURA DO MUNICÍPIO DE DIADEMA (1990) Mapa de Diadema - Levantamento Aerofotogramétrico - Escala 1: 2000 - Folhas 333643, 334531 e 334532.

REDMAN, J.D. \& ANNAN, A.P. (1992) Dieletric Permitivity monitoring in a sandy aquifer following the controlled release of a DNAPL. Proceedings of Fourth International Conference on Ground Penetrating Radar, Rovaniemi, Finland. Geological Survey of Finland, Special Paper (in Press).

SCHENEIDER, G.W \& GREENHOUSE, J.P. (1992). Geophysical detection of perchloroethylene in a sandy aquifer using resistivity and nuclear logging techniques. Proceedings of the Symposium on the Application of Geophysics to Engineering and Environmental Problems. Chicago, IIllinois.

SHERRIF, R.E. (1989) Geophysical Methods. New Jersey, Prentice Hall. 605p

SOARES, P.C.; LANDIM, P.M.B.; FÚlFARO, V.J.; SOBREIRO, A.F. (1980) Ensaio de caracterização estratigráfica do cretáceo no Estado de São Paulo: Grupo Bauru. Revista Brasileira de Geociências. v. 10, n. 3, p. 177-185.

STREET, G.J. \& ENGEL, R. (1990) Geophysical surveys of dryland salinity. In: Stanley H. Ward (Editor), Geotechnical and Environmental Geophysics, SEG. v. 2, p. 187-199.

TELFORD, W.M.; GELDART, L.P.; SHERRIF, R.E. (1990) Applied geophysics. Cambridge, Cambridge University Press. 770p

URISH, D.W. (1983) The Practical Application of Surface Electrical Resistivy to Detection of Ground-water Polluition. Ground Water. v. 21, n 2, p 144-152.

VANHALA, H.; SOININEN, H.; KUKKONEN, 1. (1992) Detecting Organic Chemical Contaminants by Spectral-induced Polarization Method in Glacial Till Environment. Geophysics. v. 57, n 8, p 1014-1017. 
WORTHINGTON, P.F. (1993) The uses and abuses of the Archie equations, 1: The formation factor-porosity relationship. Journal of Applied Geophysics. Elsevier Science Publishers B.V., Amsterdam. n 30, p 215-228. 


$$
\text { A NEXO I }
$$

Plantas de Localização dos Pontos Investigados por Geofísica nas Áreas de Estudo 







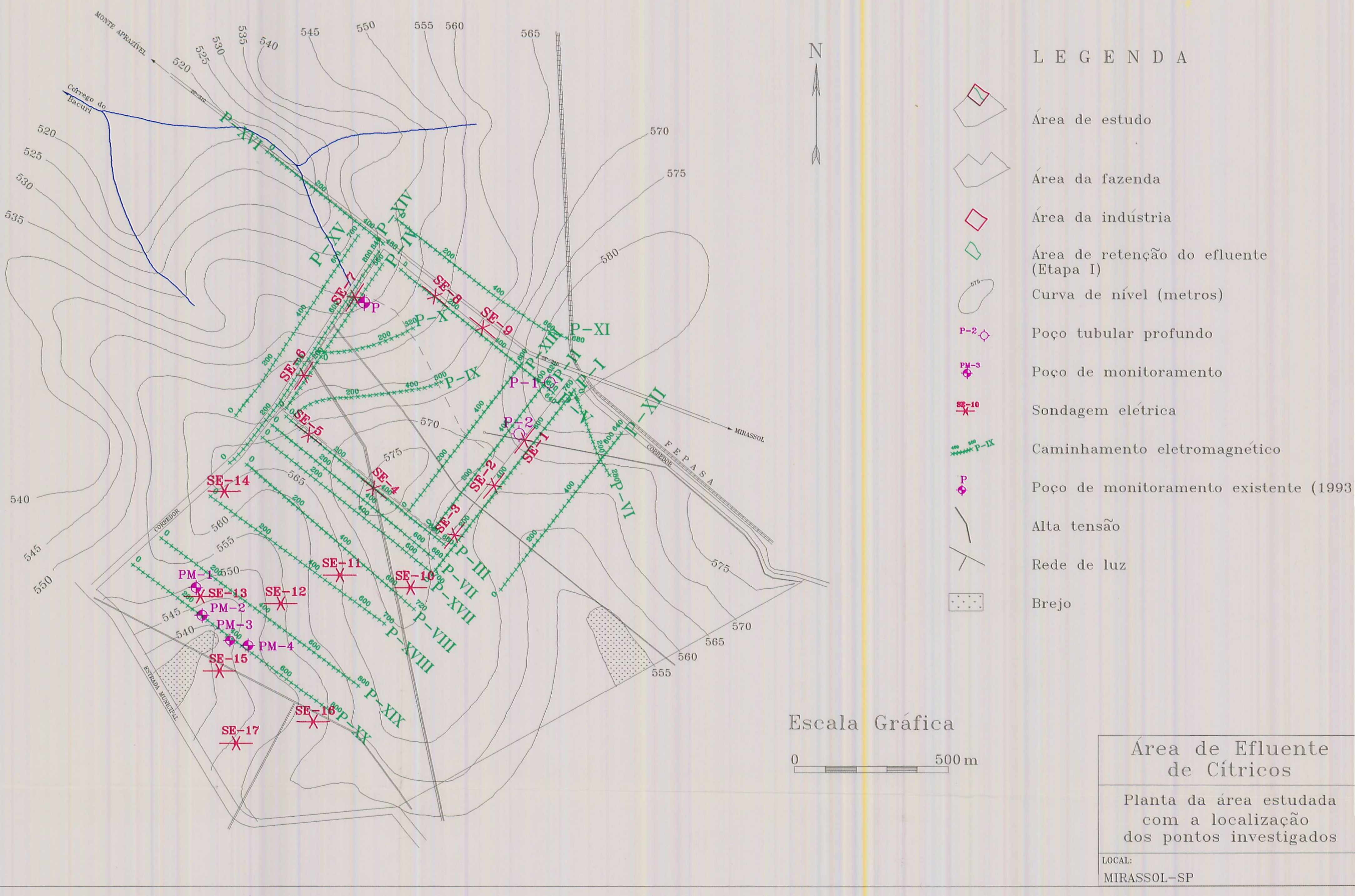




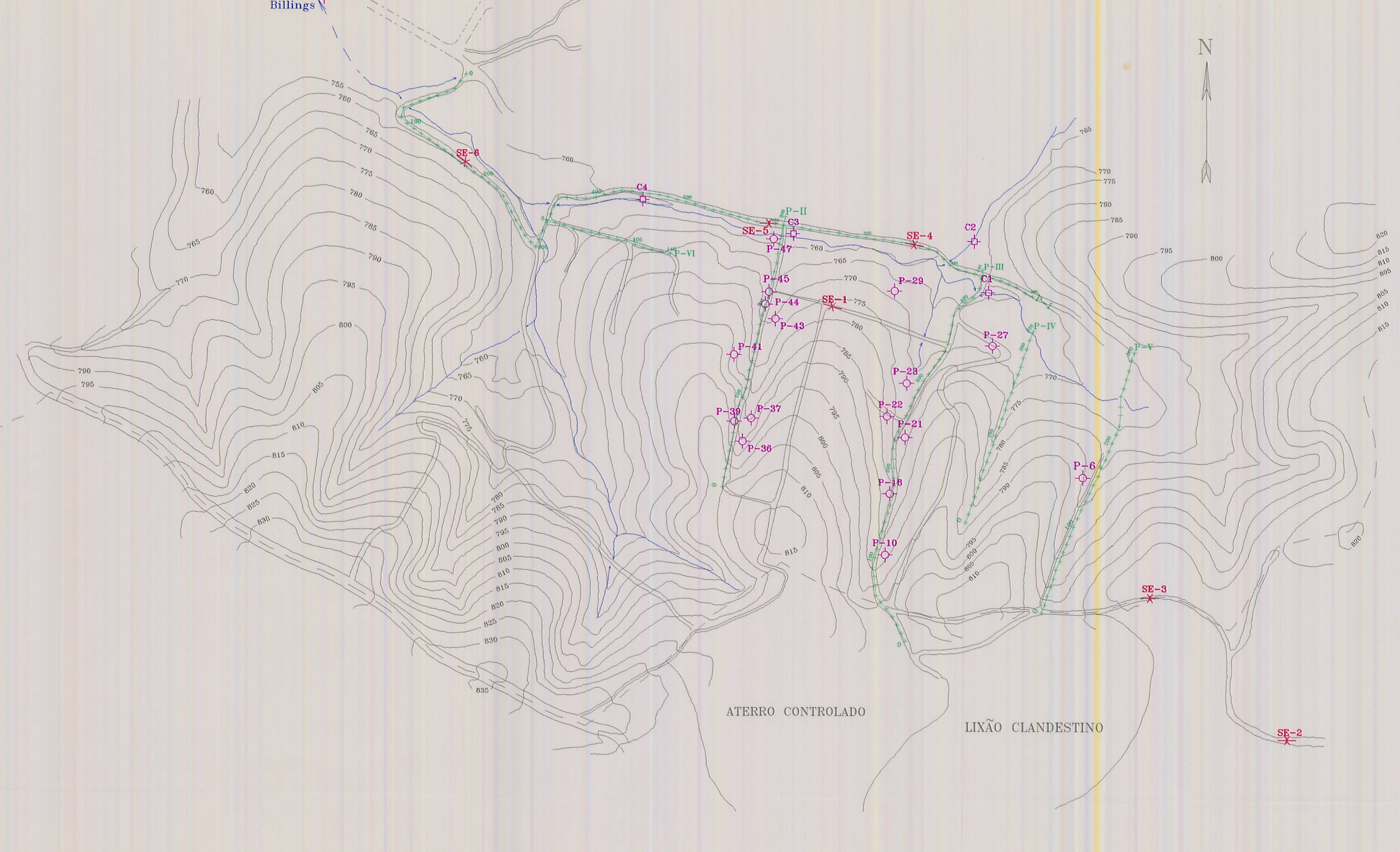

$\stackrel{\text { SE-3 }}{*}$ Sondagem elétrica

LEGENDA

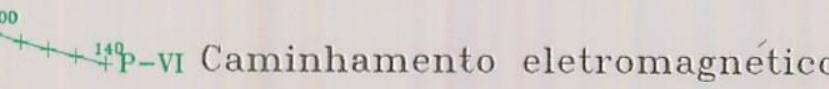

P-23 Ponto de amostragem em cacimba

C3 Ponto de amostragem em córrego

Divisa de município

Curva de nível

Rua de terra

Córrego

Rua de asfalto

ESCALA GRÁFICA

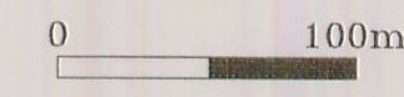

Área do Aterro Sanitário Planta da área estudada com a localização dos pontos investigados 


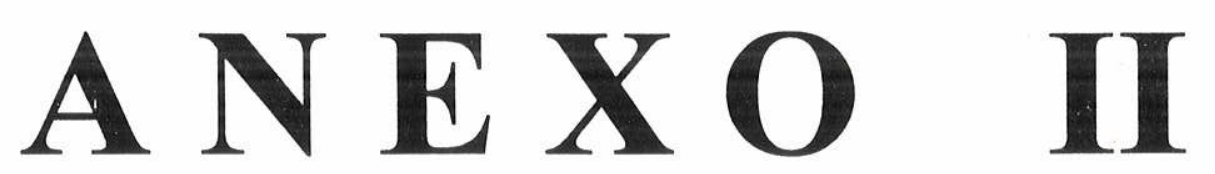

Curvas de Resistividade Elétrica

Aparente (SE) 


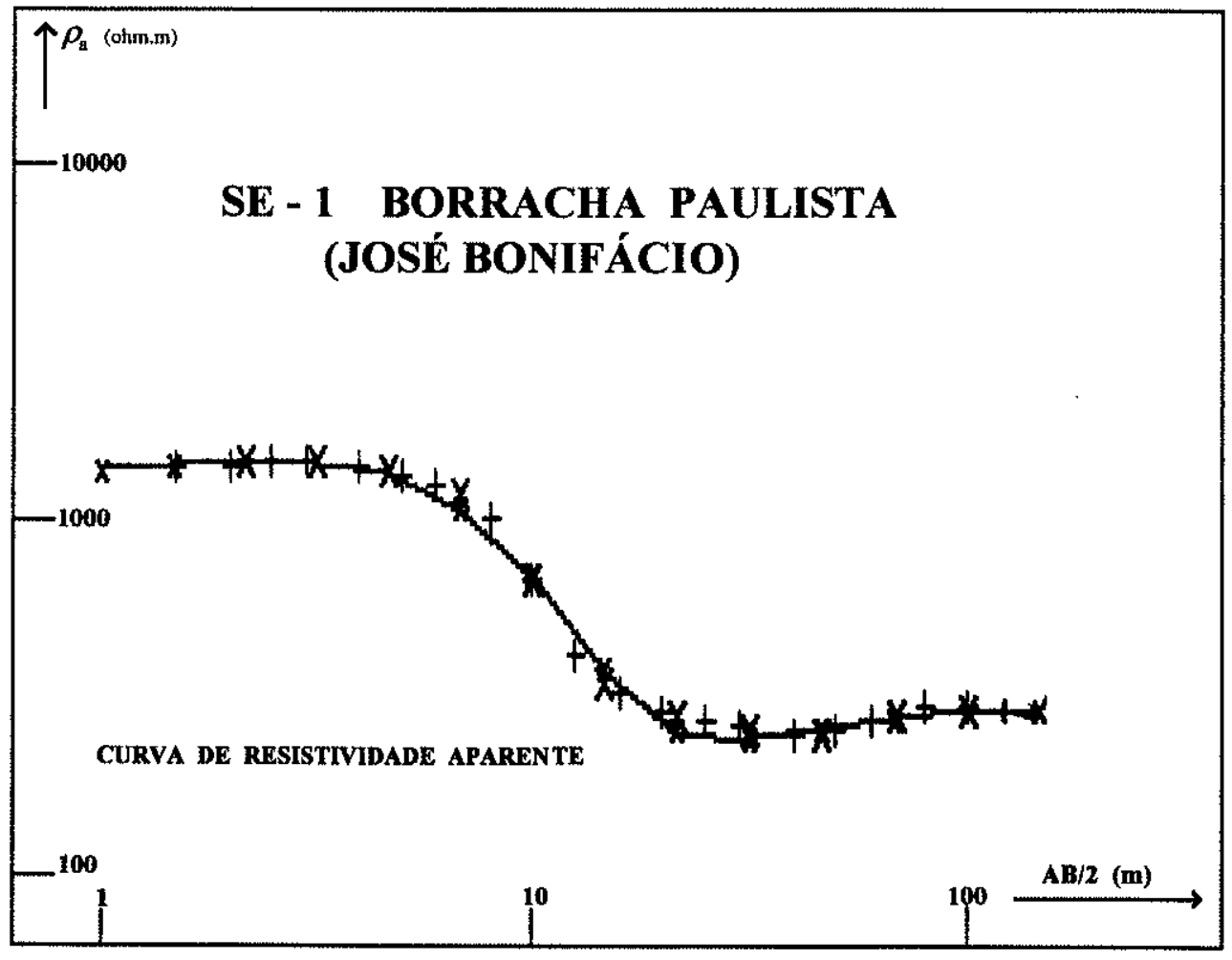

\section{MODELO SCHLUMBERGER DE SONDAGEM SE - 1}

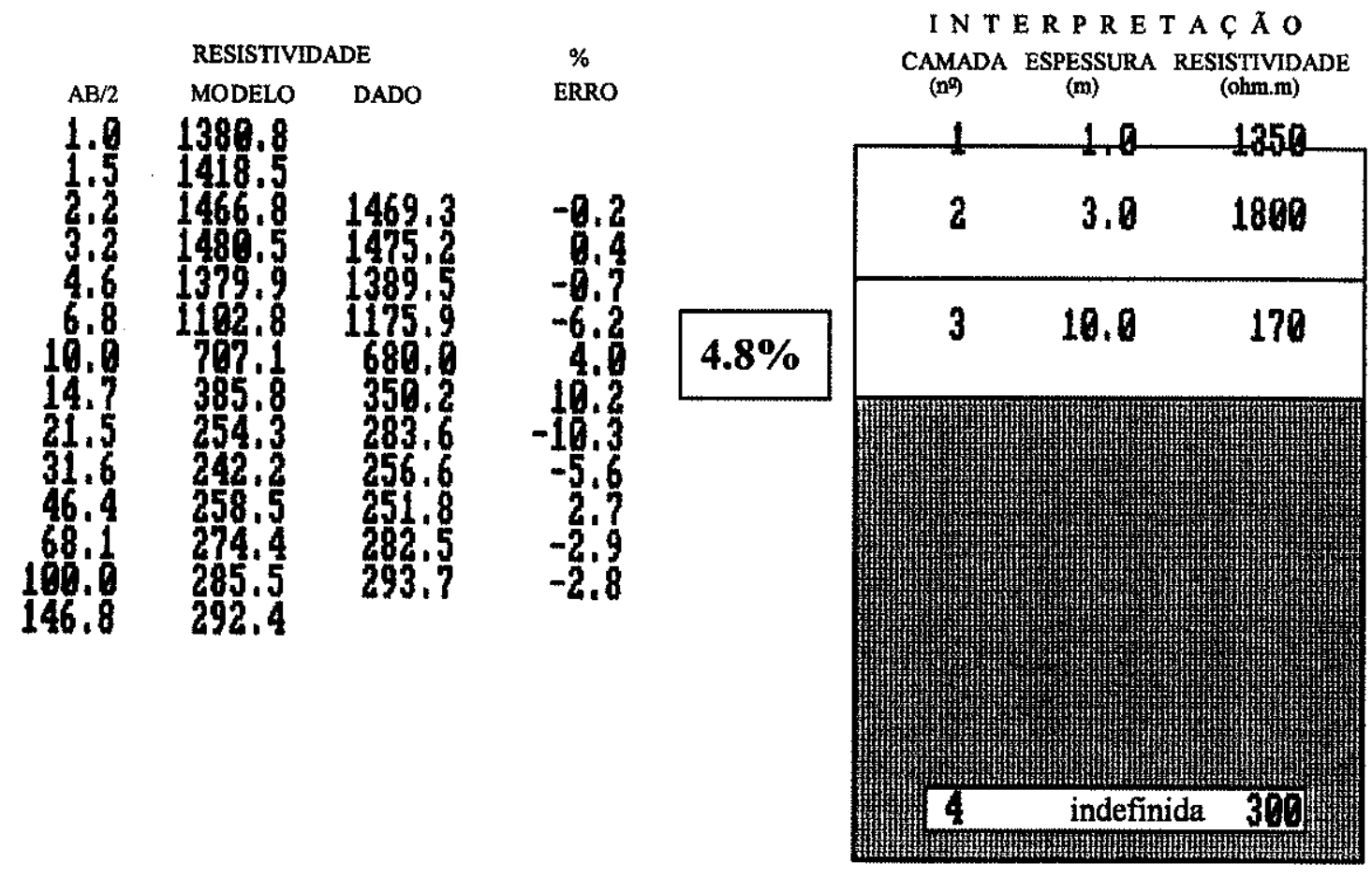




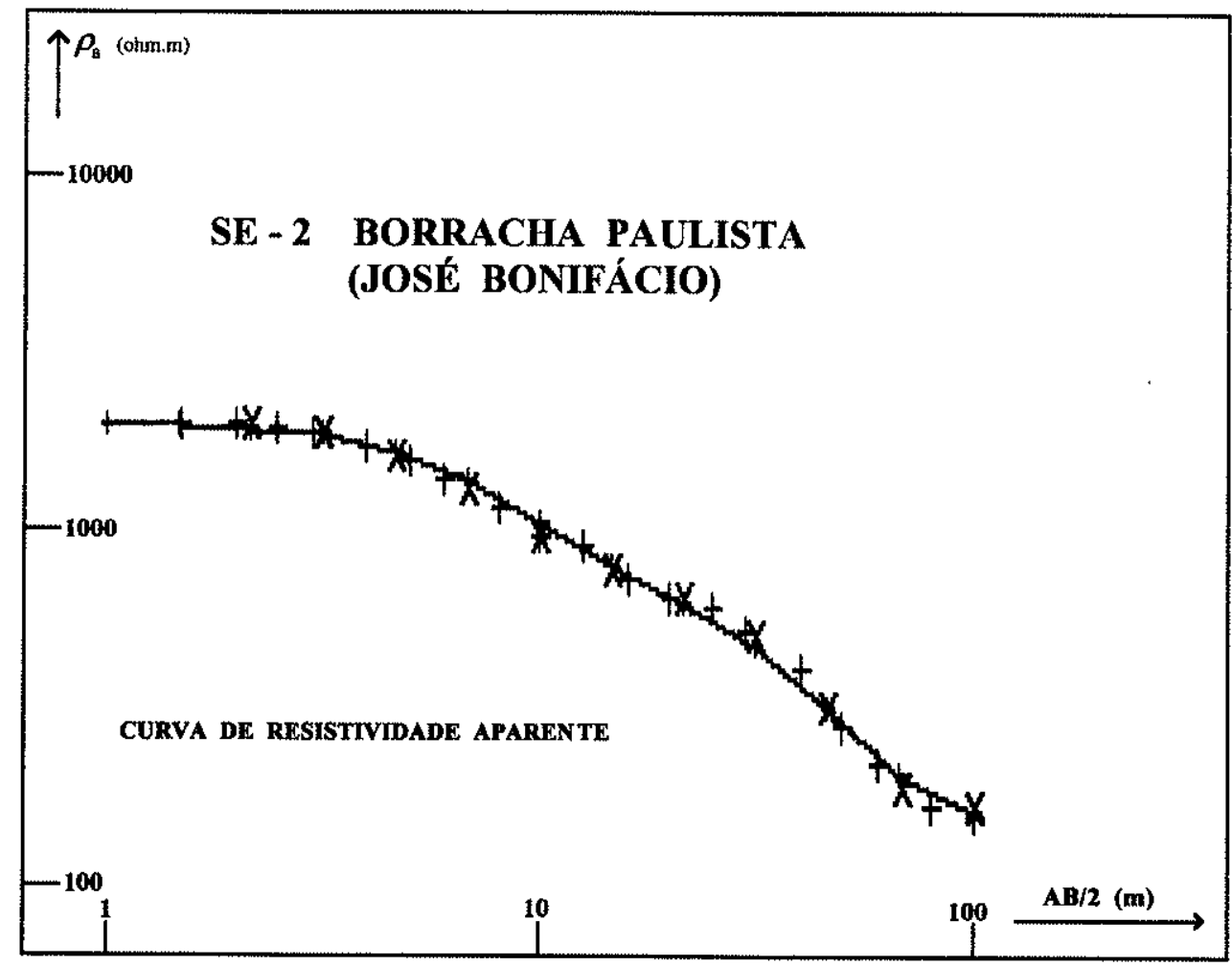

MODELO SCHLUMBERGER DE SONDAGEM SE - 2

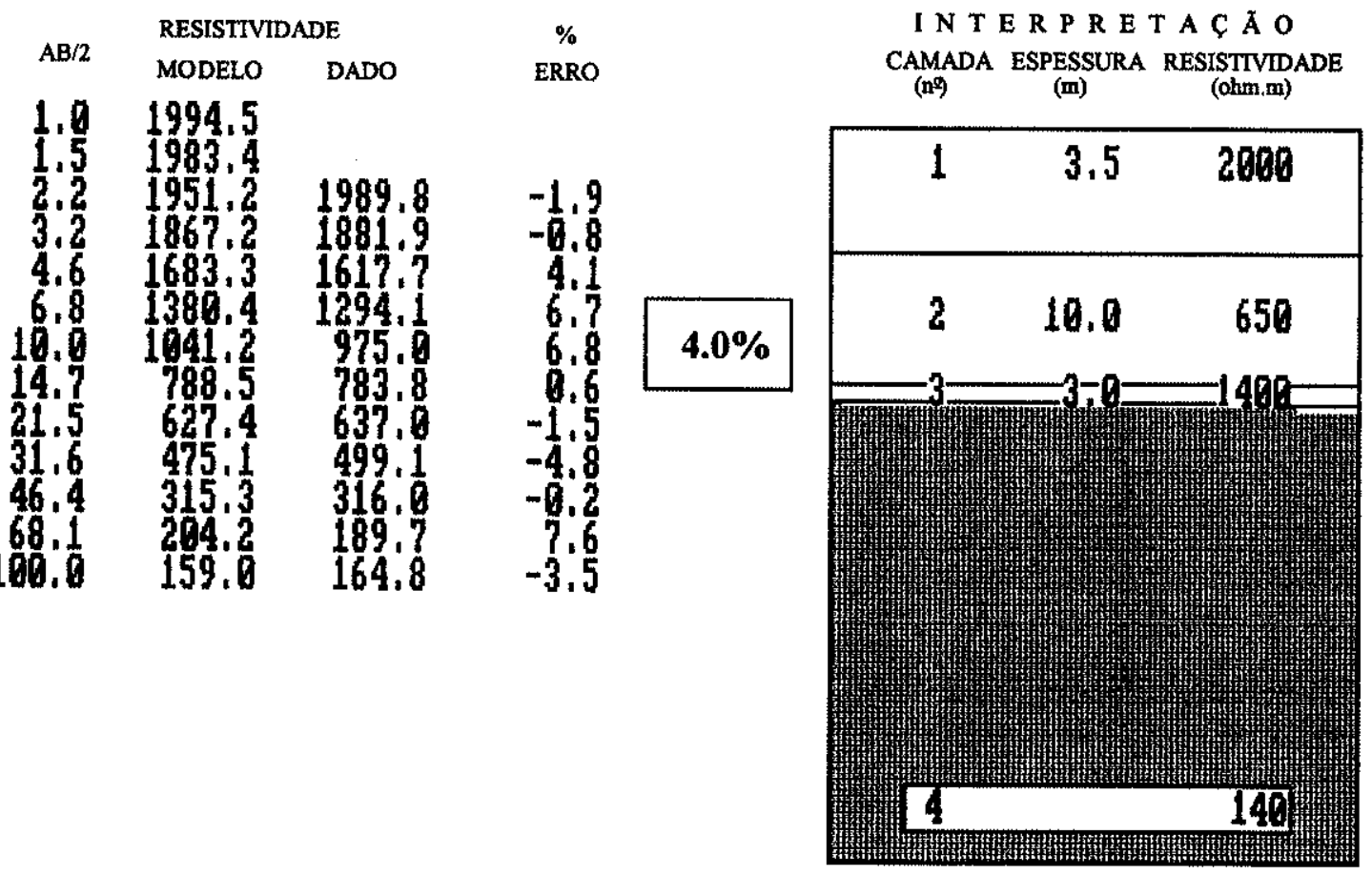




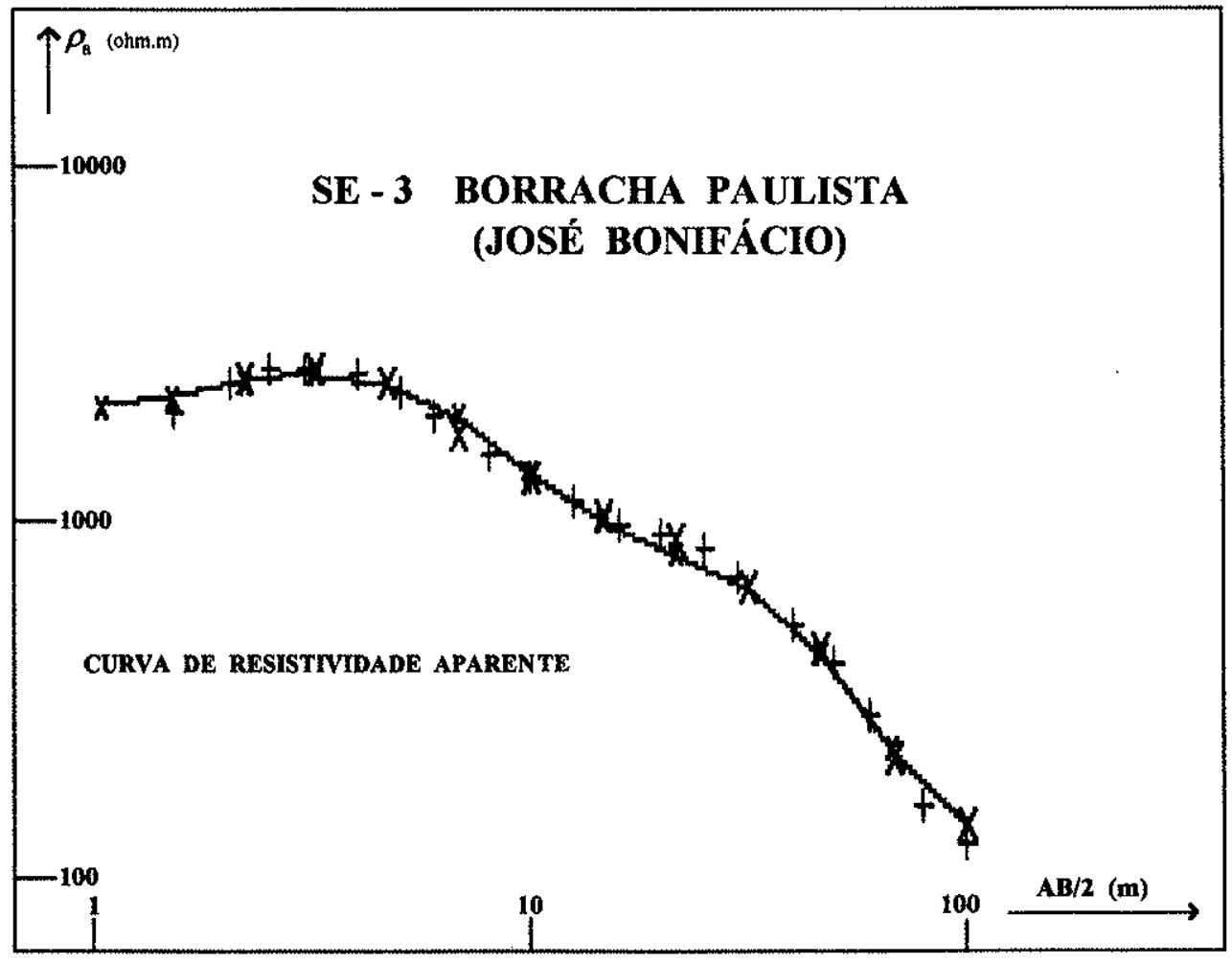

MODELO SCHLUMBERGER DE SONDAGEM SE - 3

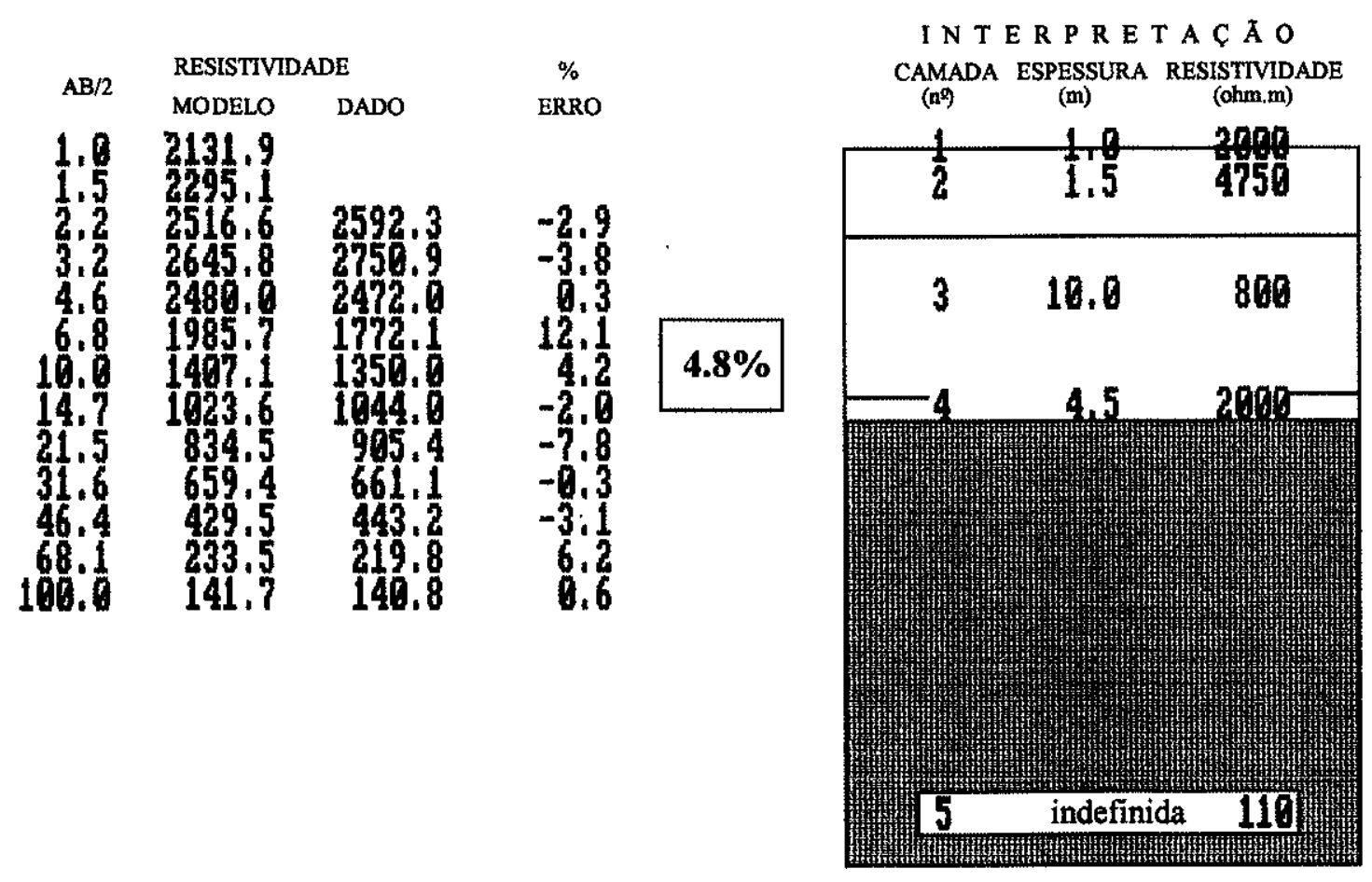




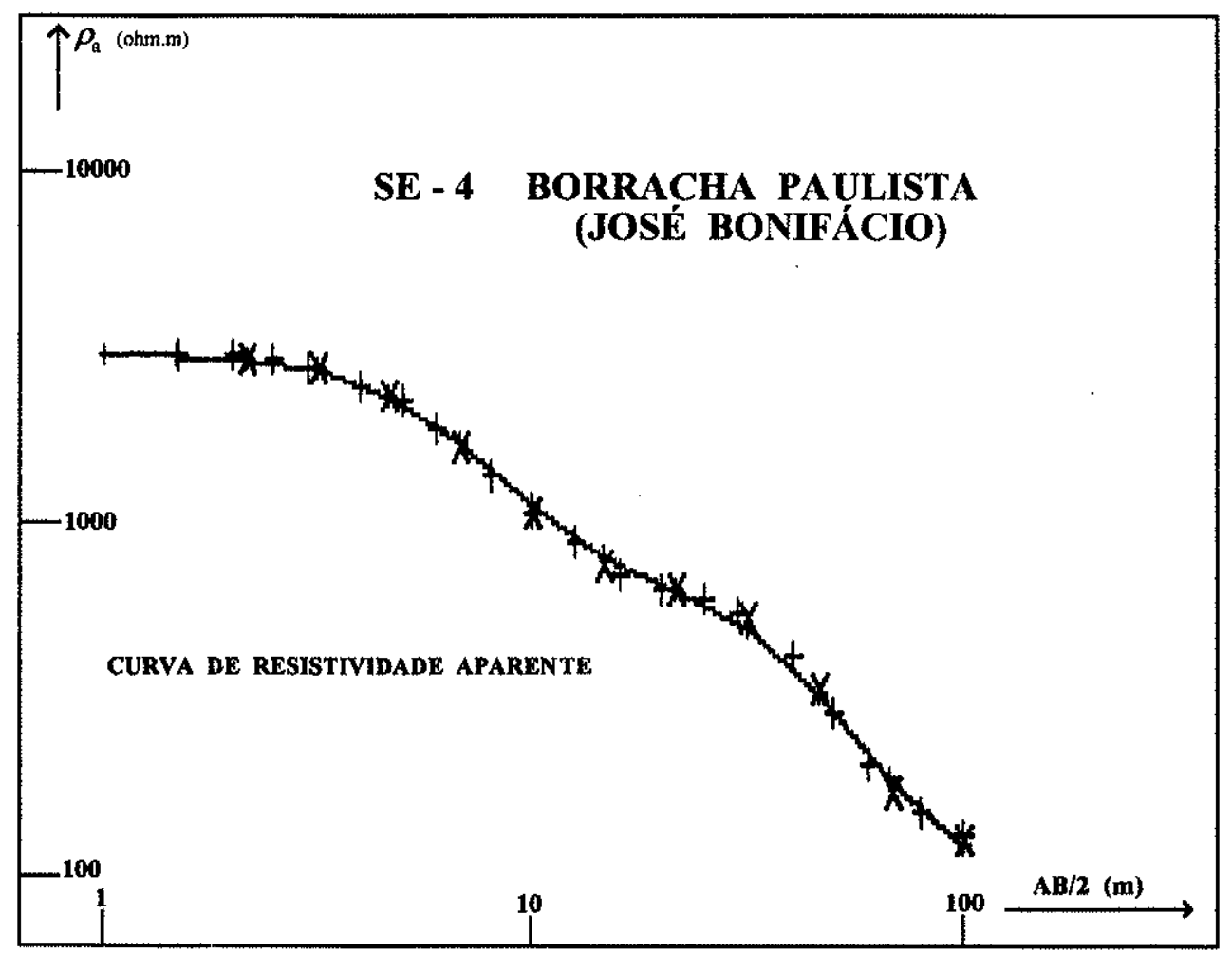

MODELO SCHLUMBERGER DE SONDAGEM SE - 4

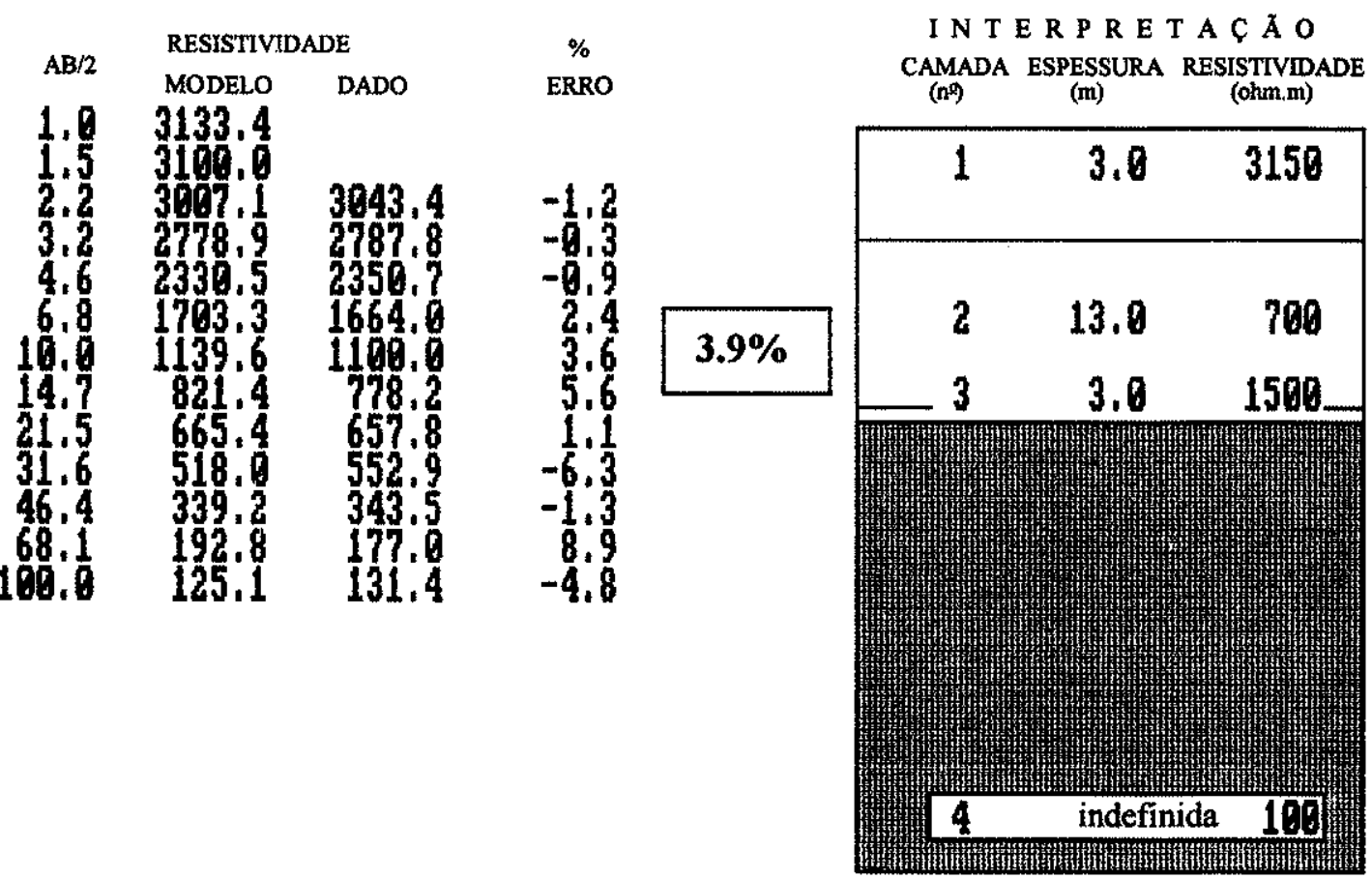




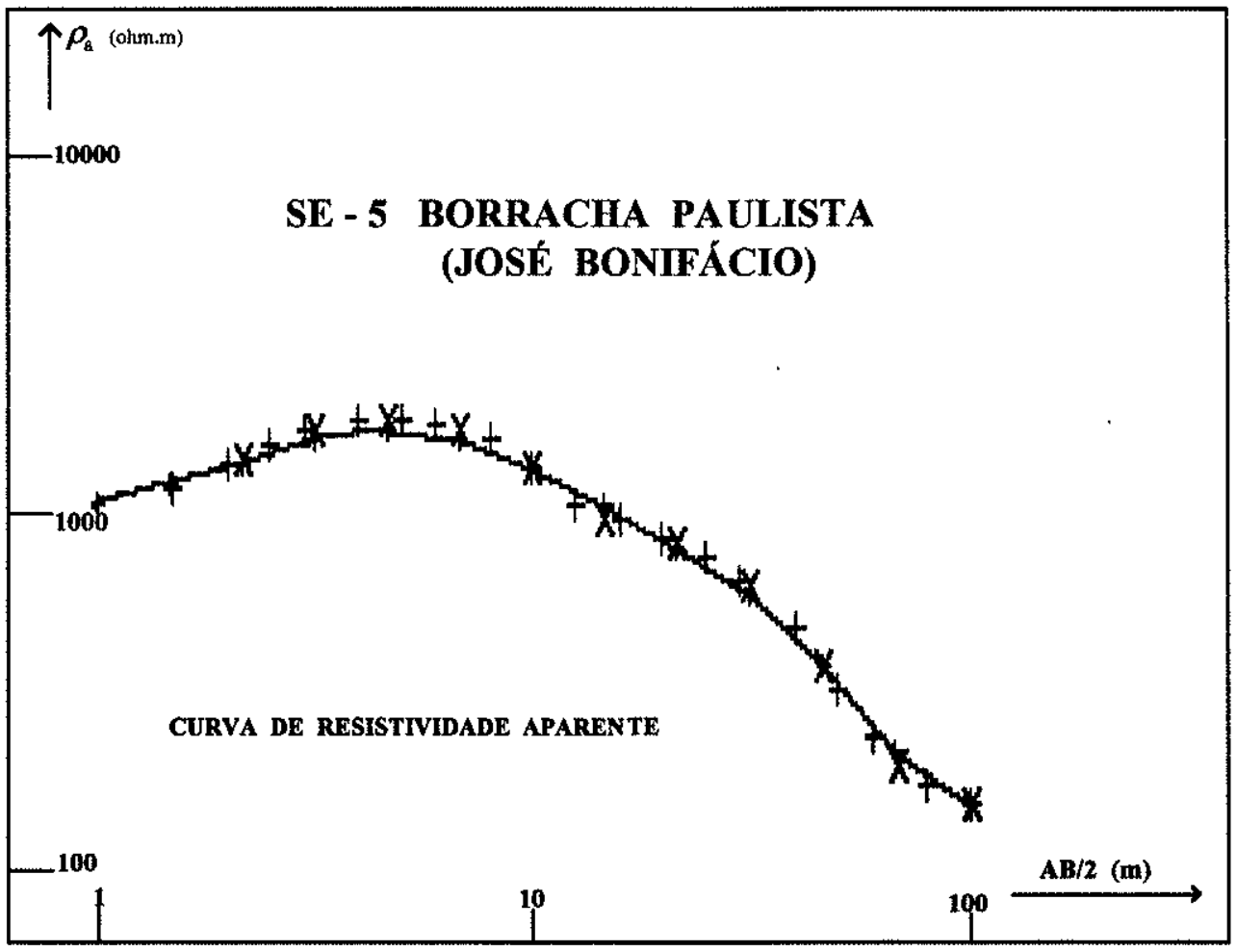

MODELO SCHLUMBERGER DE SONDAGEM SE - 5

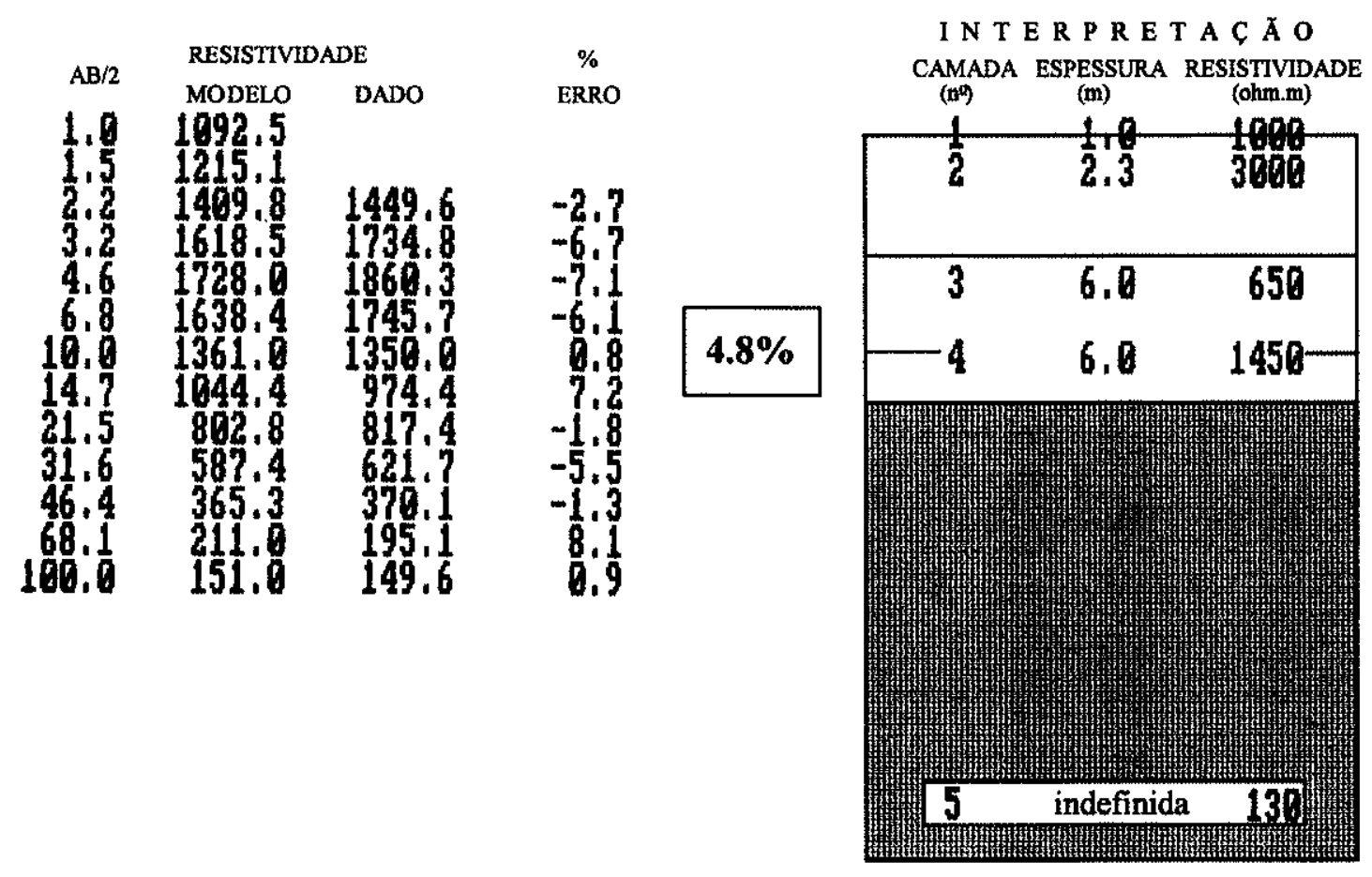




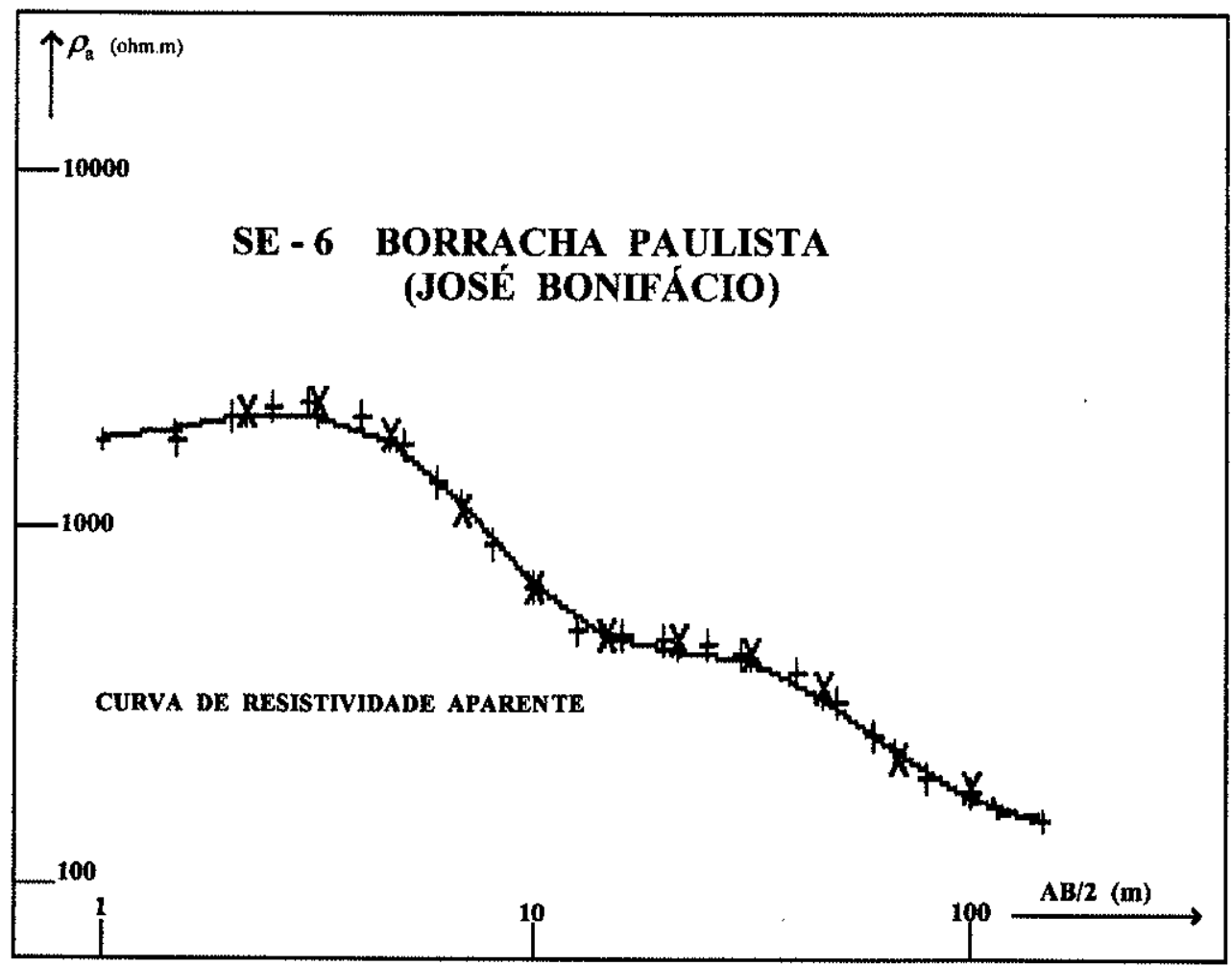

MODELO SCHLUMBERGER DE SONDAGEM SE - 6

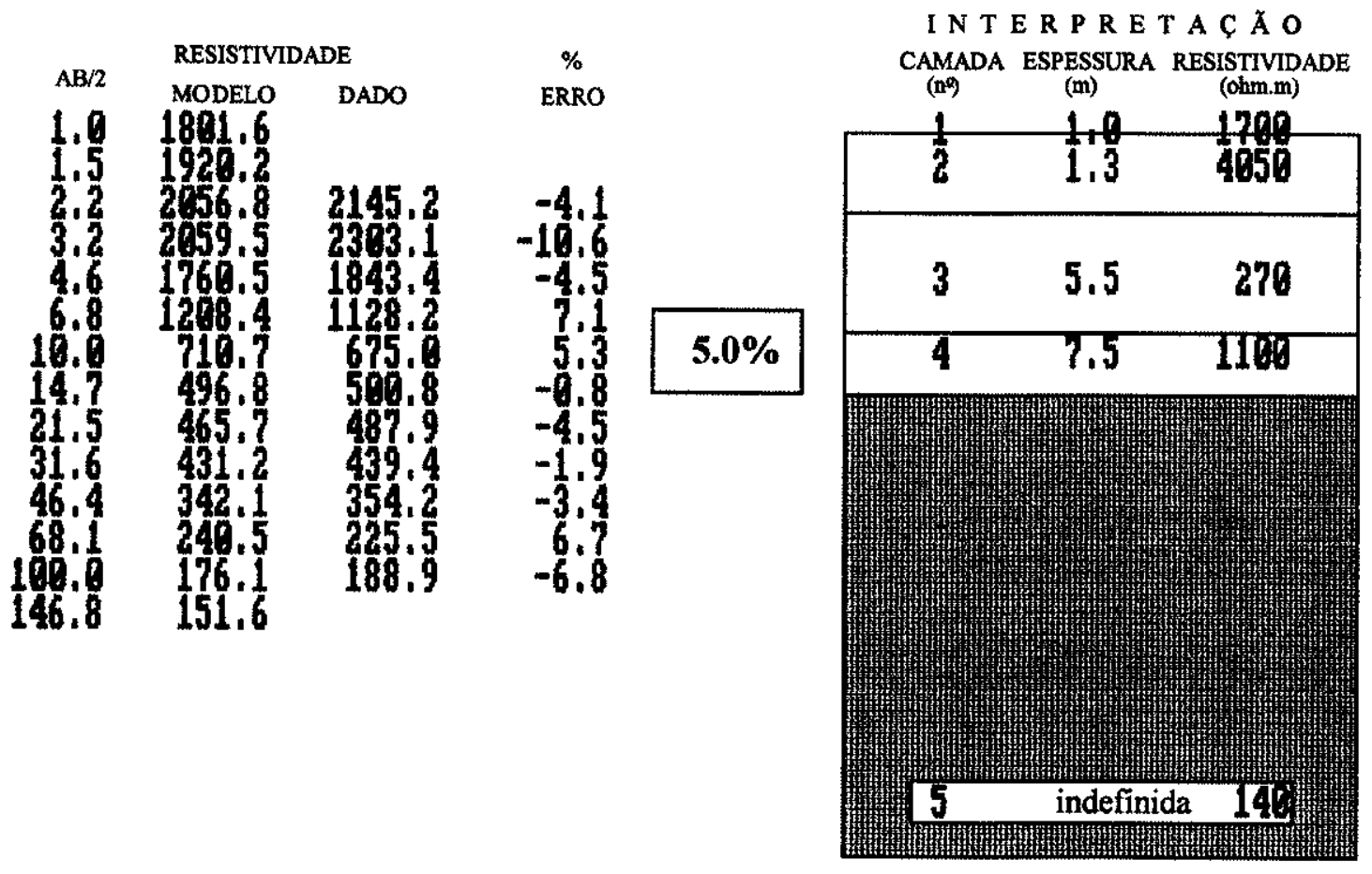




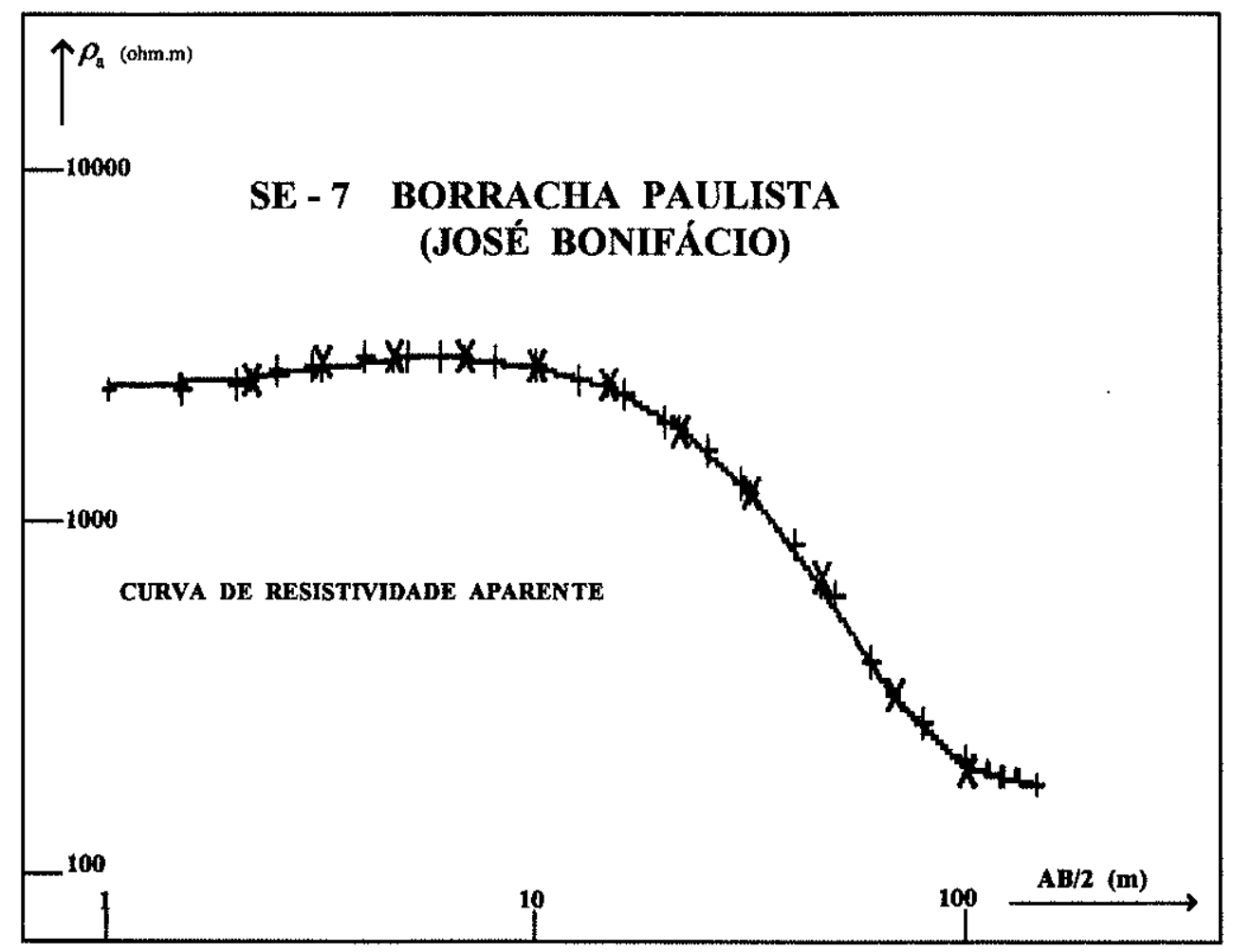

MODELO SCHLUMBERGER DE SONDAGEM SE - 7

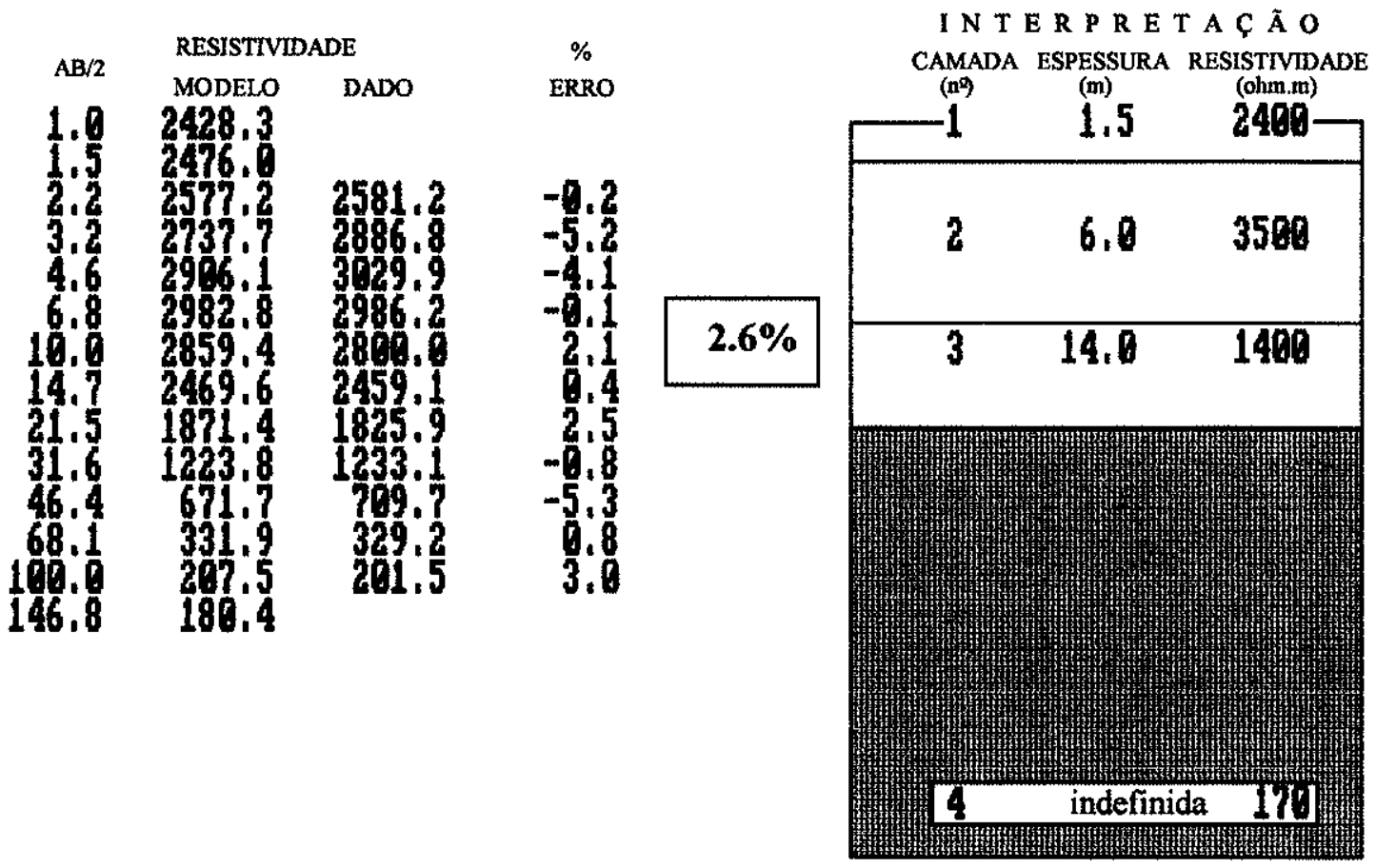




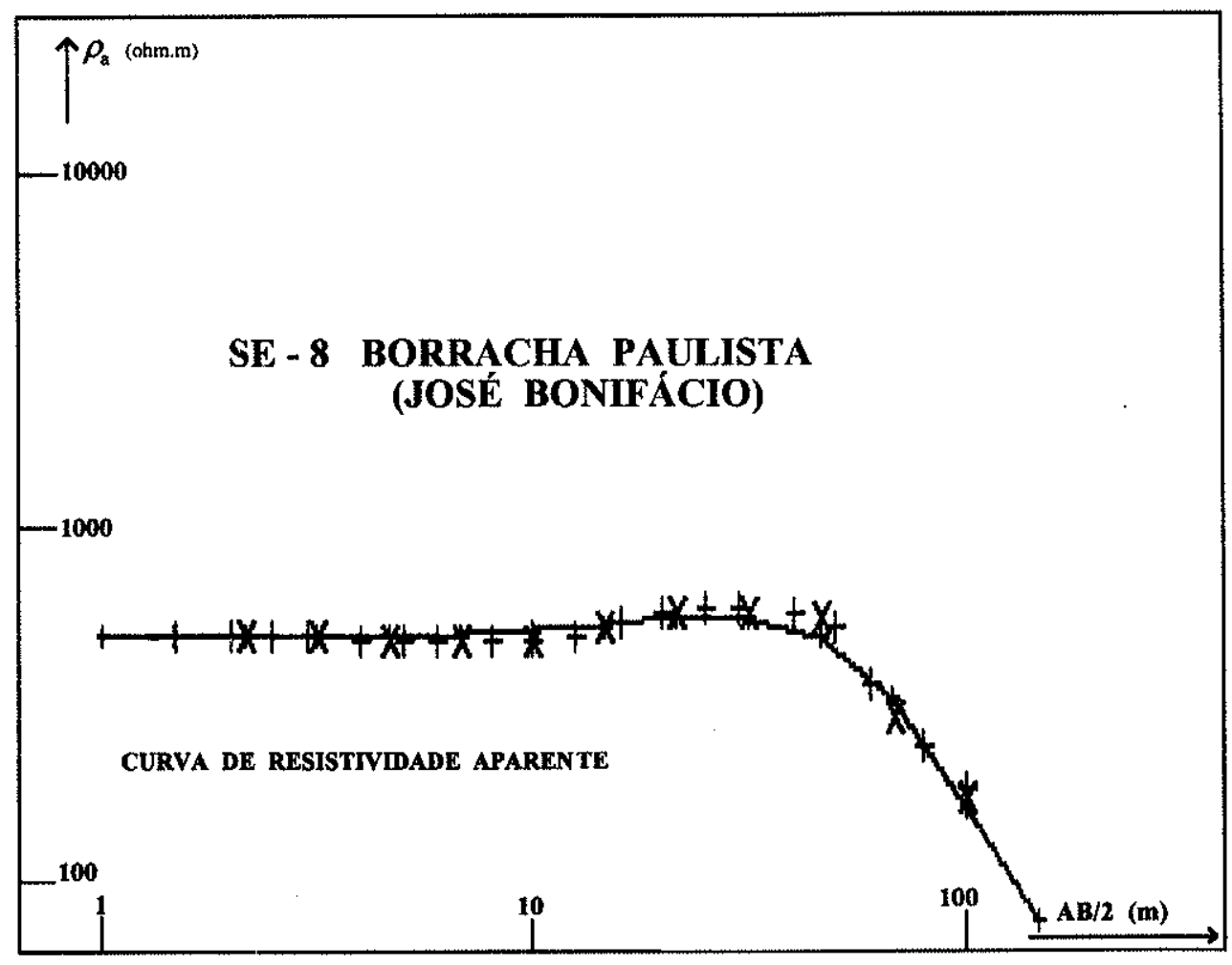

MODELO SCHLUMBERGER DE SONDAGEM SE - 8

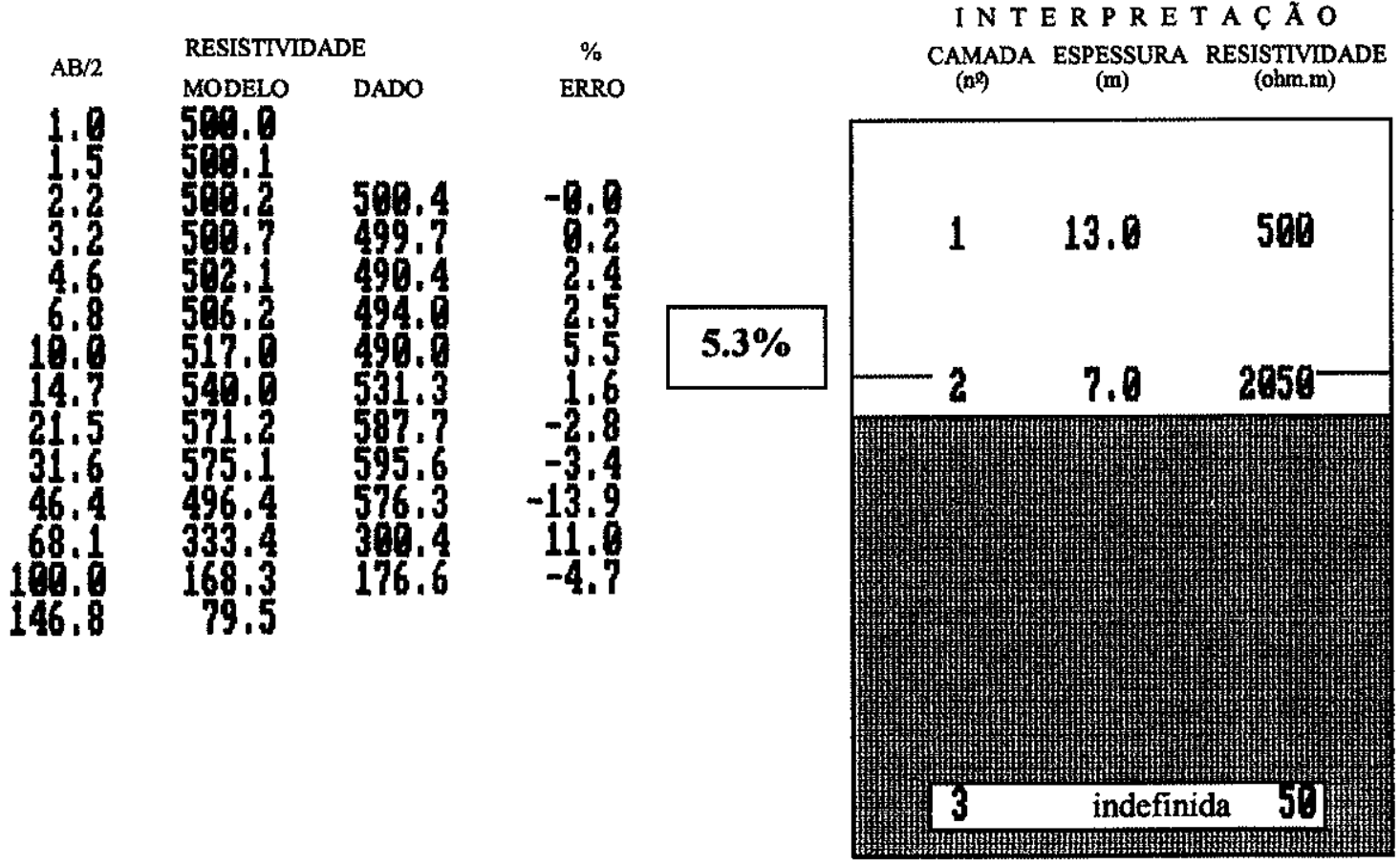




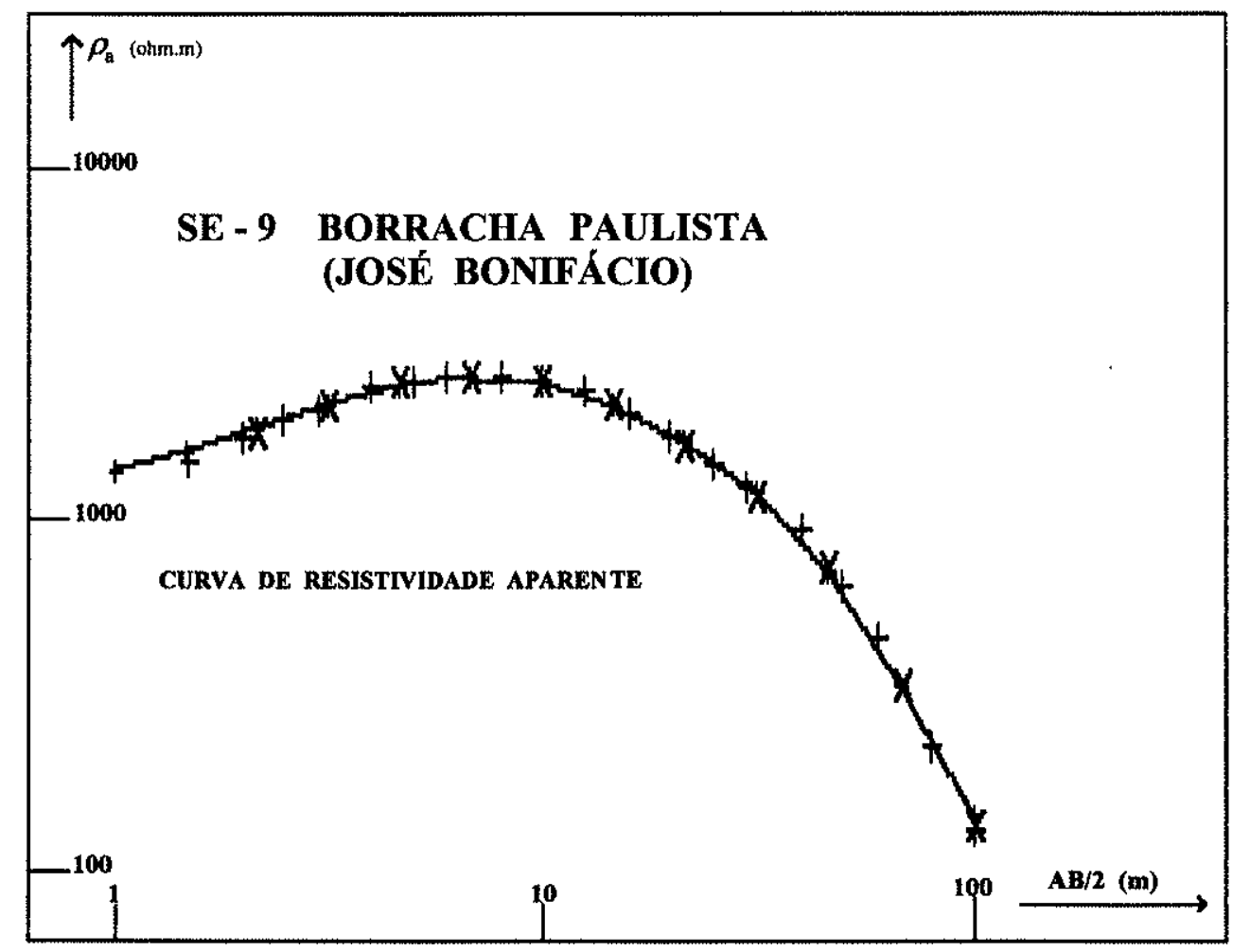

MODELO SCHLUMBERGER DE SONDAGEM SE - 9

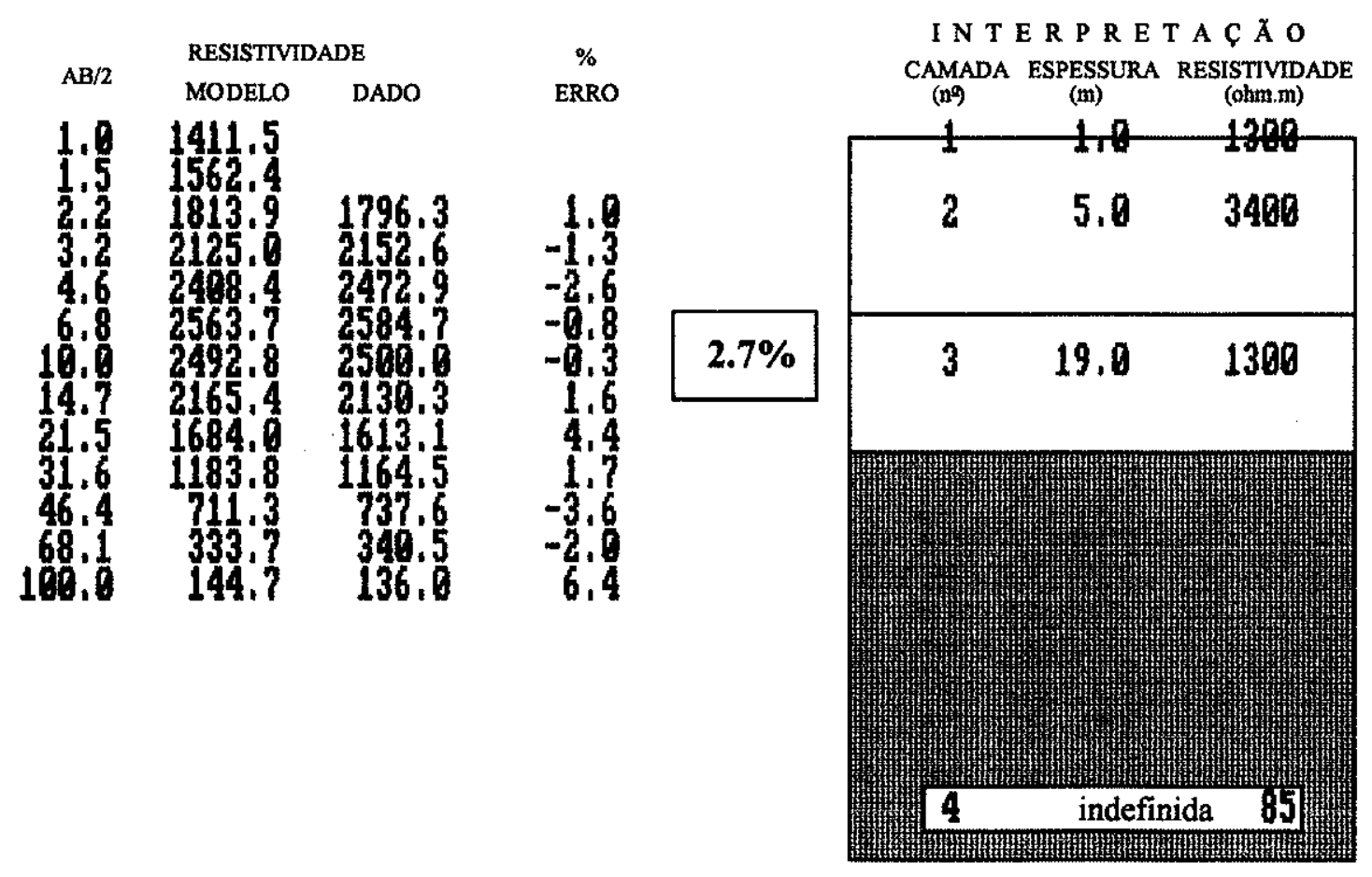




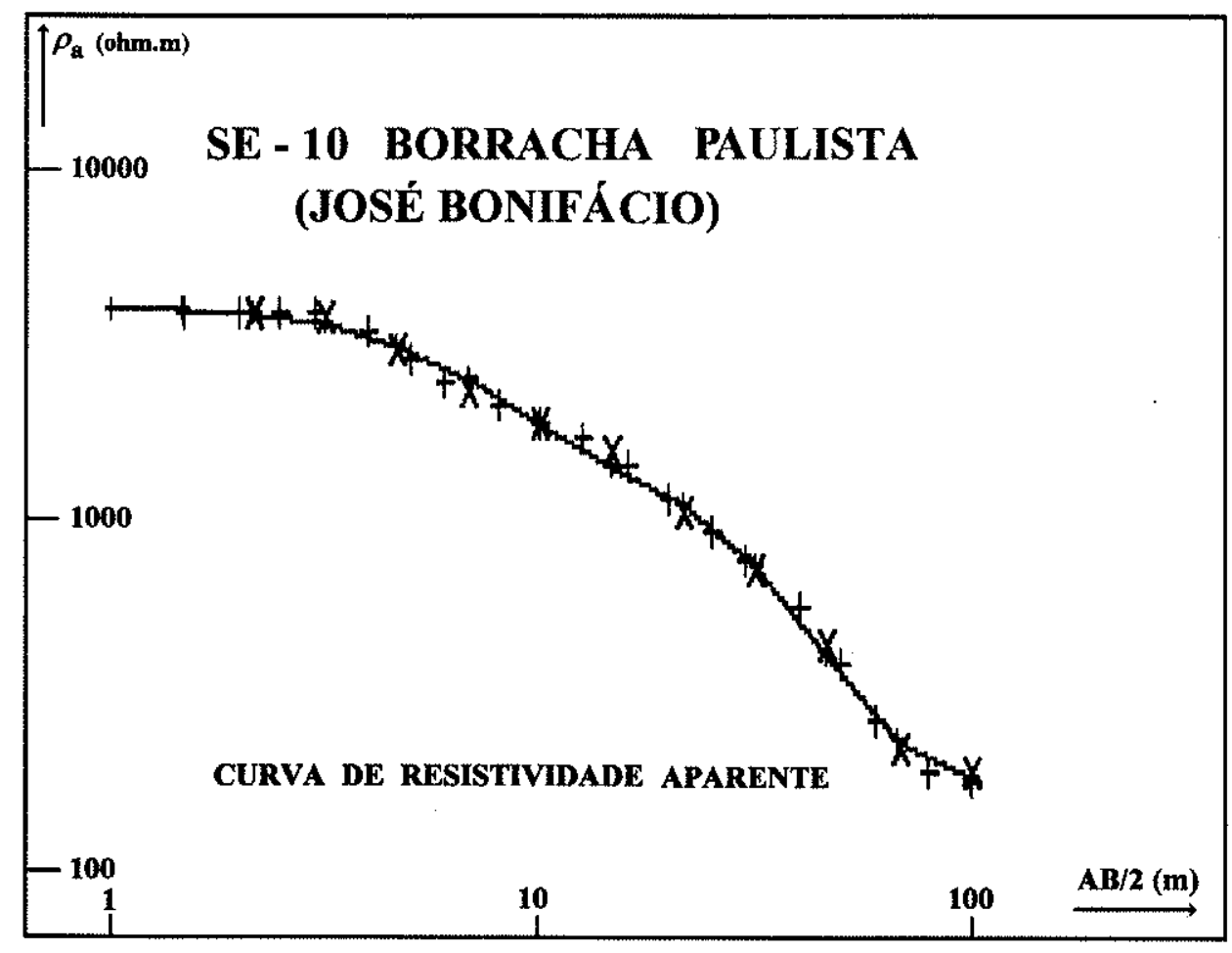

MODELO SCHLUMBERGER DE SONDAGEM SE - 10

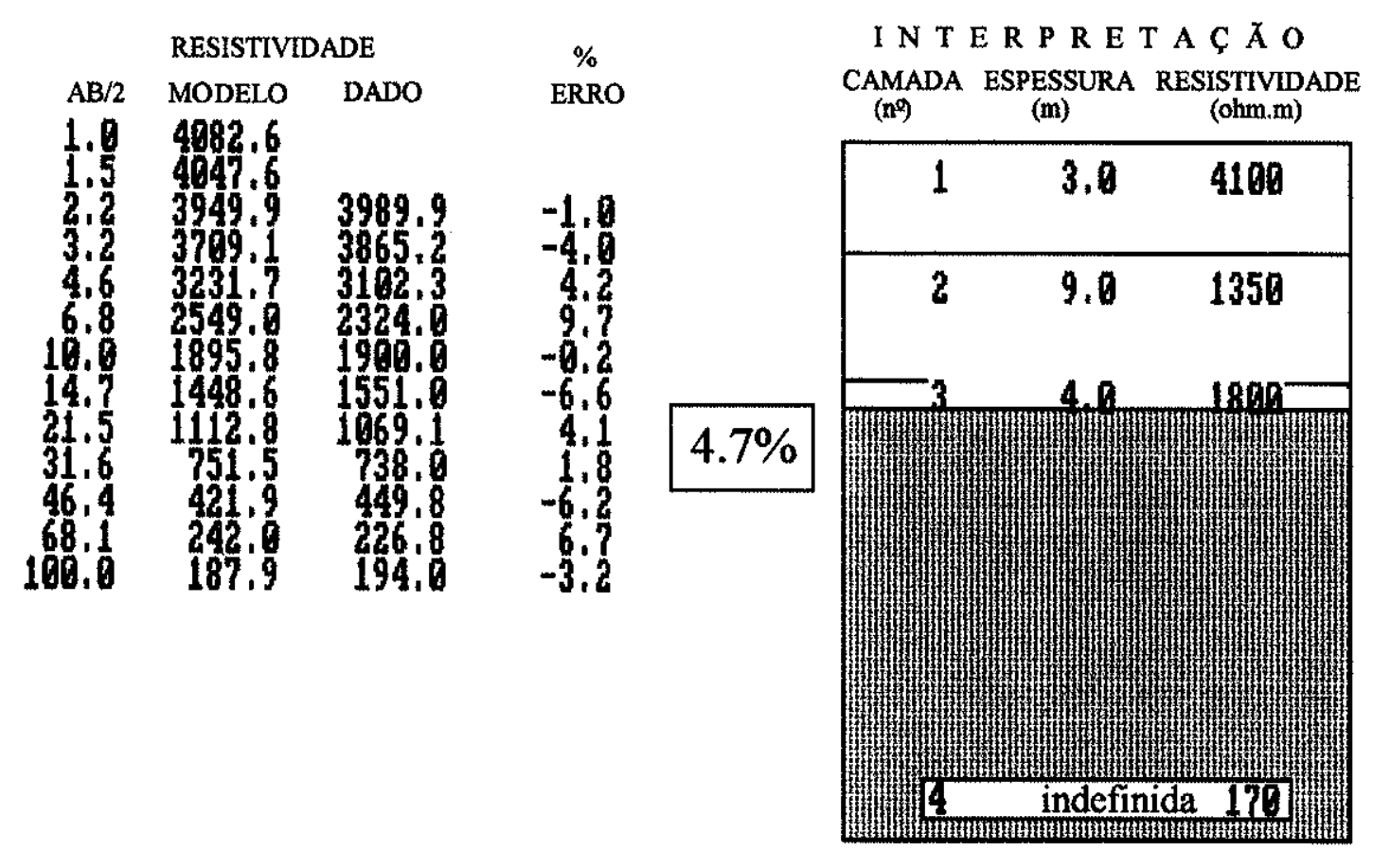




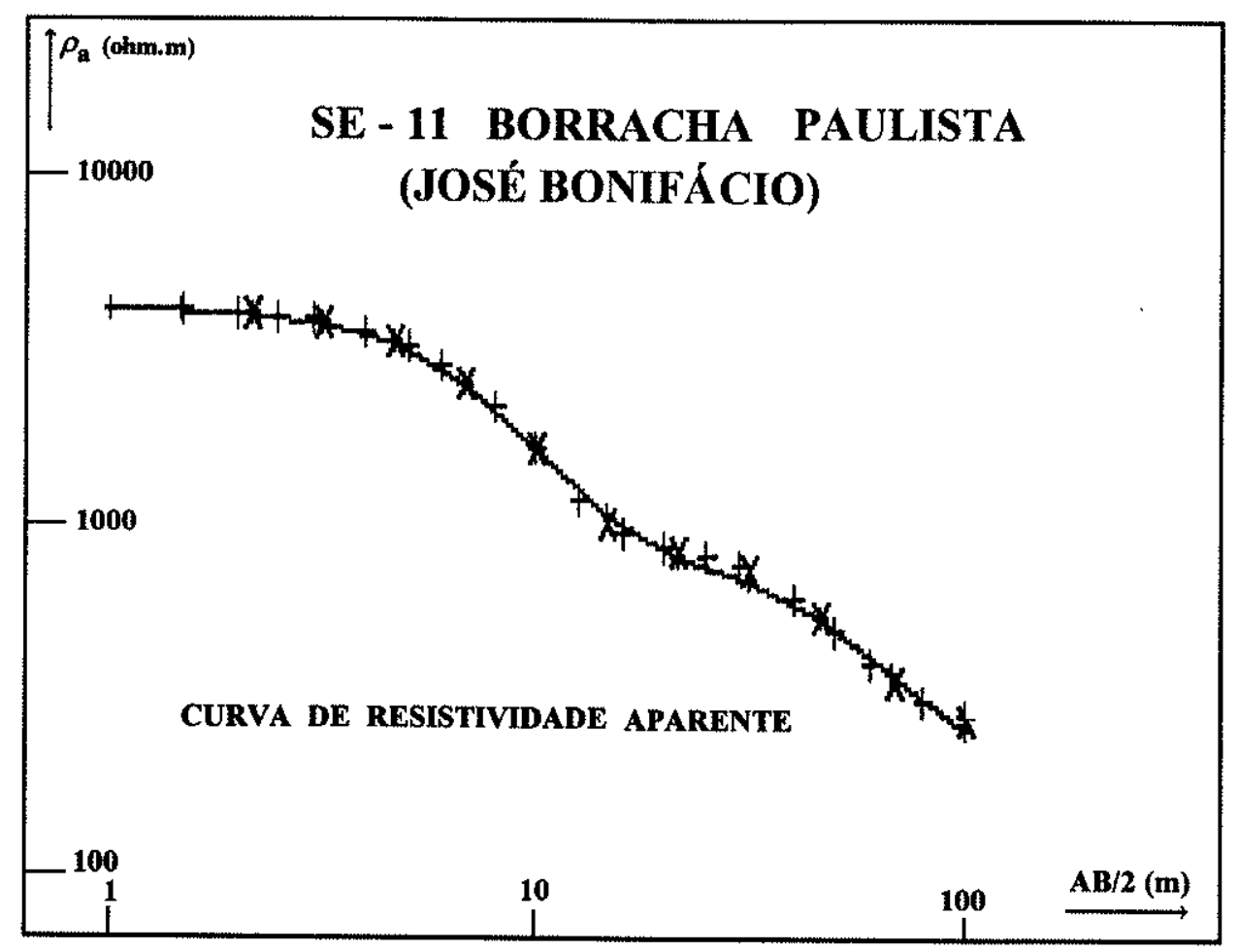

\section{MODELO SCHLUMBERGER DE SONDAGEM SE-11}

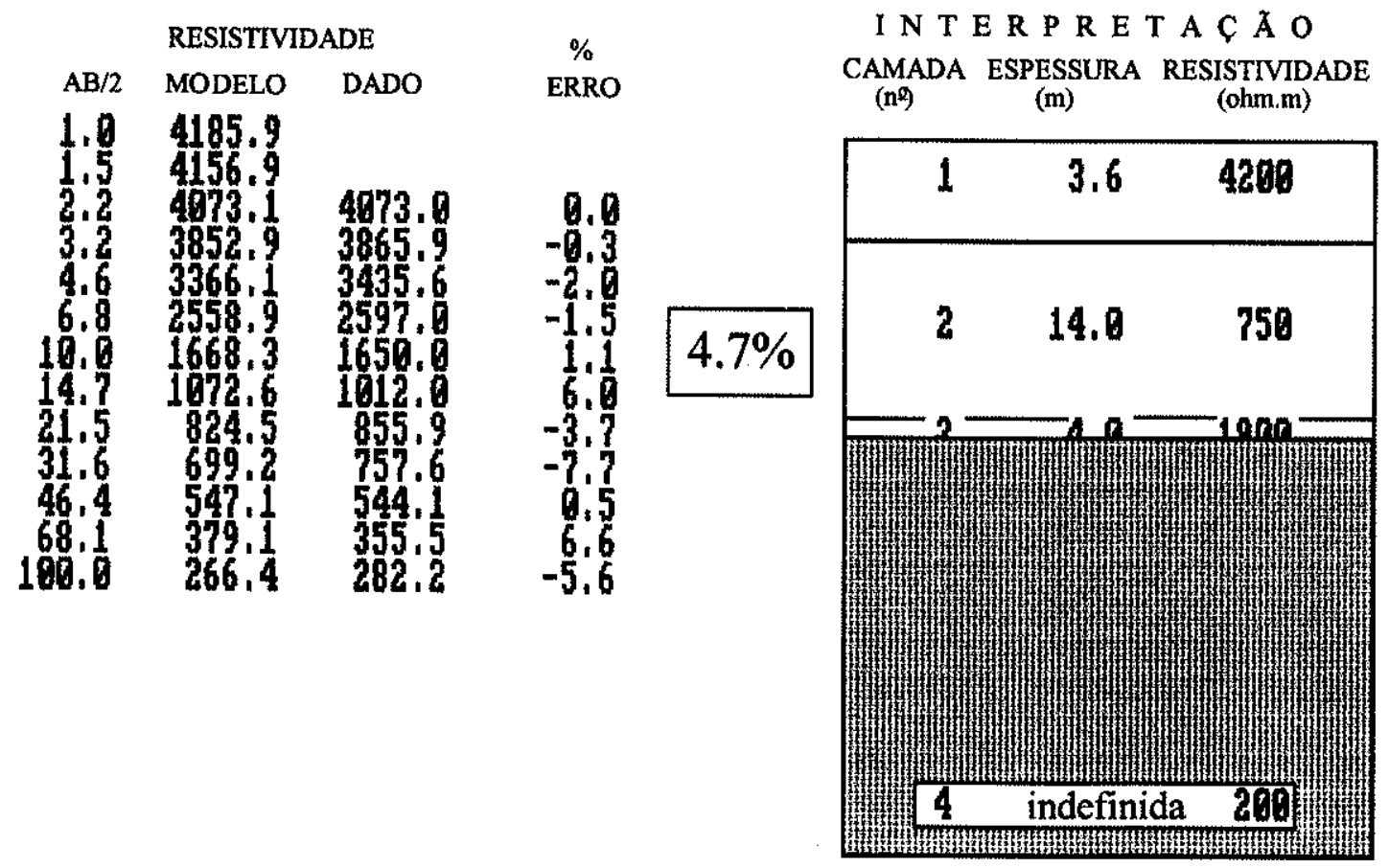




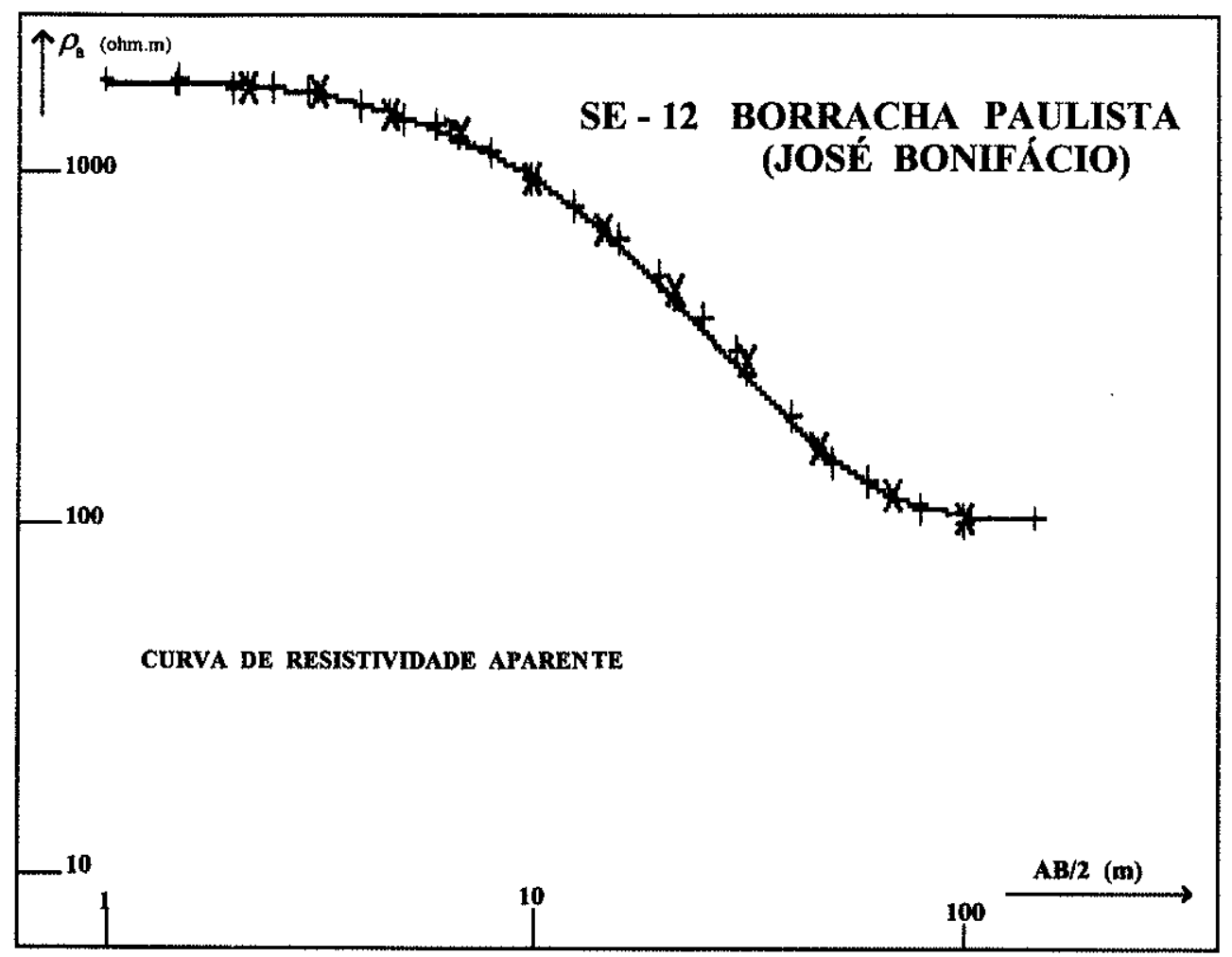

MODELO SCHLUMBERGER DE SONDAGEM SE - 12

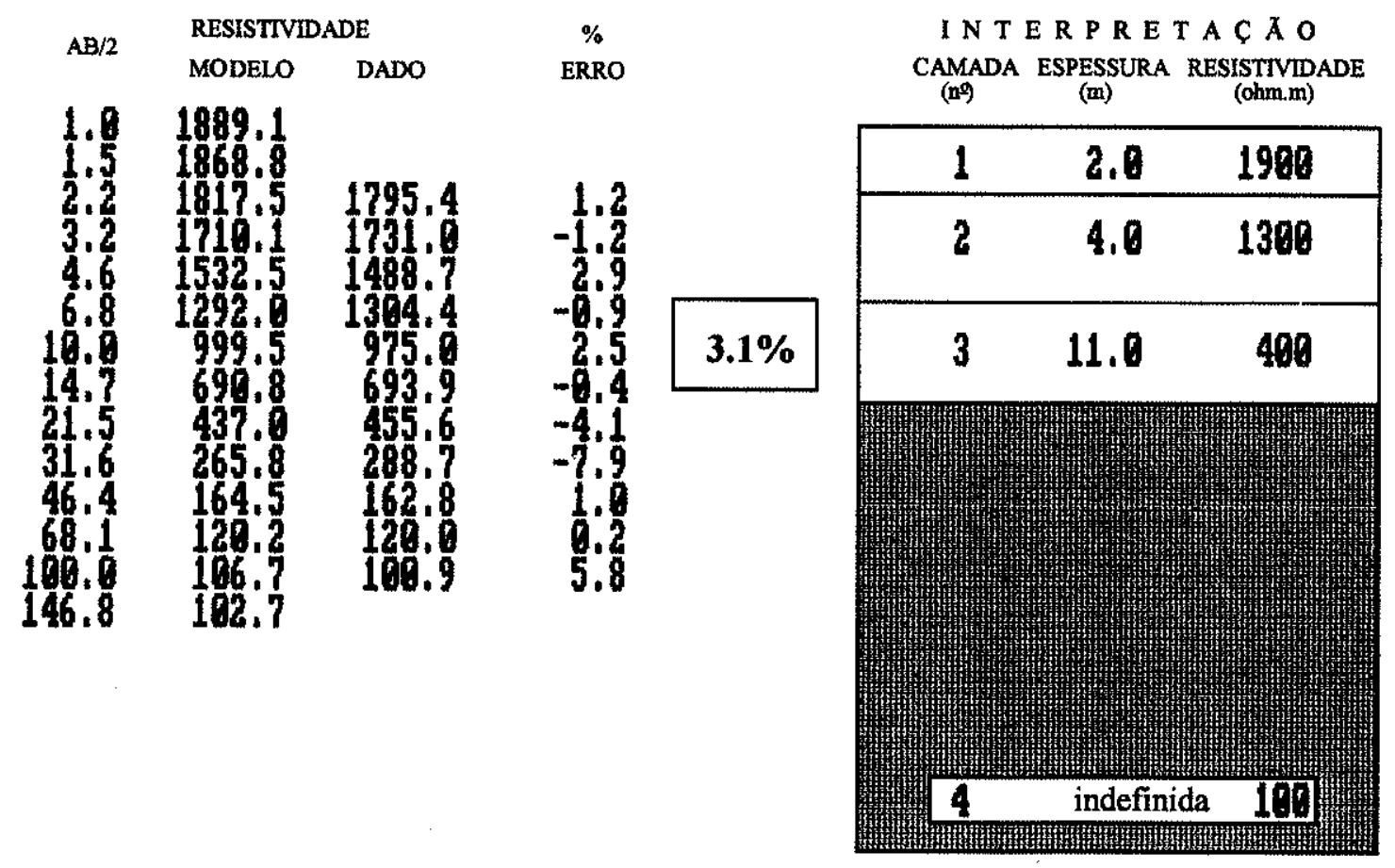




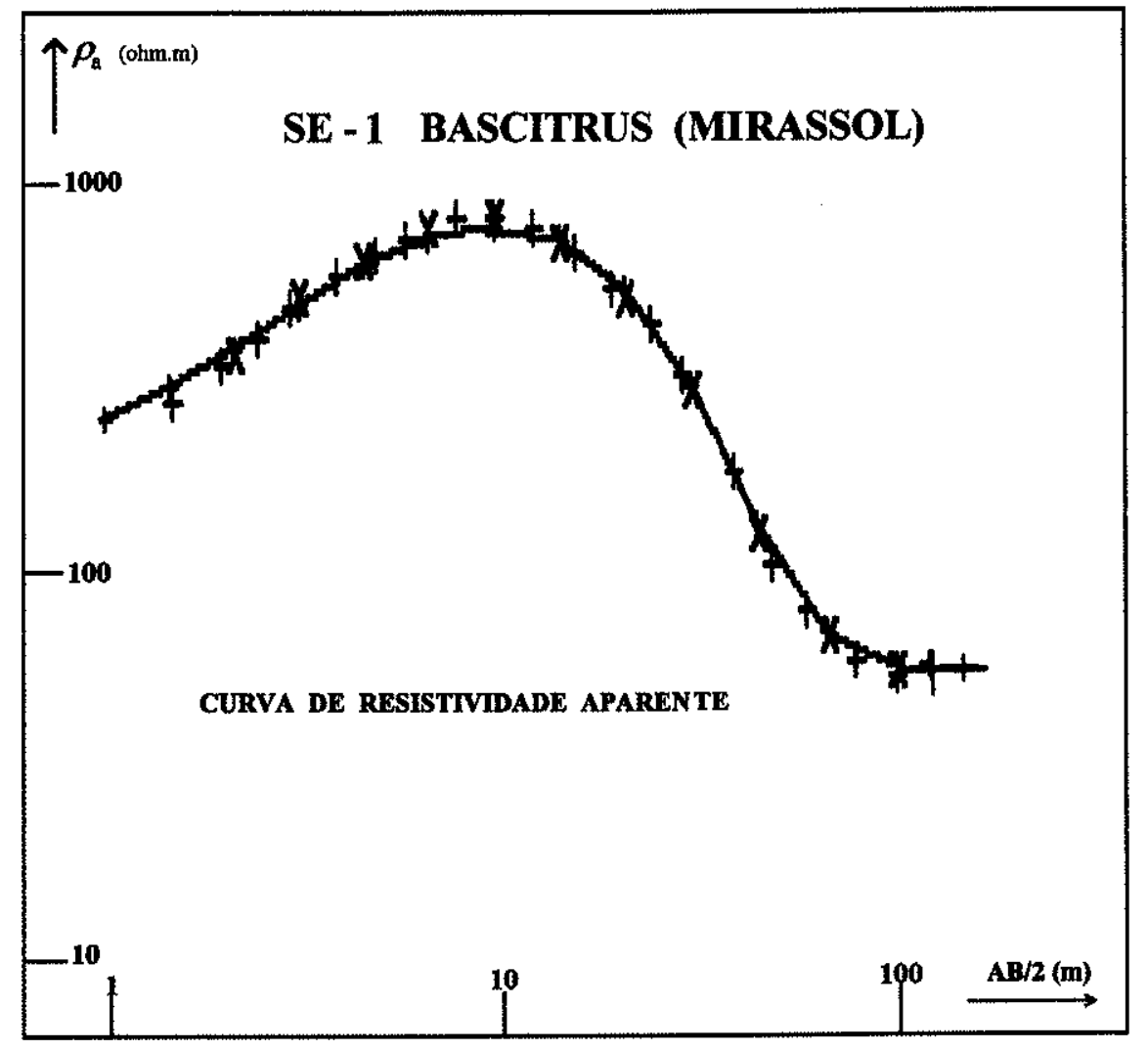

\section{MODELO SCHLUMBERGER DE SONDAGEM SE - 1}

IN T E R P RE T A Ç Ã O

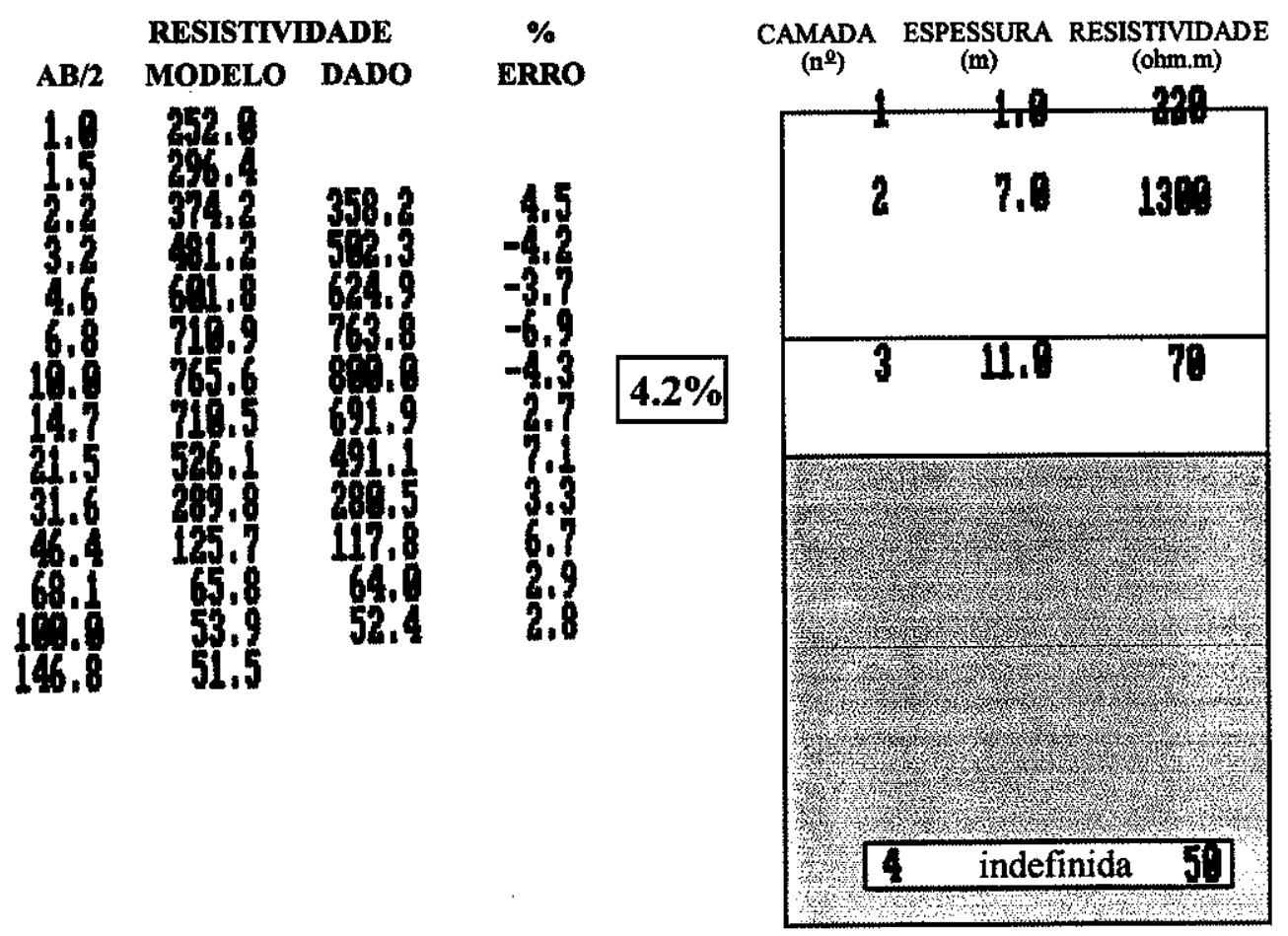




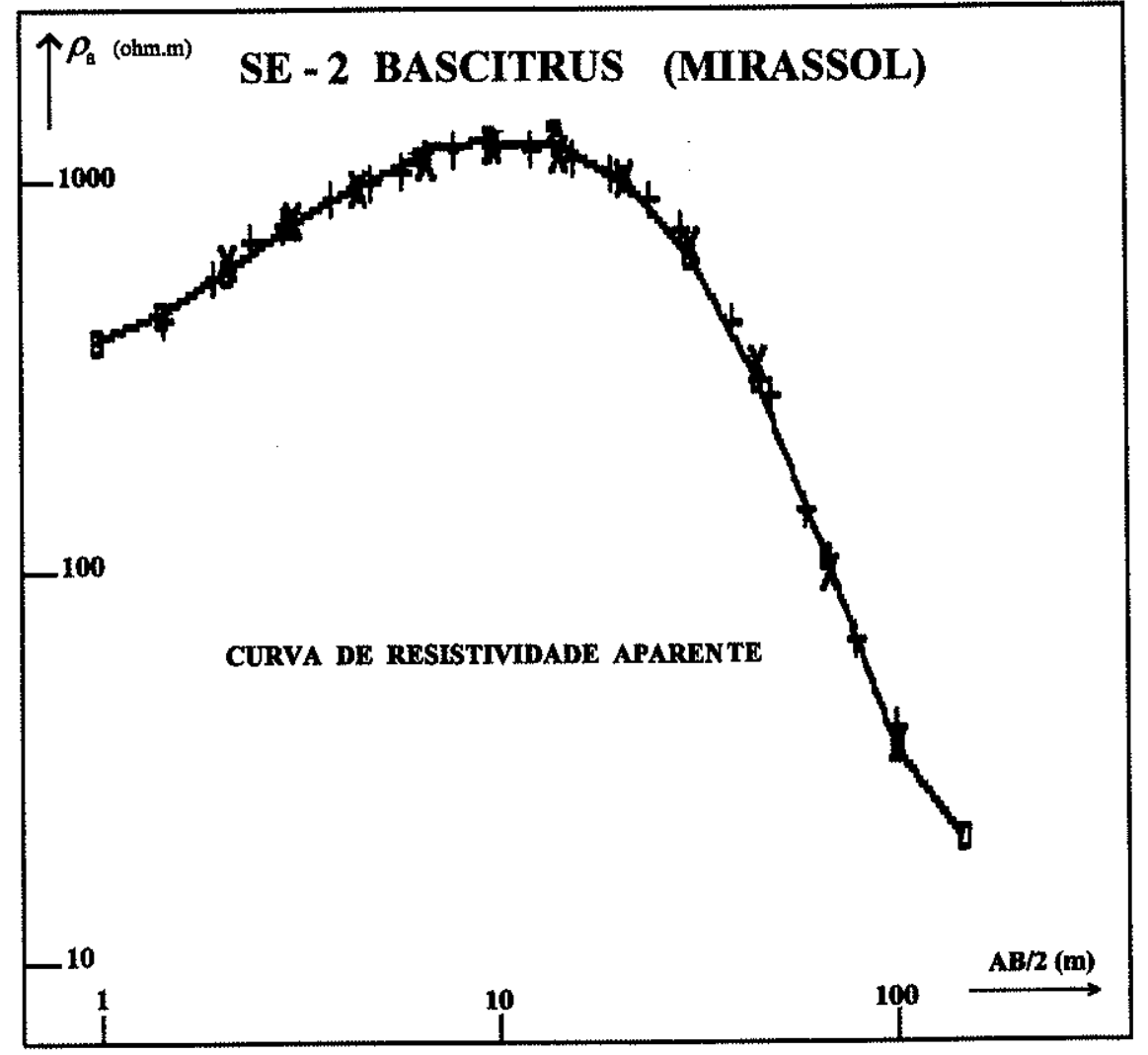

MODELO SCHLUMBERGER DE SONDAGEM SE - 2

IN T ER PRE T A C Ã O

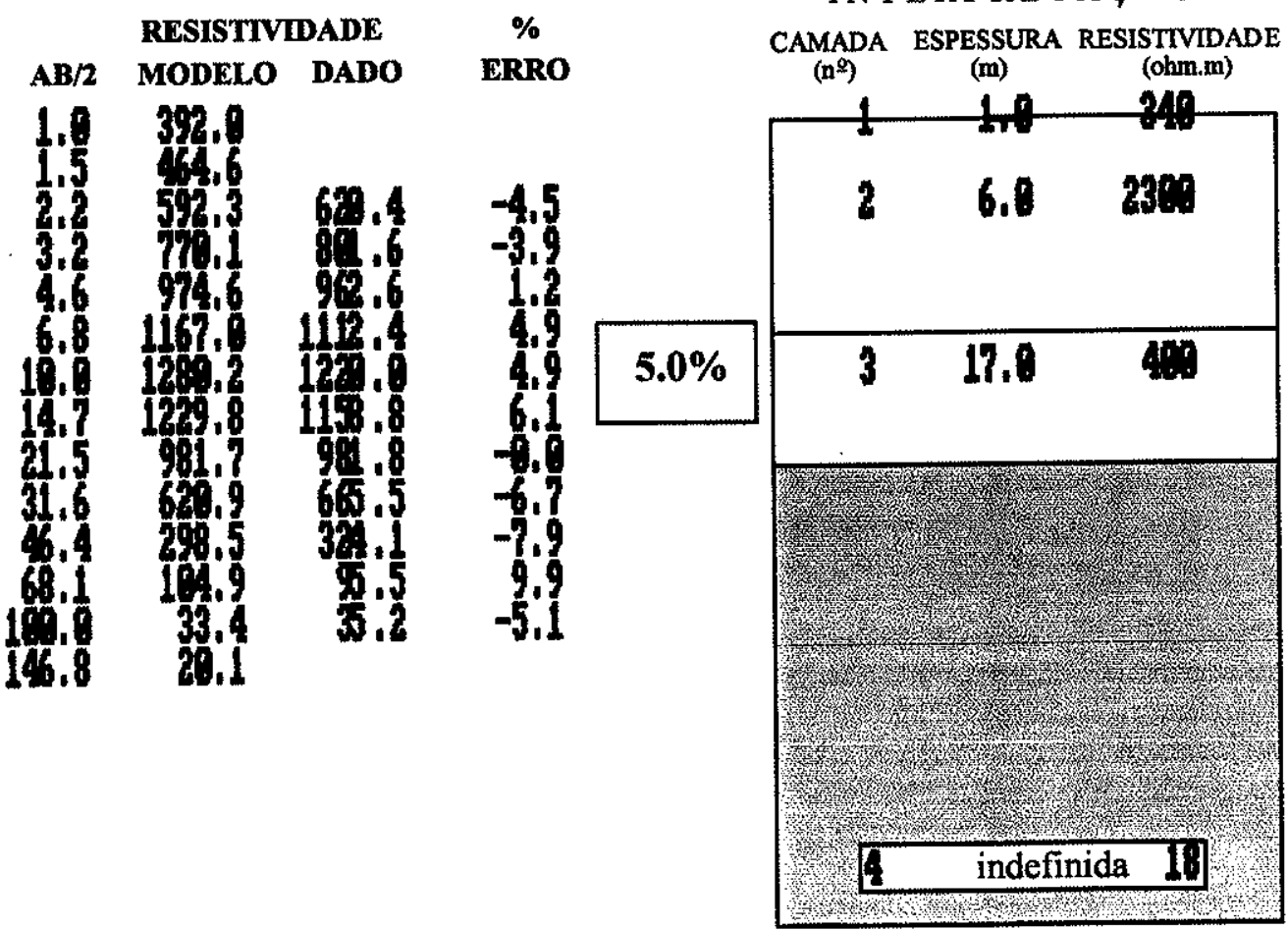




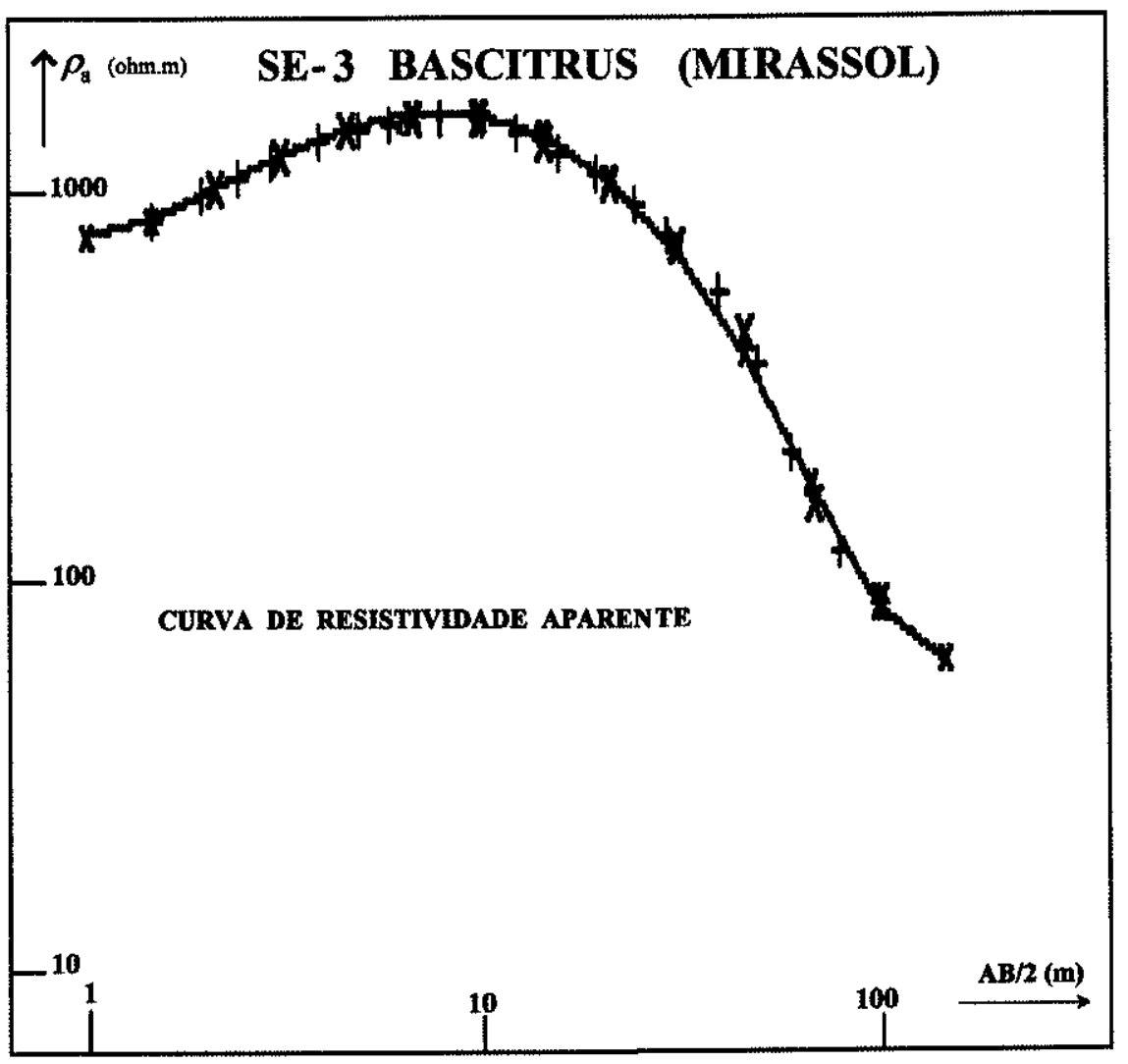

\section{MODELO SCHLUMBERGER DE SONDAGEM SE - 3}

IN T ER P RET A Ç Ã O

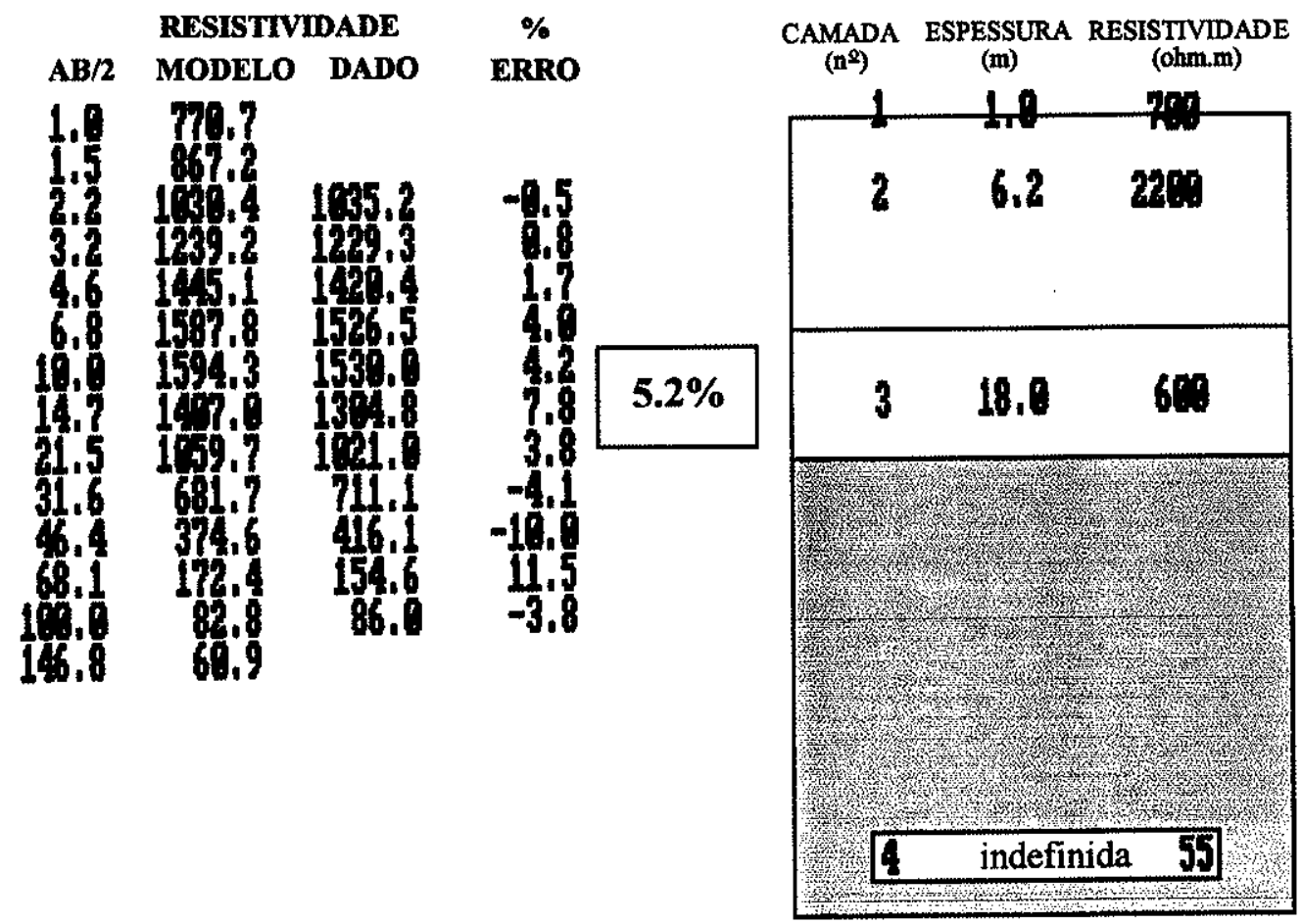




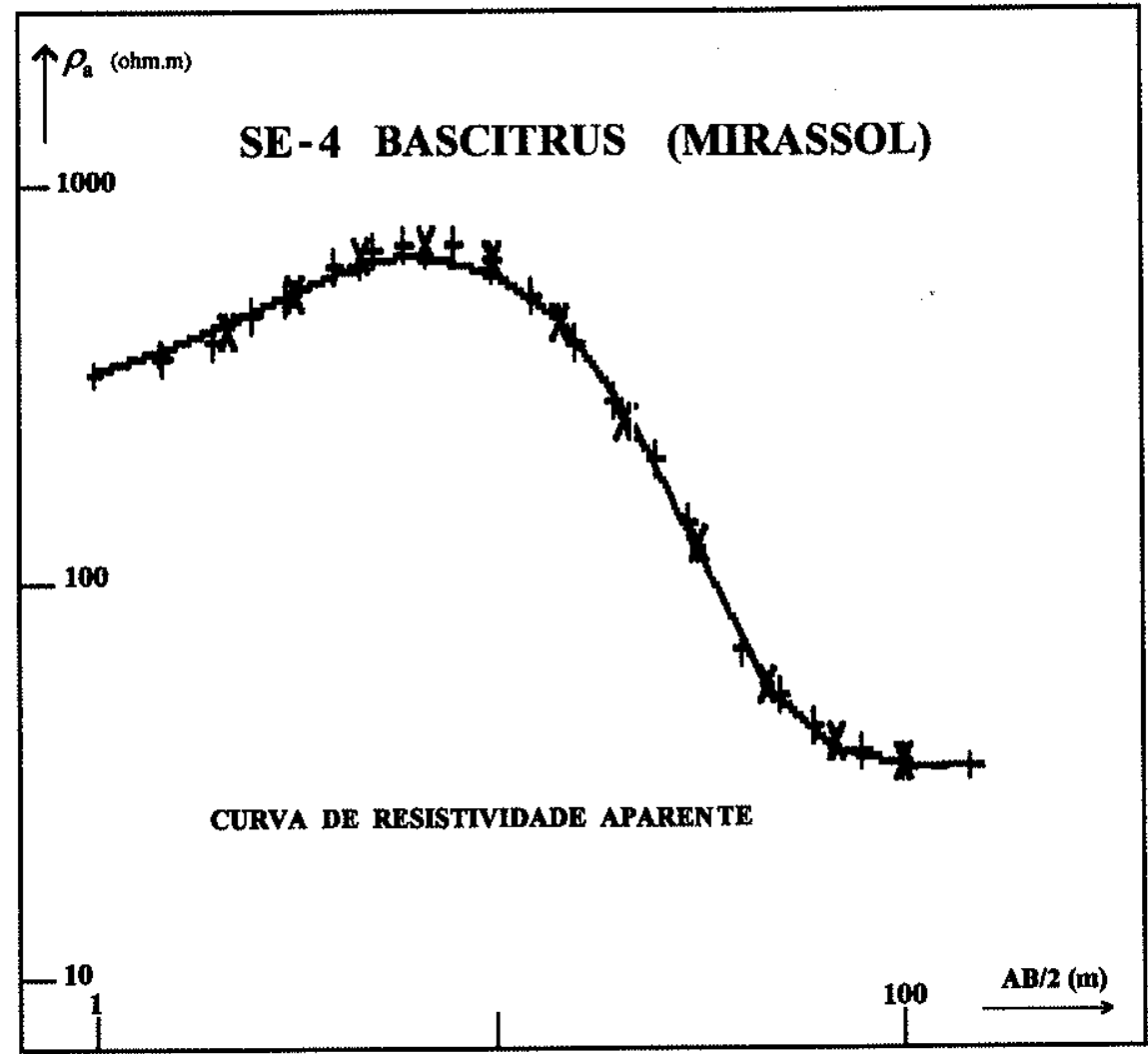

\section{MODELO SCHLUMBERGER DE SONDAGEM SE - 4}

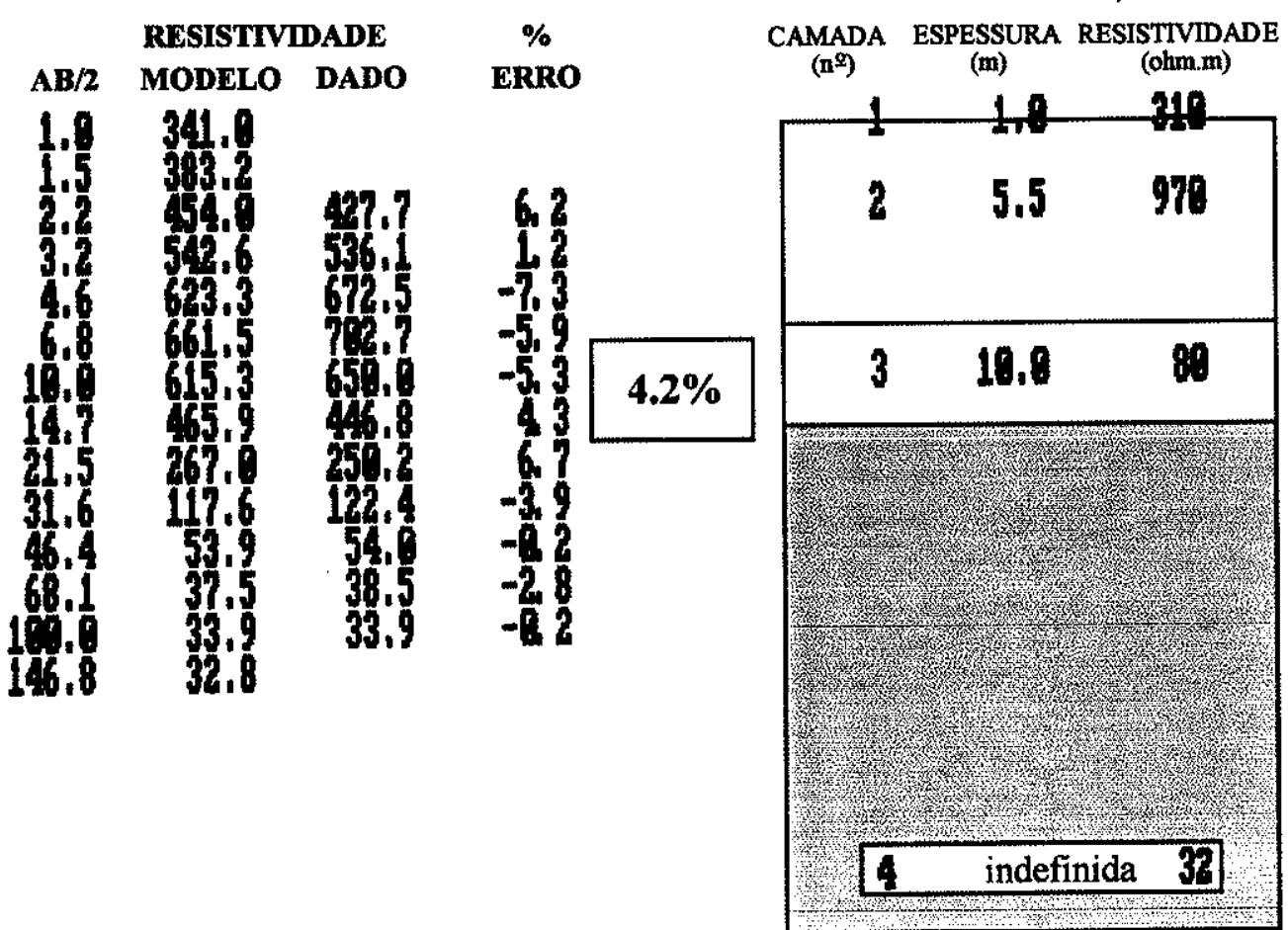




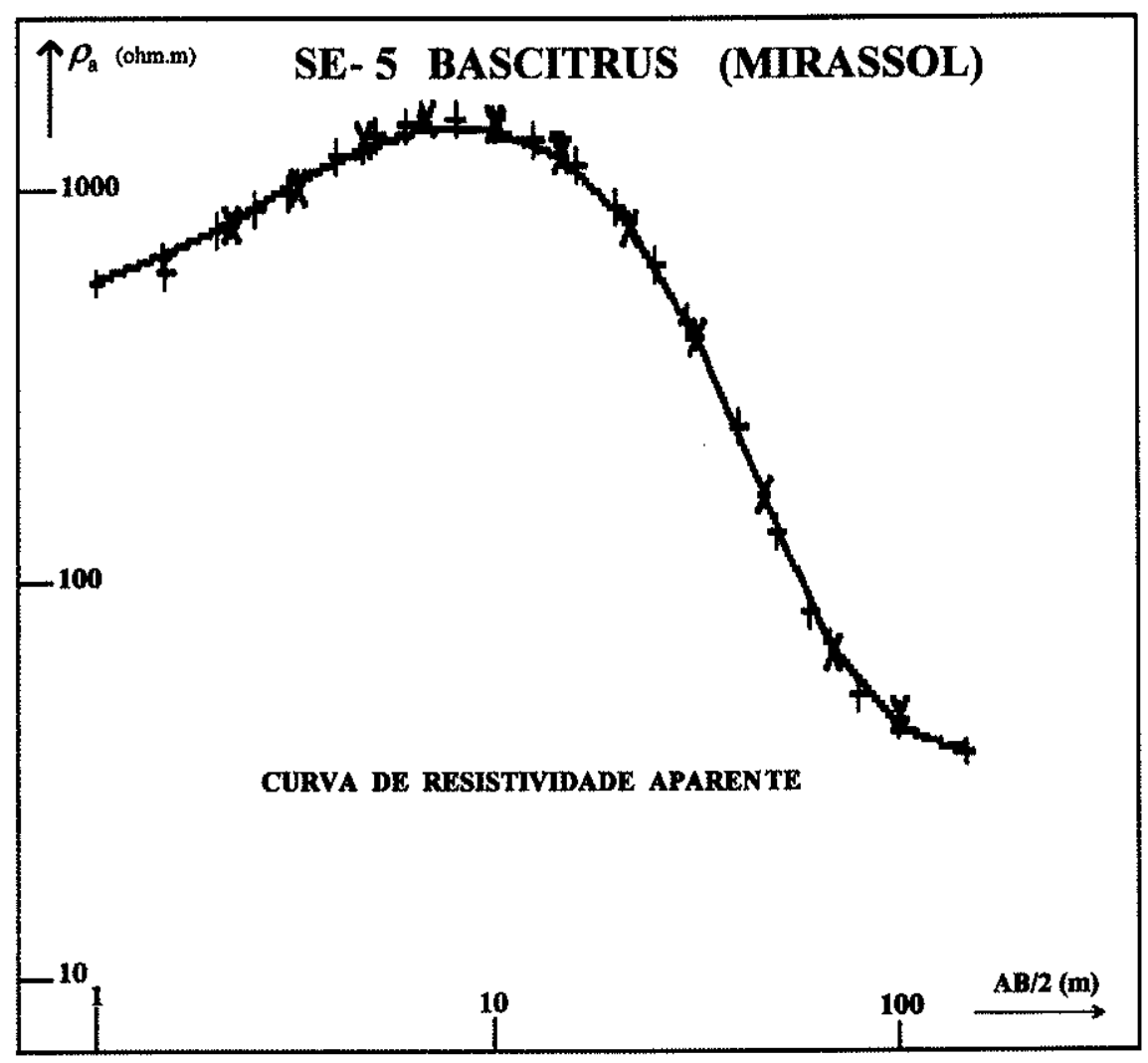

MODELO SCHLUMBERGER DE SONDAGEM SE - 5

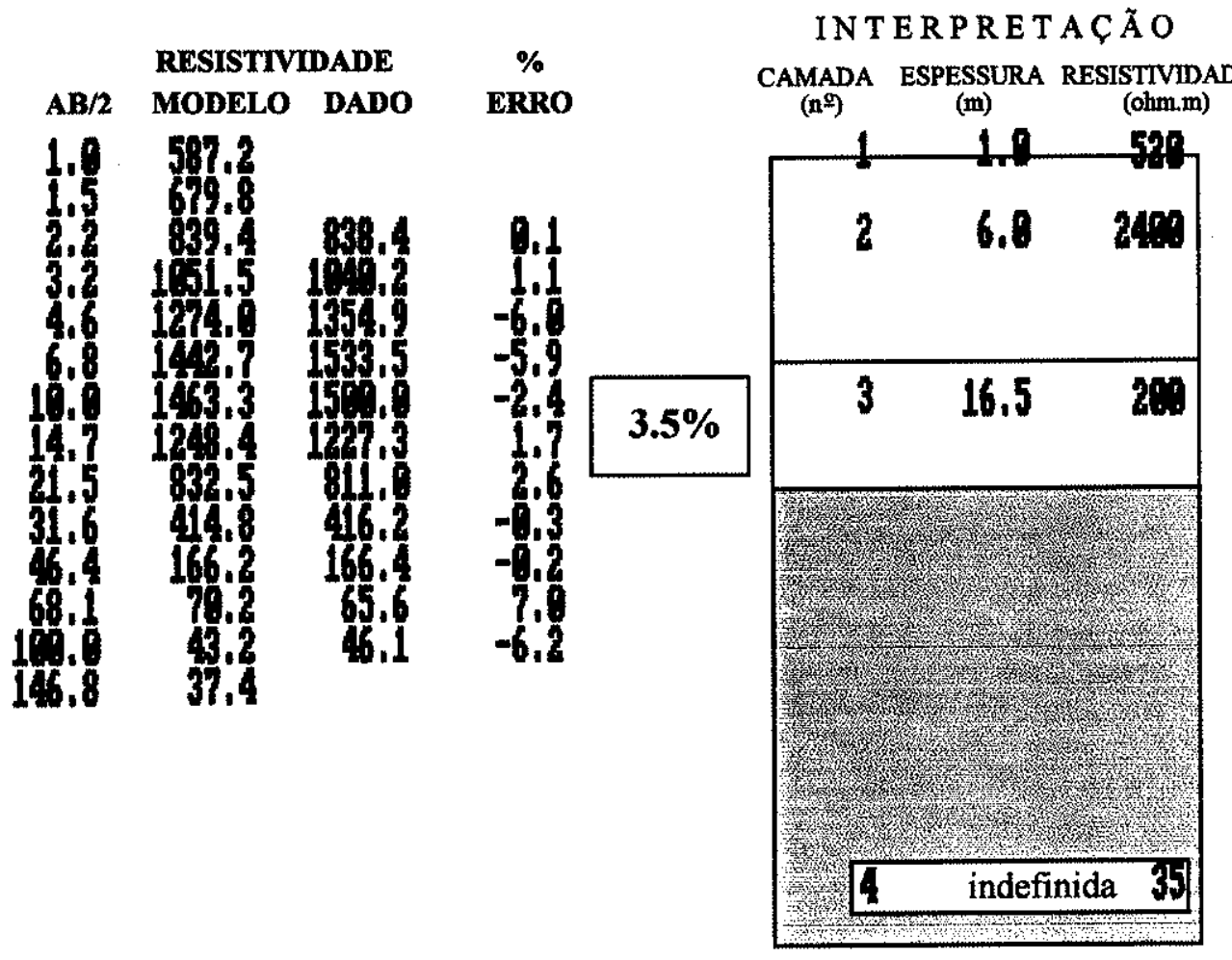




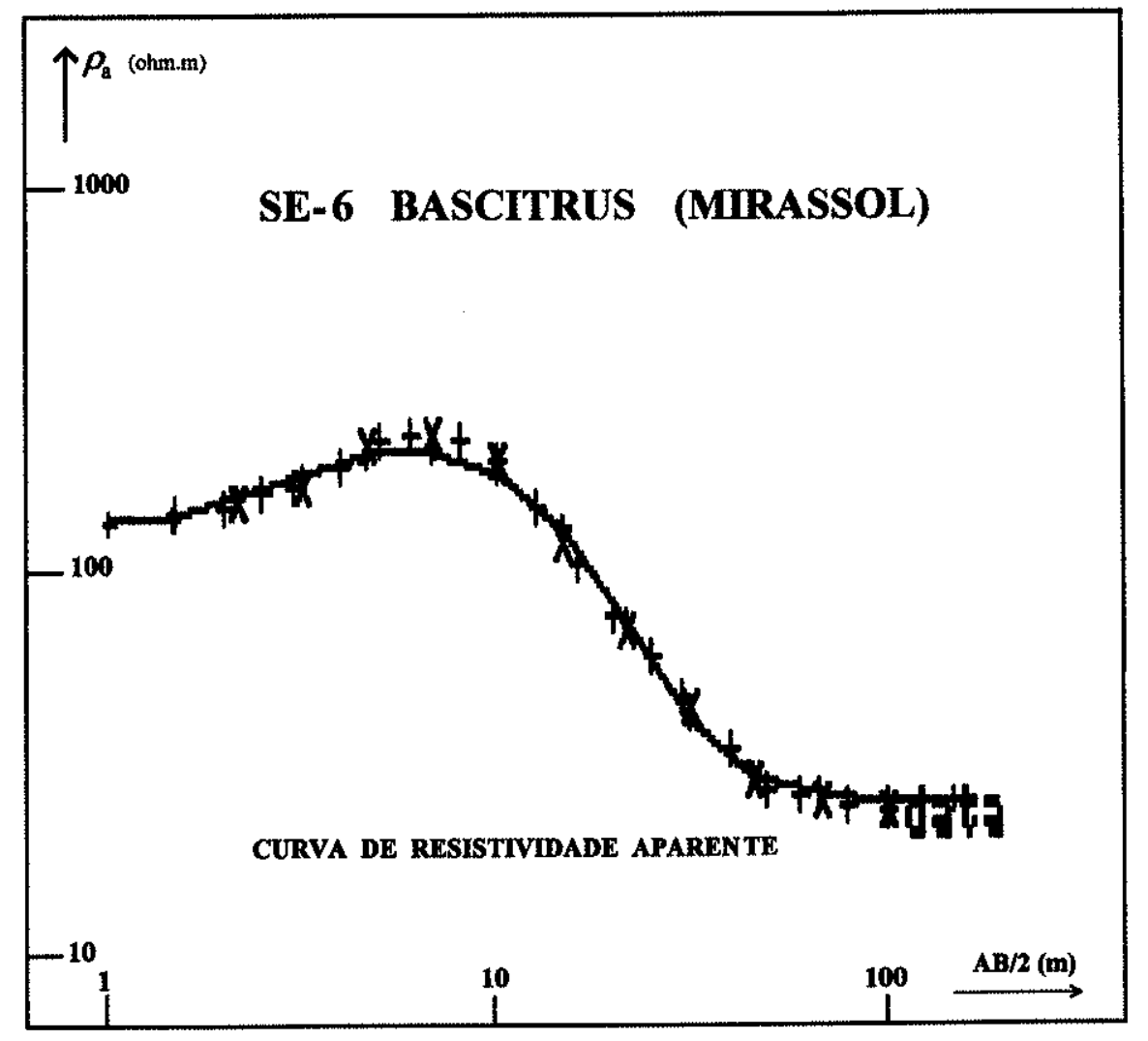

MODELO SCHLUMBERGER DE SONDAGEM SE - 6

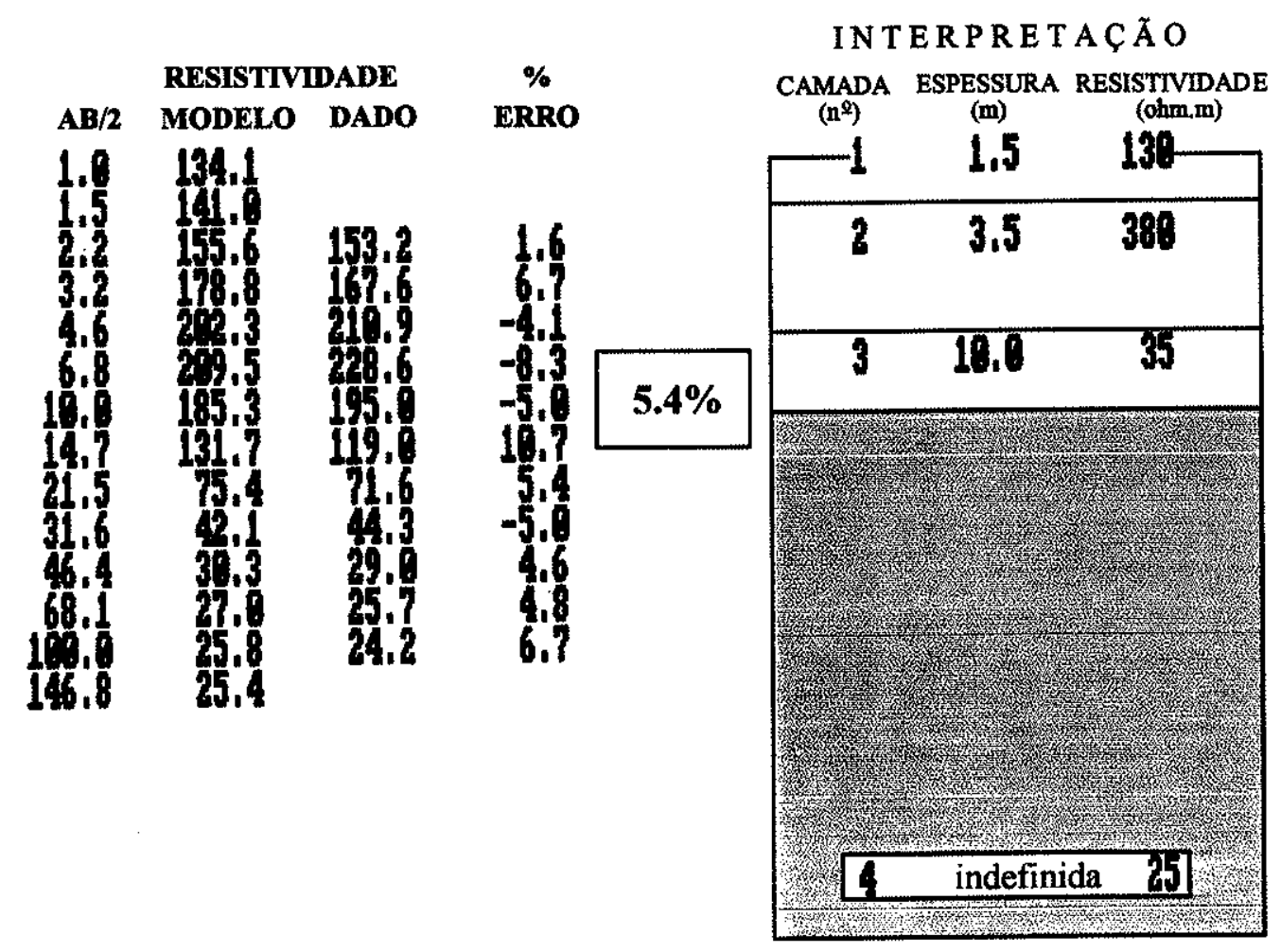




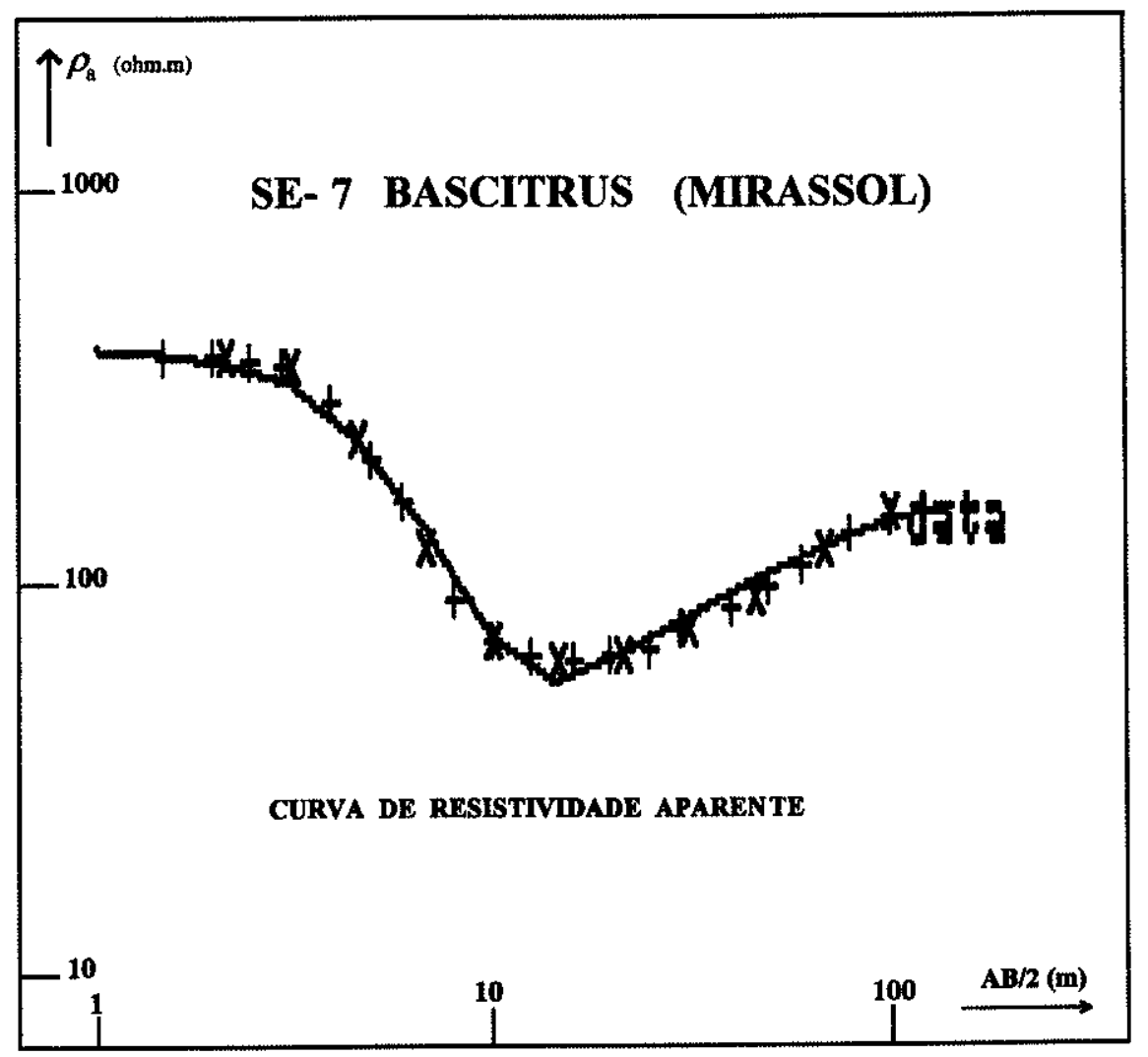

MODELO SCHLUMBERGER DE SONDAGEM SE - 7

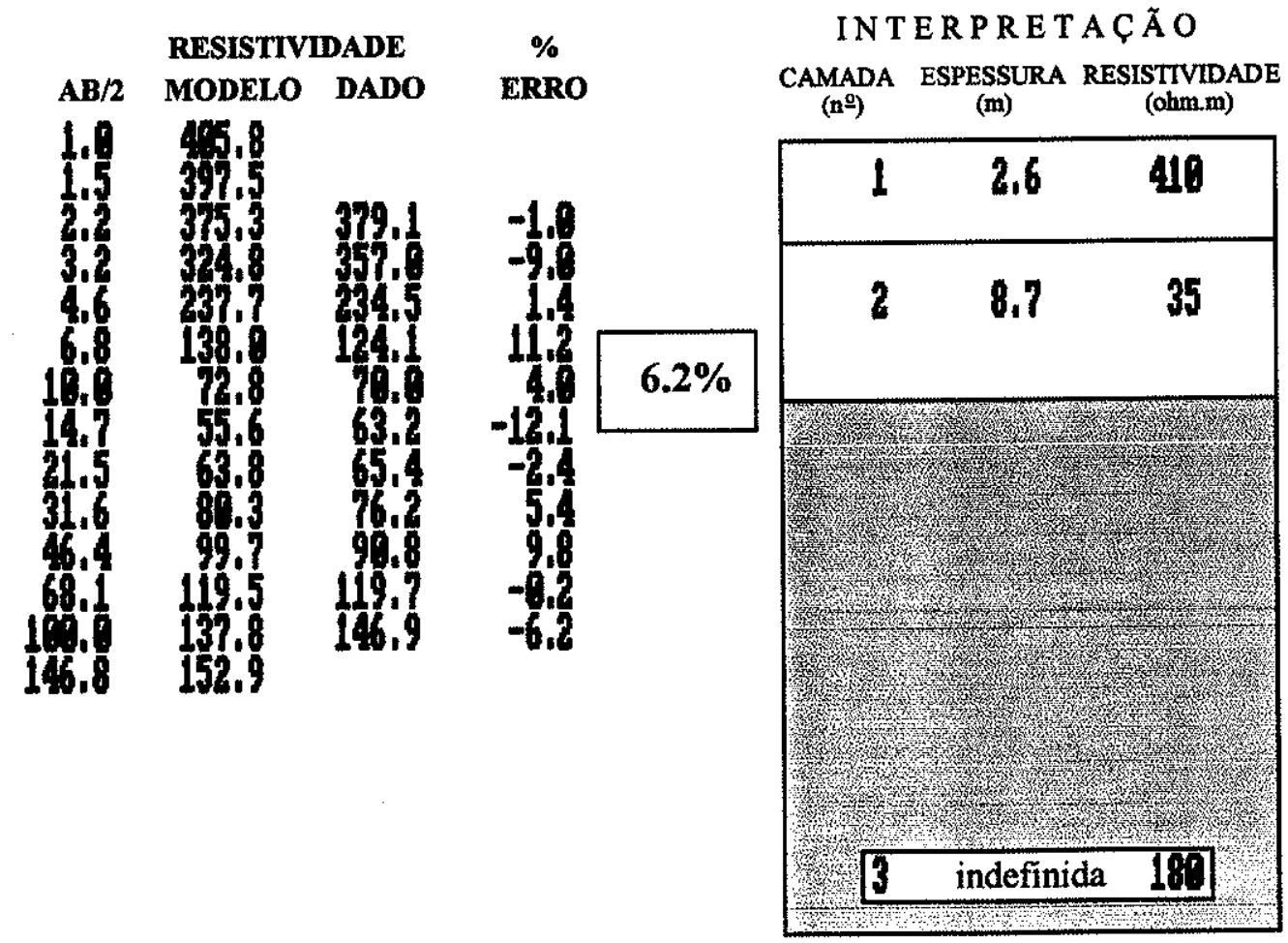




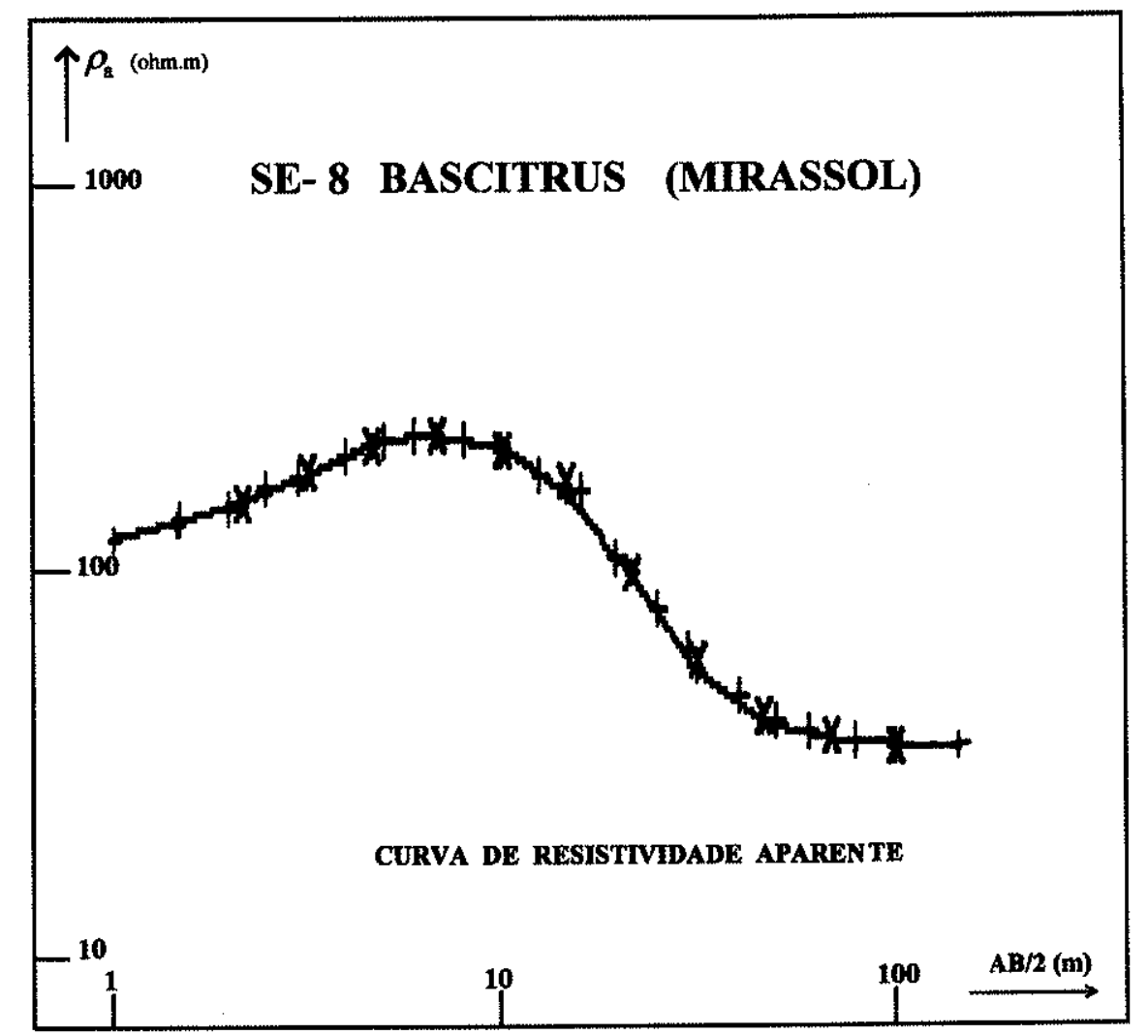

\section{MODELO SCHLUMBERGER DE SONDAGEM SE - 8}

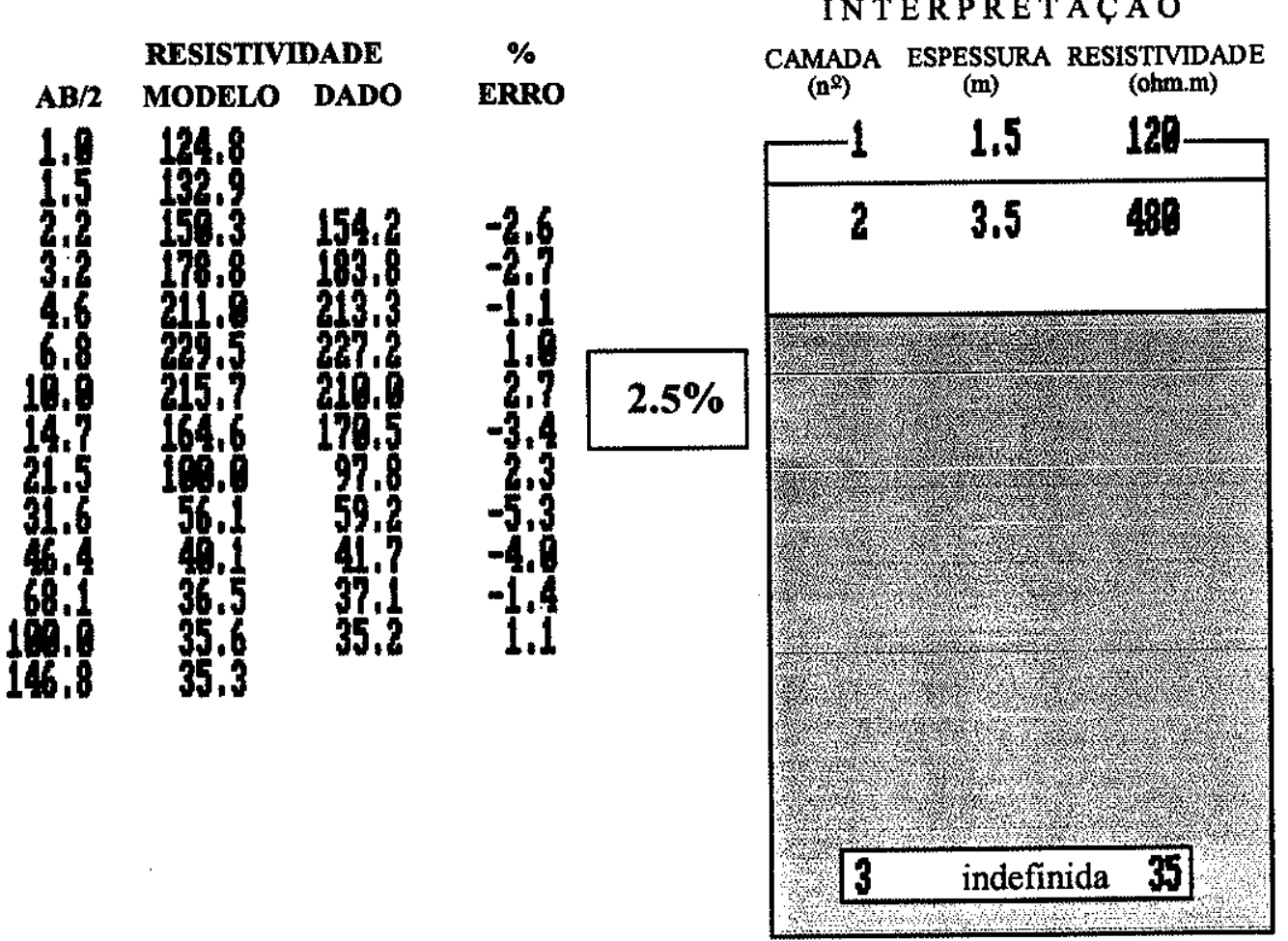




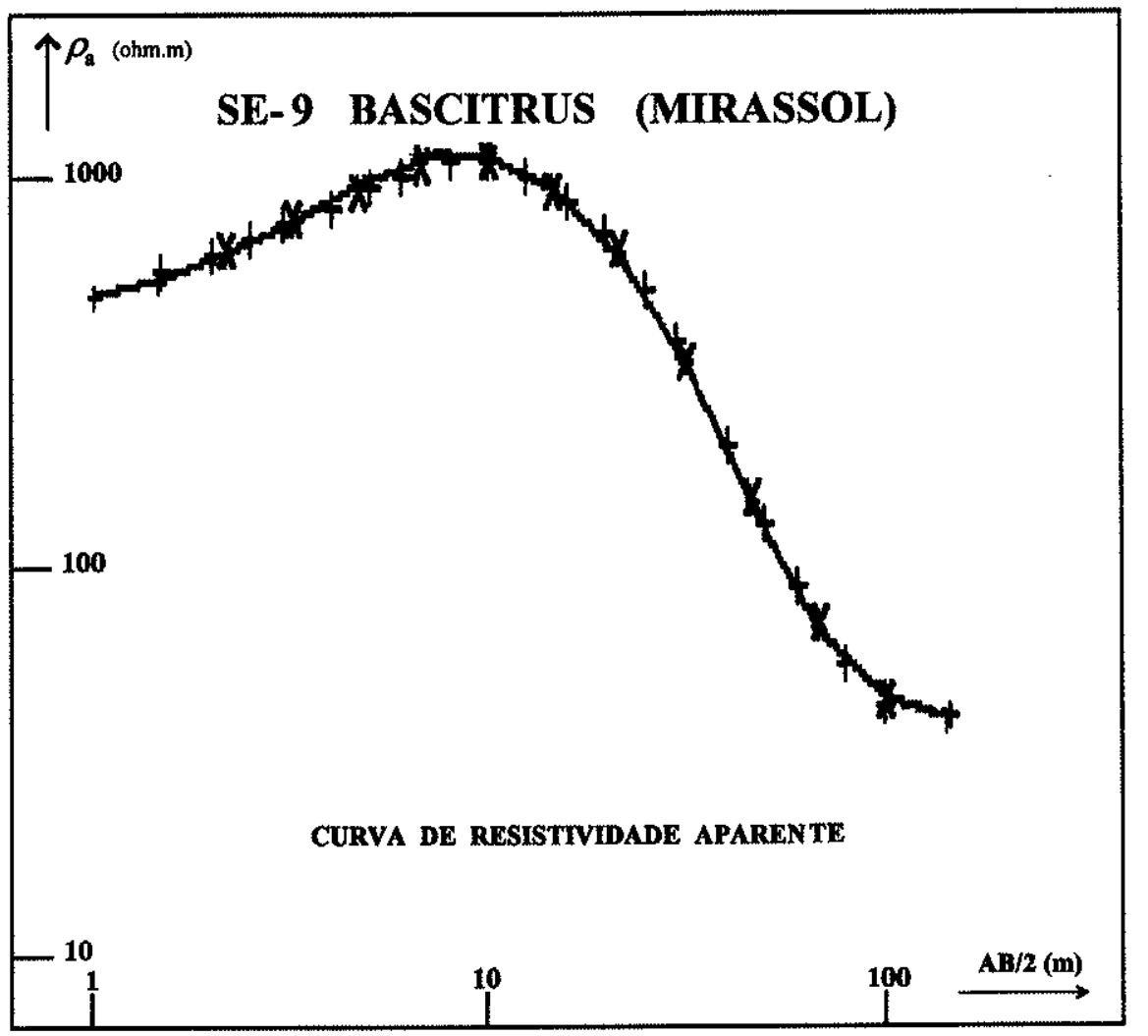

\section{MODELO SCHLUMBERGER DE SONDAGEM SE - 9}

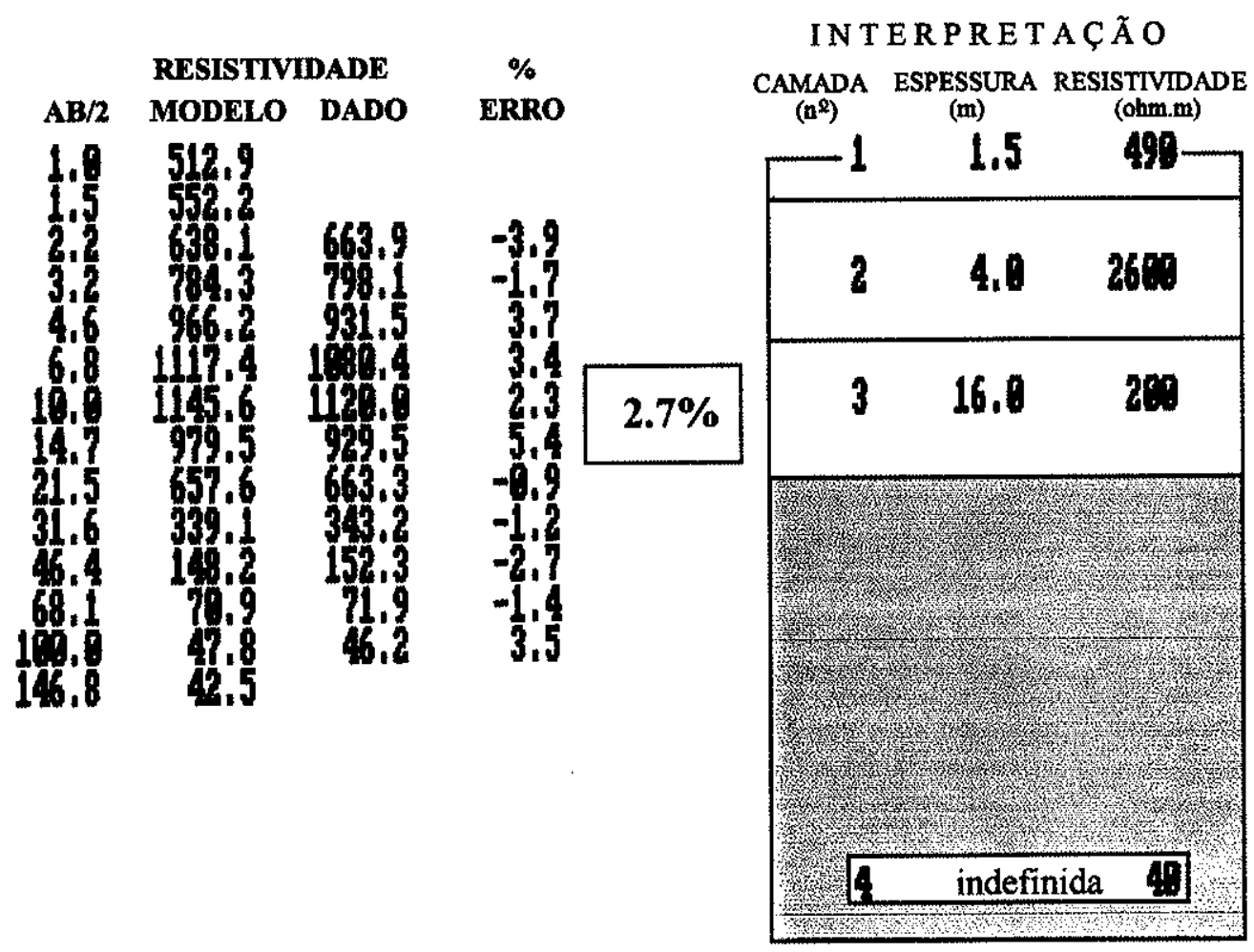




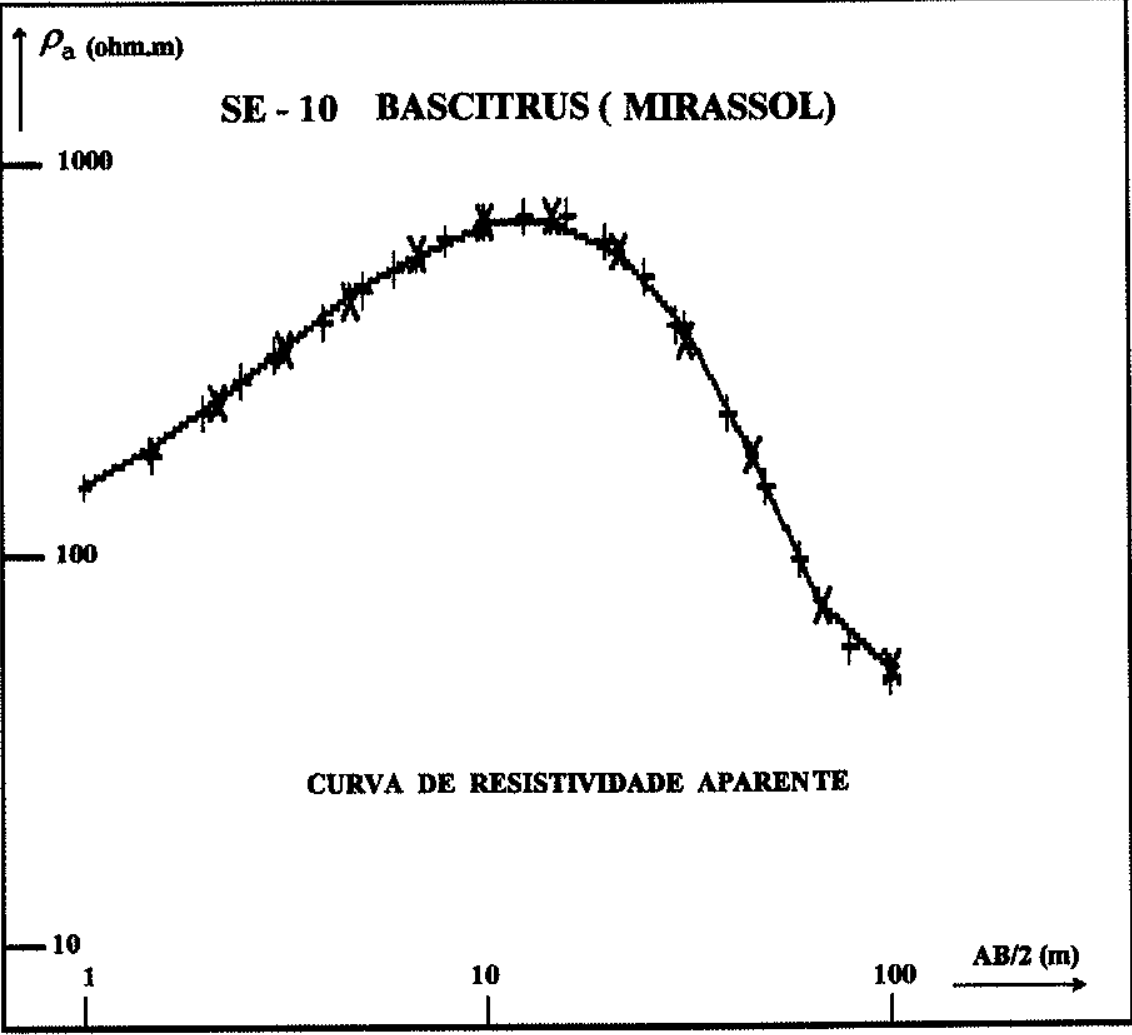

MODELO SCHLUMBERGER DE SONDAGEM SE-10

RESISTIVIDADE

AB/2 MODELO DADO

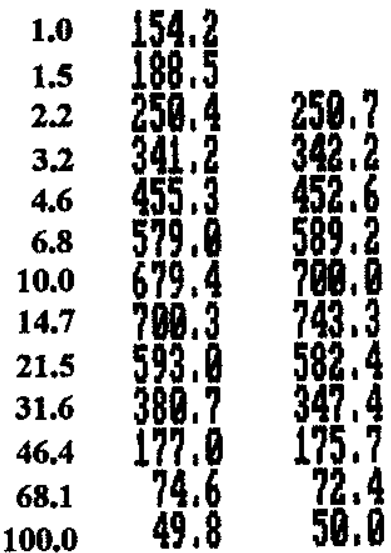

IN T E R P R E T A C Ã O

CAMADA ESPESSURA RESISTIVIDADE (n)

(m)

ERRO

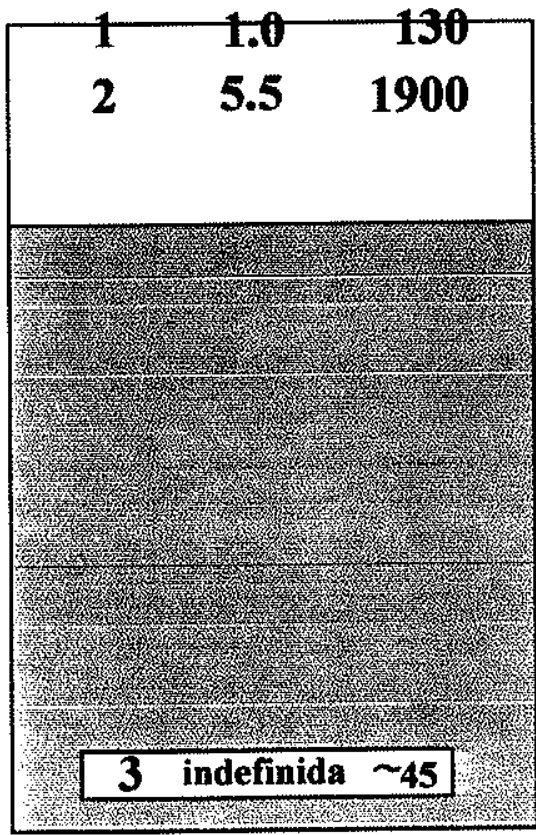




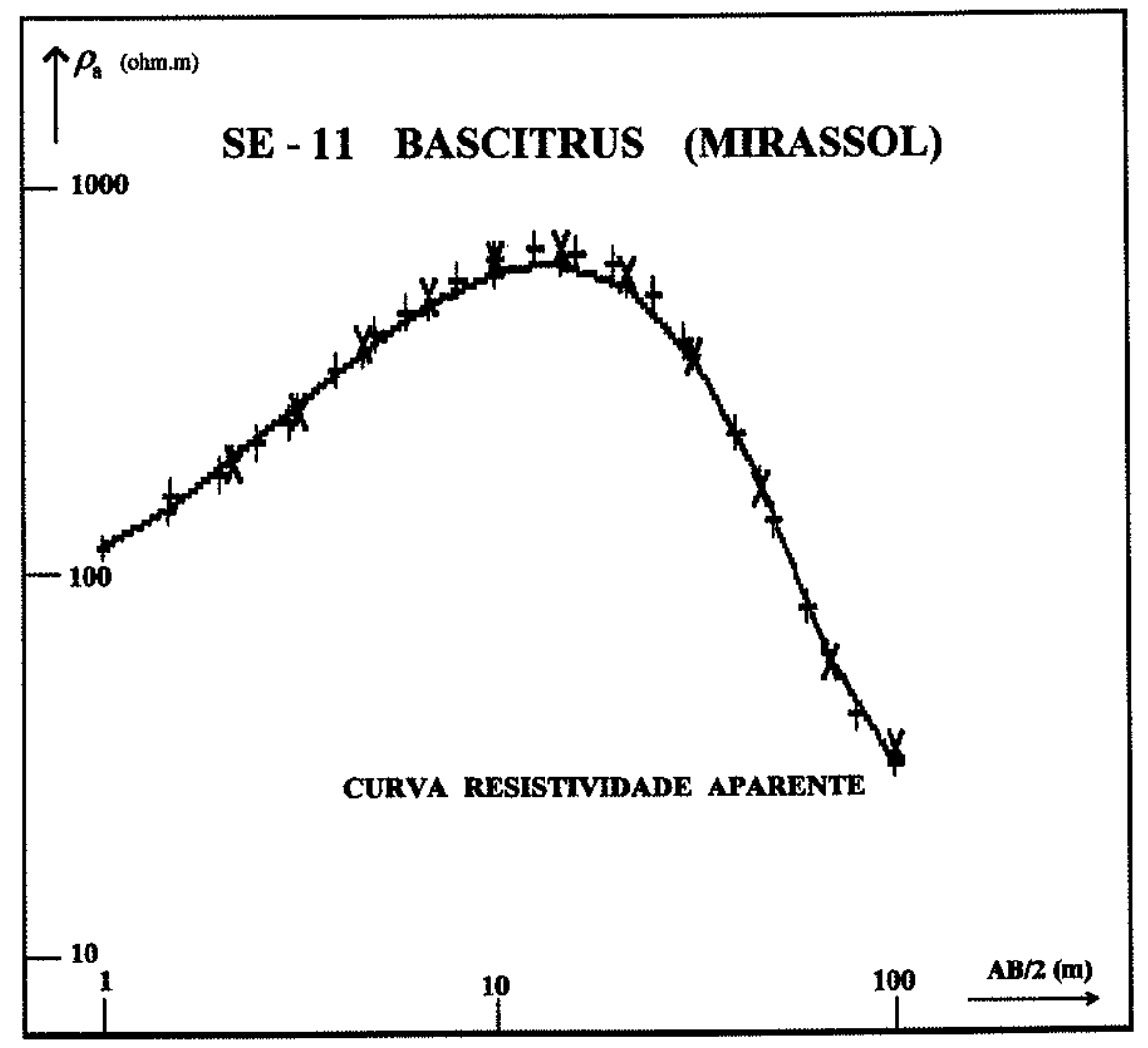

\section{MODELO SCHLUMBERGER DE SONDAGEM SE - 11}

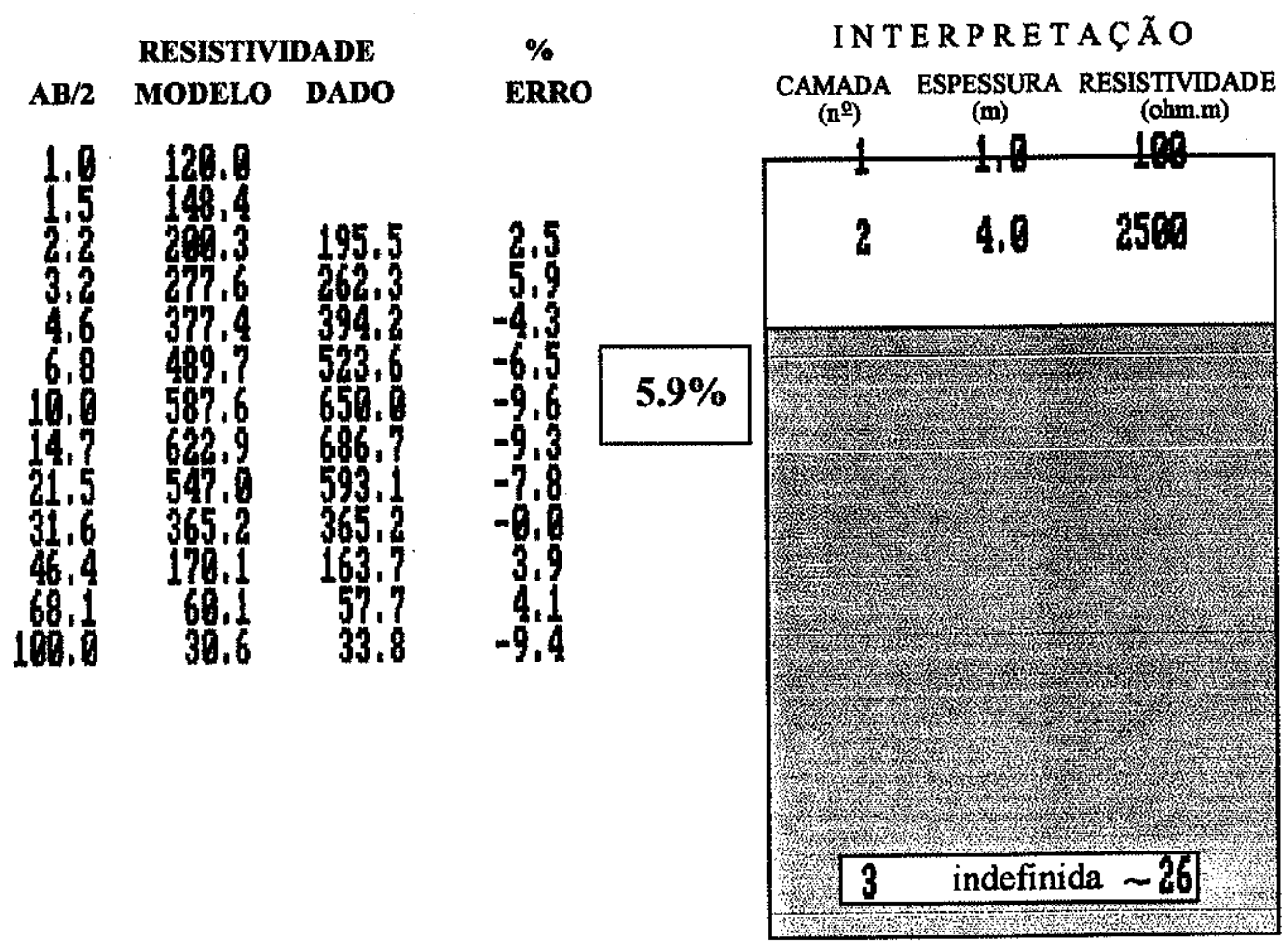




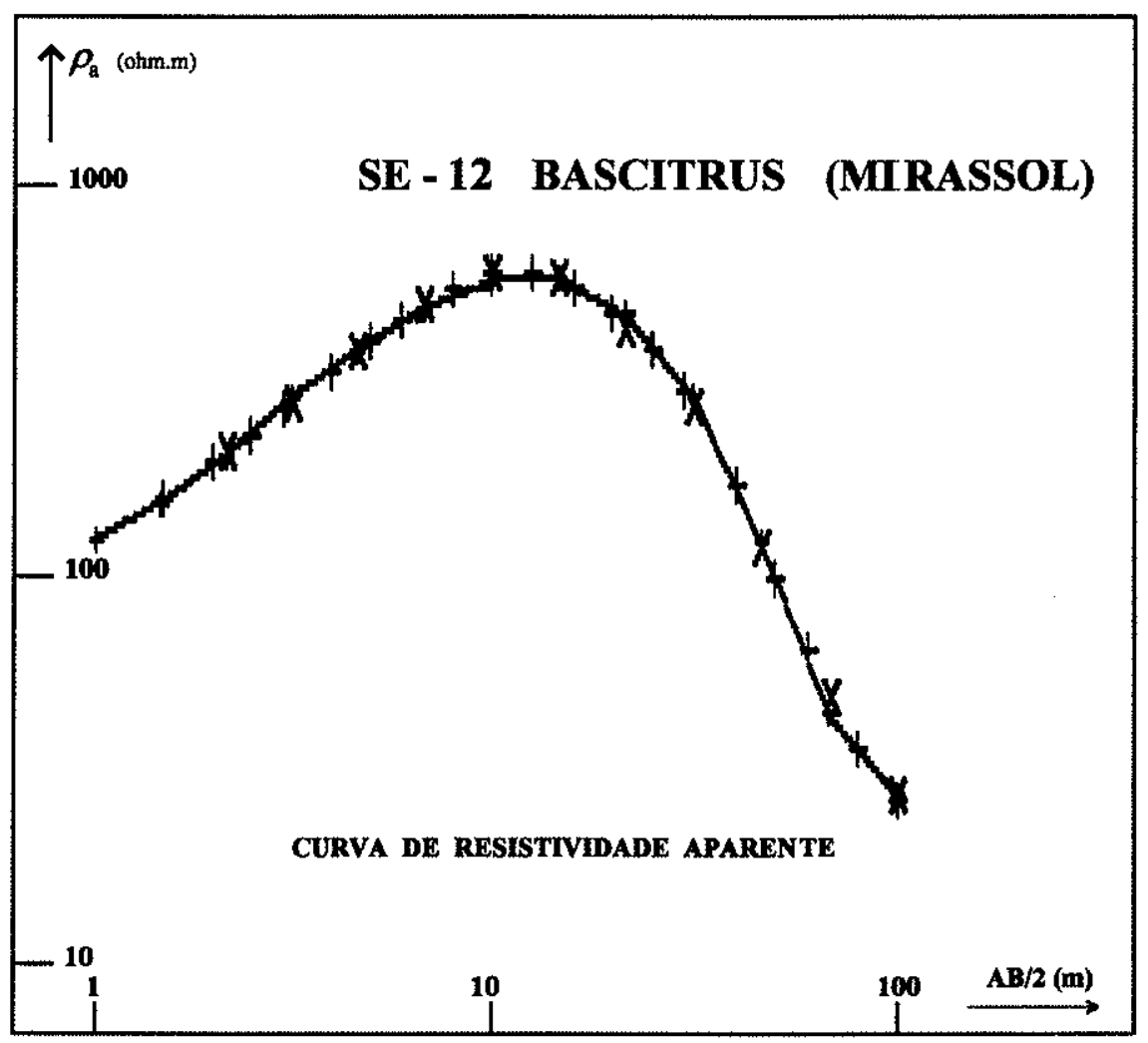

\section{MODELO SCHLUMBERGER DE SONDAGEM SE - 12}

\section{RESISTIVIDADE}

AB/2 MODELO DADO

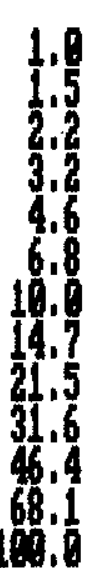

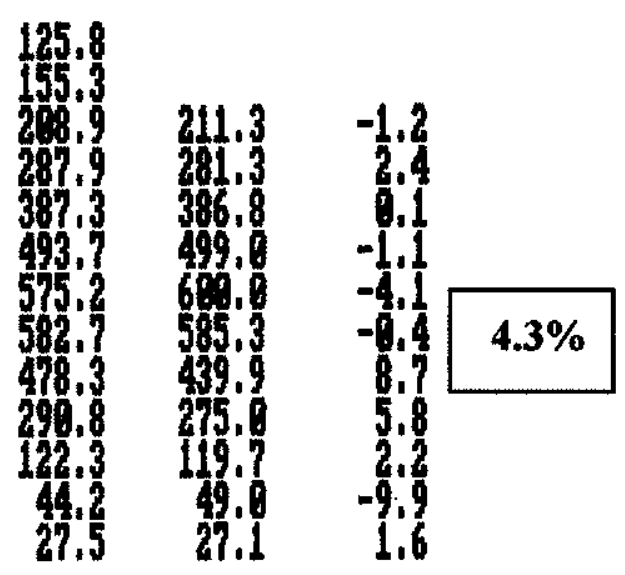

IN T E R P RE T A Ç Ã O

CAMADA ESPESSURA RESISTIVIDADE

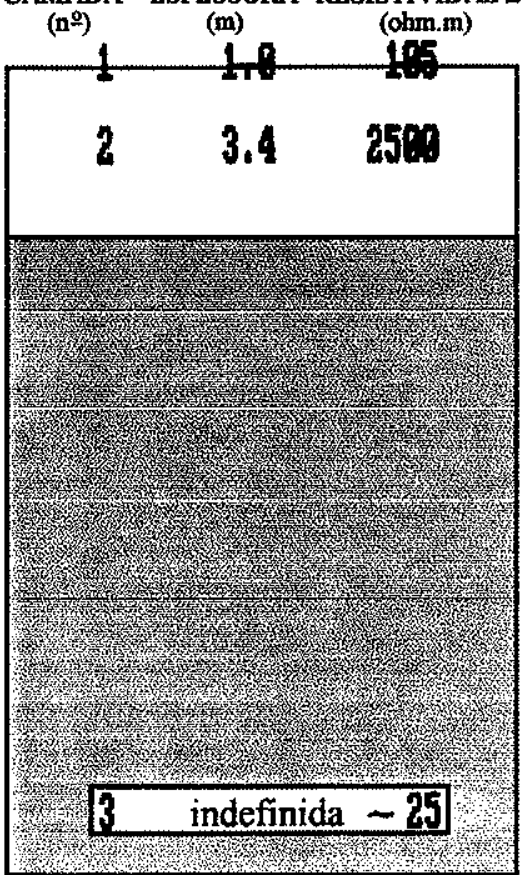




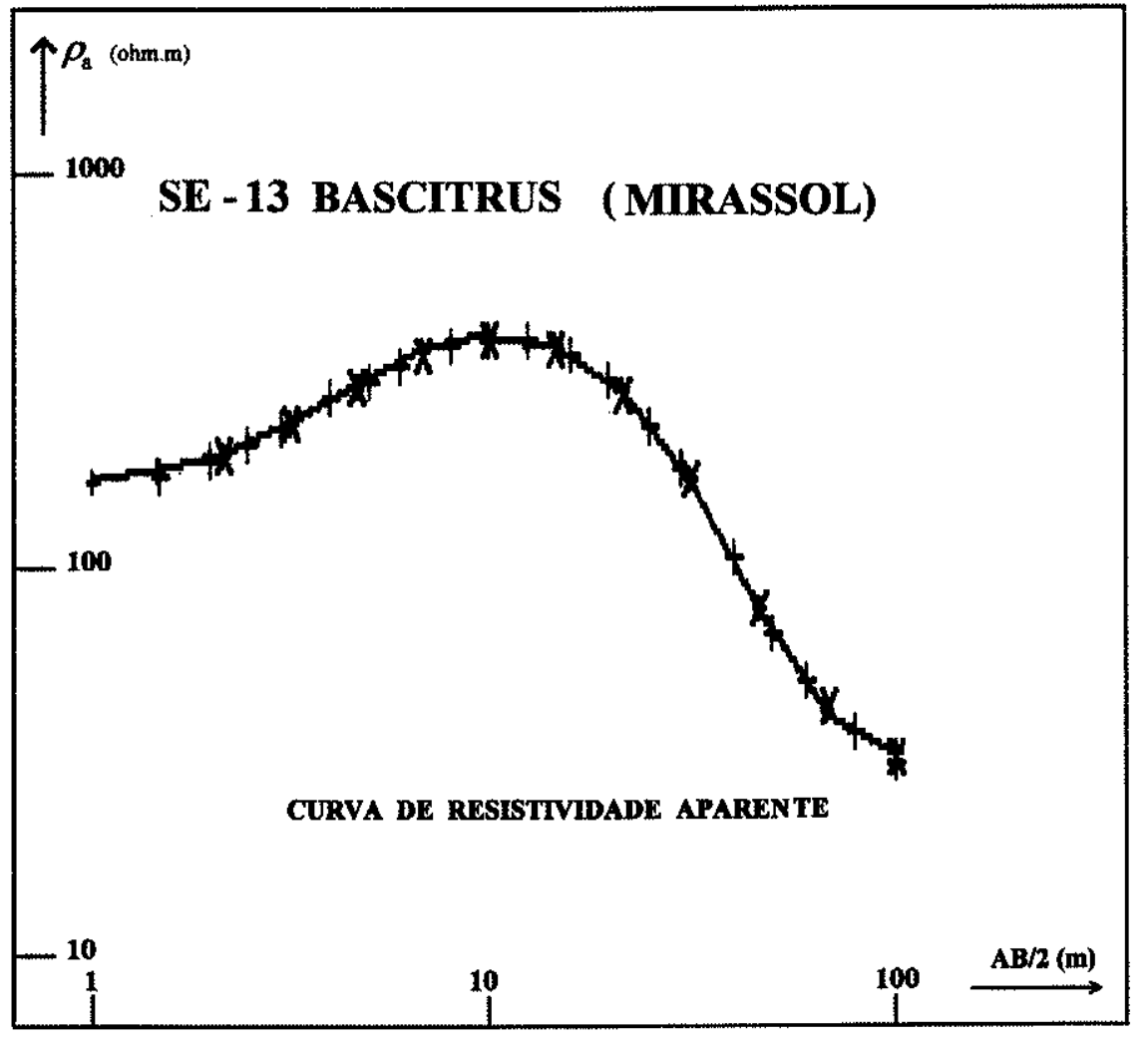

MODELO SCHLUMBERGER DE SONDAGEM SE - 13

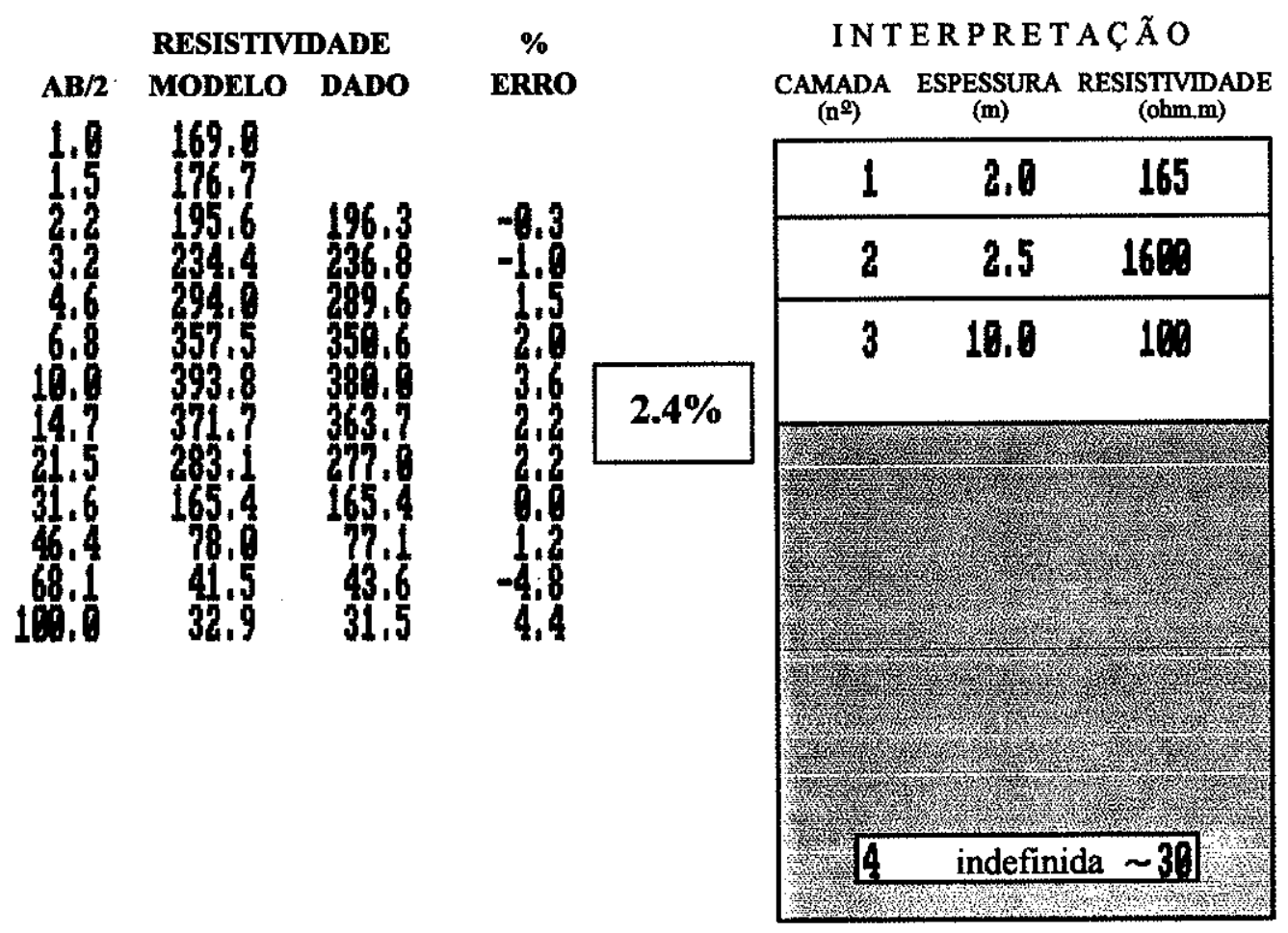




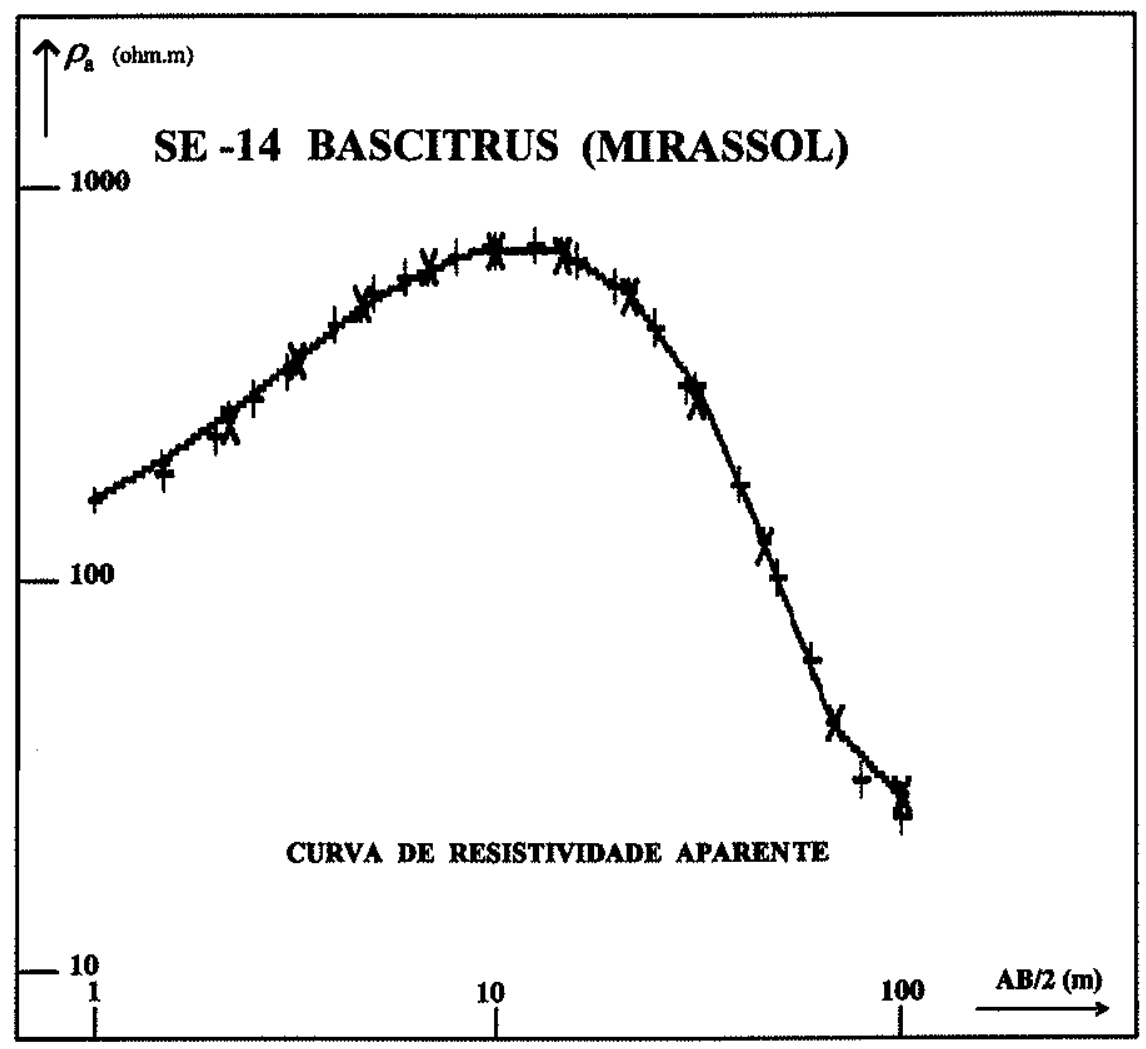

MODELO SCHLUMBERGER DE SONDAGEM SE - 14

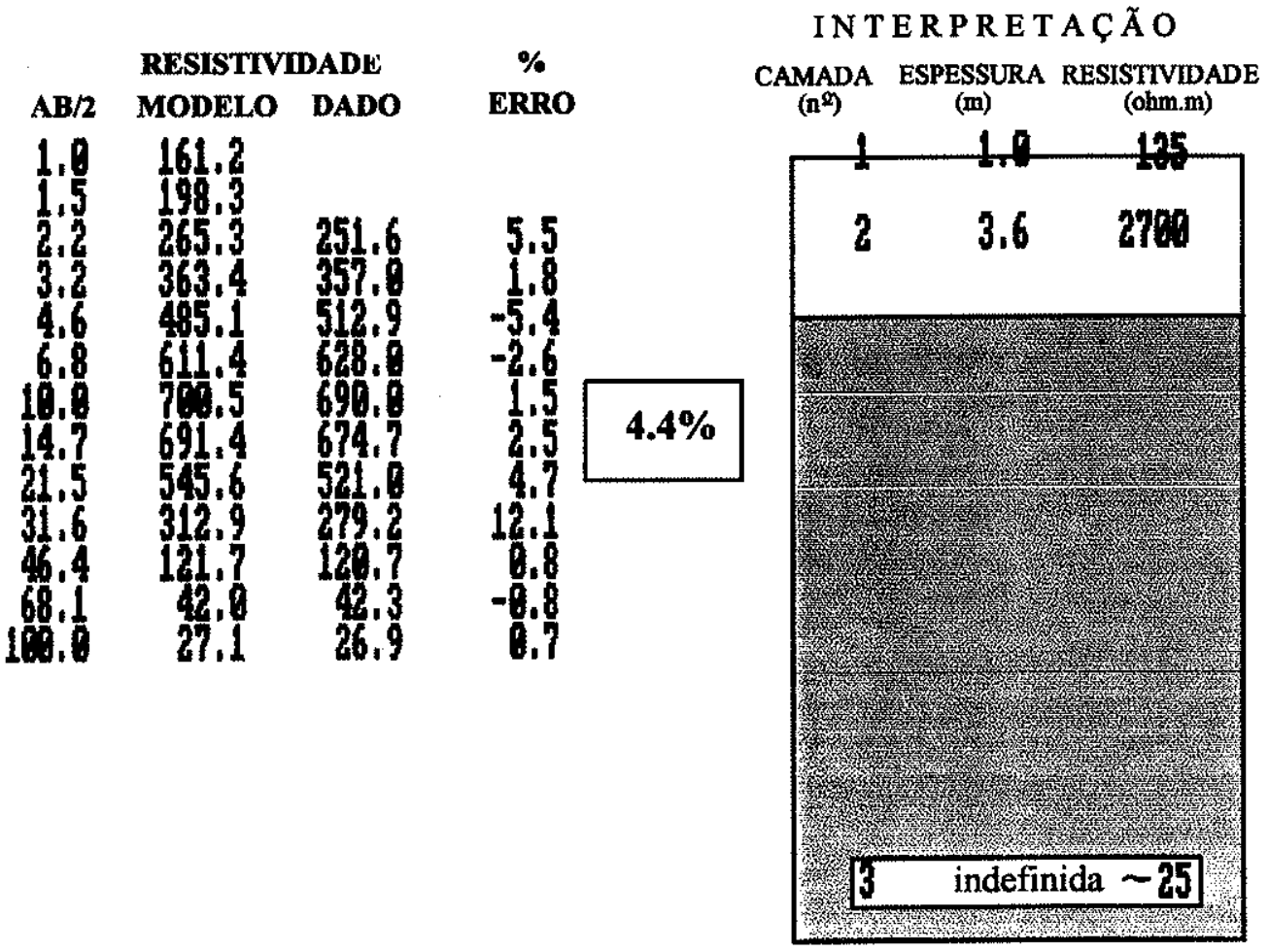




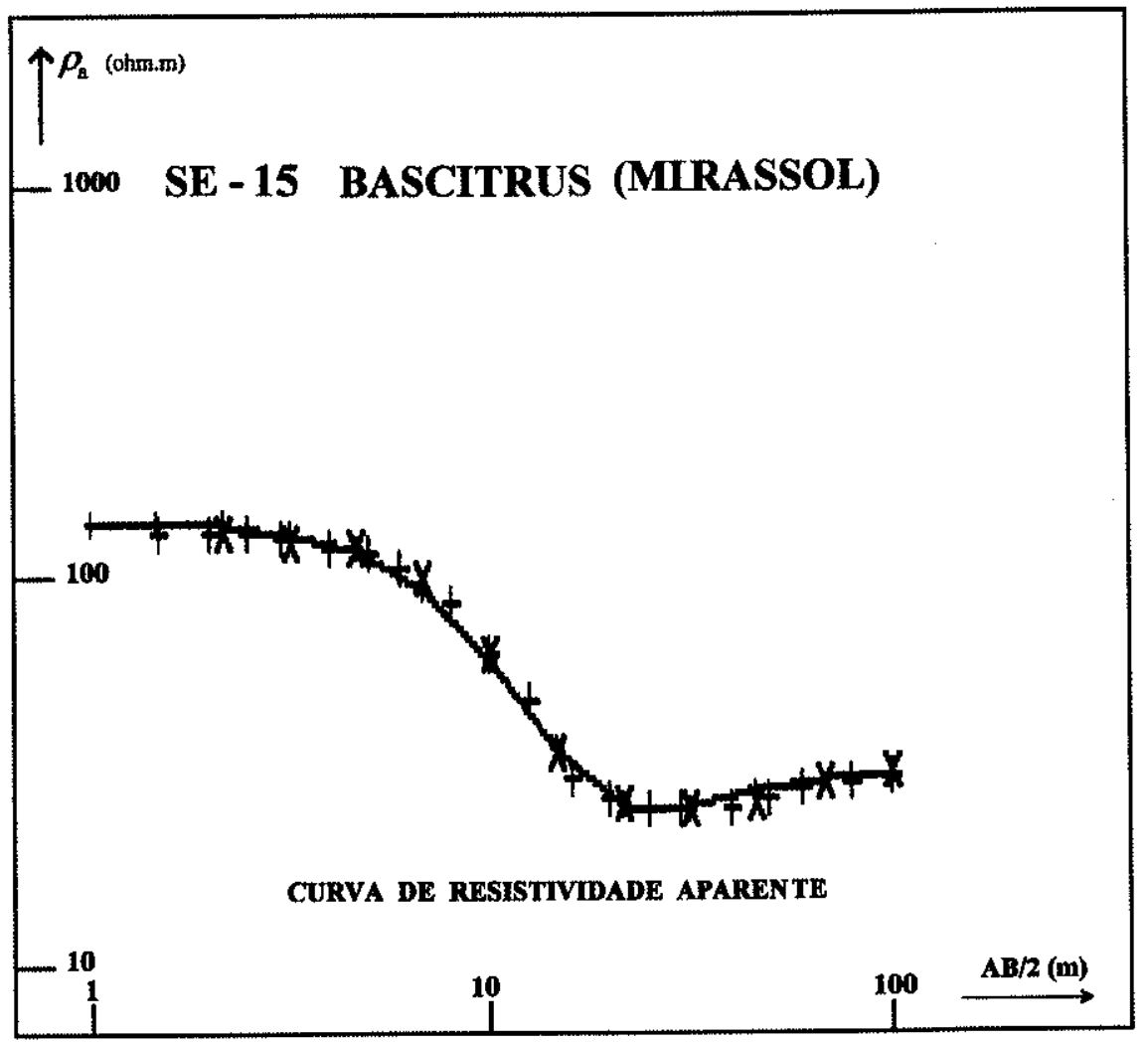

MODELO SCHLUMBERGER DE SONDAGEM SE - 15

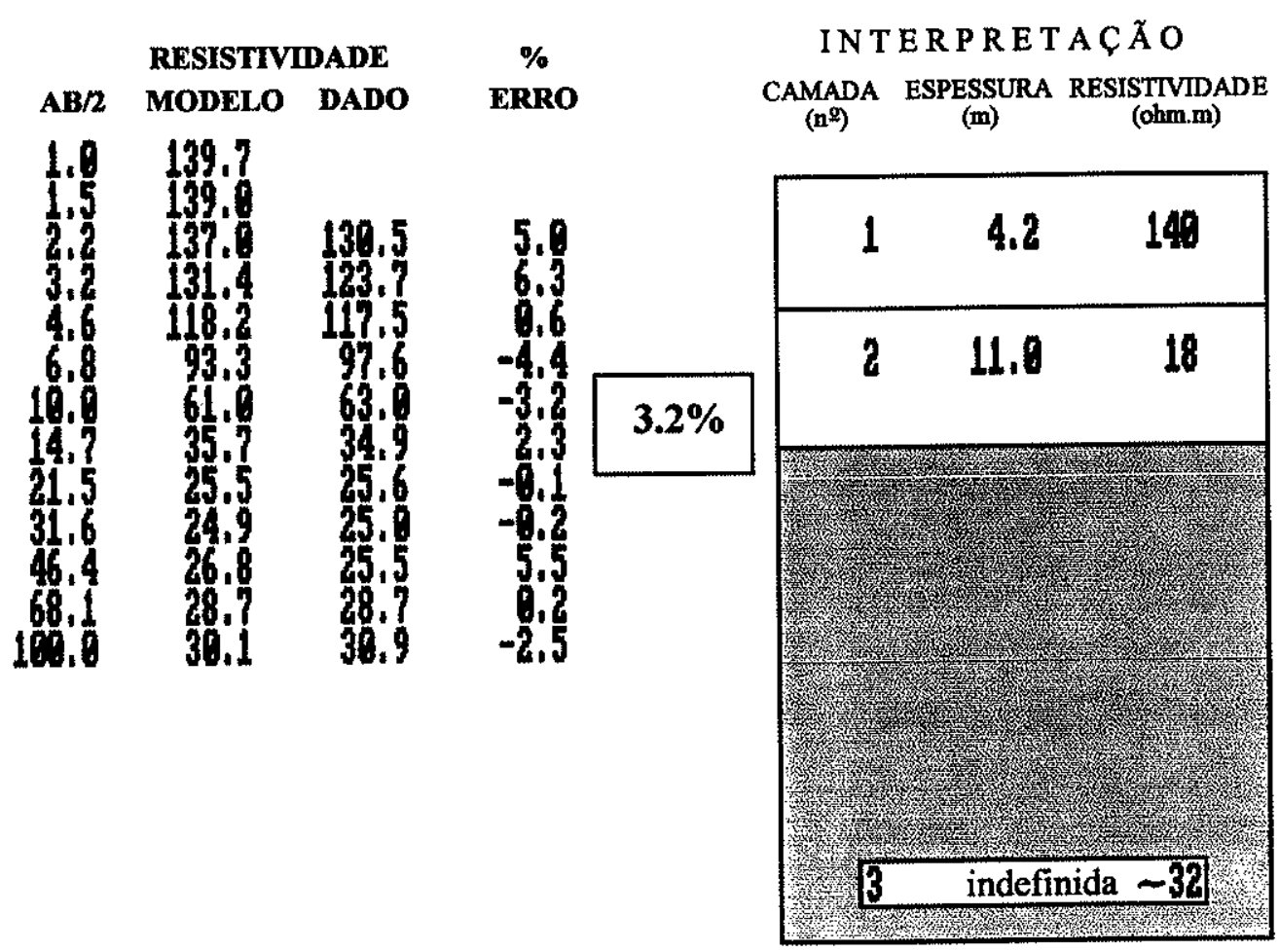




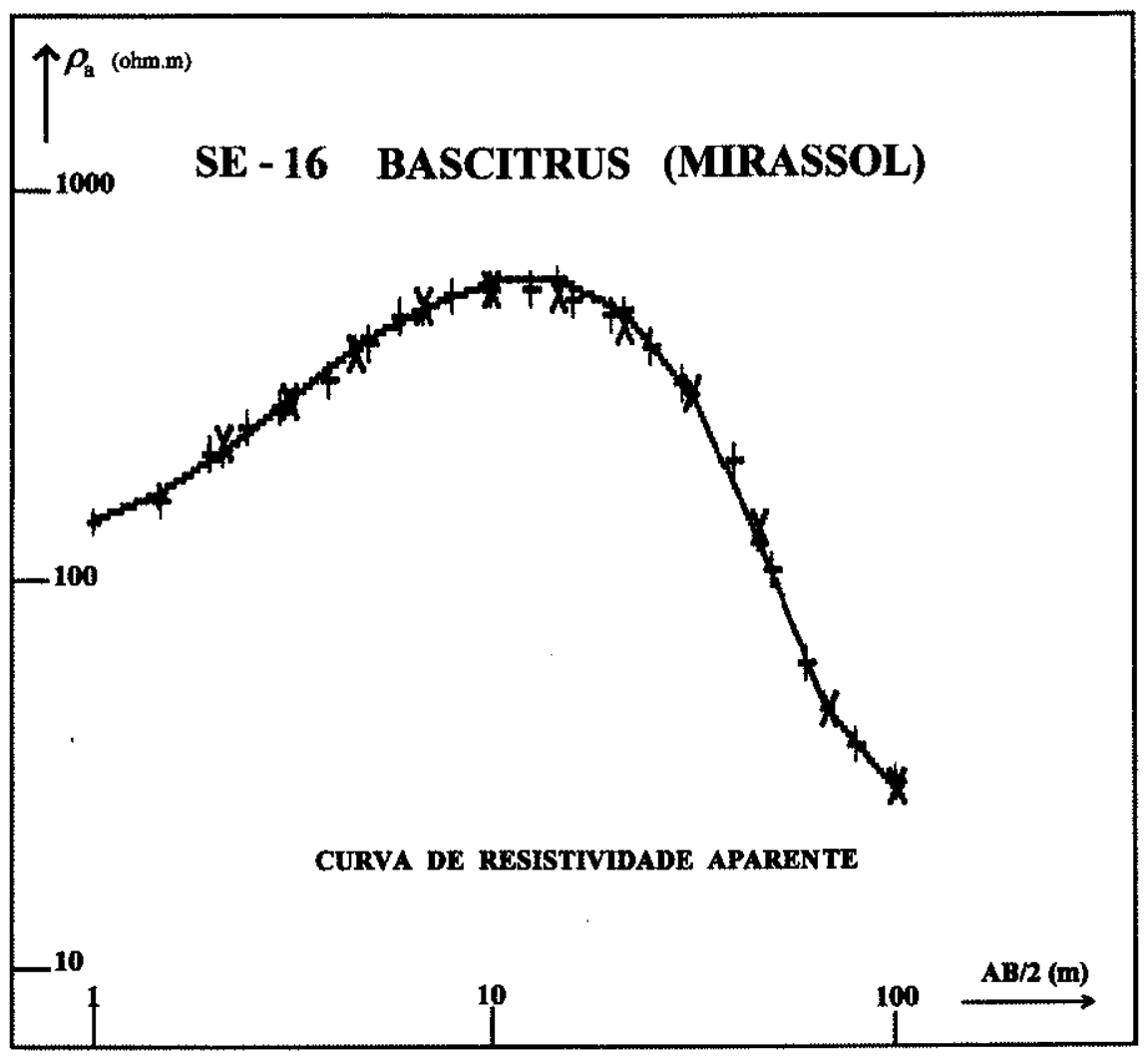

\section{MODELO SCHLUMBERGER DE SONDAGEM SE - 16}

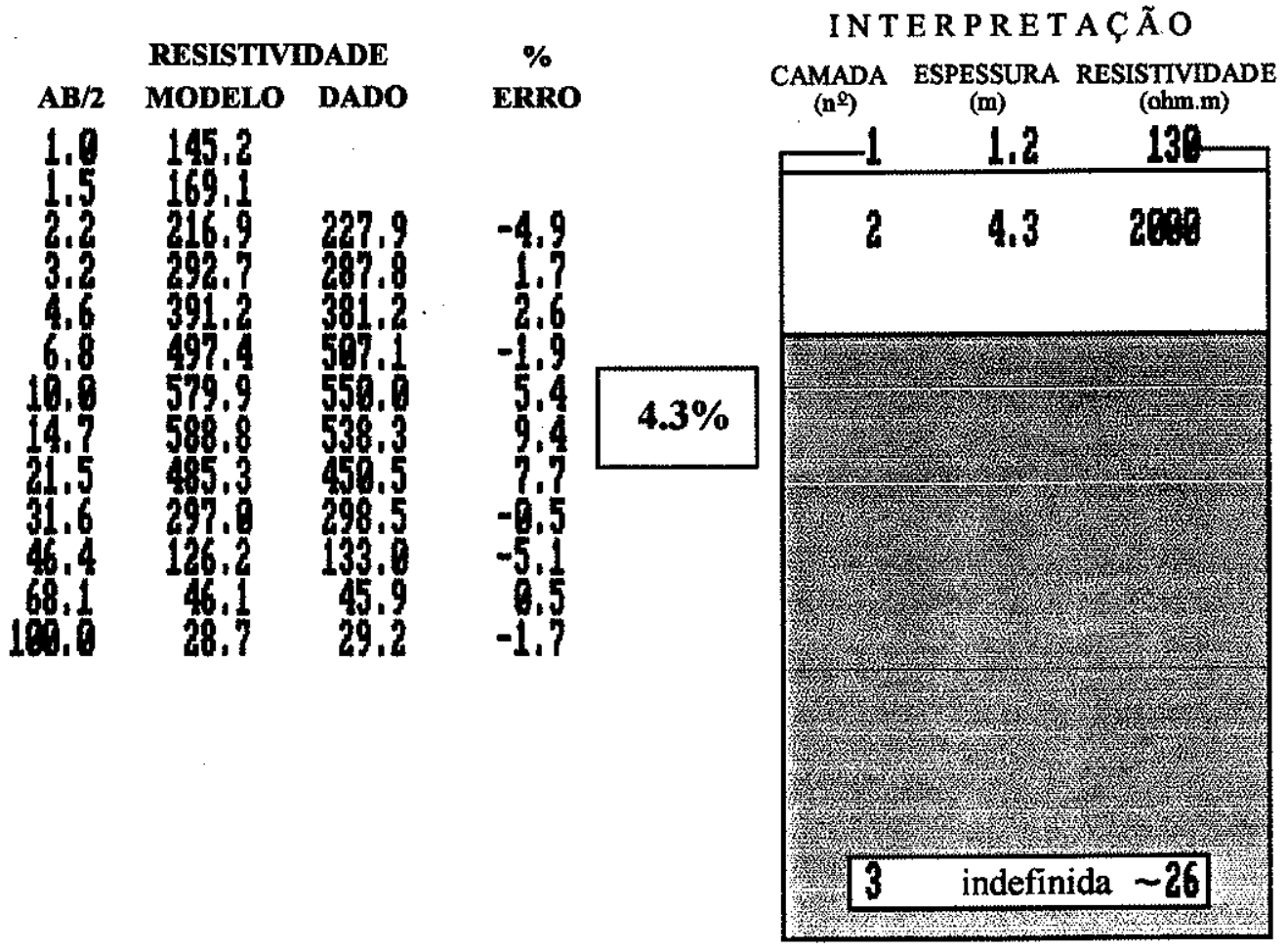




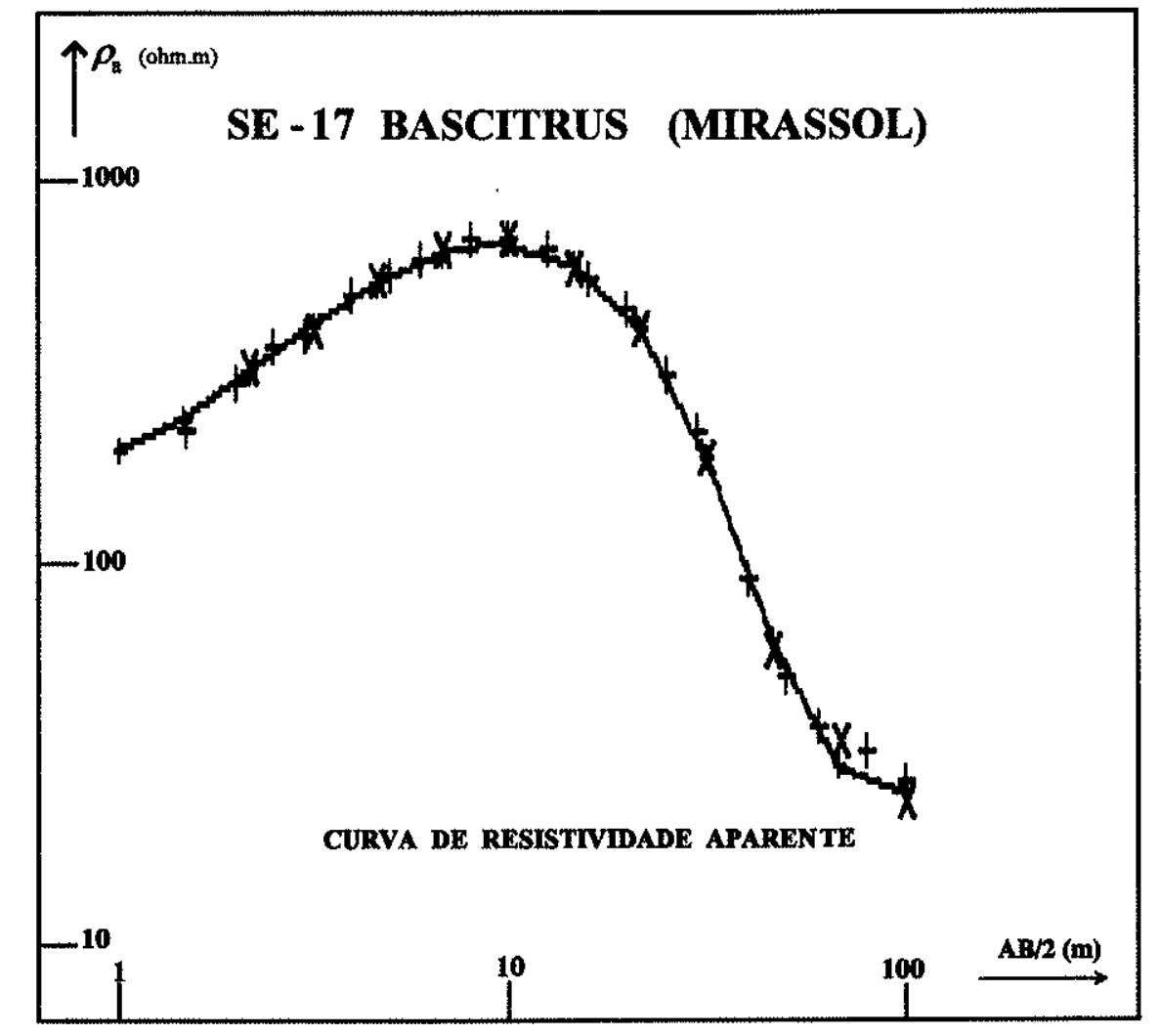

MODELO SCHLUMBERGER DE SONDAGEM SE - 17

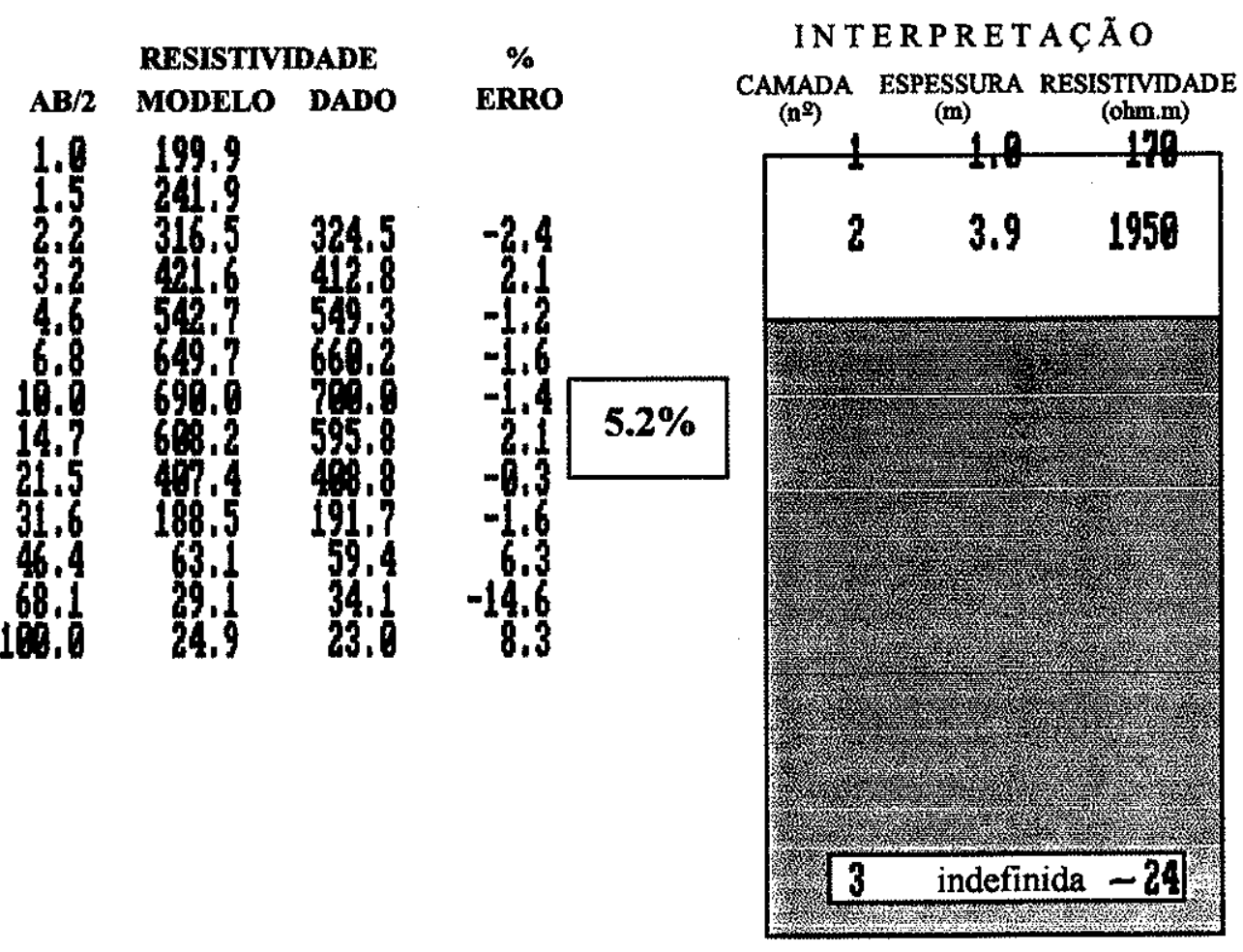




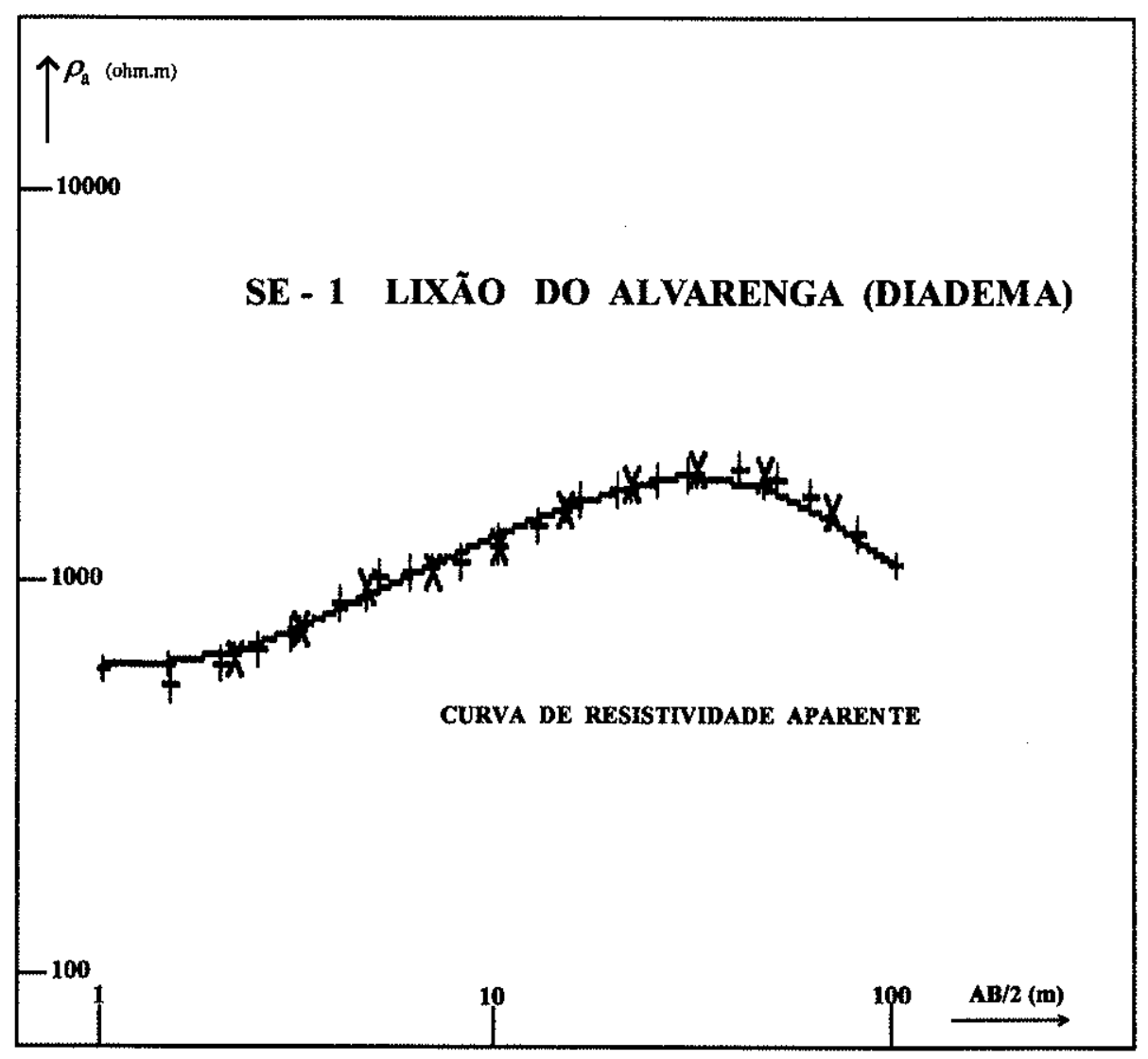

MODELO SCHLUMBERGER DE SONDAGEM SE - 1

IN T ERPR E T A C Ã O

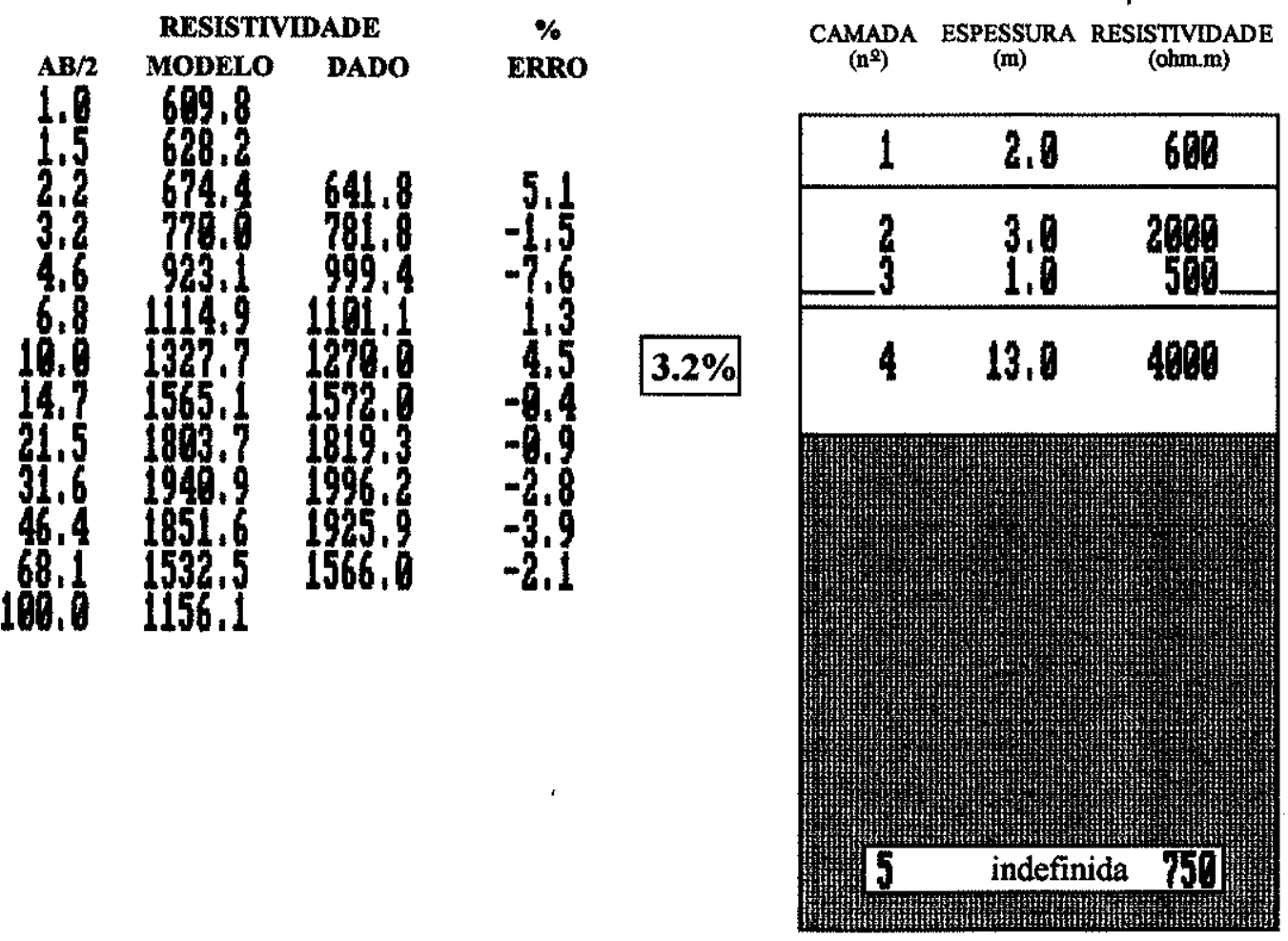




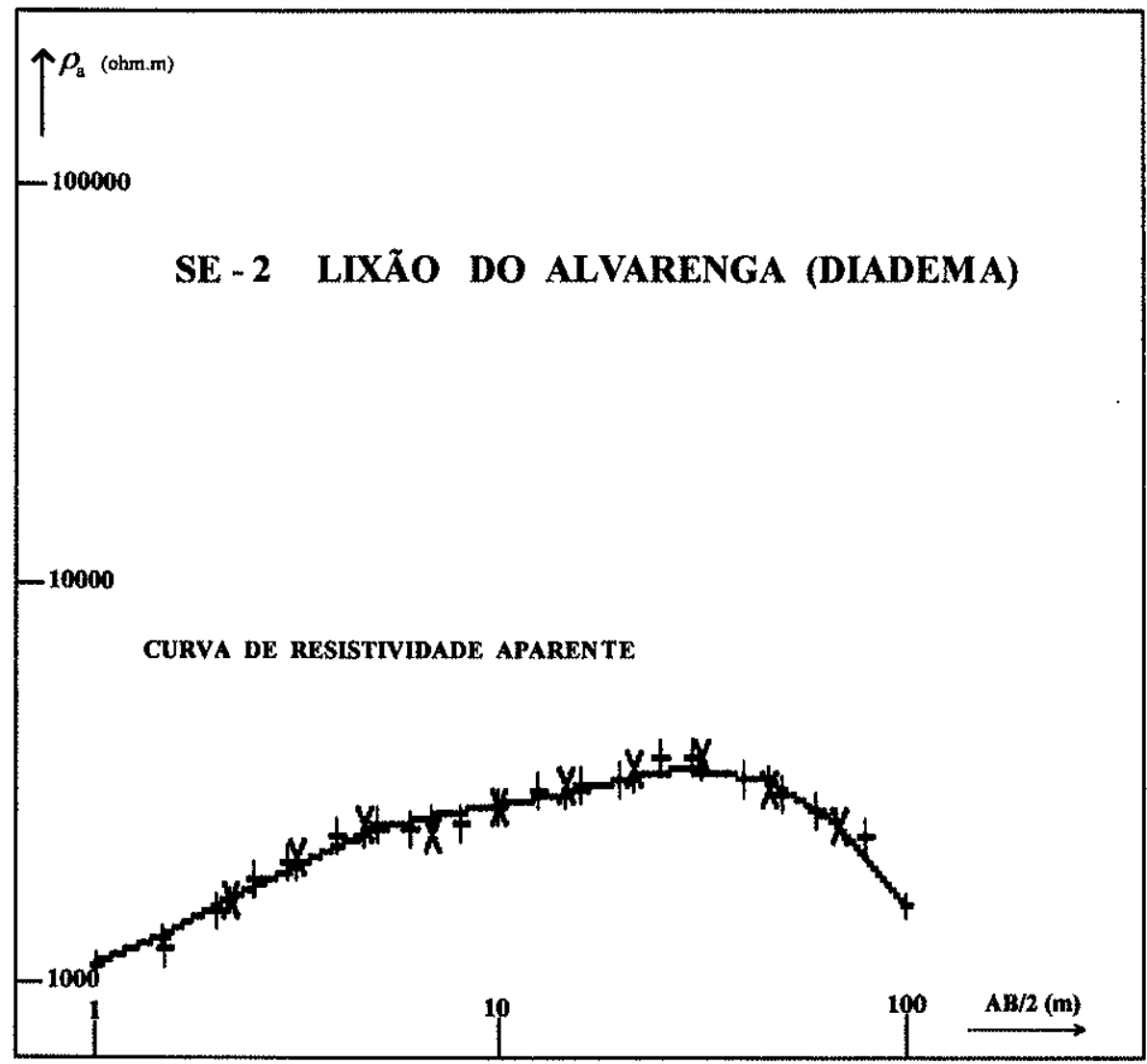

MODELO SCHLUMBERGER DE SONDAGEM SE - 2

IN T ER P RET A Ç Ã O

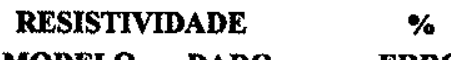

AB/2 MODELO DADO ERRO

1.21125 .7

$1.5 \quad 1297.6$

$2.2 \quad 1589.4 \quad 1614.0 \quad-1.5$

$3.2 \quad 1963.2 \quad 254.3 \quad-4.4$

4.6 73fo. $244.5 \quad-4.8$

$6.8 \quad 2587.2 \quad 2364.4 \quad 9.4$

$18.6 \quad 2739.3 \quad 270.0$

$14.7 \quad 9887.8 \quad 367.9$

$21.5 \quad 3167.8 \quad 3324$

$31,6 \quad 3383,5$

$46.4 \quad 3178,1$

68.1244 .0

$10.0 \quad 1524,1$

3546.9

3012.4

248.1

$\underset{\left(\mathrm{n}^{2}\right)}{\operatorname{CAMADA}} \underset{(\mathrm{m})}{\operatorname{ESSPESSUA}} \underset{\text { (ohm.m) }}{\text { RESISTIVIDADE }}$

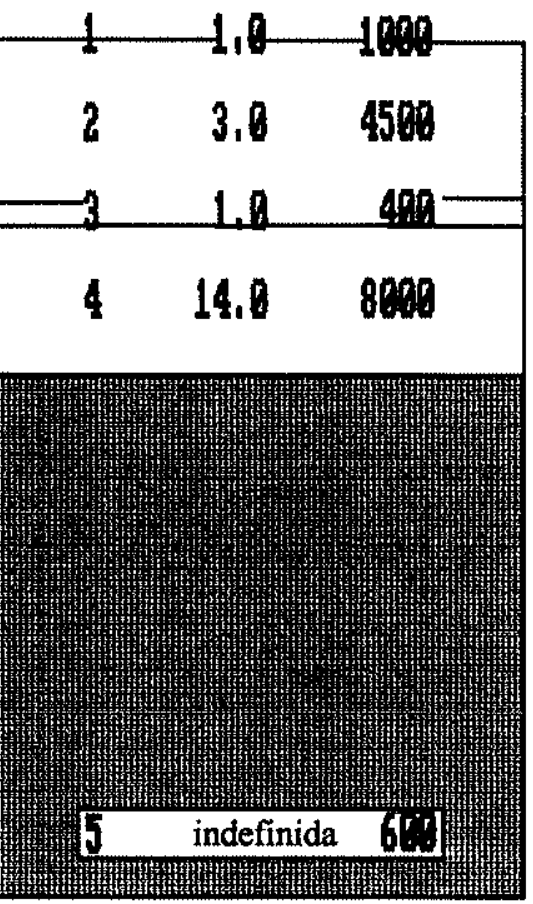




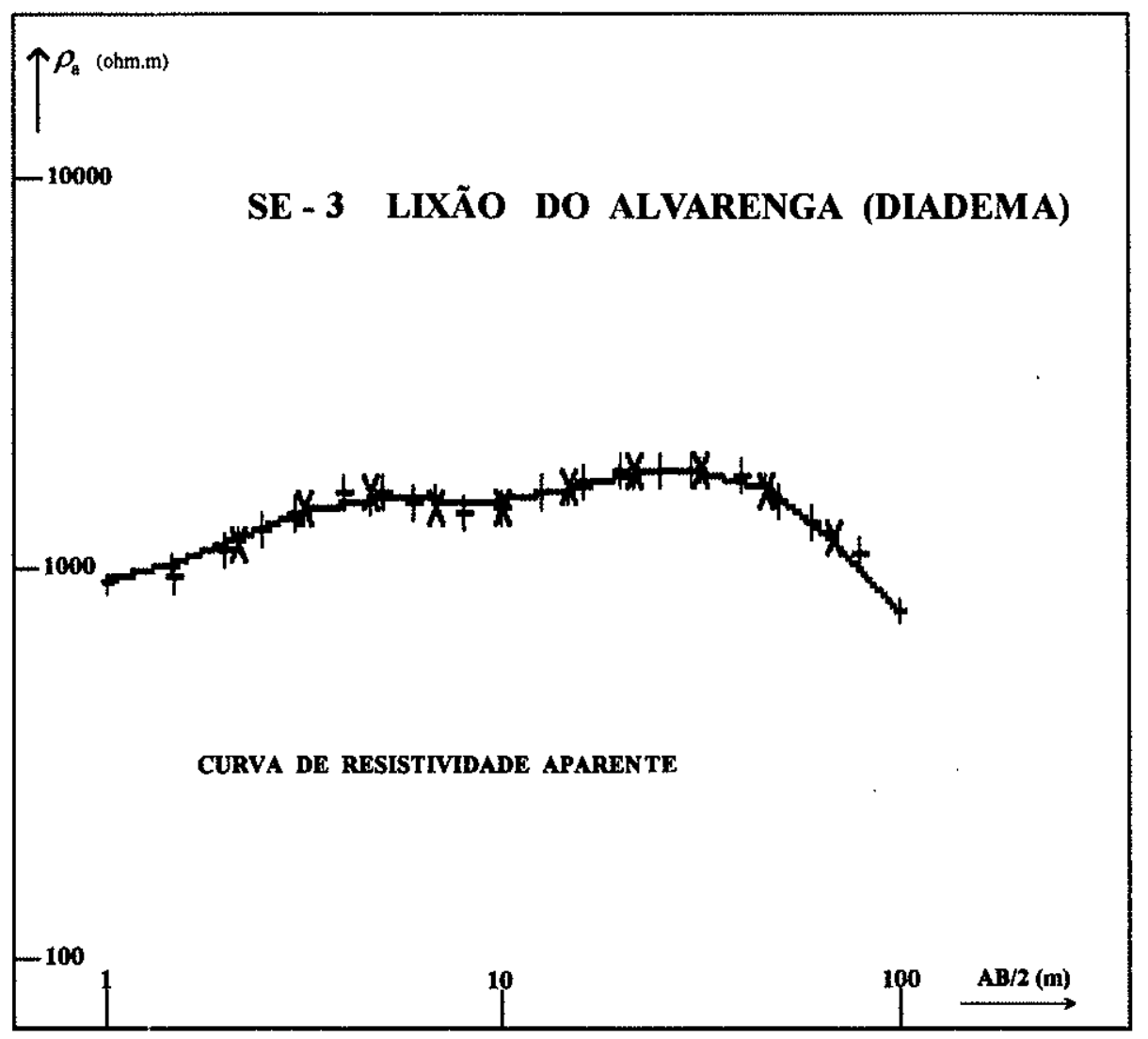

MODELO SCHLUMBERGER DE SONDAGEM SE - 3

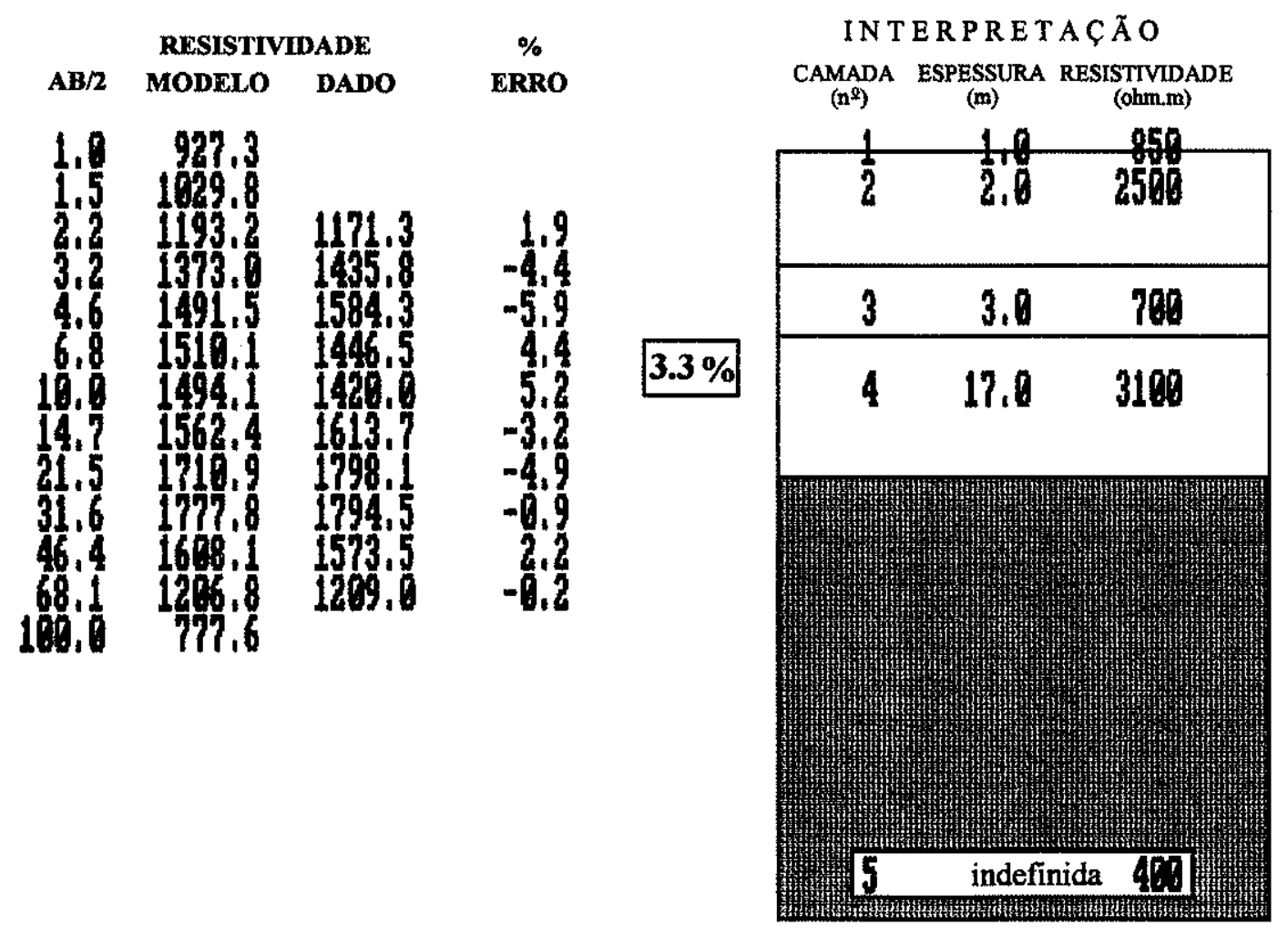




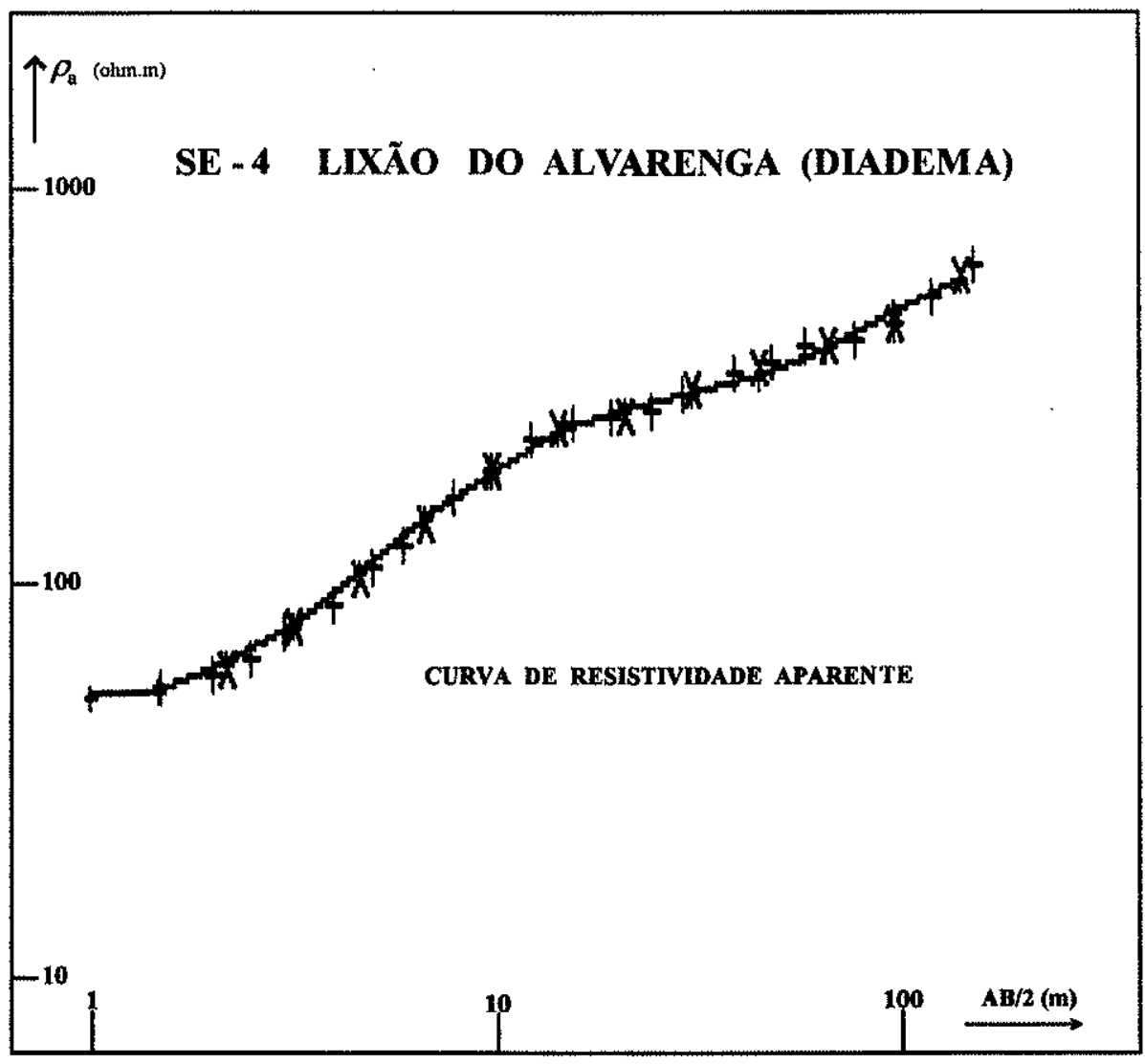

\section{MODELO SCHLUMBERGER DE SONDAGEM SE - 4}

IN T E R P RE T A Ç Ã O

\begin{tabular}{cccc}
\multicolumn{2}{c}{ RESISTIVIDADE } & $\%$ \\
AB/2 & MODELO & DADO & ERRO
\end{tabular}

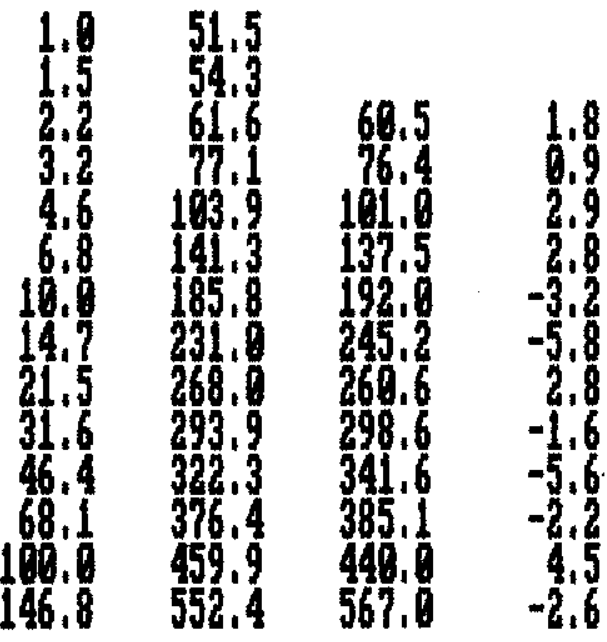

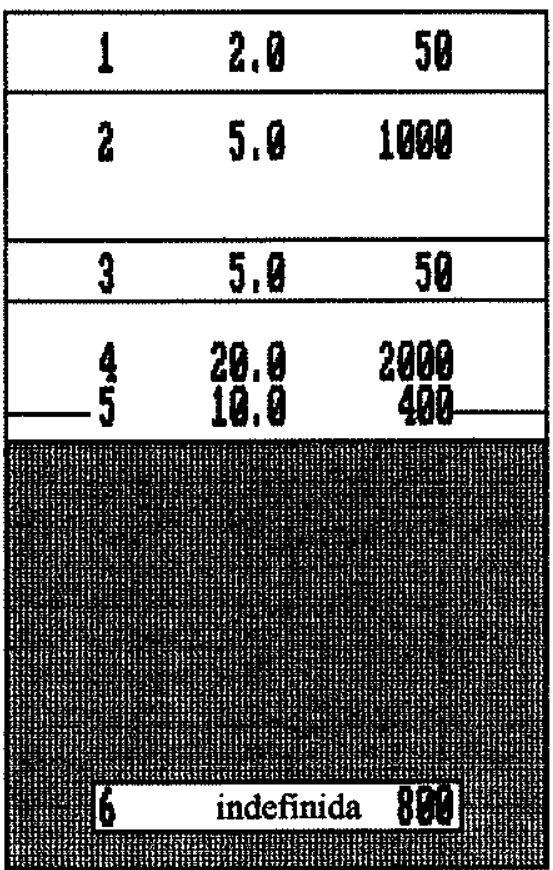




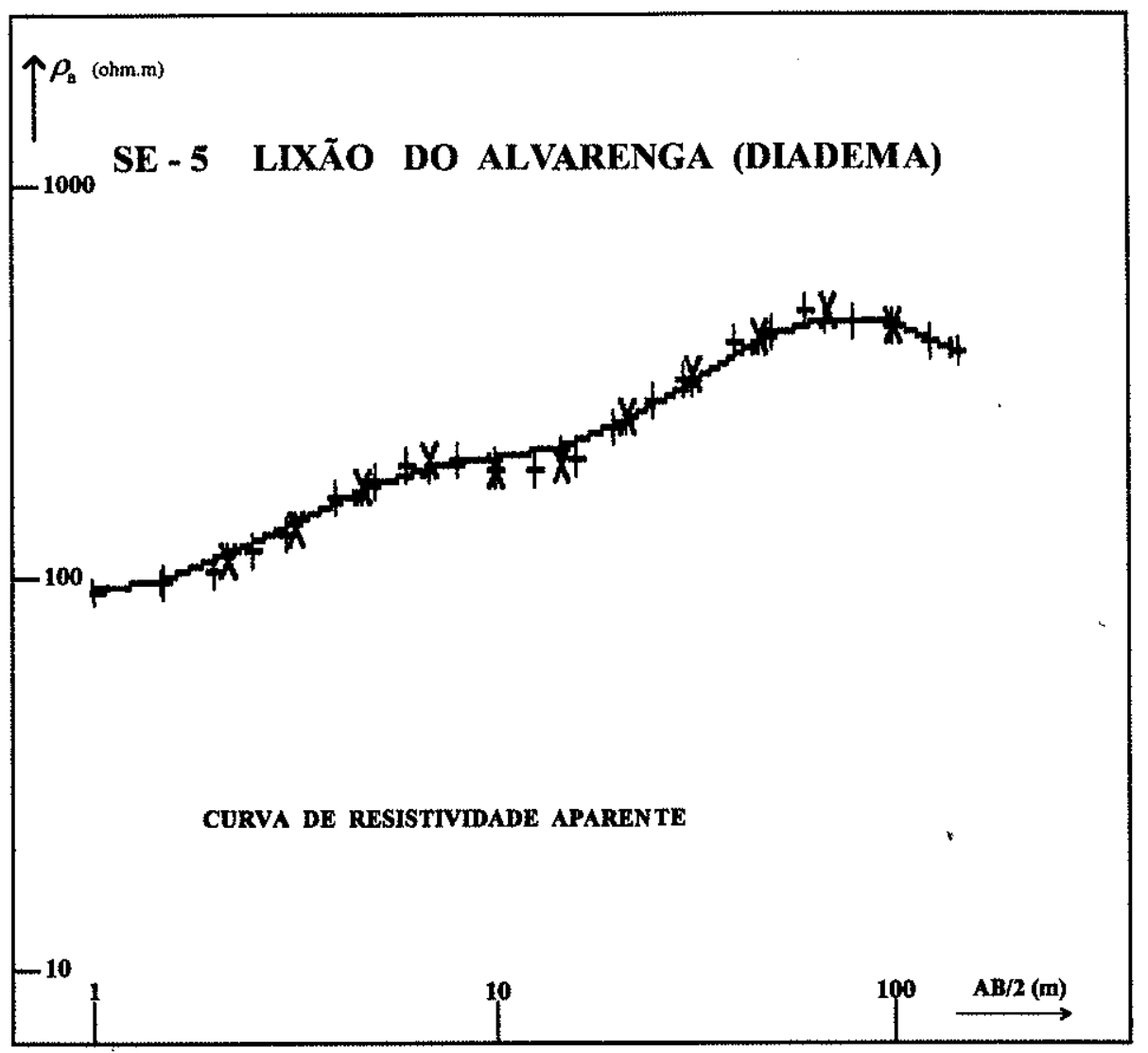

\section{MODELO SCHLUMBERGER DE SONDAGEM SE - 5}

I N T ER P R E T A Ç Ã O

$\mathbf{A B} / \mathbf{2}$

RESISTTVIDADE

$\%$

$\underset{\left(\mathbf{n}^{\mathbf{2}}\right)}{\operatorname{CAMAADA}} \underset{(\mathrm{m})}{\operatorname{ESPESSURA}} \underset{(\mathrm{ohm} \cdot \mathrm{m})}{\mathrm{RESISTIVIDADE}}$

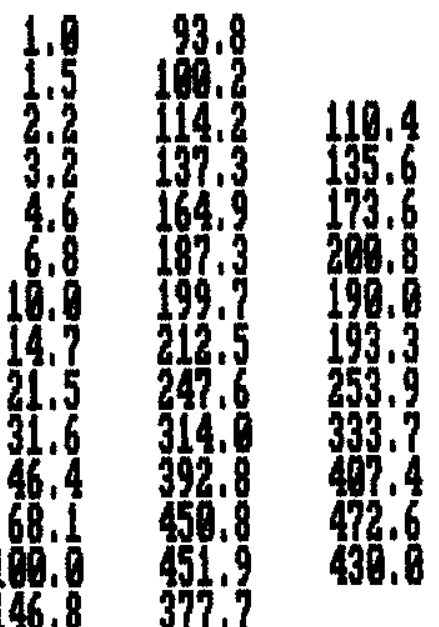

3.4

1.3

$-5.1$

$-6.7$

$4.7 \%$

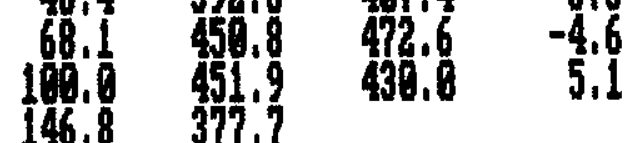

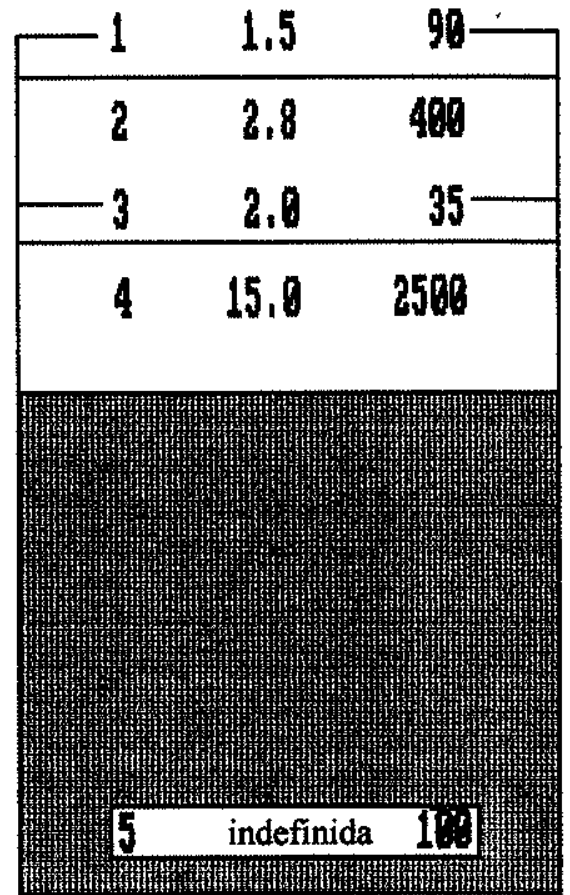




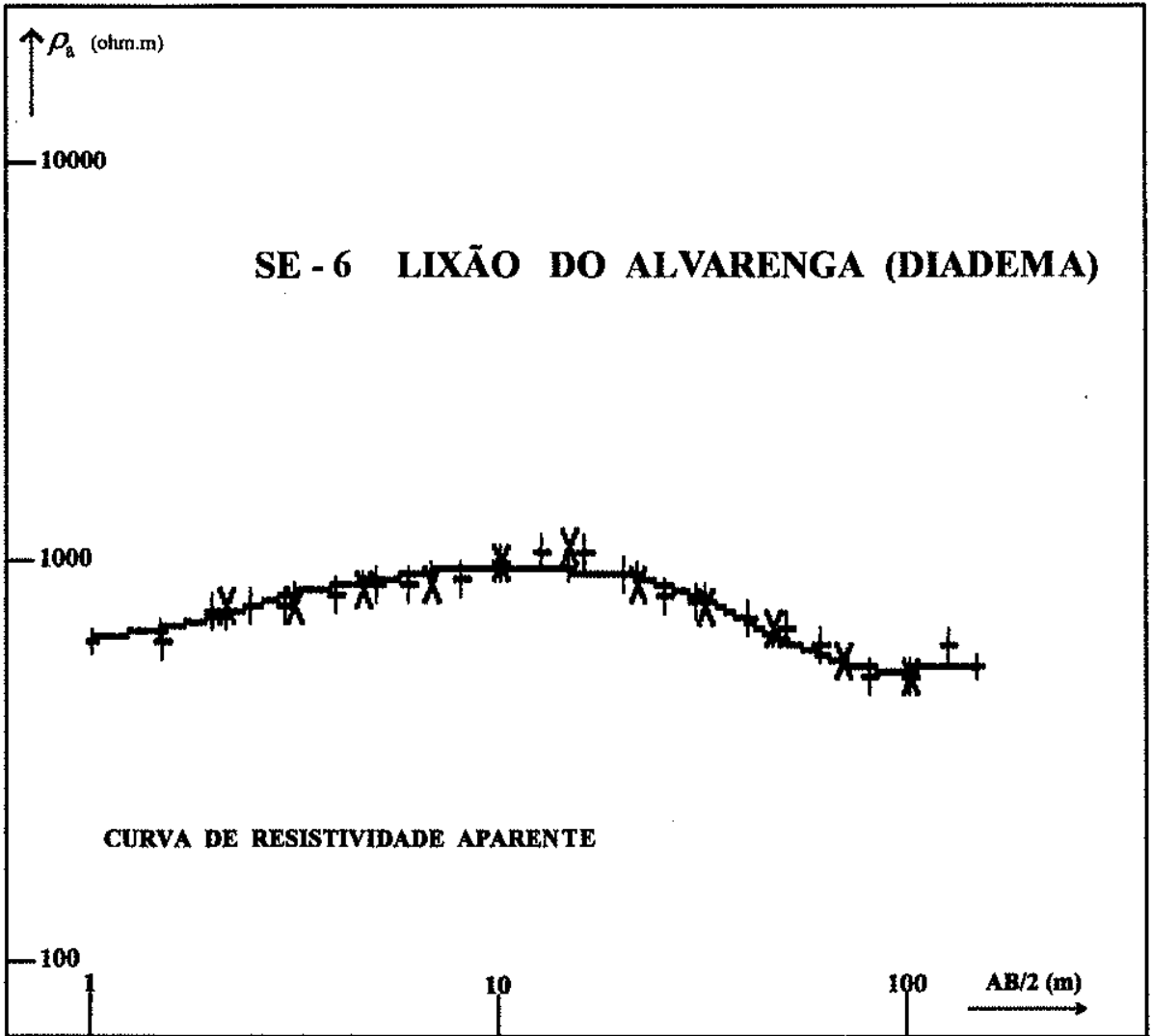

MODELO SCHLUMBERGER DE SONDAGEM SE - 6

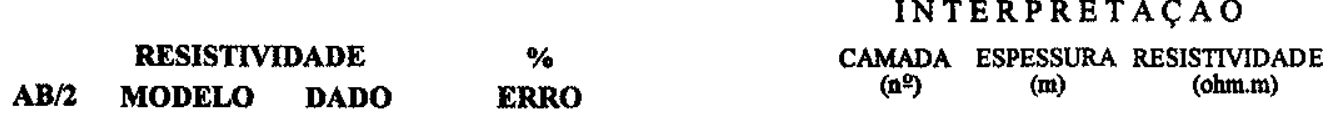

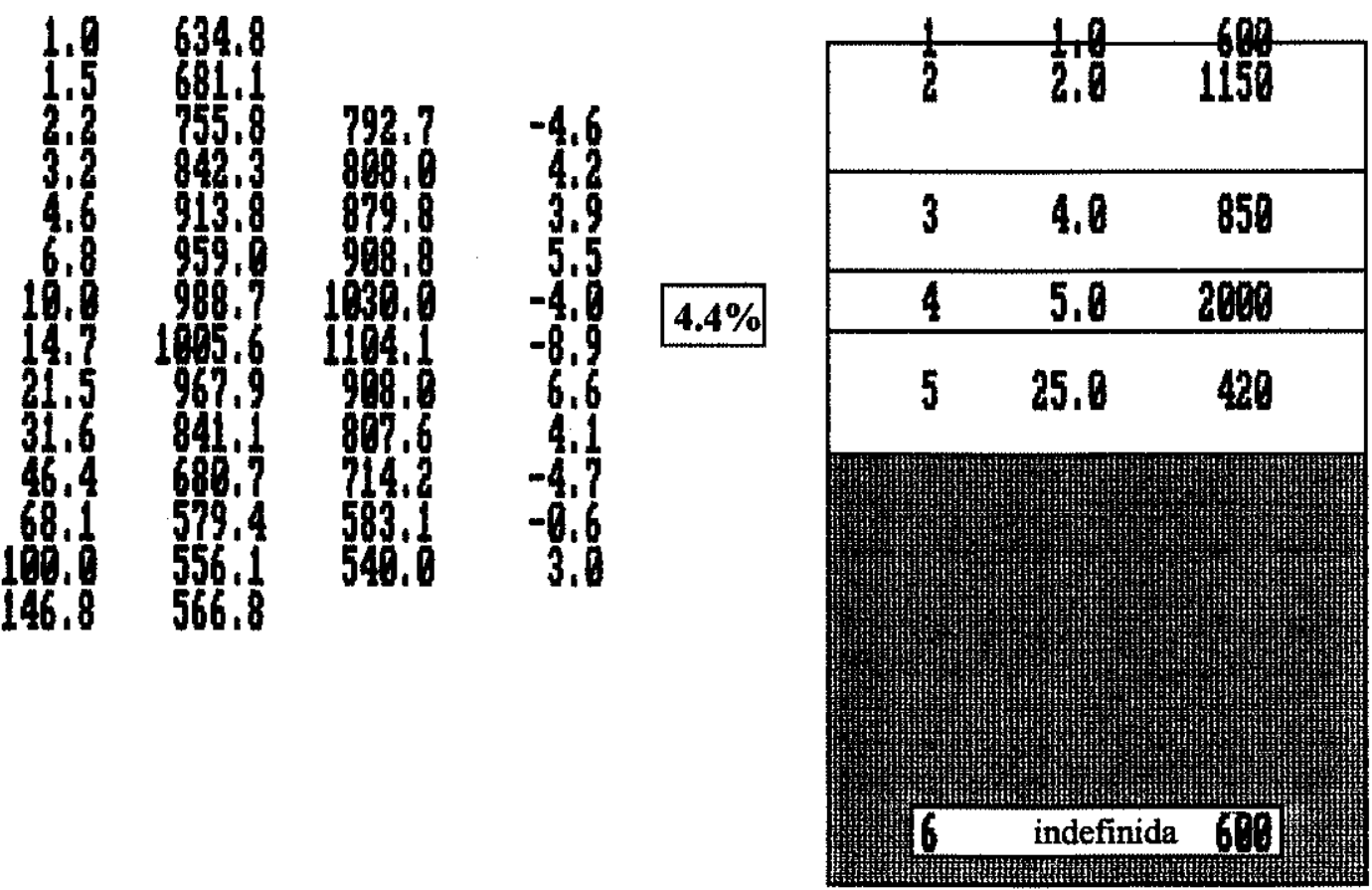




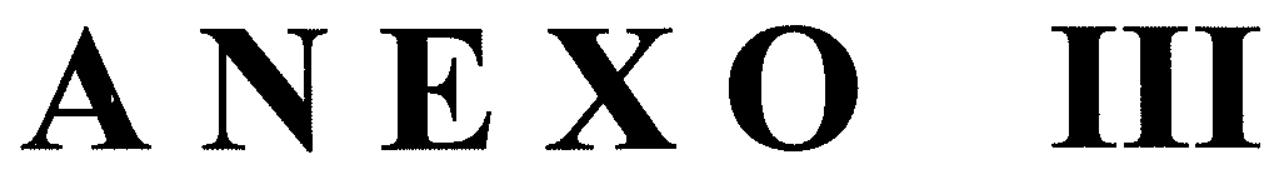

Perfis de Condutividade Elétrica Aparente (CEM) 
CAMINHAMENTO ELETROMAGNÉTICO -PERFIL I

(Borracha Paulista - Jose Boniffício)

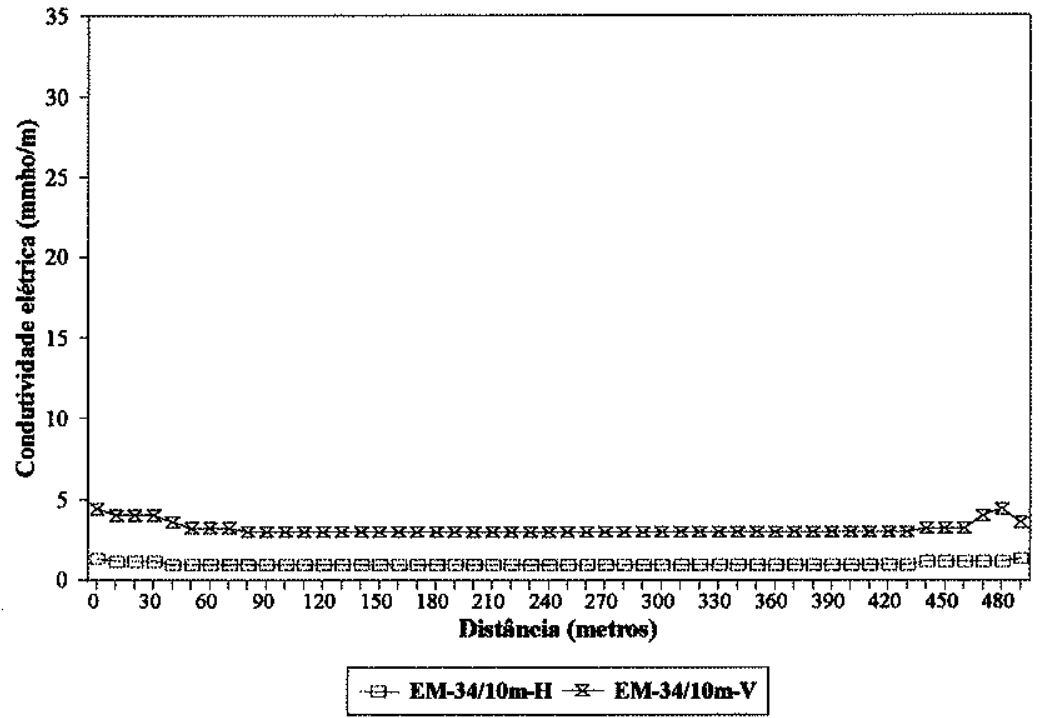

\section{CAMINHAMENTO ELETROMAGNÉTICO-PERFIL II} (Borracha Paulista - José Bonifácio)

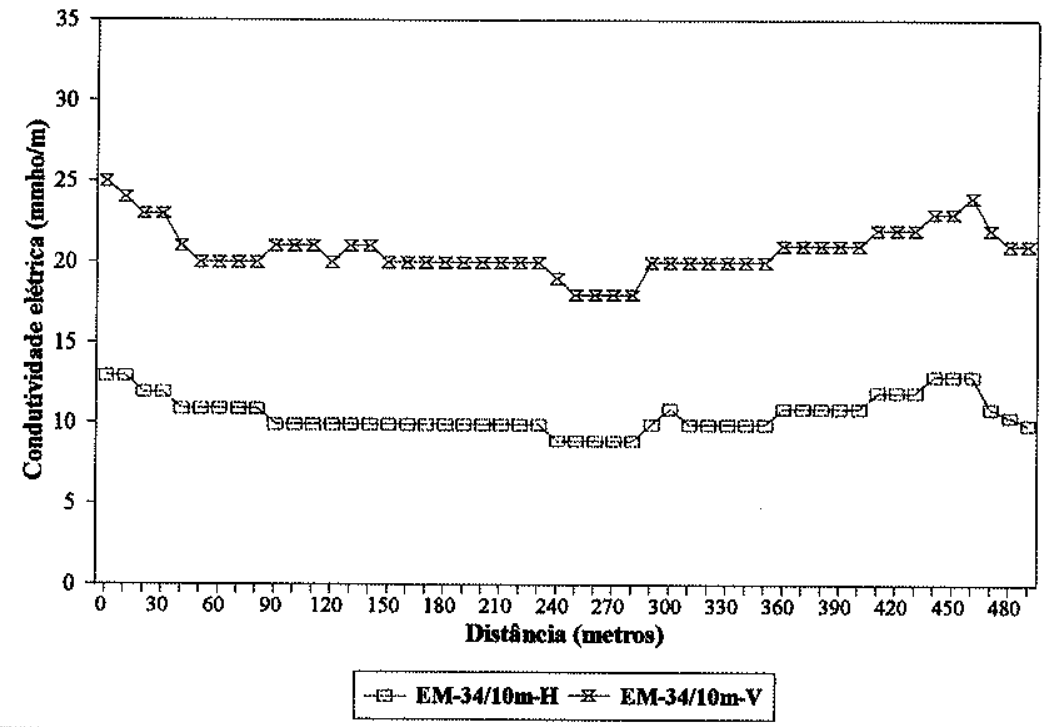

\section{CAMINHAMENTO ELETROMAGNÉTICO-PERFILIII} (Borracha Paulista - José Bonlfácio)

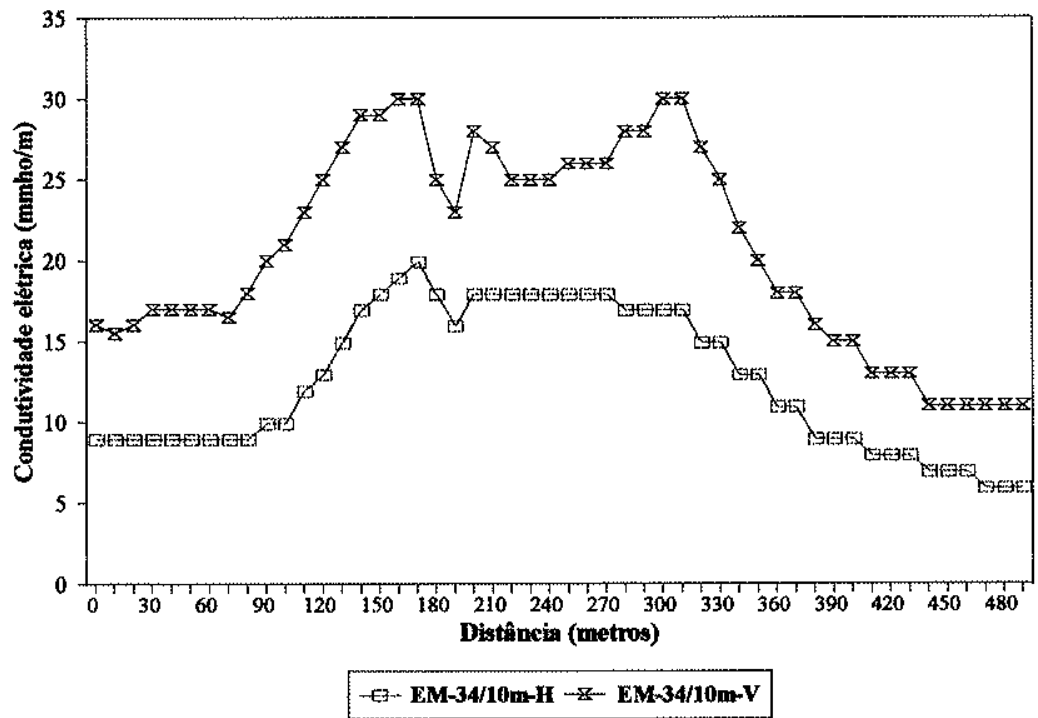



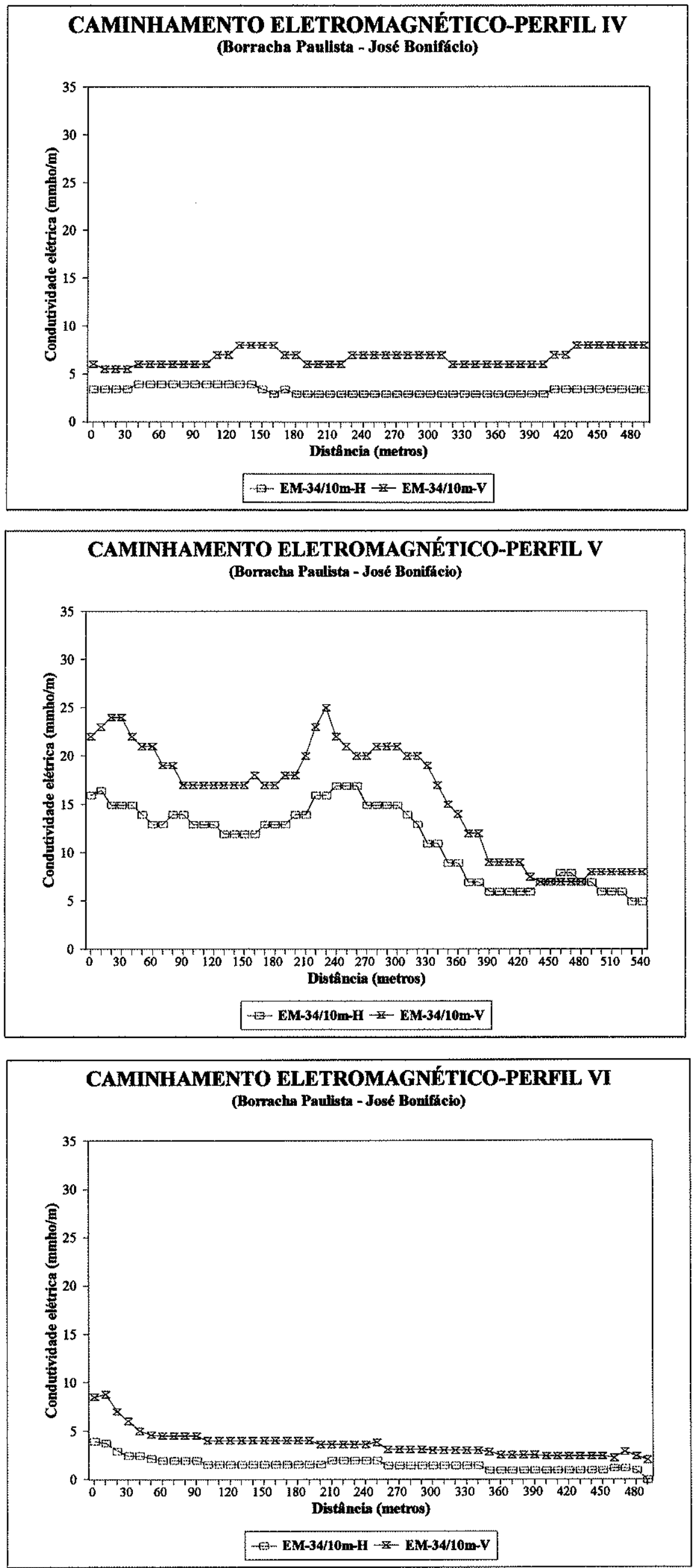


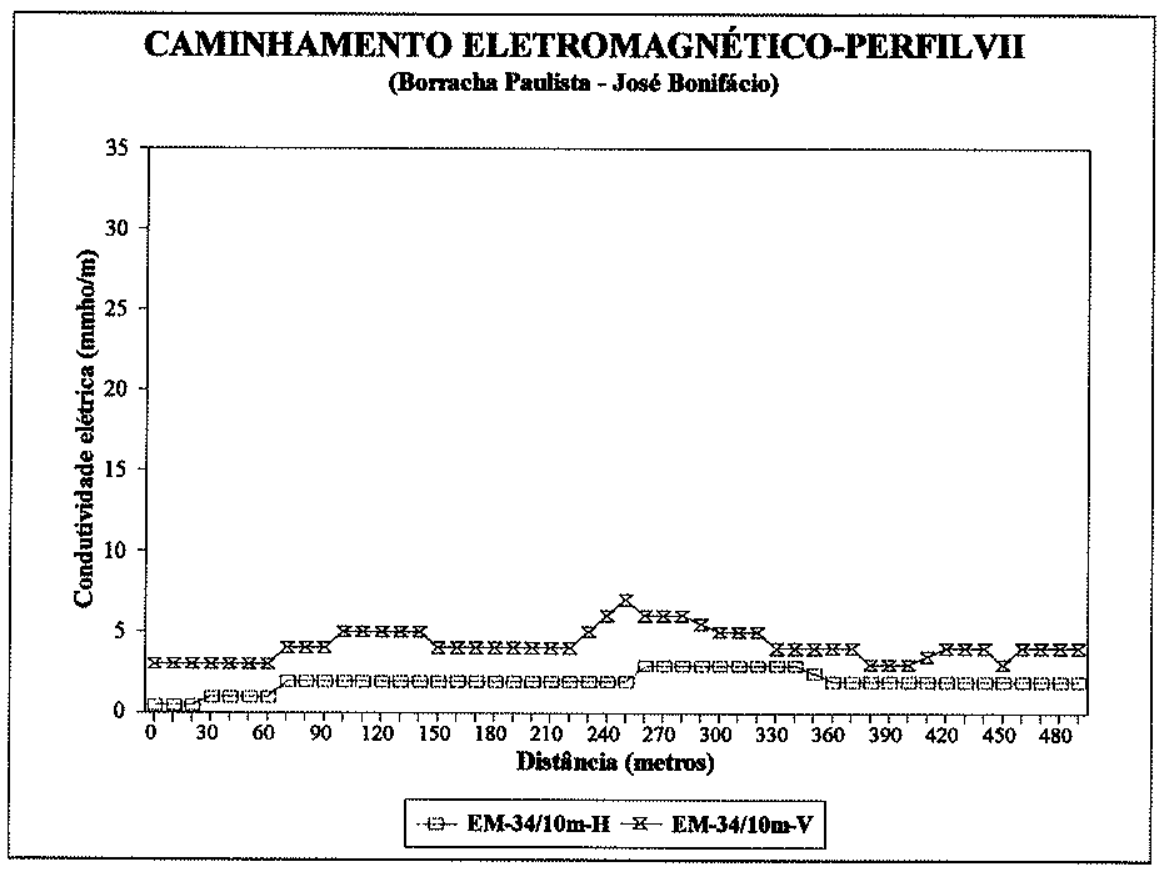

\section{CAMINHAMENTOELETROMAGNÉTICO-PERFILVIII} (Borracha Paulista - José Bonffáço)

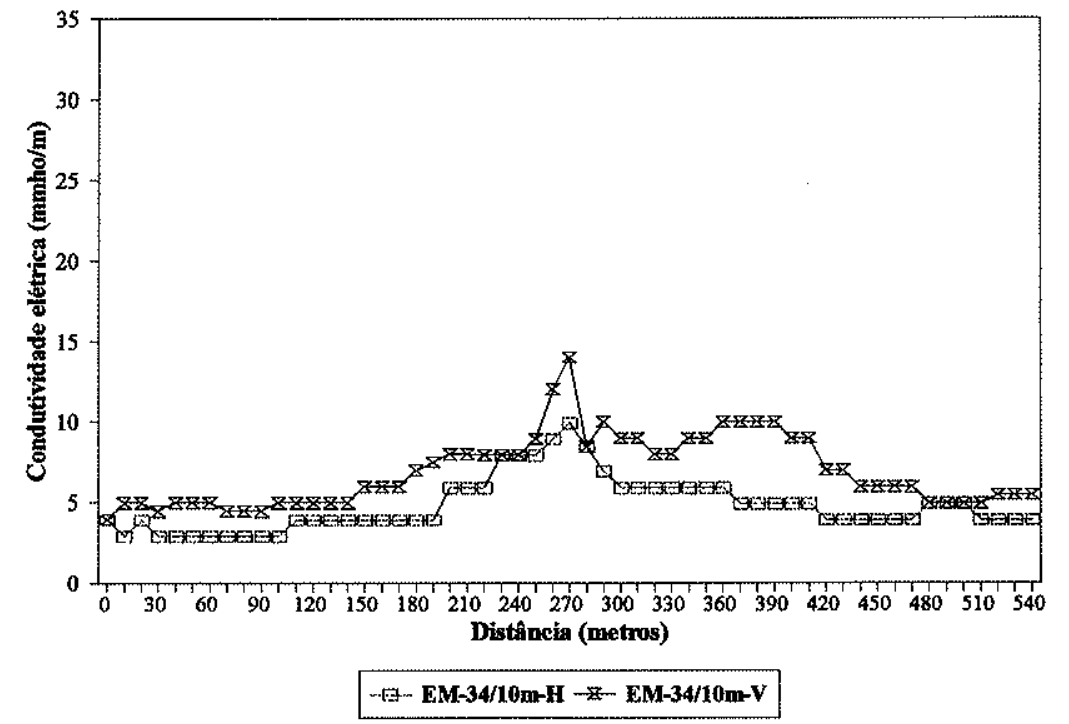

\section{CAMINHAMENTO ELETROMAGNÉTICO-PERFIL IX} (Borracha Paulista - José Bonif́ácio)

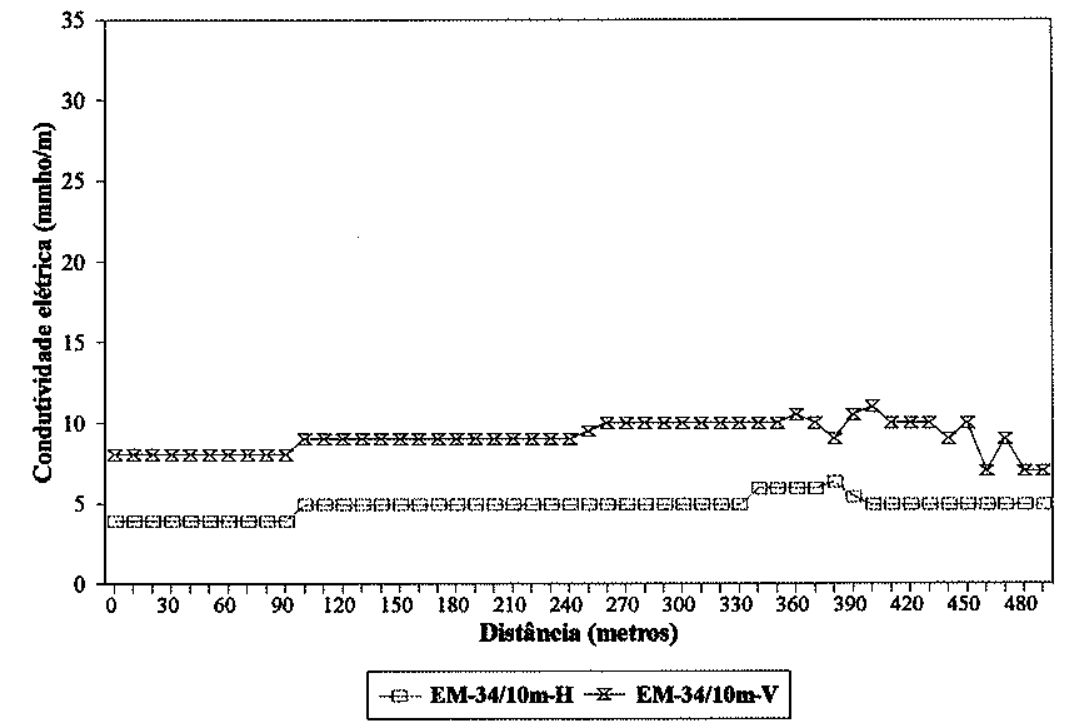



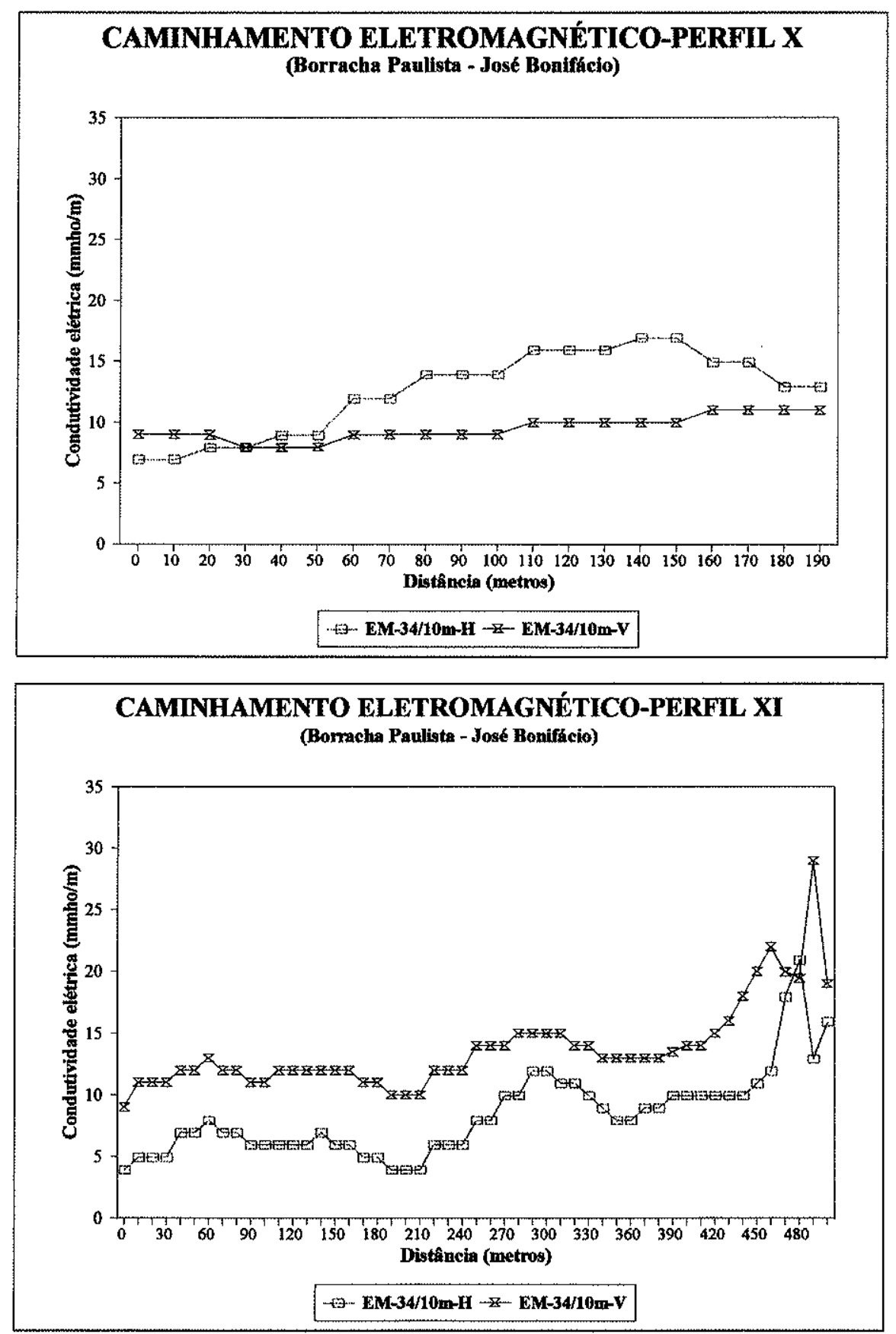

\section{CAMINHAMENTO ELETROMAGNÉTICO-PERFILXII} (Borracha Paulista - José Bonifácto)

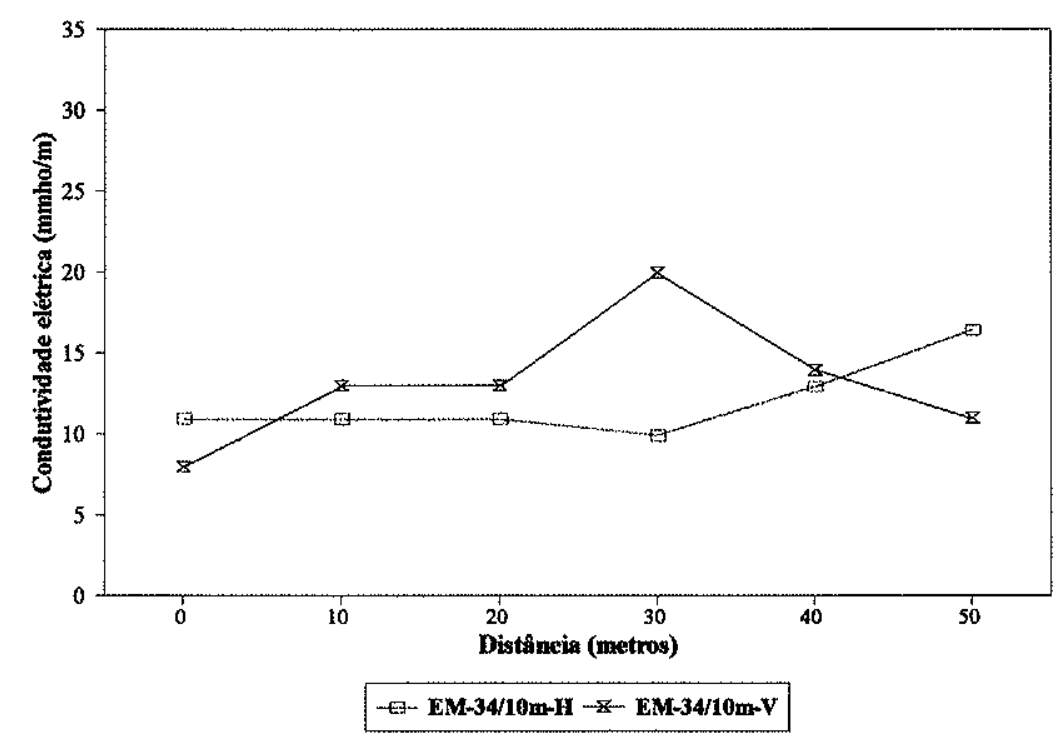




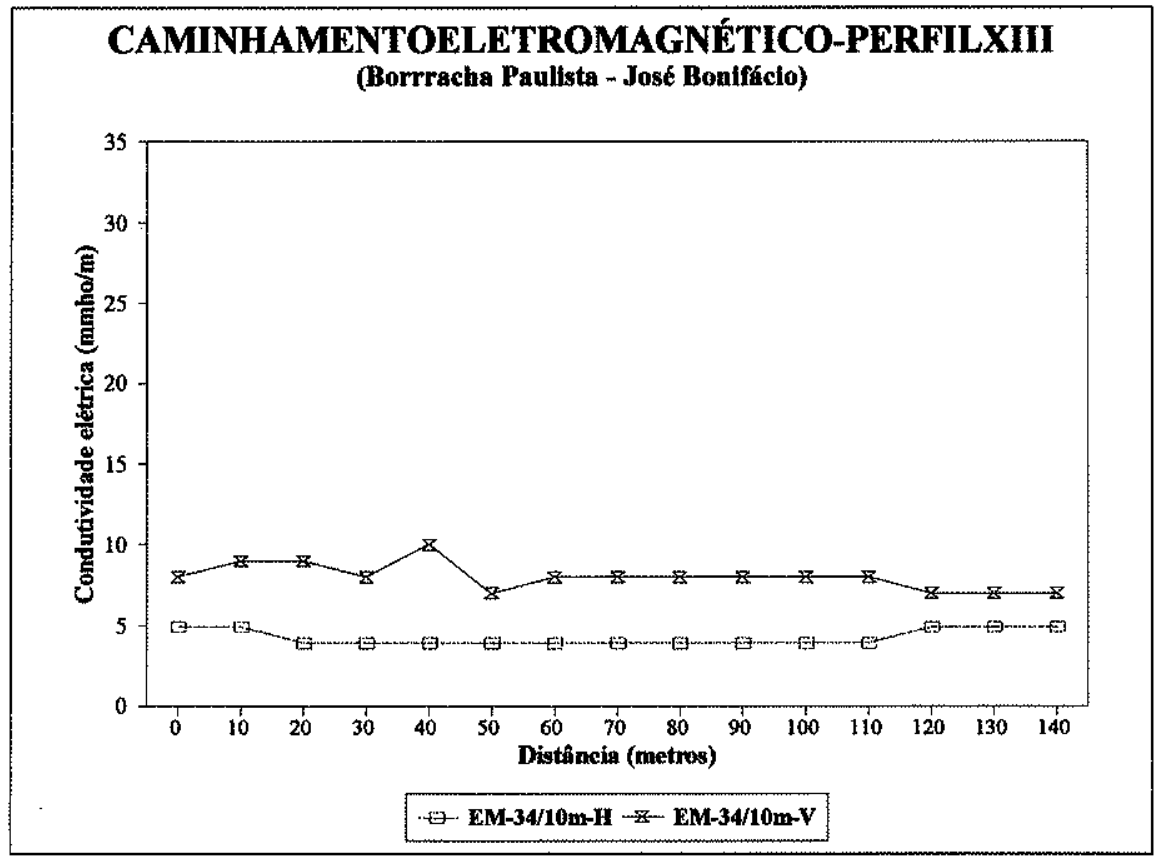

\section{CAMINHAMENTO ELETROMAGNÉTICO-PERFILXIV (Borracha Paulista - José Bonifácto)}

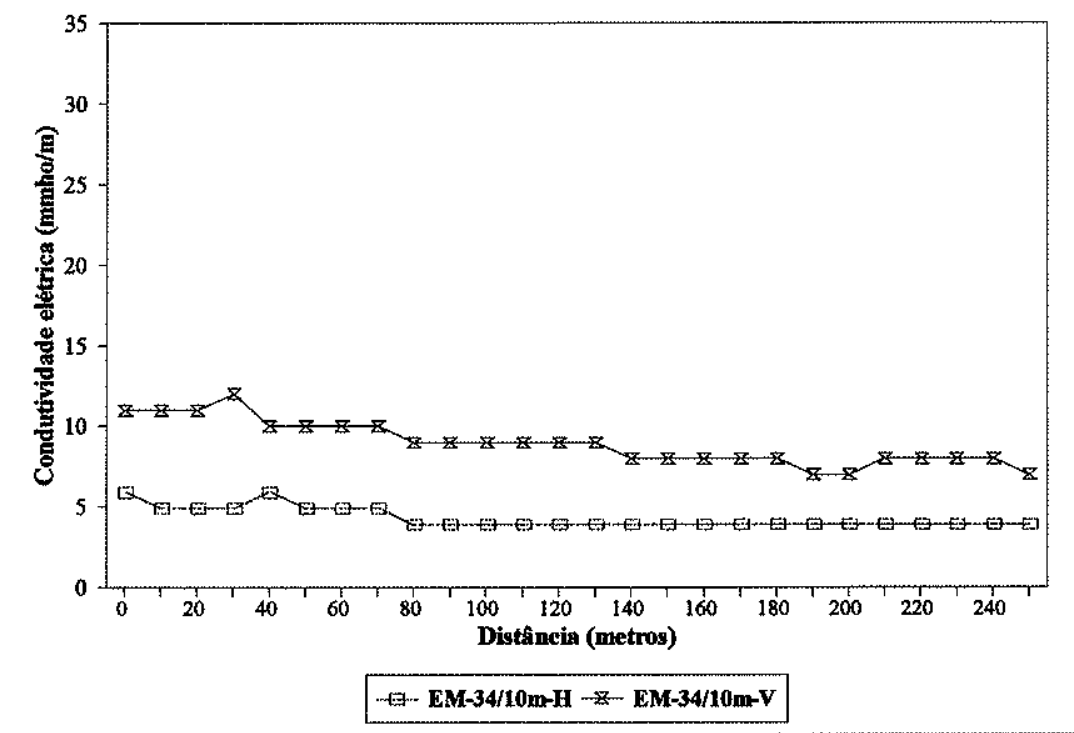

\section{CAMINHAMENTO ELETROMAGNÉTICO-PERFIL XV} (Borracha Paulista - José Boniffacio)

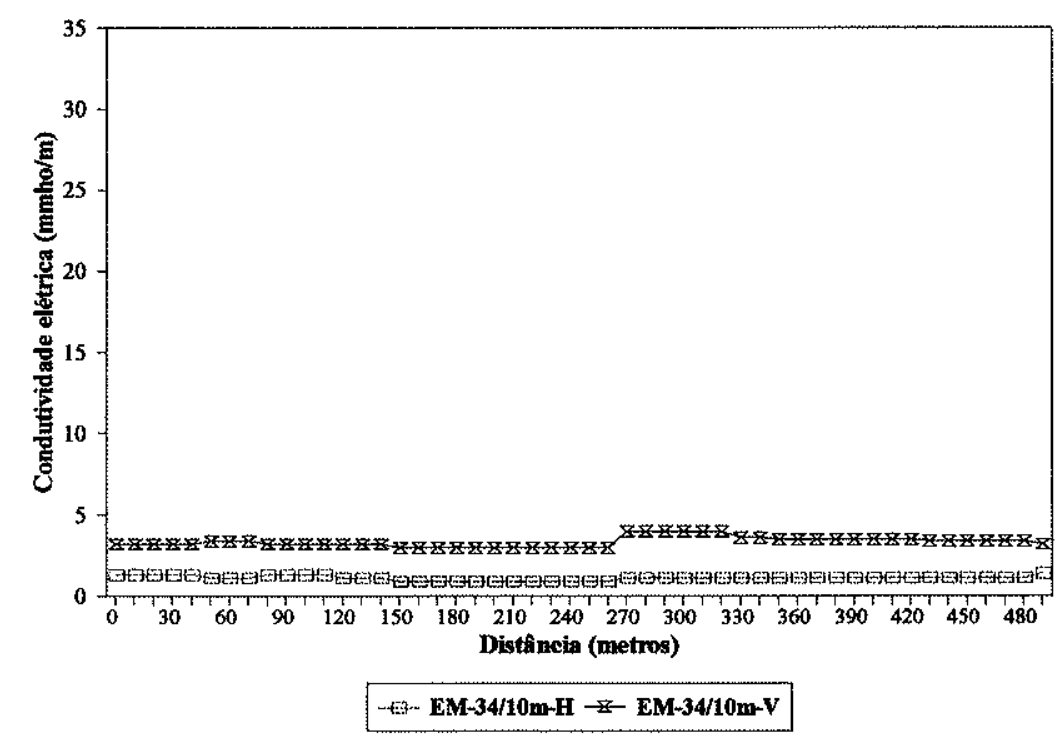



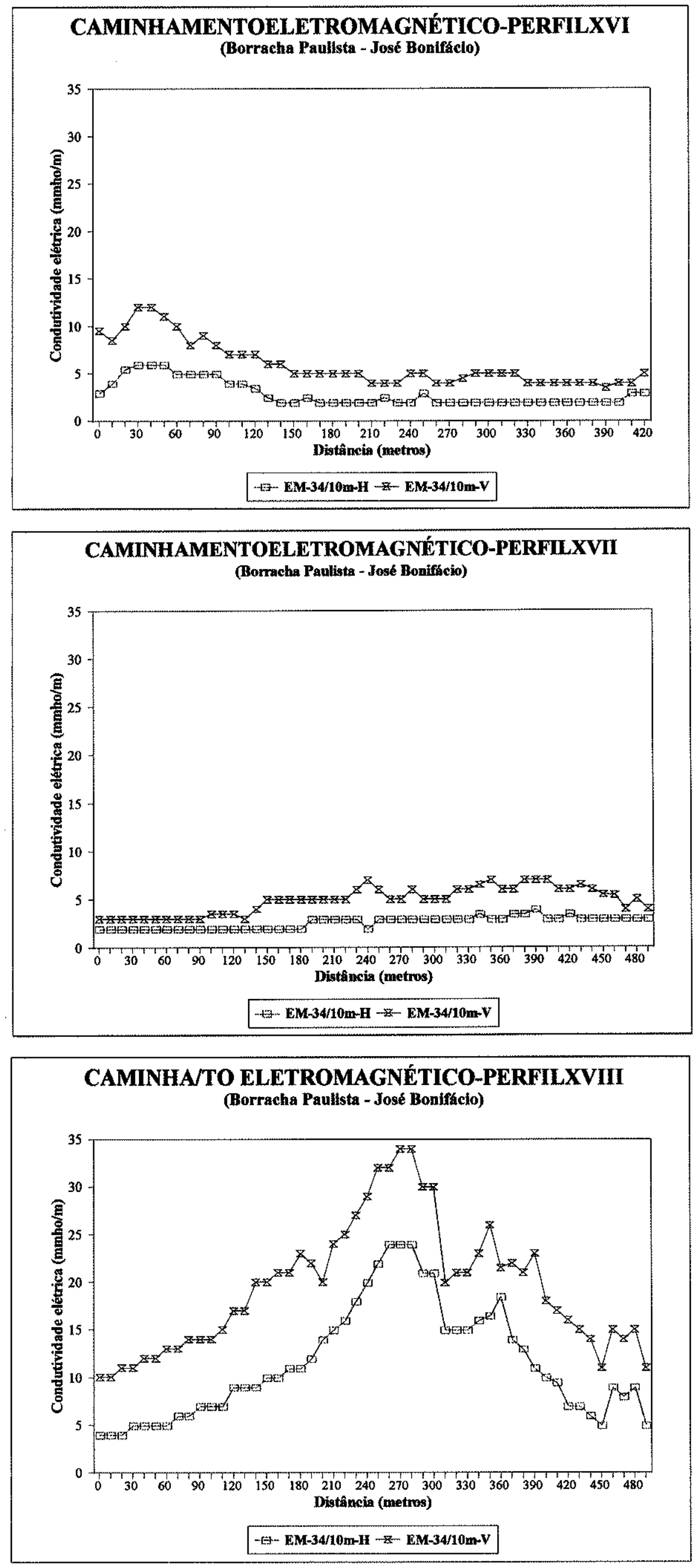


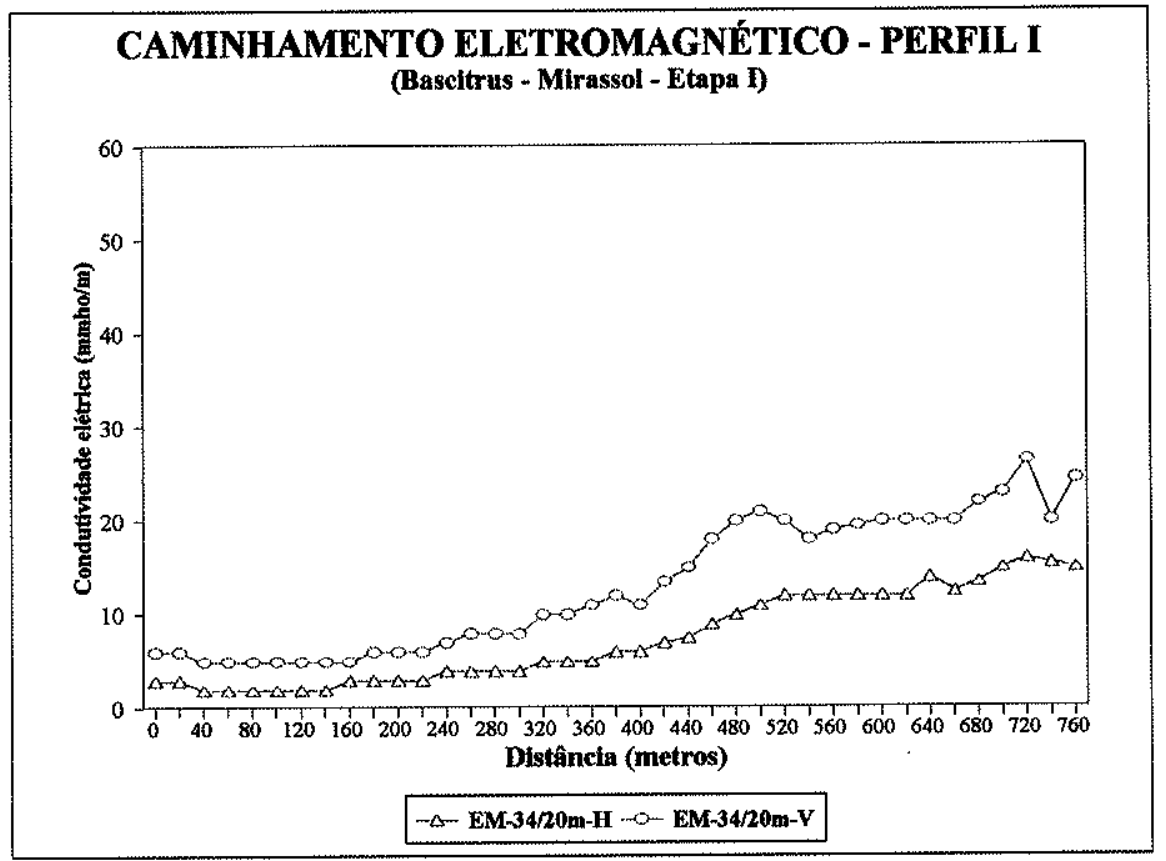

\section{CAMINHAMENTO ELETROMAGNÉTICO-PERFIL II}

(Baseltrus - Mirassol - Etapa I)

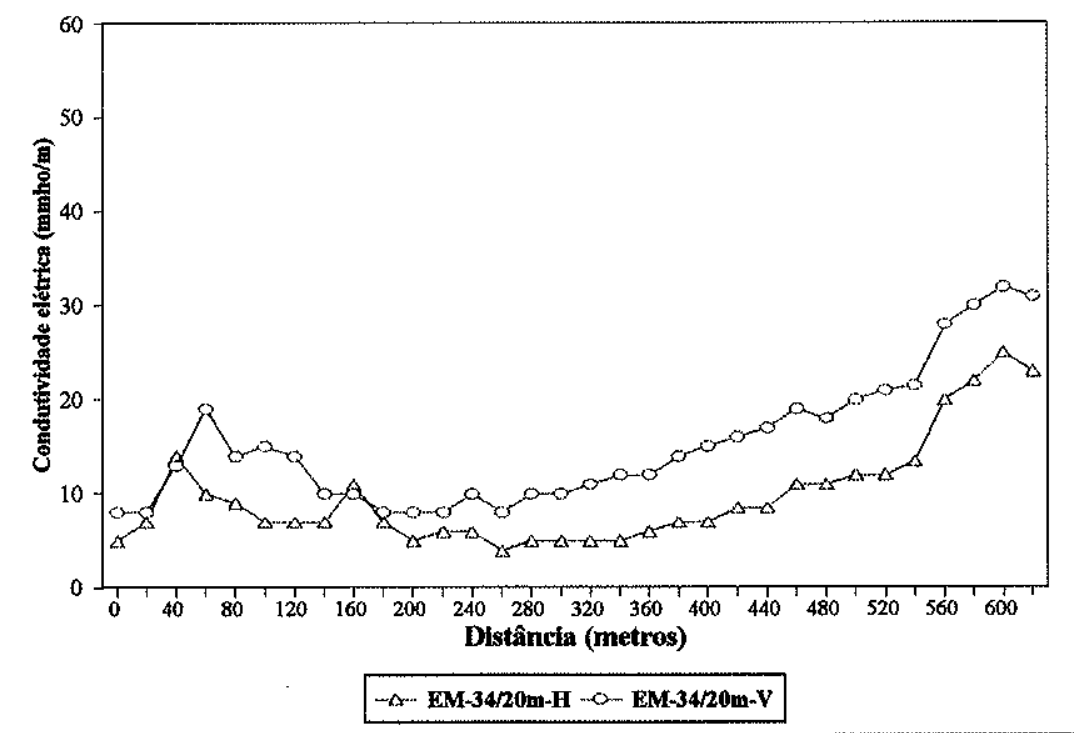

CAMINHAMENTO ELETROMAGNÉTICO-PERFILIII

(Bascitrus - Mirassol - Etapa I)

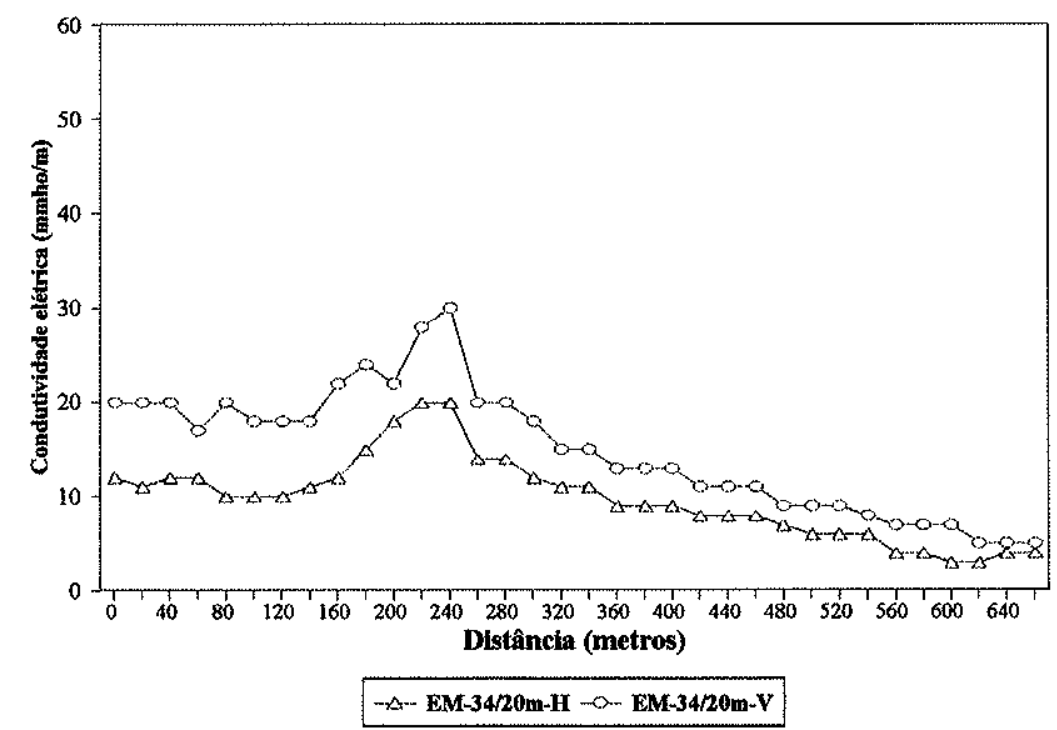



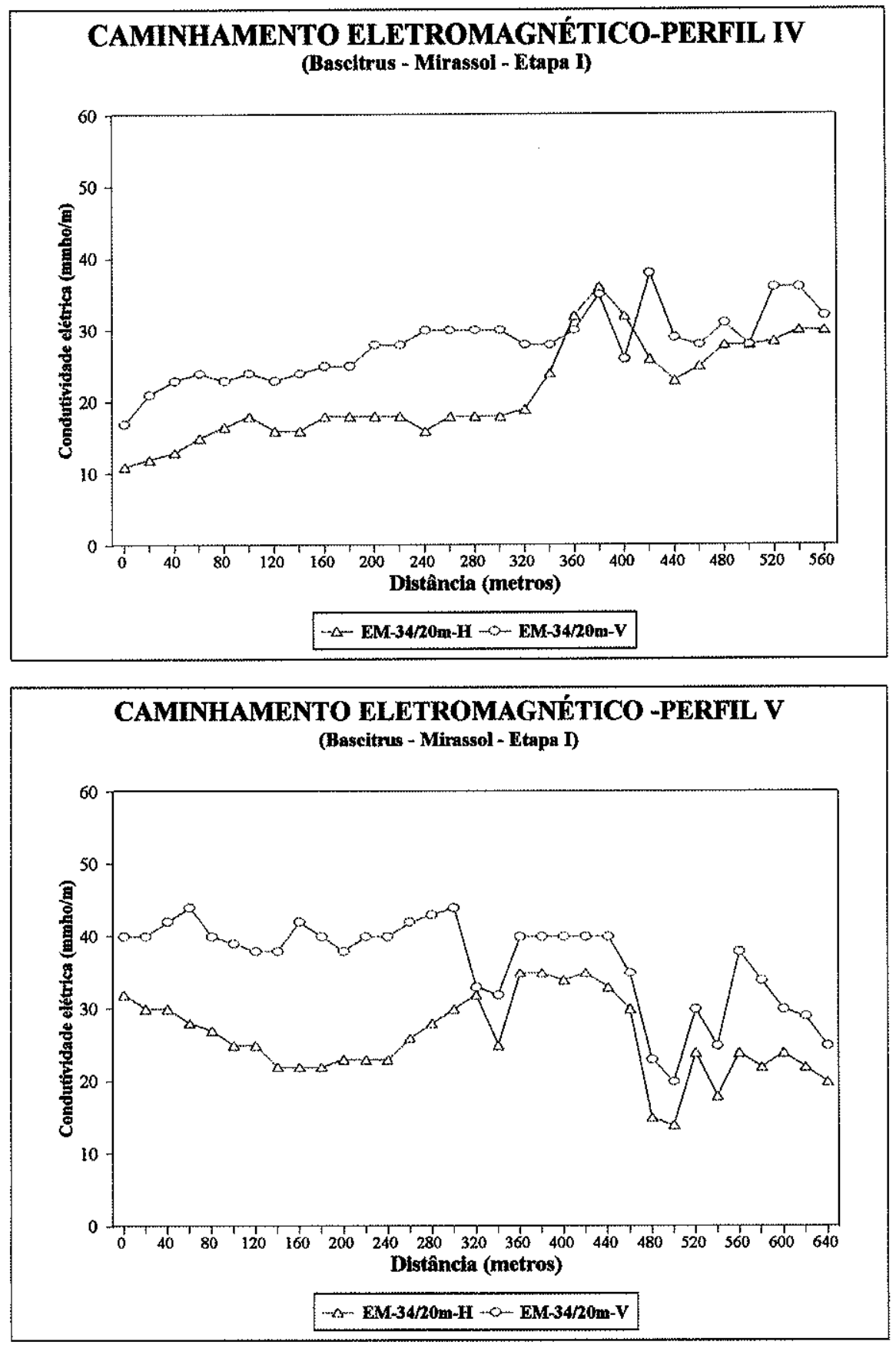

\section{CAMINHAMENTO ELETROMAGNÉTICO-PERFIL VI \\ (Bascitrus - Mirassol - Etapa I)}

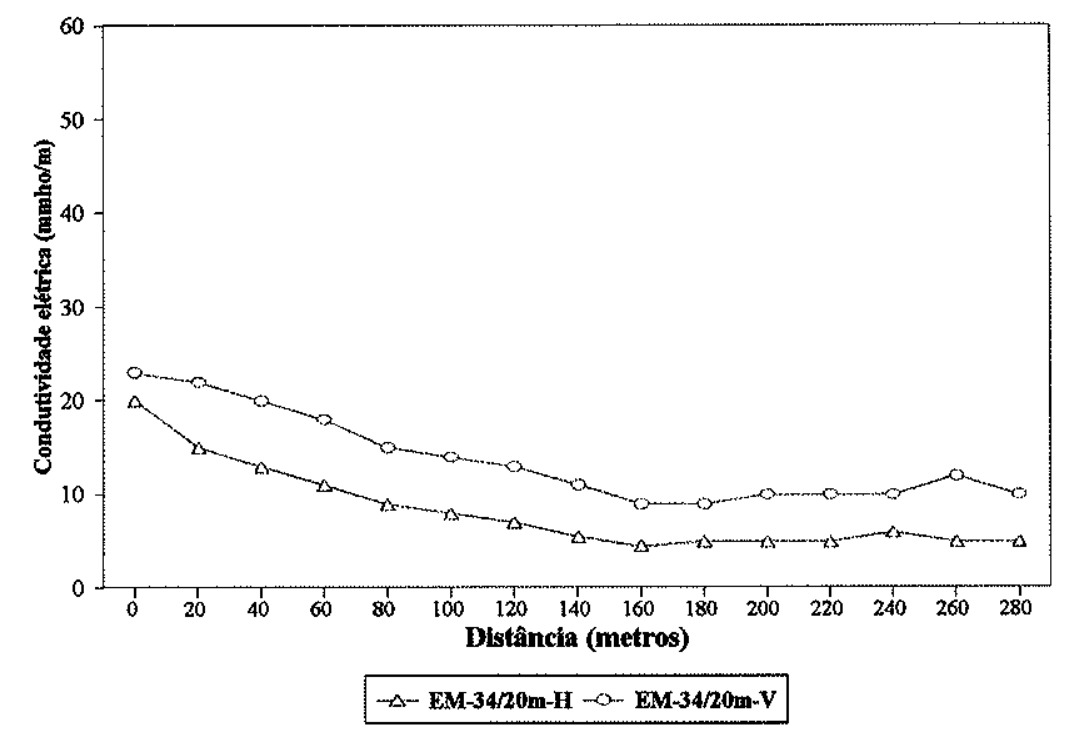




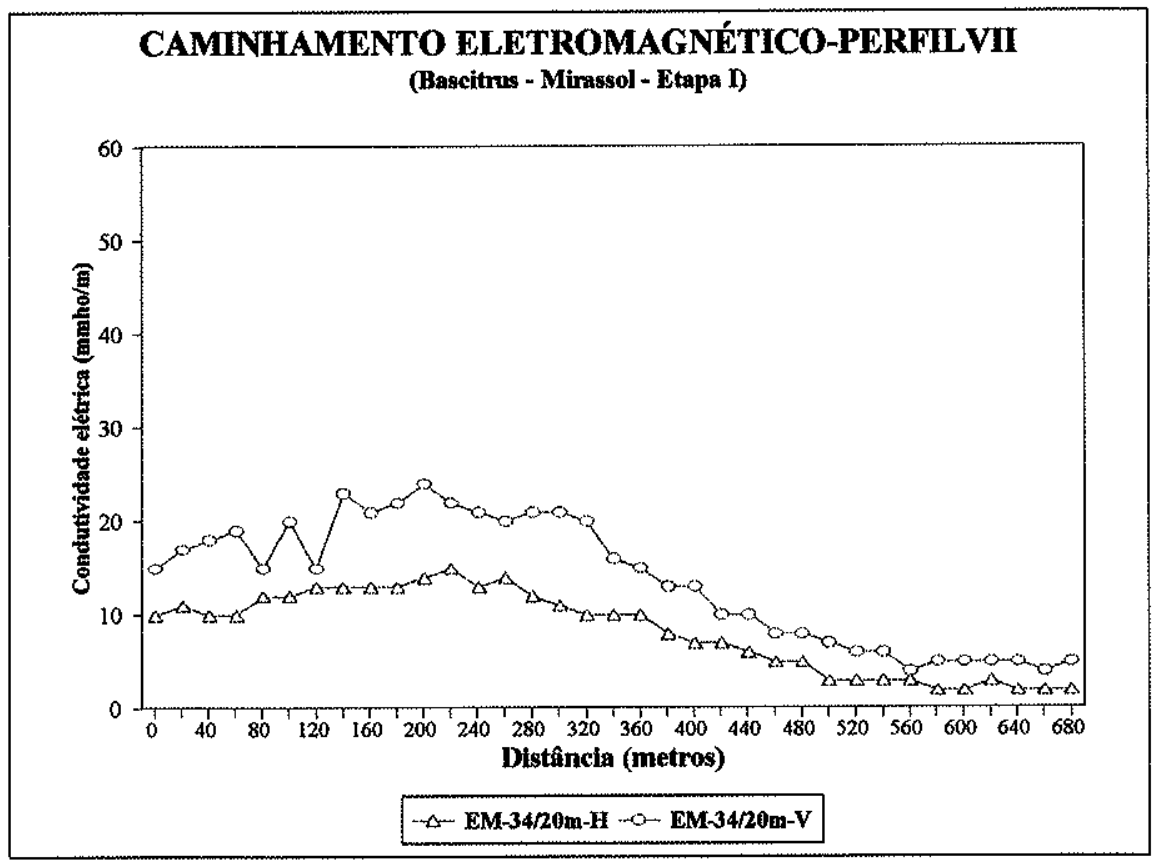

\section{CAMINHAMENTOELETROMAGNÉTICO-PERFILVIII (Bascitrus - Mirassol - Etapa I)}

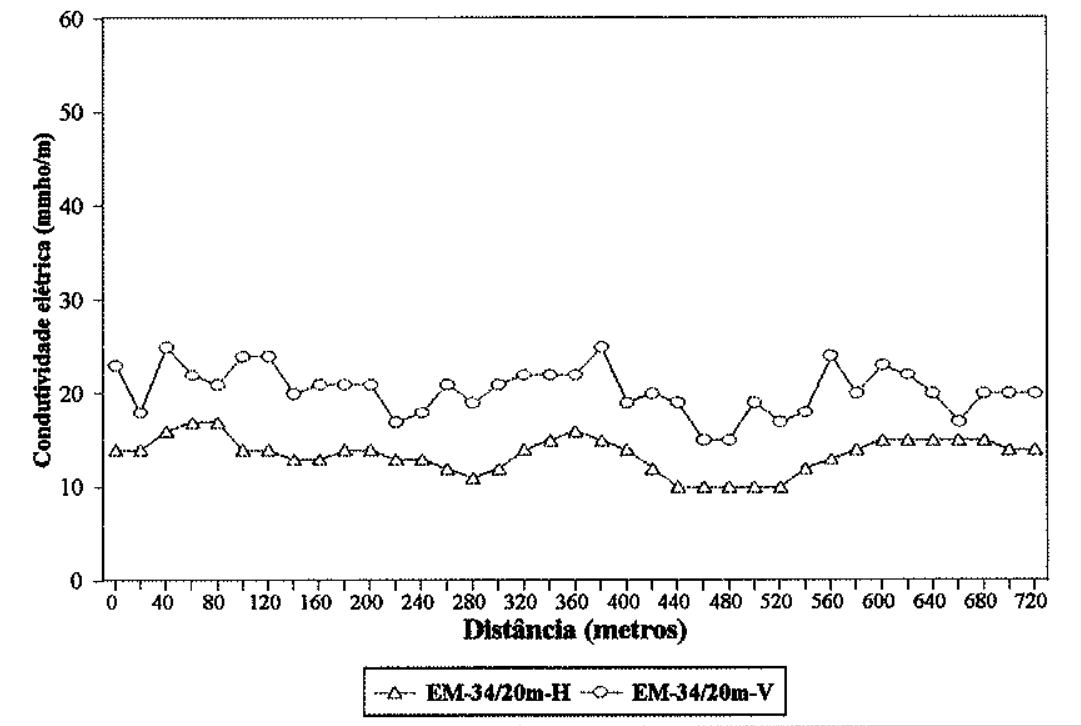

\section{CAMINHAMENTO ELETROMAGNÉTICO-PERFIL IX \\ (Bascitrus - Mirassol - Etapa I)}

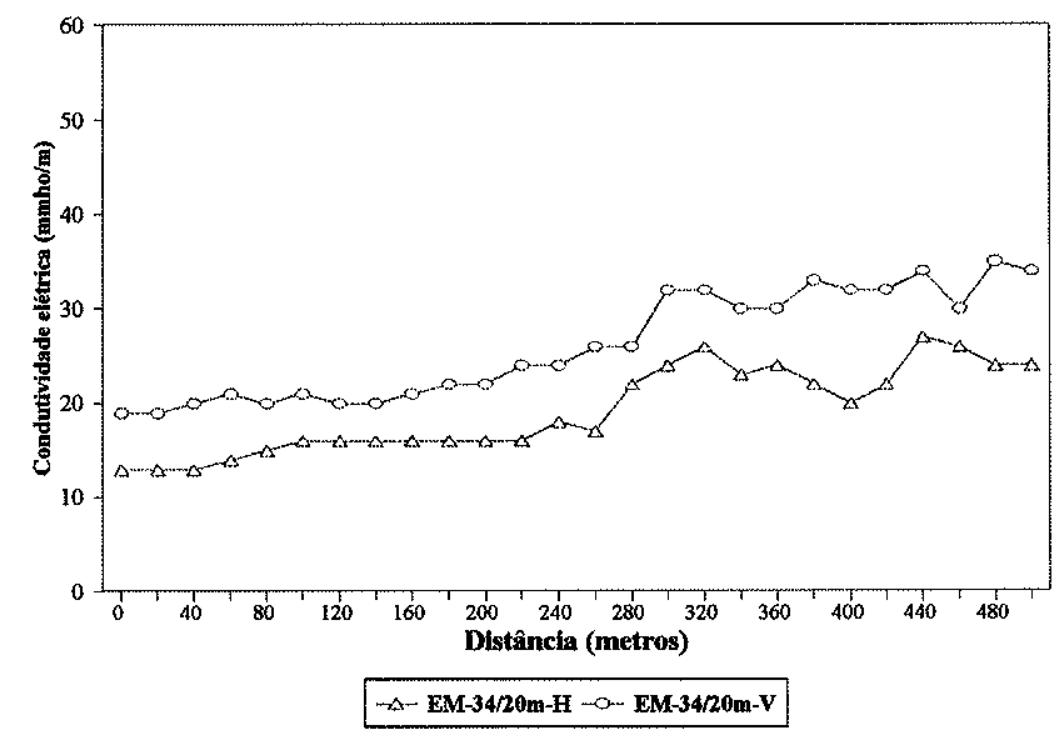




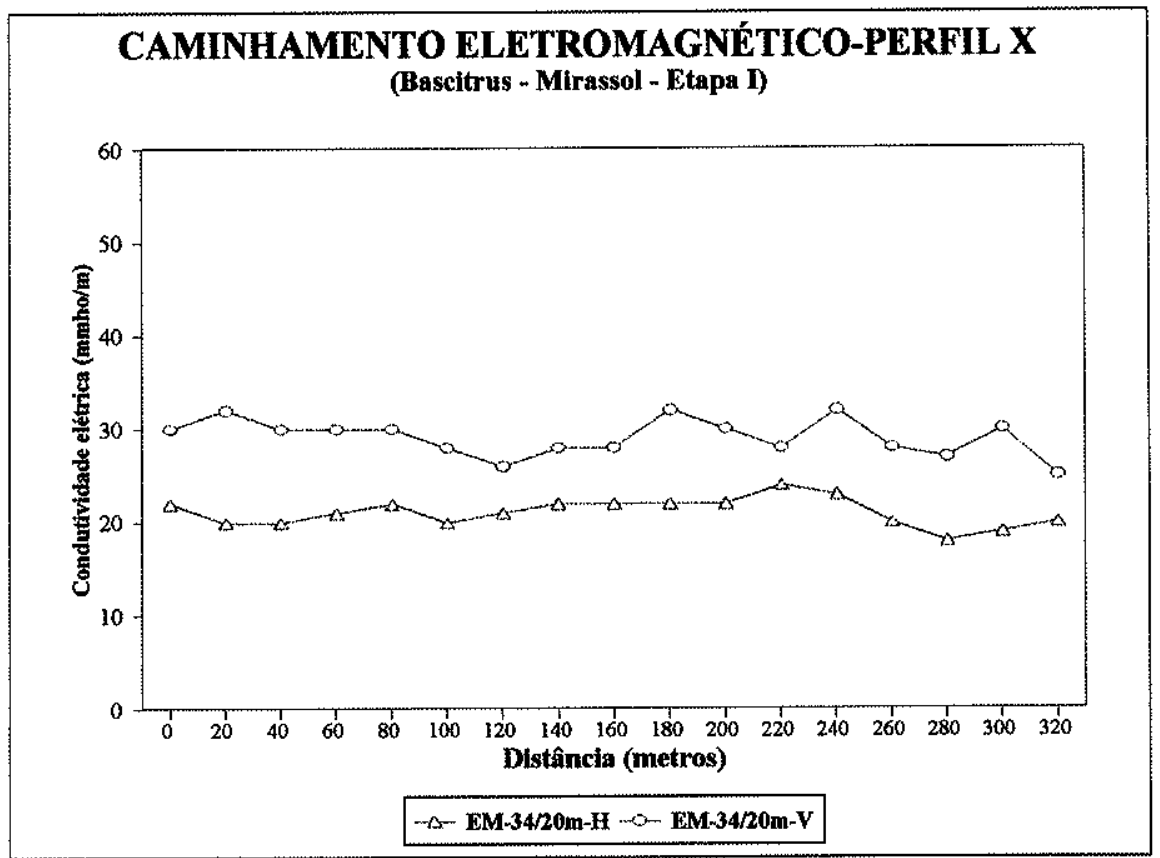

\section{CAMINHAMENTO ELETROMAGNÉTICO-PERFIL XI}

(Bascitrus - Mirassol - Etapa I)

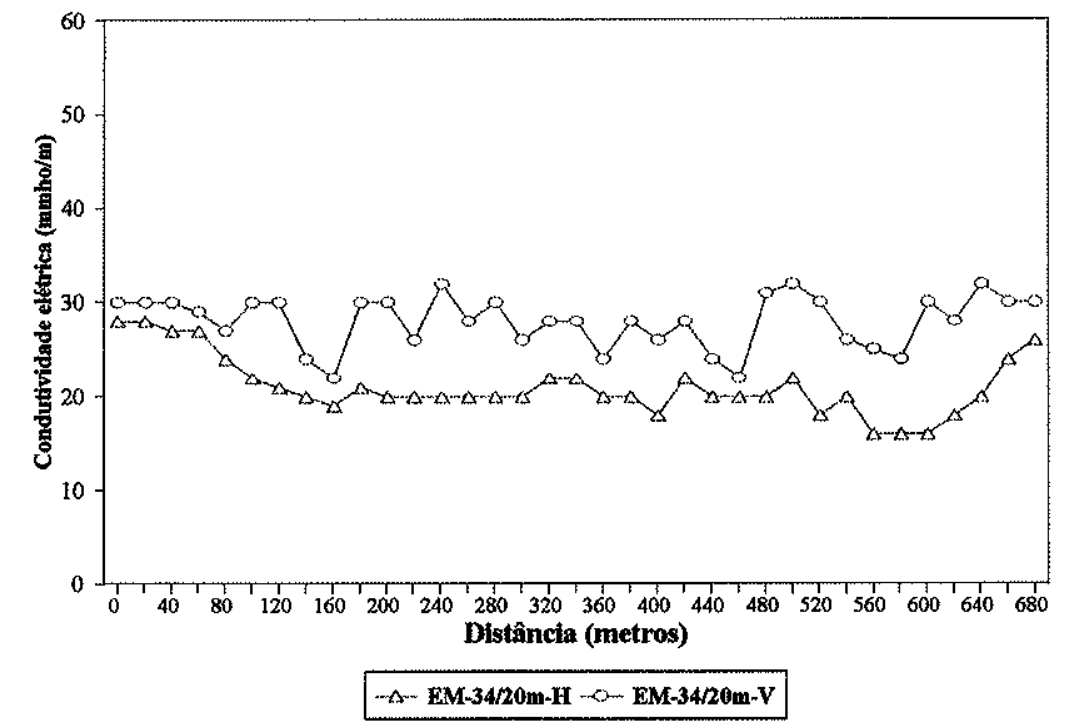

\section{CAMINHAMENTO ELETROMAGNÉTICO-PERFILXII} (Bascitrus - Mirassol - Etapa I)

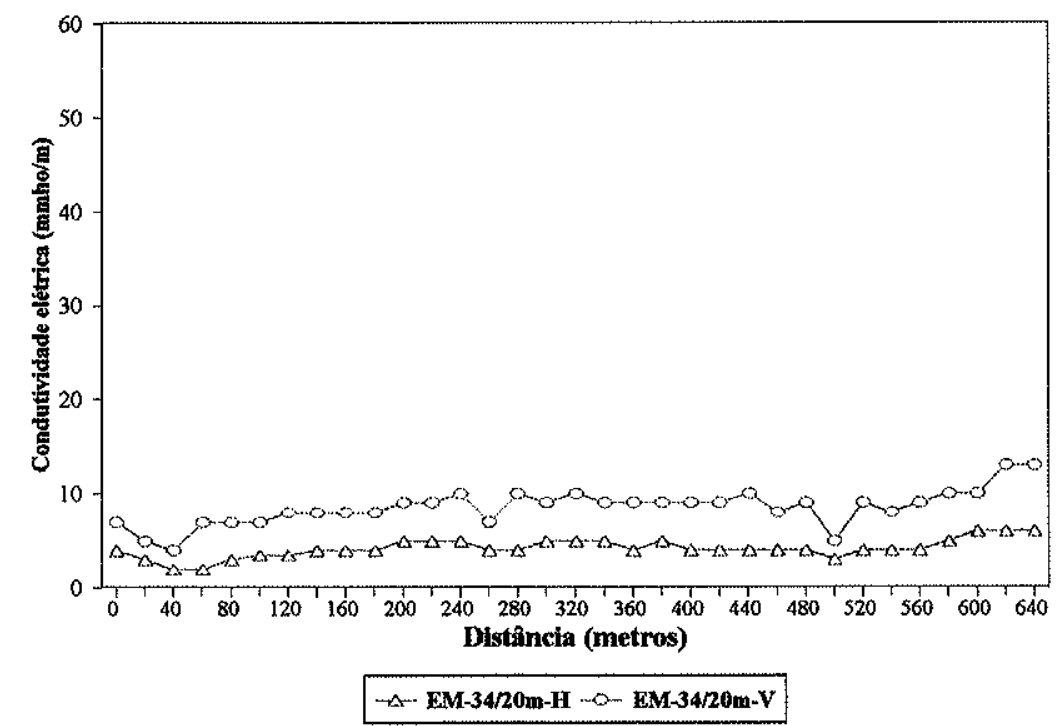



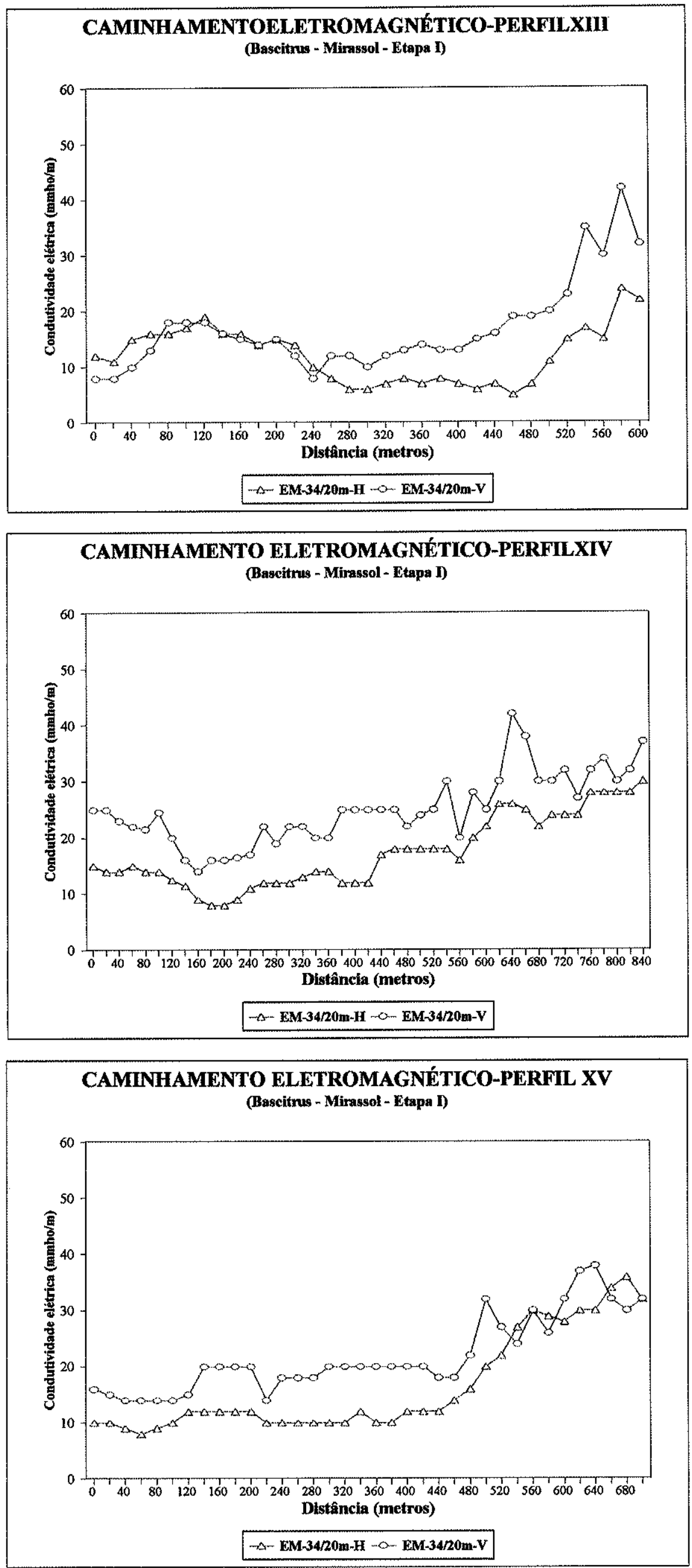


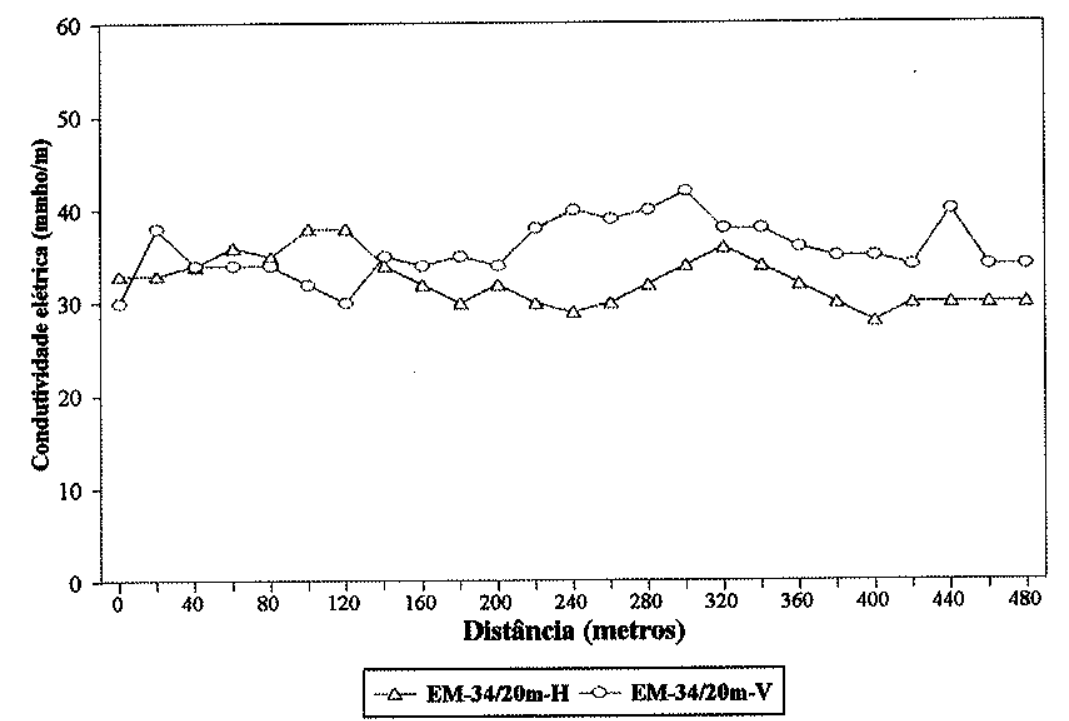

\section{CAMINHAMENTOELETROMAGNÉTICO-PERFILXVII \\ (Baseitrus - Mirassol - Etapa II)}

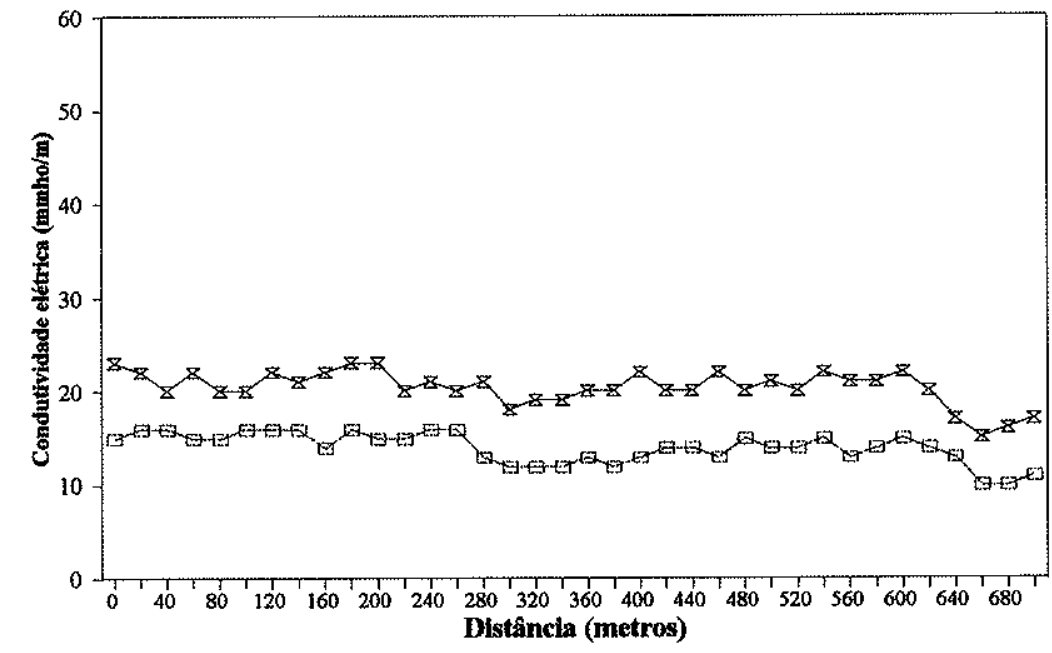

EH- EM-34/10m-H Z EM-34/10m-V

\section{CAMINHAMENTOELETROMAGNÉTICO-PERFILXVII}

(Baseitrus - Mirassol - Etapa II)

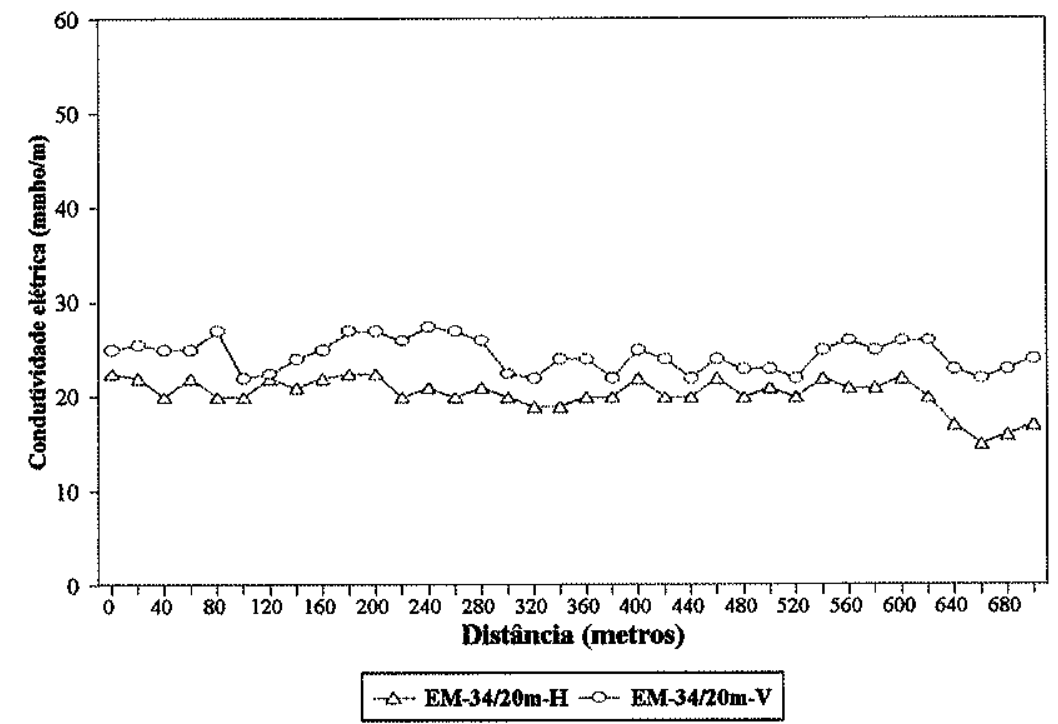



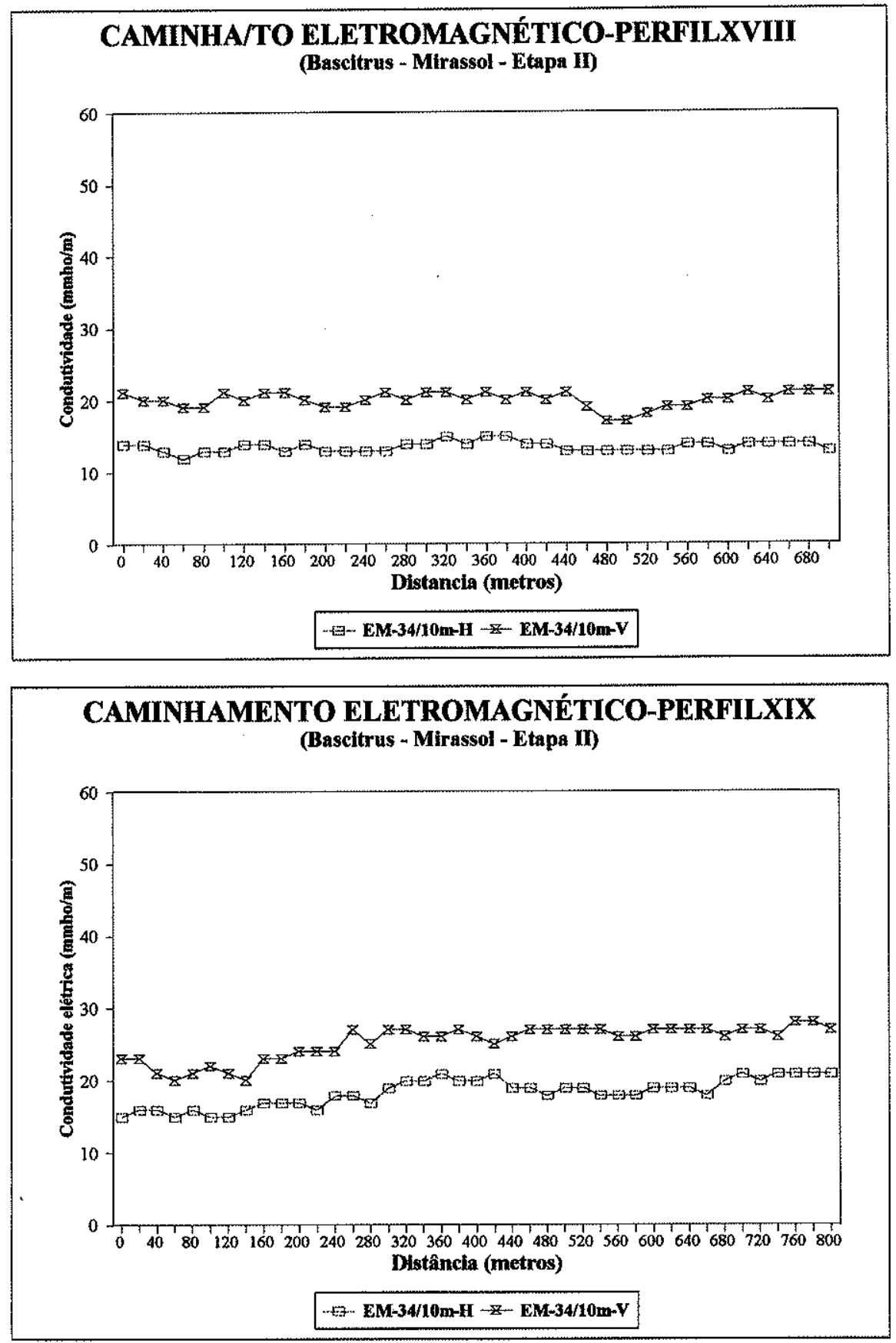

\section{CAMINHAMENTO ELETROMAGNÉTICO -PERFILXX (Bascitrus - Mirassol - Etapa II)}

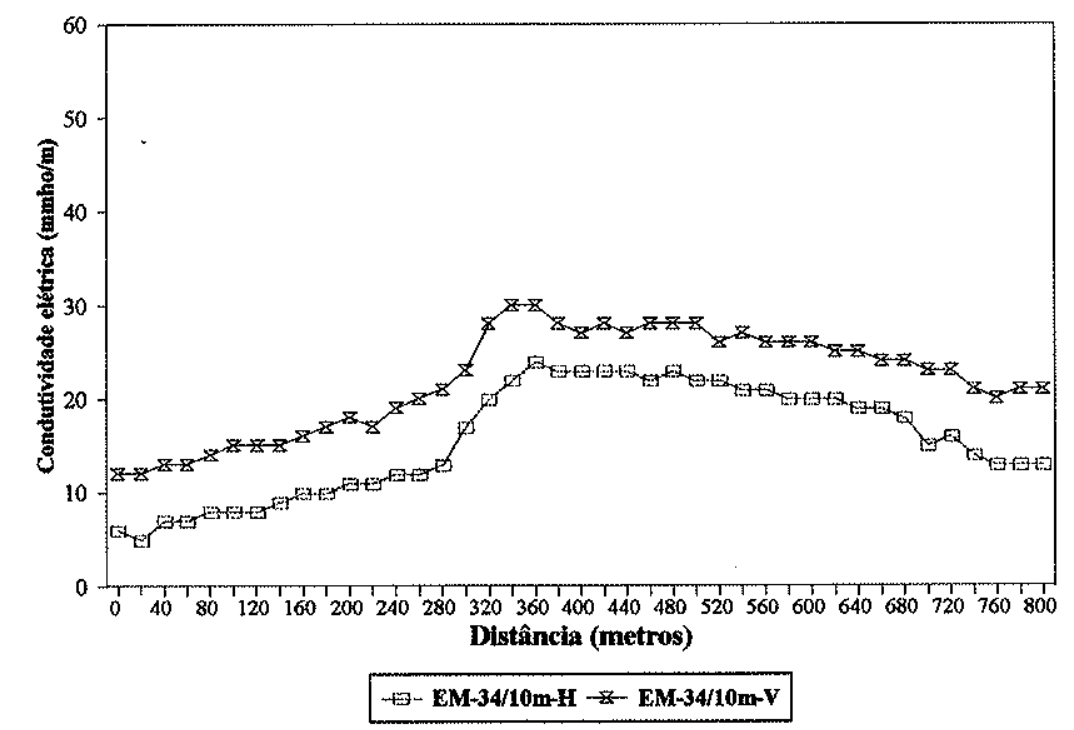




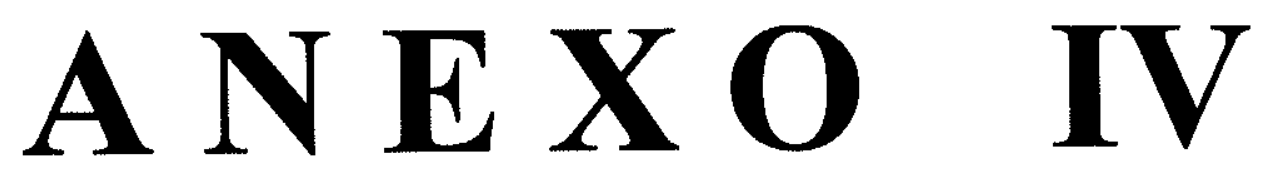

Mapas de Isocondutividade e Modelos Tridimensionais das Medidas de Condutividade Elétrica Aparente (CEM) 


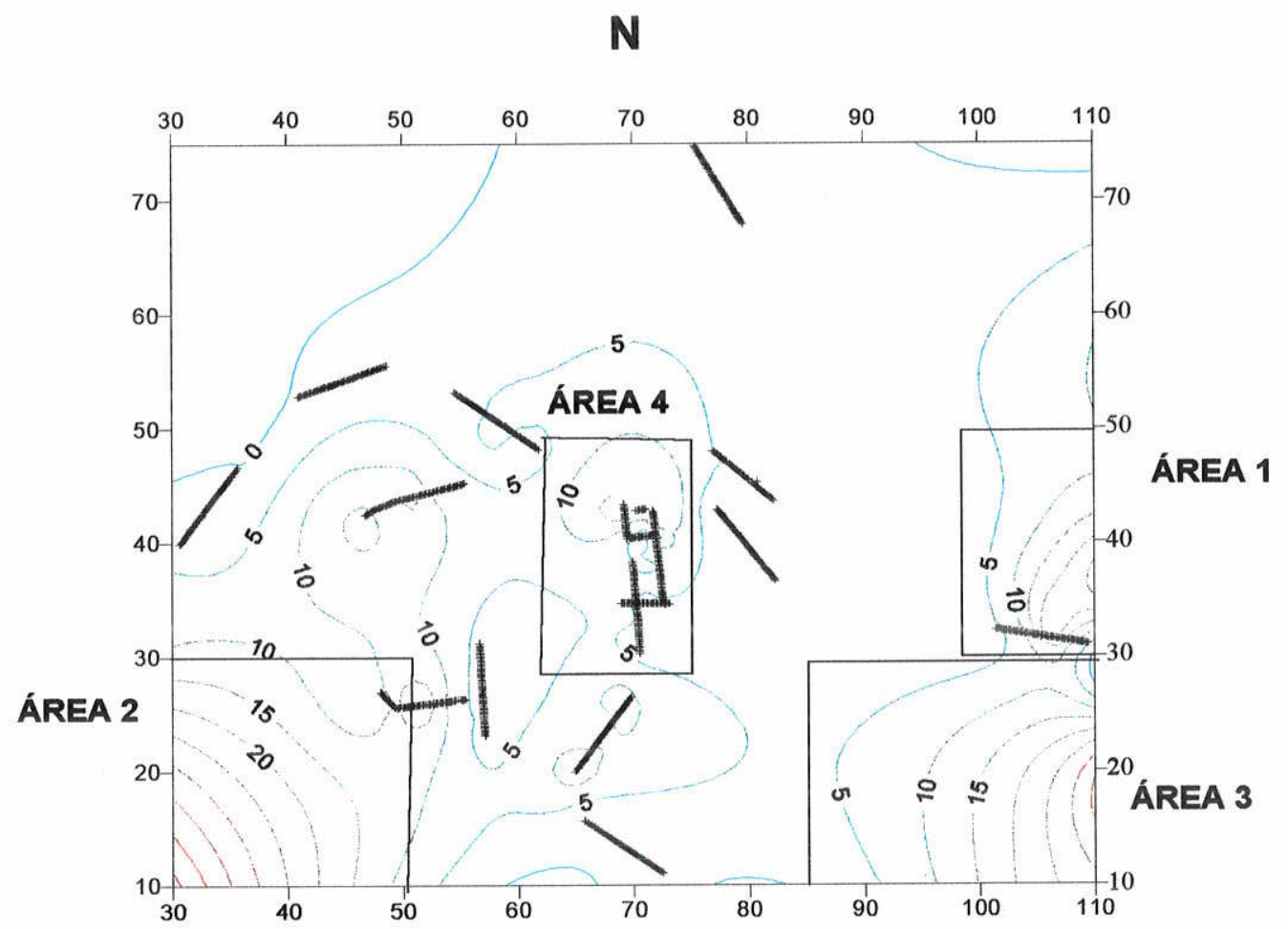

MAPA DE ISOCONDUTIVIDADE - EM-34/10m-H - BORRACHA PAULISTA (Valores em $\mathbf{m m h o} / \mathrm{m}$ )

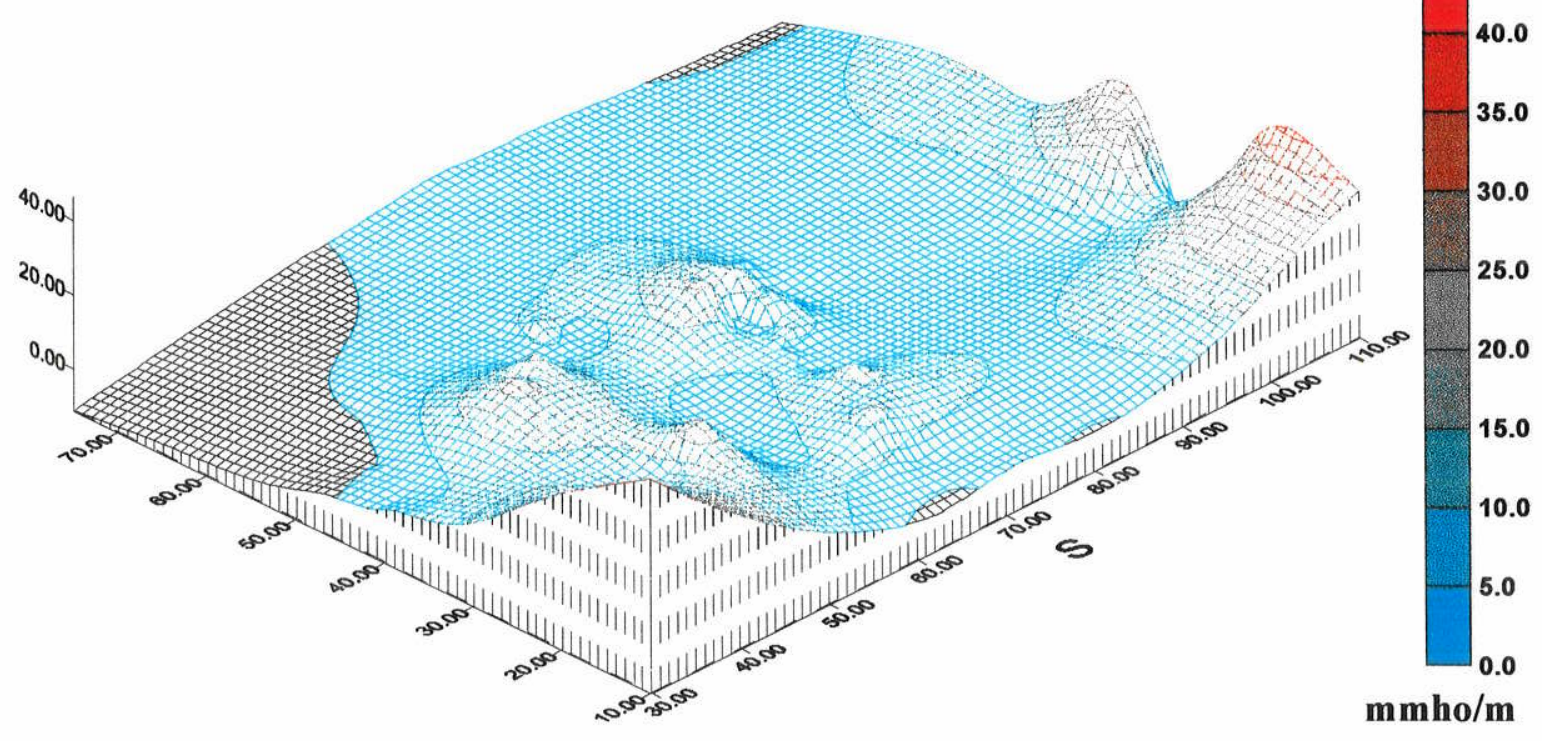

MODELO TRIDIMENSIONAL DAS MEDIDAS DE CONDUTIVIDADE ELÉTRICA EM-34/10m-H - BORRACHA PAULISTA 


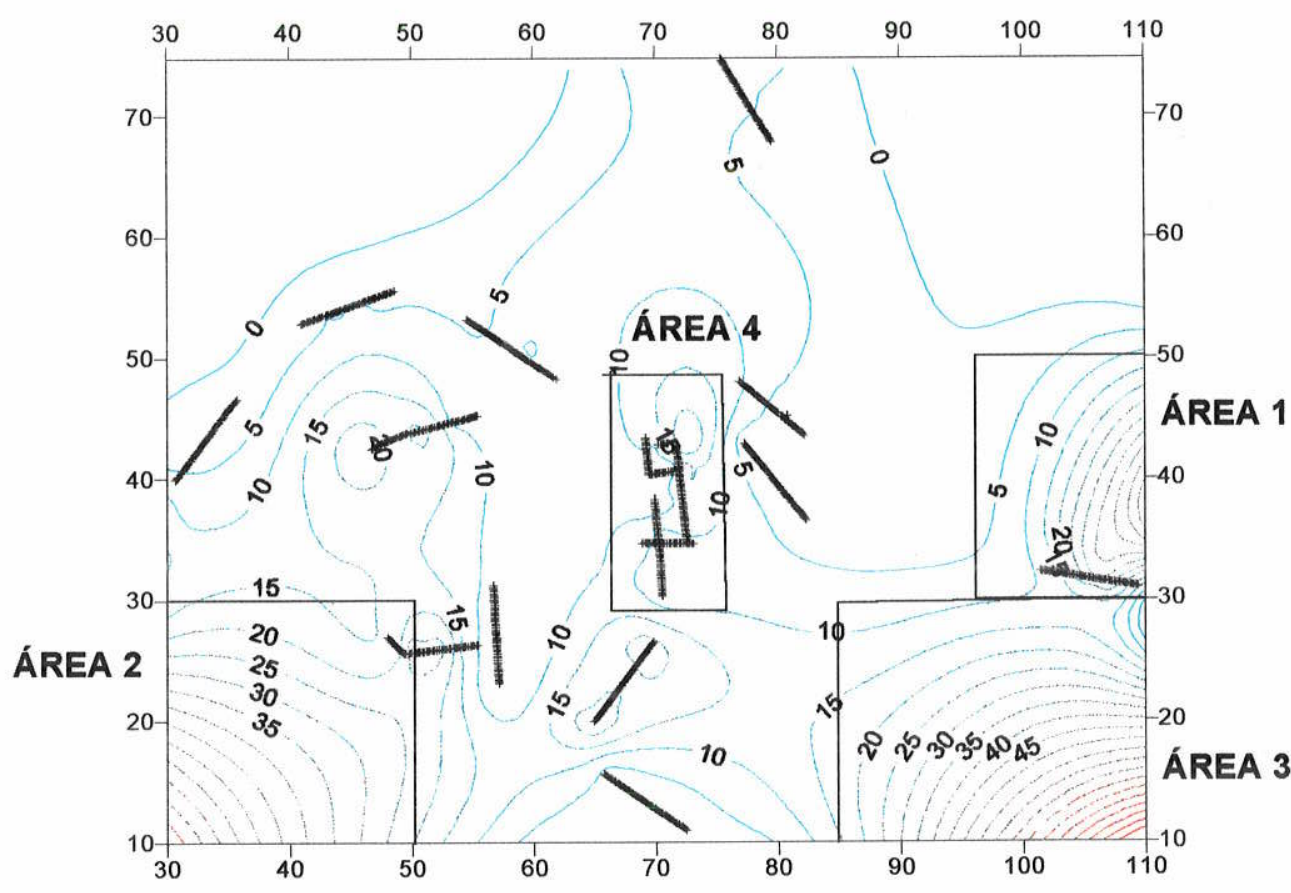

MAPA DE ISOCONDUTIVIDADE - EM-34/10m-V - BORRACHA PAULISTA (Valores em $\mathrm{mm} \mathrm{ho/m}$ )

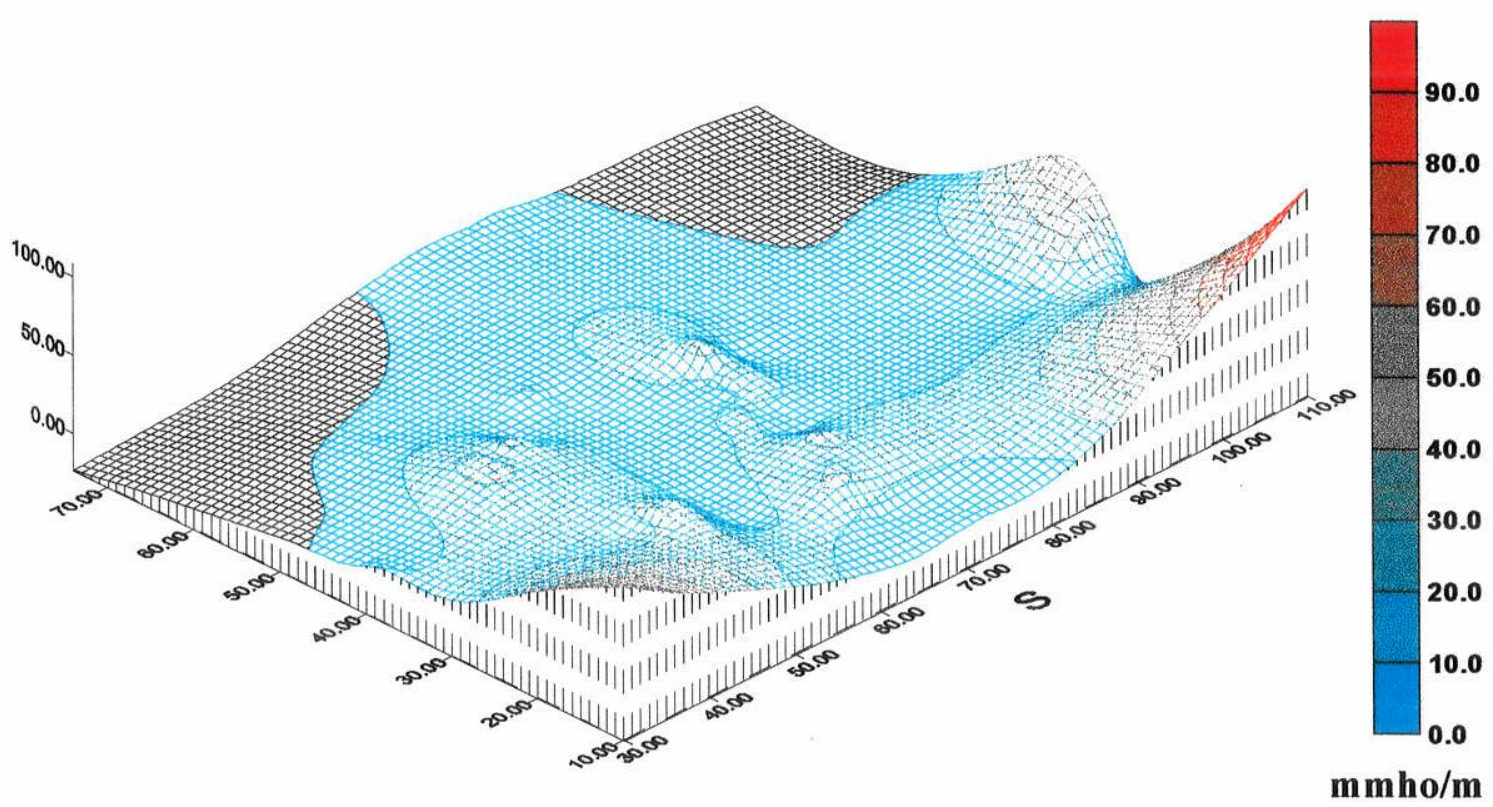

MODELO TRIDIMENSIONAL DAS MEDIDAS DE CONDUTIVIDADE ELÉTRICA EM-34/10m-V - BORRACHA PAULISTA 


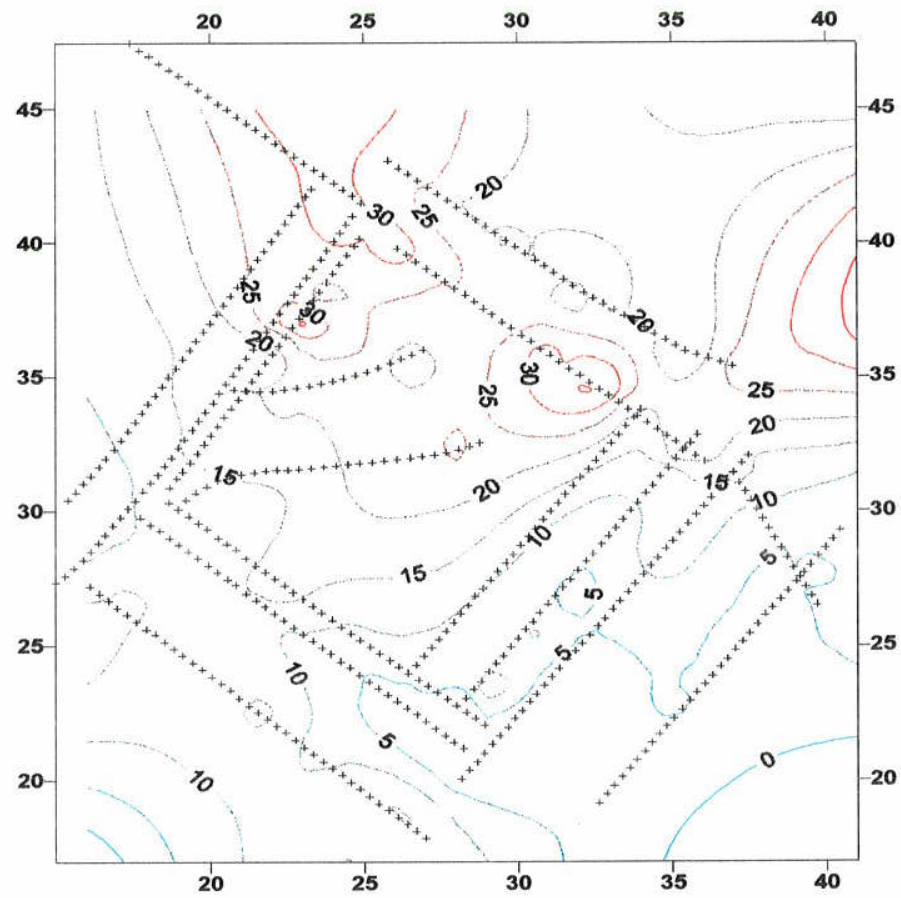

MAPA DE ISOCONDUTIVIDADE - EM-34/20m-H - BASCITRUS

(Valores em $\mathrm{mmho} / \mathrm{m}$ )

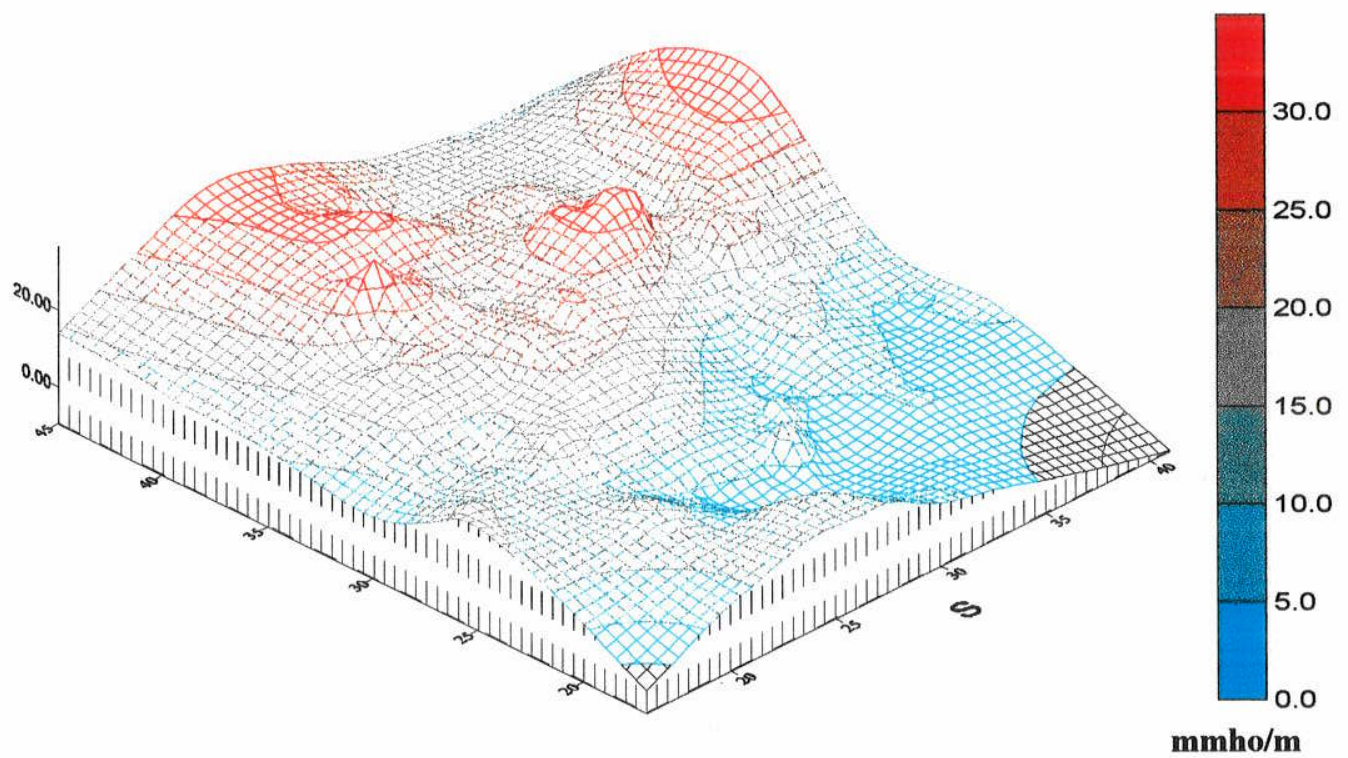

MODELO TRIDIMENSIONAL DAS MEDIDAS DE CONDUTIVIDADE ELÉTRICA EM-34/20m-H - BASCITRUS 


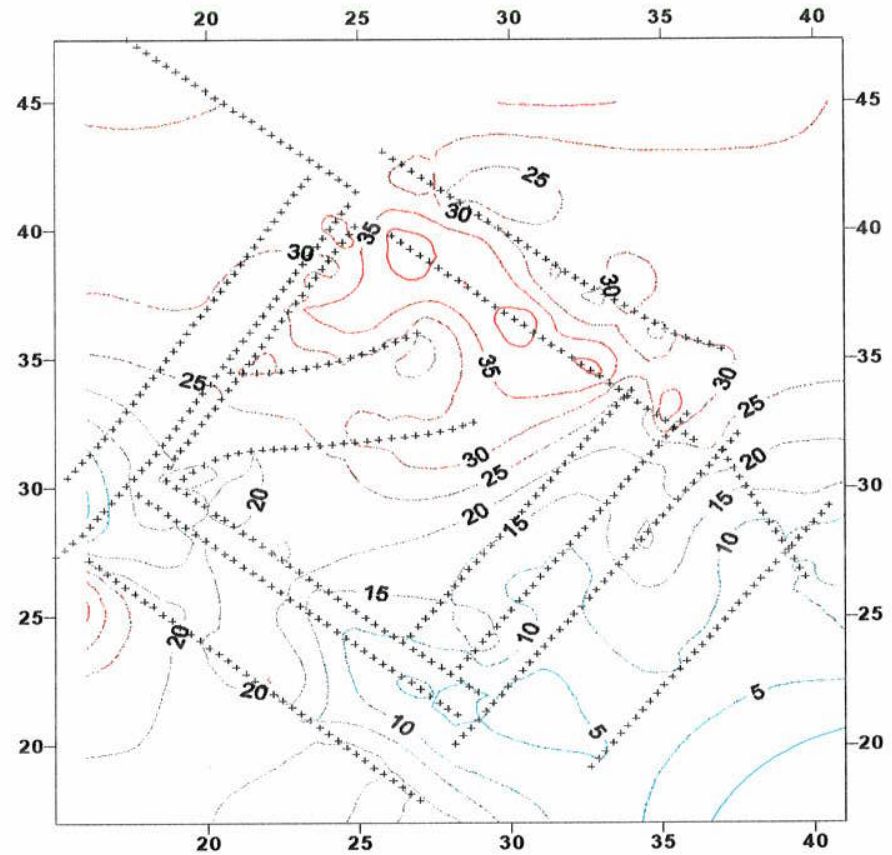

MAPA DE ISOCONDUTIVIDADE - EM-34/20m-V - BASCITRUS (Valores em $\mathbf{m m h o} / \mathrm{m}$ )

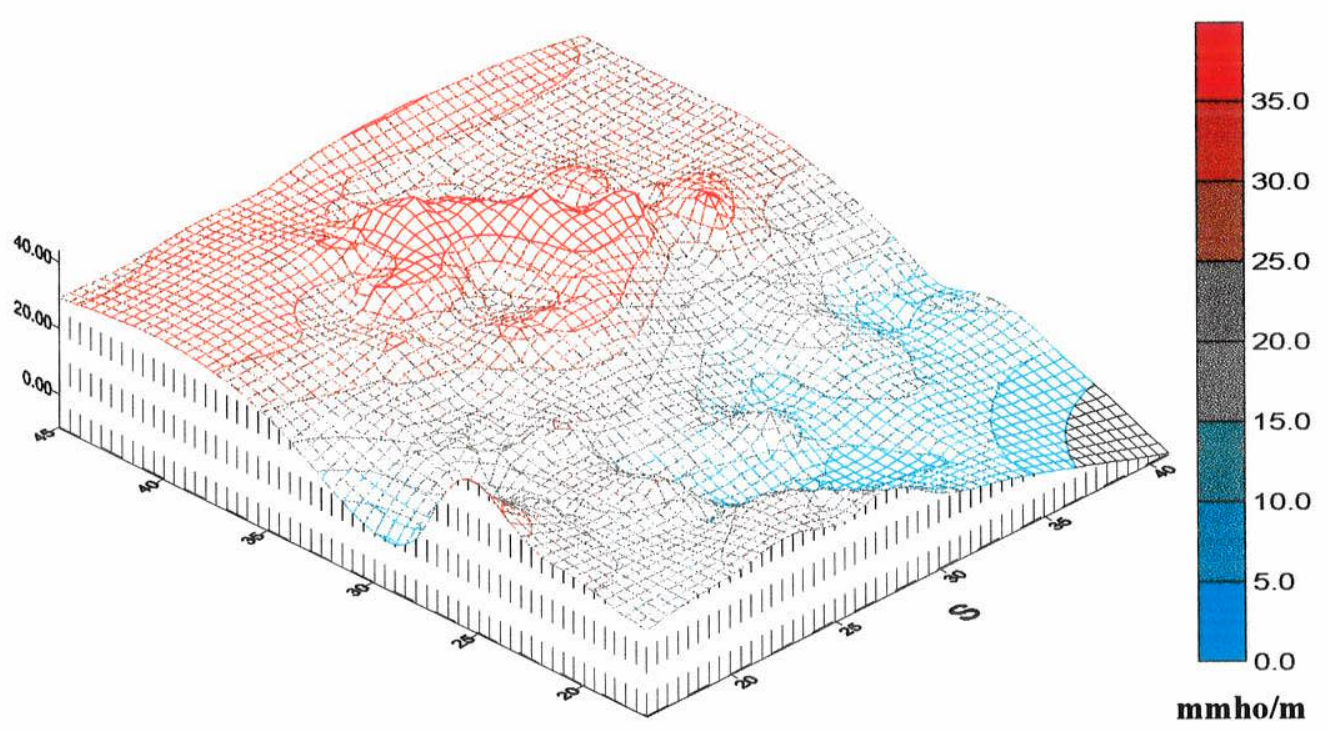

MODELO TRIDIMENSIONAL DAS MEDIDAS DE CONDUTIVIDADE ELÉTRICA EM-34/20m-V - BASCITRUS 


\section{$\mathbf{N}$}

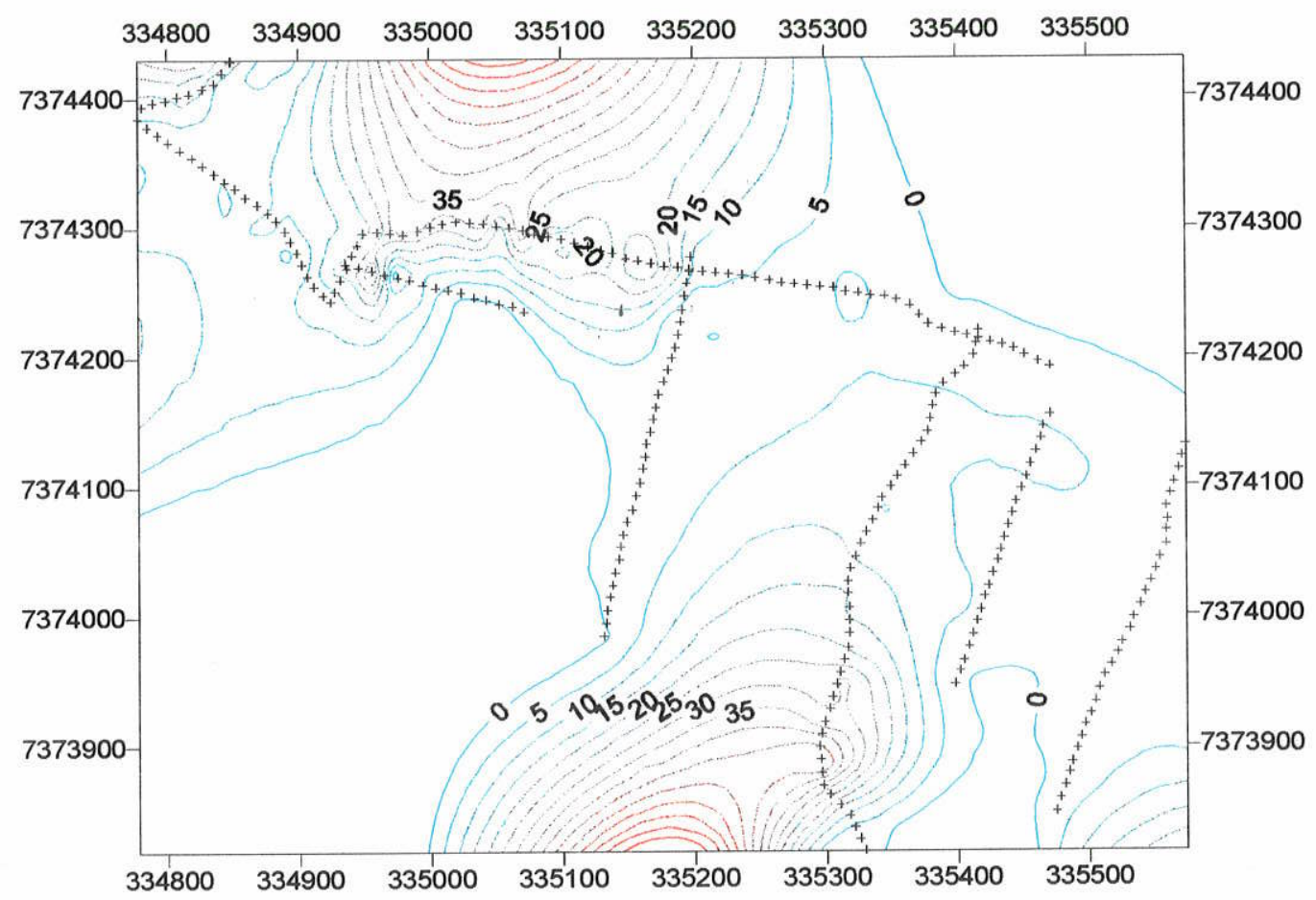

MAPA DE ISOCONDUTIVIDADE - EM-34/20m-H - LIXÃO DO ALVARENGA

(Valores em $\mathrm{mmho} / \mathrm{m}$ )
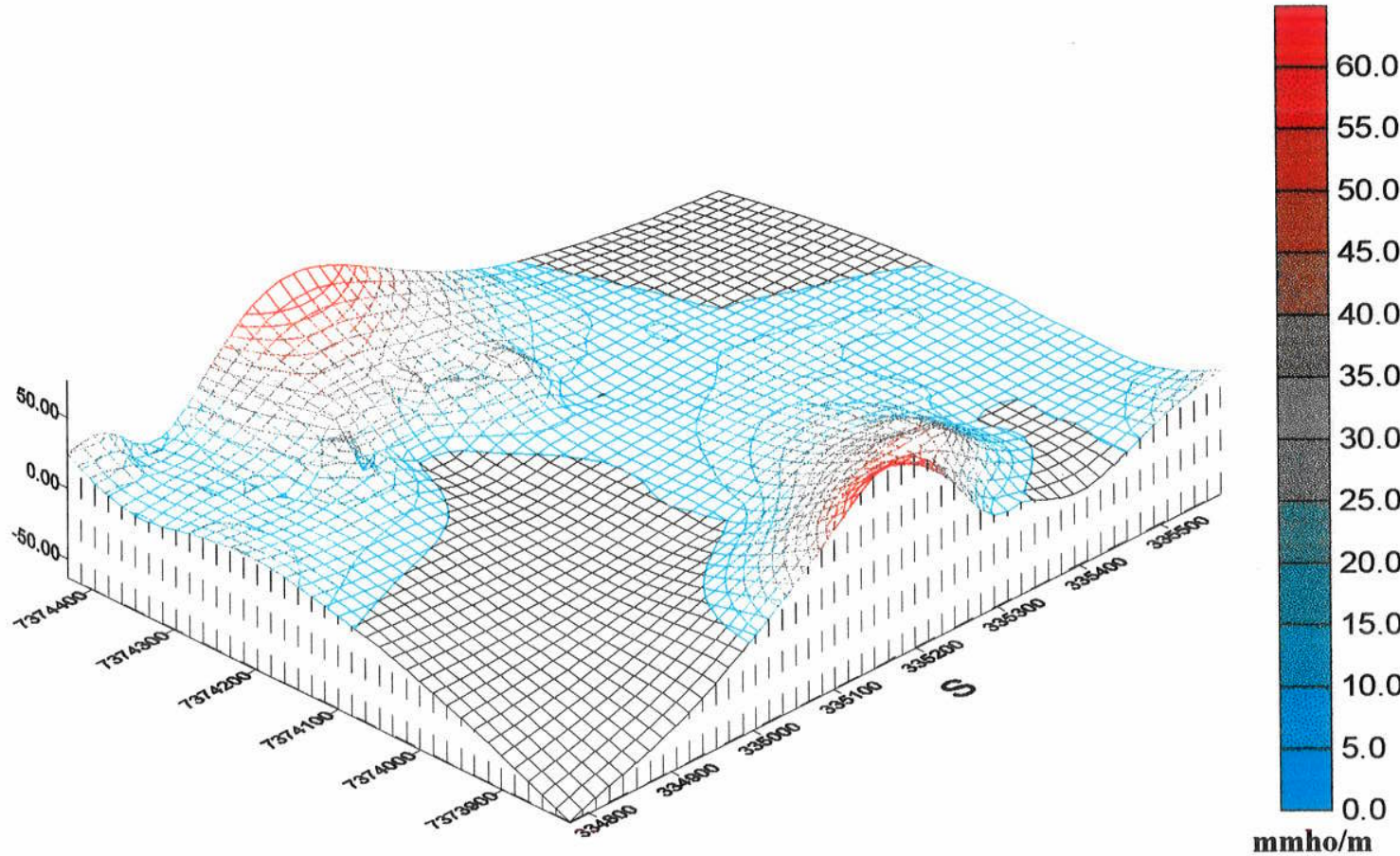

$\mathbf{m m h o} / \mathbf{m}$

MODELO TRIDIMENSIONAL DAS MEDIDAS DE CONDUTIVIDADE ELÉTRICA EM-34/20m-H - LIXÃO DO ALVARENGA 


\section{$\mathbf{N}$}

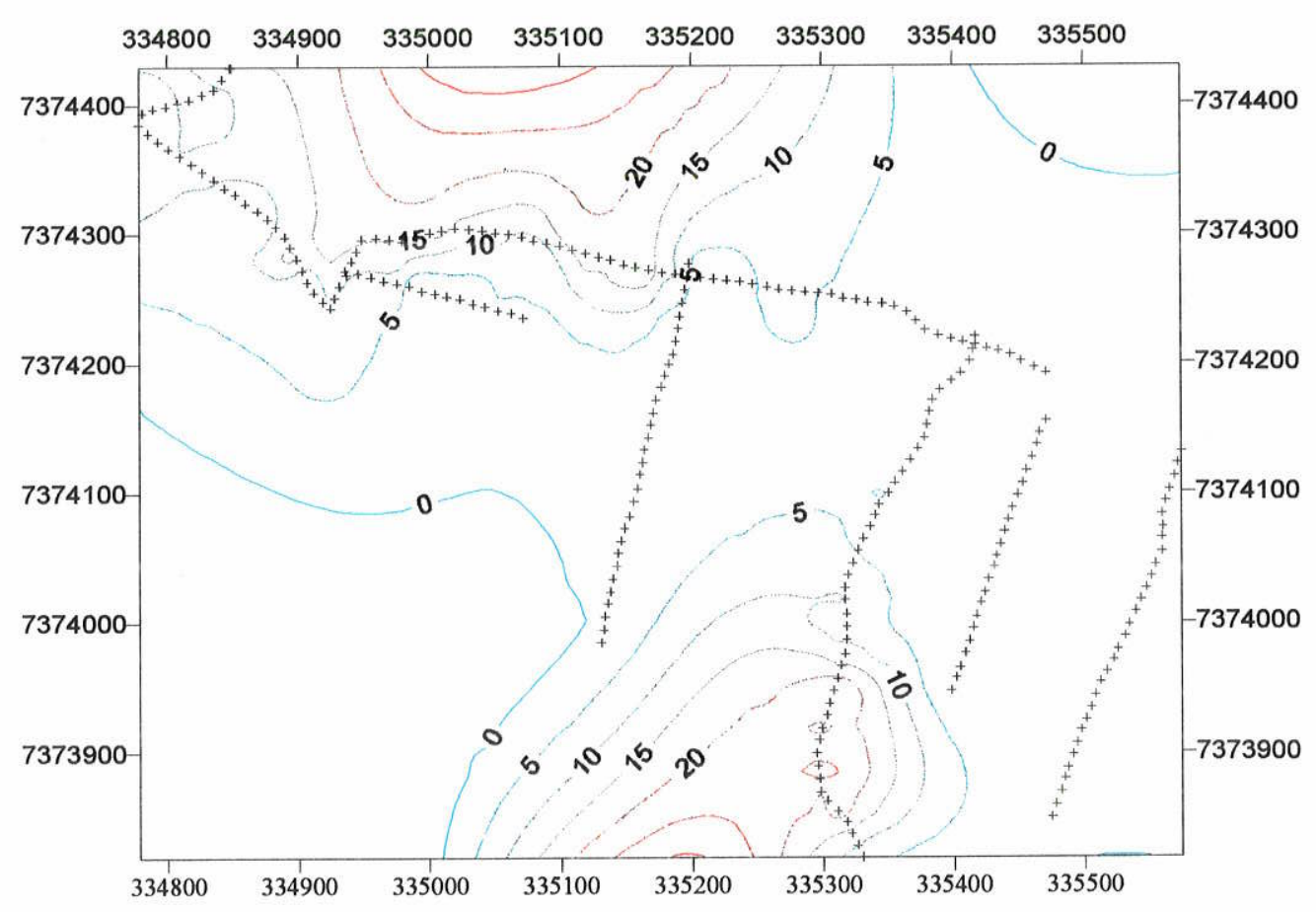

MAPA DE ISOCONDUTIVIDADE - EM-34/20m-V - LIXÃO DO ALVARENGA

(Valores em $\mathrm{mmho} / \mathrm{m}$ )
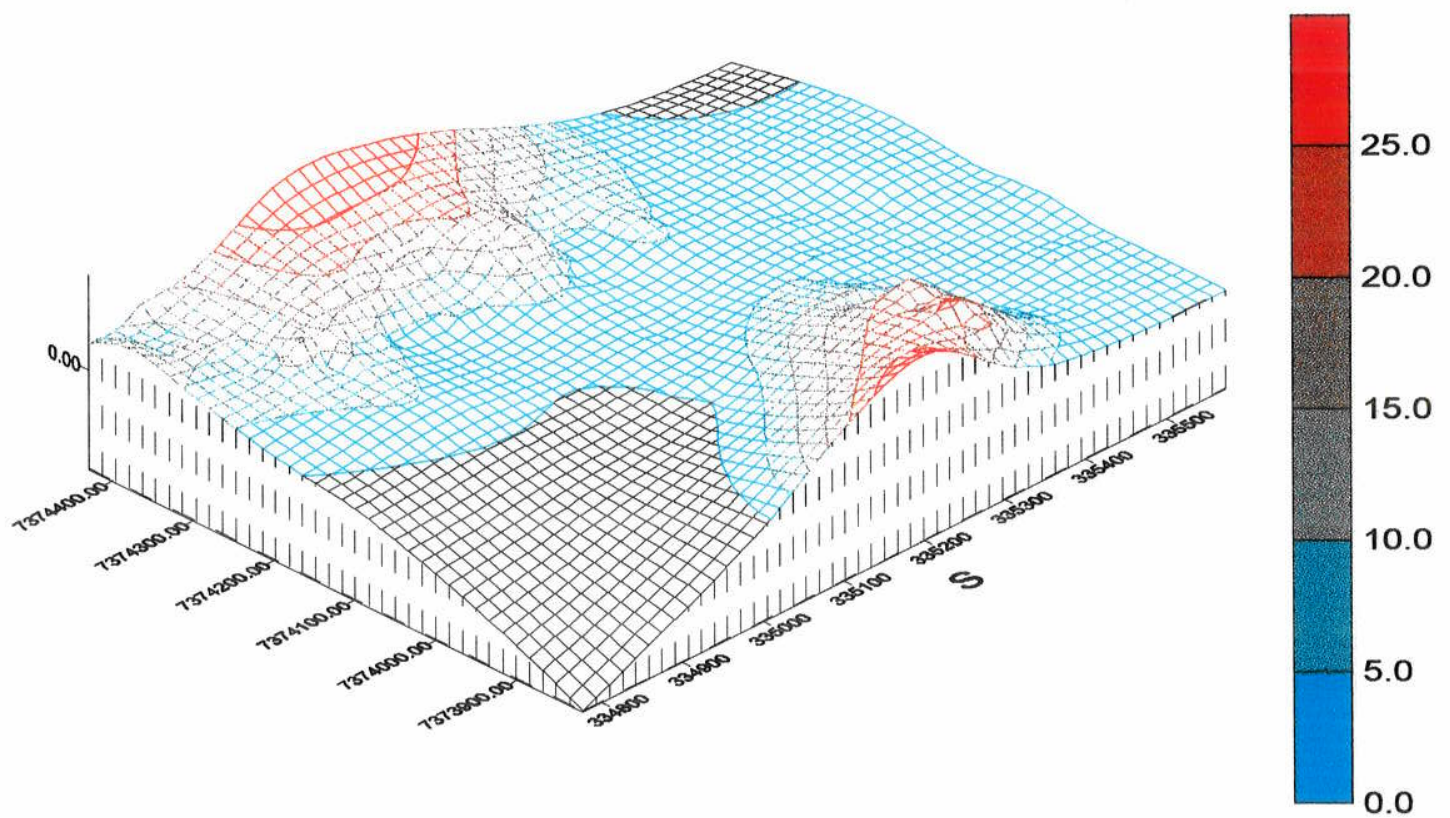

$\mathbf{m m h o} / \mathbf{m}$

MODELO TRIDIMENSIONAL DAS MEDIDAS DE CONDUTIVIDADE ELÉTRICA EM-34/20m-V - LIXÃO DO ALVARENGA 


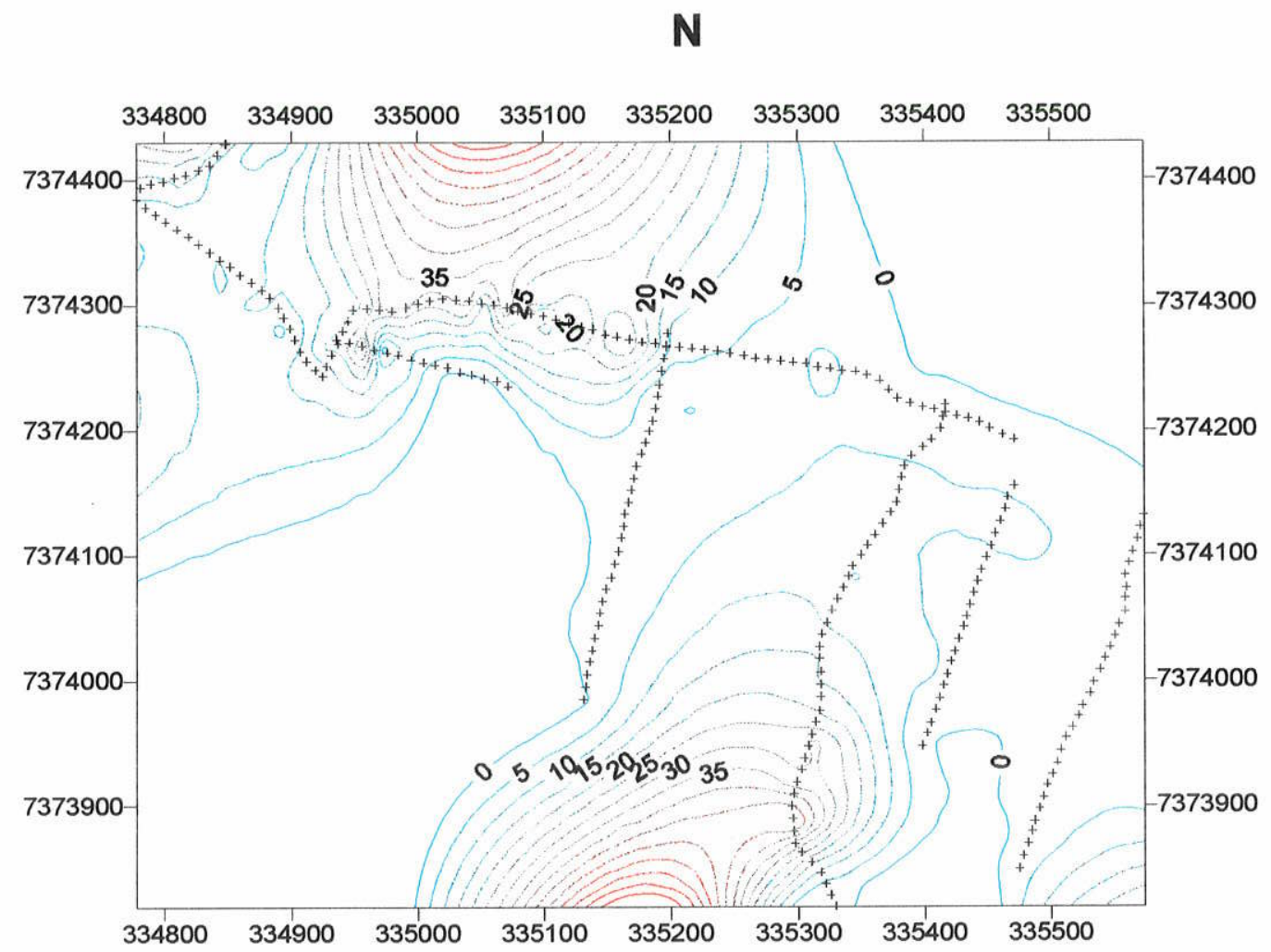

MAPA DE ISOCONDUTIVIDADE - EM-34/20m-H - LIXÃO DO ALVARENGA

(Valores em $\mathbf{m m h o} / \mathrm{m}$ )

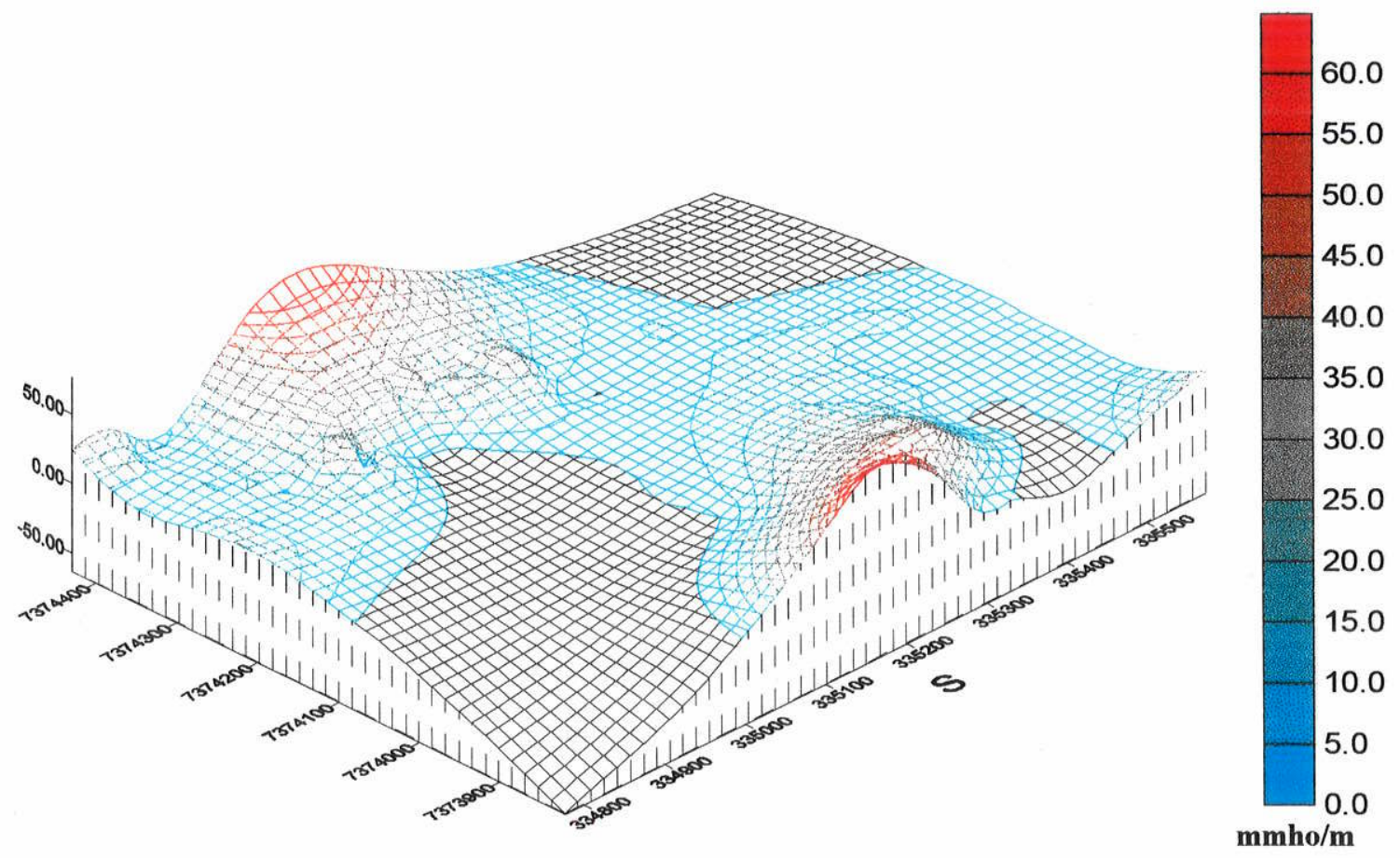

MODELO TRIDIMENSIONAL DAS MEDIDAS DE CONDUTIVIDADE ELÉTRICA EM-34/20m-H - LIXÃO DO ALVARENGA 
$\mathbf{N}$

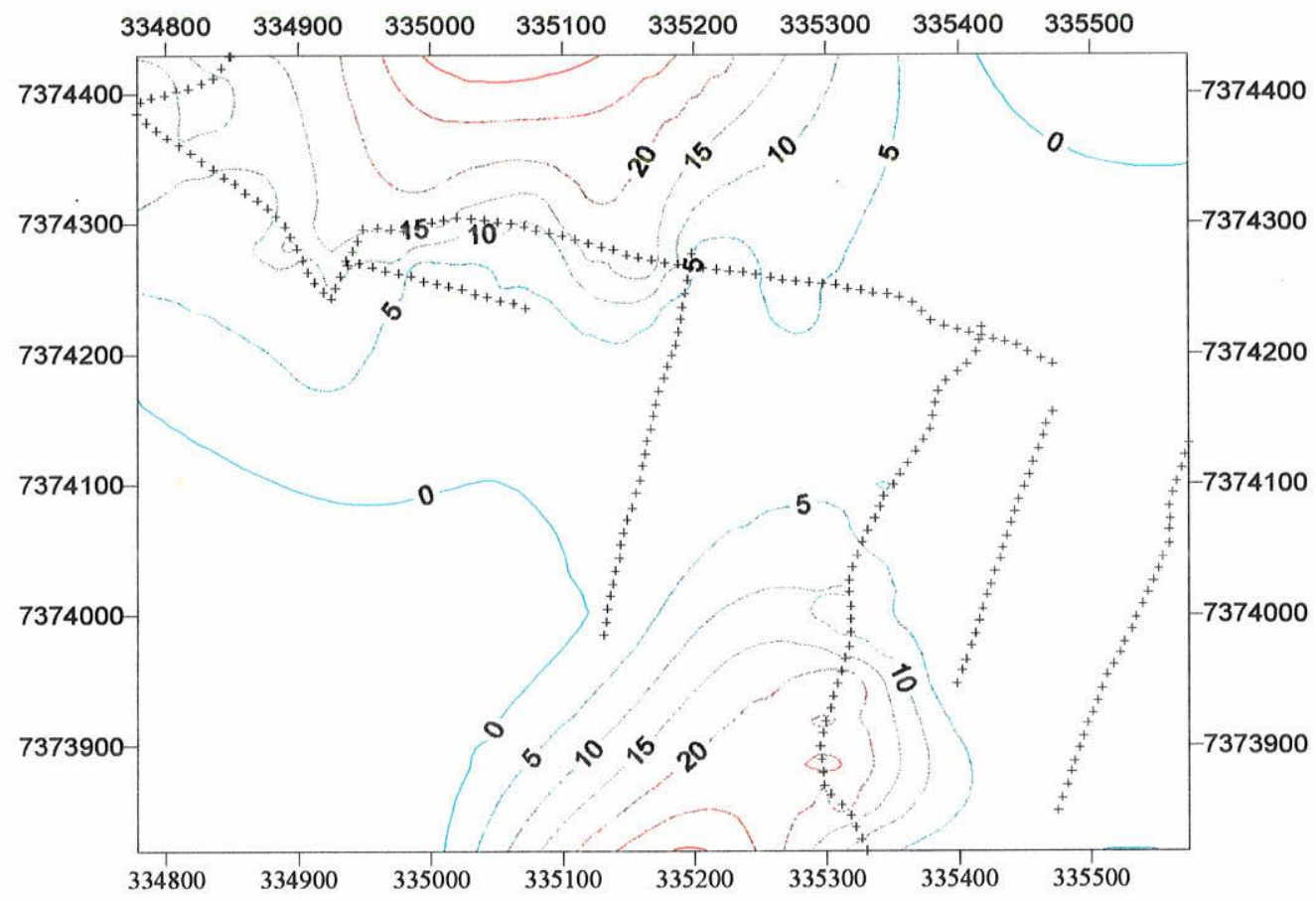

MAPA DE ISOCONDUTIVIDADE - EM-34/20m-V - LIXÃO DO ALVARENGA (Valores em mmho/m)

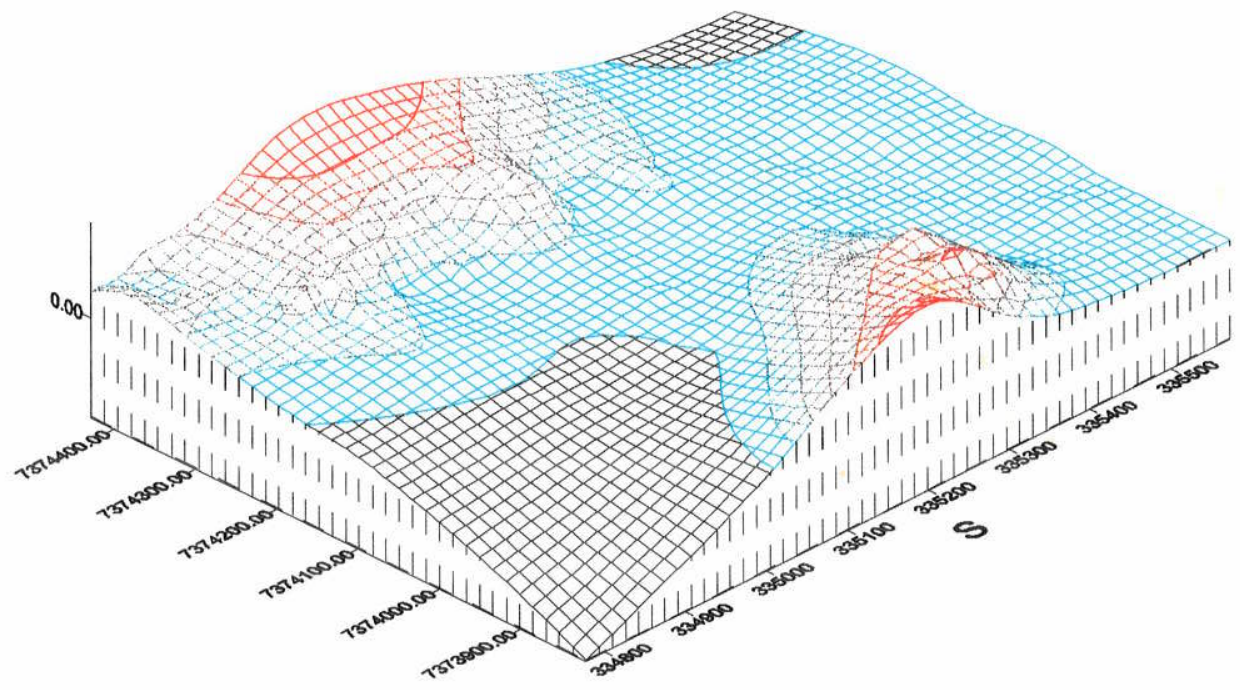

